\title{
(4)
}

UNIVERSIDAD PERUANA DE CIENCIAS APLICADAS

FACULTAD DE INGENIERÍA

CARRERA DE INGENIERÍA INDUSTRIAL

\section{PROPUESTA DEL DISEÑO DEL PROCESO \\ LOGÍSTICO PARA MEJORAR LA PRODUCTIVIDAD \\ DEL SECTOR AGRÍCOLA, PALTA HASS, EN LA \\ IRRIGACIÓN CABEZA DE TORO DEL \\ DEPARTAMENTO ICA, PERÚ}

TESIS

Para optar el título profesional de: Ingeniero Industrial

AUTORES

Corahua Benites, Andrea Adela (0000-0002-4572-5780)

Mendoza Silva, Patricia Helen (0000-0002-6317-0248)

ASESOR DE TESIS

Sotelo Raffo, Juan Luis Fernando (0000-0001-5452-369X)

Lima, 27 de noviembre del 2018 
Dedicado a Dios y a nuestros padres por su amor, trabajo y apoyo incondicional en todos estos años, gracias por su aliento constante para poder llegar a este objetivo, ya que ustedes son pieza fundamental en nuestras vidas y nuestro más grande motivo para ser mejores cada día. Dedicado a nuestro profesor Fernando Sotelo, gracias por su asesoramiento, retroalimentación e instrucciones durante el desarrollo de nuestro trabajo. Al ser parte de este logro, esperamos que su dedicación por enseñarnos sea vea reflejado en esta tesis.

\section{Agradecimientos}

Agradecemos a la Cooperativa Agro Inka por brindarnos su apoyo, el cual fue esencial para lograr este proyecto de investigación.

Agradecemos a nuestra casa de estudios Universidad Peruana de Ciencias Aplicadas por ser nuestra base y guía durante estos cinco años de carrera. 


\section{RESUMEN}

Esta tesis tiene como propósito fundamental diseñar un proceso logístico en la Cooperativa Agraria de Servicios Agro-Inka C.P.P. Ltda.

A través de un sistema de gestión por procesos, el cual incluye al proceso logístico se aumentará la productividad monetaria y en rendimiento de la cooperativa.

En el CAPÍTULO 1; se desarrolla la base teórica para respaldar la presente tesis a través de la revisión de la literatura, así como el marco teórico y casos de éxito que ayudan a la investigación.

En el CAPÍTULO 2; se describe la situación actual del sector agrícola como de la cooperativa a través del levantamiento de la información y se analiza la metodología de la investigación, con el cual se identifica el problema y su relación con el proceso logístico.

En el CAPÍTULO 3; se desarrolla la propuesta general y específica, siendo la primera el sistema básico de gestión por procesos y la propuesta del diseño del proceso logístico, el cual comprende los flujogramas, los procedimientos, la caracterización del subproceso y la ficha del indicador para medir el desempeño.

En el CAPÍTULO 4; se realiza la validación del modelo de Gestión por Procesos y Gestión Logística mediante el juicio de expertos y resultados de los agricultores.

Finalmente, en el CAPÍTULO 5; se describe las conclusiones, recomendaciones y futuras líneas de investigación que permitirán la futura implementación del sistema y alcanzar el objetivo de la presente tesis.

Palabras Clave: Gestión por Procesos, Gestión Logística Integral, productividad, sector agrícola, MYPES, levantamiento de información y datos. 


\section{ABSTRACT}

This thesis has as its fundamental purpose to design a logistic process in the "Cooperativa Agraria de Servicios Agro-Inka C.P.P. Ltda"

Through a process management system, which includes the logistics process will increase the monetary productivity and performance of the cooperative.

In CHAPTER 1; the theoretical basis is developed to support the present thesis through the review of the literature, as well as the theoretical framework and success cases that help research.

In CHAPTER 2; the current situation of the agricultural sector as well as the cooperative is described through the collection of information and the research methodology is analyzed, with which the problem is identified and its relationship with the logistic process.

In CHAPTER 3; the general and specific proposal is developed, first the basic process management system that includes the proposed process map and the general flow chart where all the processes interact; and the proposal of the design of the logistic process, which includes the flow charts, the procedures, the characterization of the subprocess and the indicator sheet to measure performance.

In CHAPTER 4; validation of the process management and logistics management model is carried out through expert judgment and the farmers results.

Finally, in CHAPTER 5; it describes the conclusions, recommendations and future lines of research that will allow the future implementation of the system and thereby achieve the objective of this thesis.

Key words: Process Management, Integral Logistics Management, productivity, agricultural sector, MSEs, information and data collection. 


\section{TABLA DE CONTENIDO}

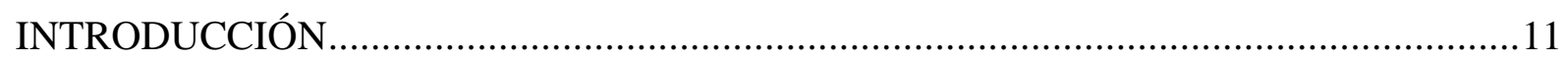

CAPÍTULO 1. ESTADO DEL ARTE Y MARCO TEÓRICO ............................................12

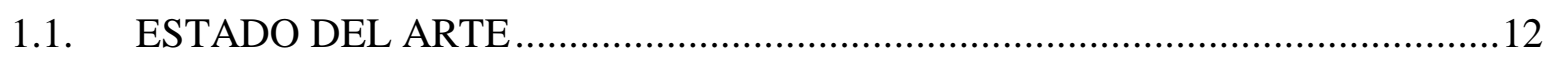

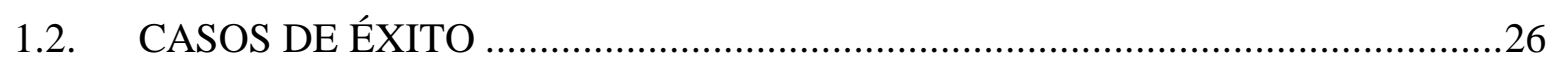

1.2.1. Caso de éxito $\mathrm{N}^{\circ}$ 1: Estudio de 2 empresas de servicios de Brasil ...................26

1.2.2. Caso de éxito $\mathrm{N}^{\circ} 2$ : Pequeña empresa mexicana de productos de maíz ...........26

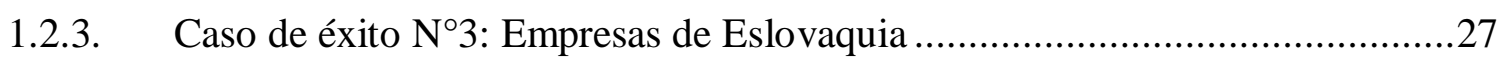

1.2.4. Caso de éxito $\mathrm{N}^{\circ} 4$ : Empresas de fabricación Checa .....................................28

1.2.5. Caso de éxito No5: Empresa pesquera Sancti Spíritus "PESCASPIR"............28

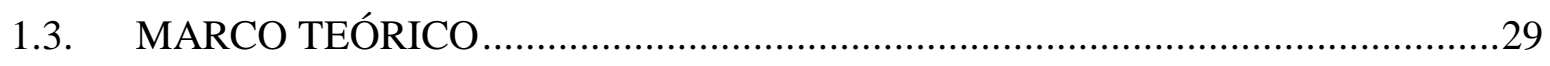

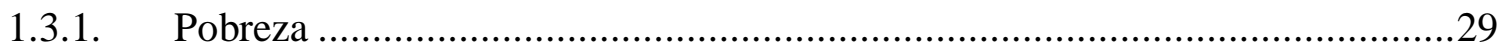

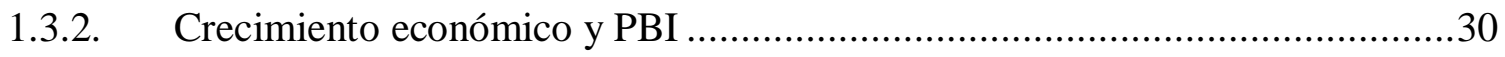

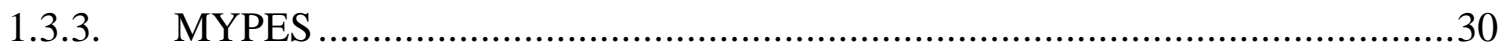

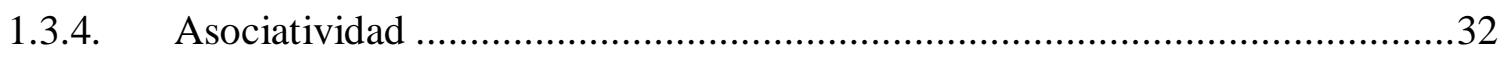

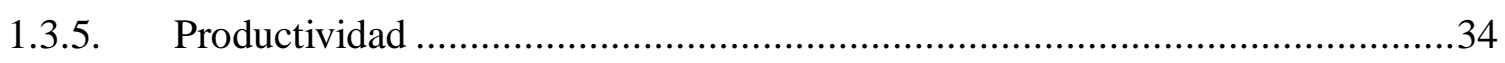

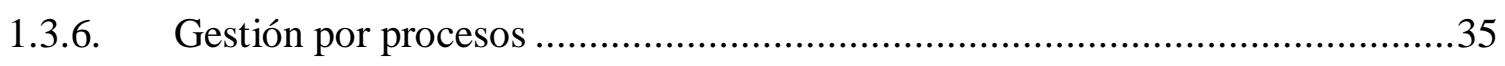

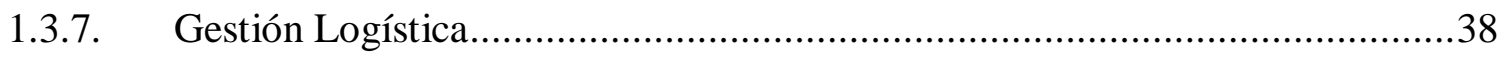

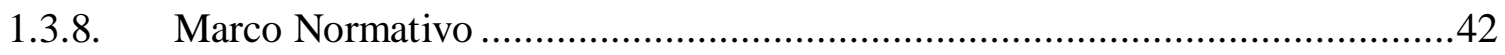

1.4. MODELO DE SOLUCIÓN.....................................................................44

CAPÍTULO 2. METODOLOGÍA DE LA INVESTIGACIÓN Y DIAGNÓSTICO...............46

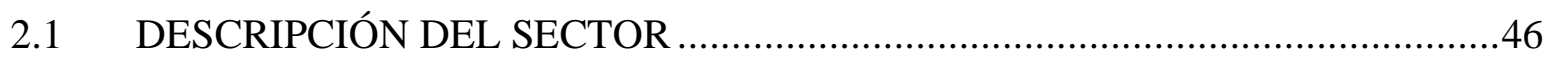

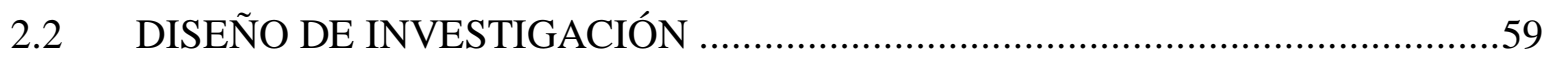

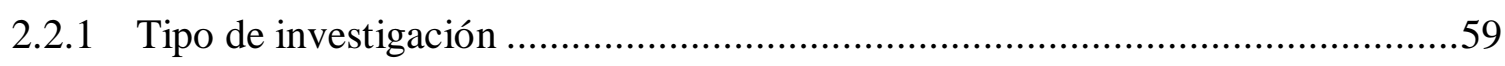

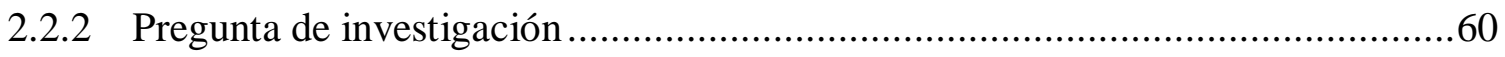

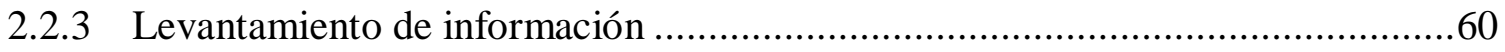

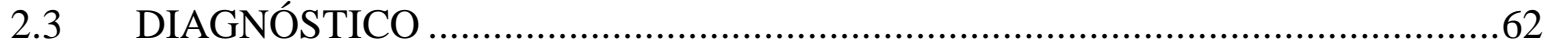

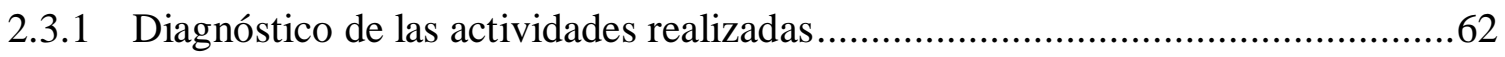

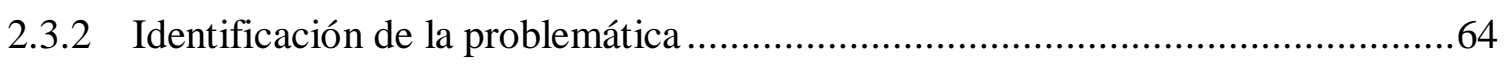

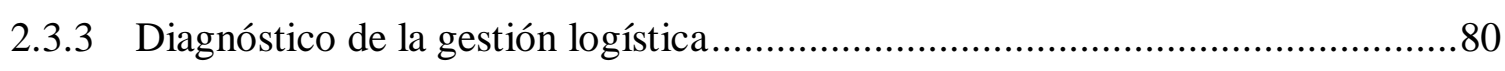

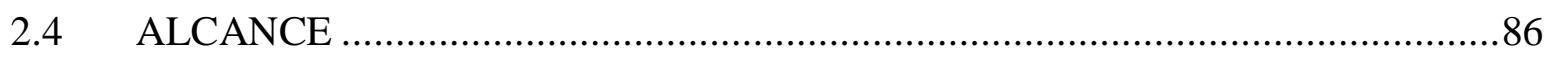

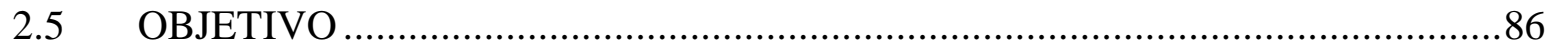




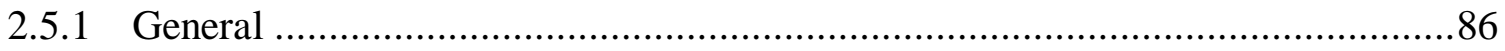

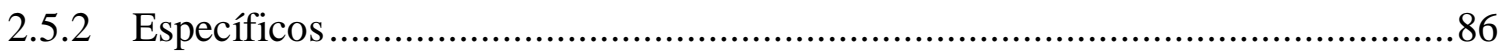

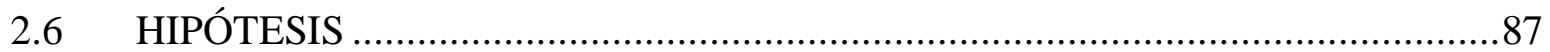

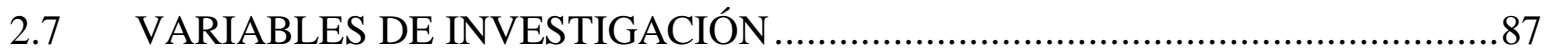

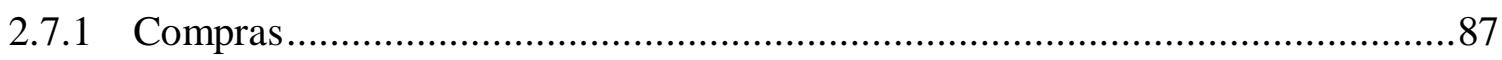

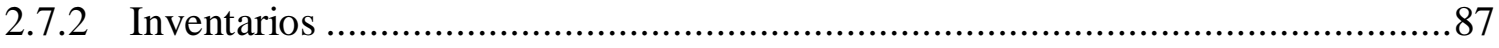

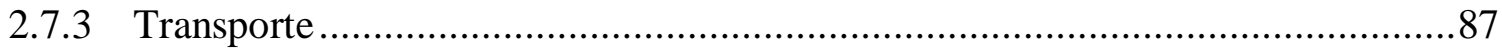

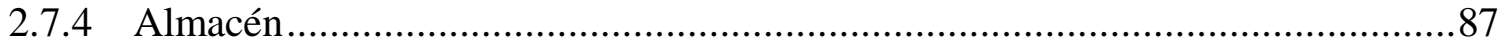

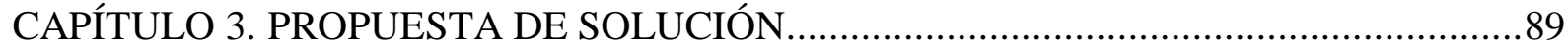

3.1 PROPUESTA DE SOLUCIÓN BASADA EN LA GESTIÓN POR PROCESOS..89

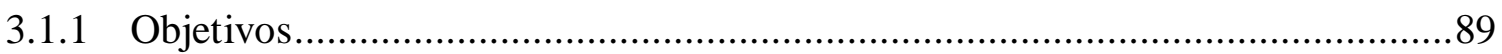

3.1.2 Mapa General de procesos propuesto...........................................................90

3.1.3 Flujograma del sistema básico de gestión propuesto …………………………......94

3.1.4 Mapa relacional de procesos..........................................................................97

3.2 PROPUESTA DE SOLUCIÓN DE LA GESTIÓN LOGÍSTICA INTEGRAL .......99

3.2.1 Diseño de la gestión logística integral...............................................................99

3.2.2 Flujograma de la gestión logística integral.......................................................101

3.2.3 Desarrollo de subprocesos de la gestión logística..............................................103

3.2.3.1 Subproceso de la gestión de inventarios......................................................... 103

3.2.3.1.1 Flujograma de la gestión de inventarios .....................................................103

3.2.3.1.2 Caracterización de la gestión de inventarios..............................................108

3.2.3.1.3 Indicador de la gestión de inventarios ......................................................108

3.2.3.2 Subproceso de gestión de compras.............................................................110

3.2.3.2.1 Flujograma de la gestión de compras ......................................................110

3.2.3.2.2 Caracterización de la gestión de compras ..................................................114

3.2.3.2.3 Indicador de la gestión de compras .........................................................114

3.2.3.3 Subproceso de gestión de almacenamiento de insumos .................................116

3.2.3.3.1 Flujograma de la gestión de almacenamiento de insumos...........................116

3.2.3.3.2 Caracterización de la gestión de almacenamiento de insumos ....................120

3.2.3.3.3 Indicador de la gestión de almacenamiento de insumos .............................120

3.2.3.4 Subproceso de repartición de insumos ........................................................... 121

3.2.3.4.1 Flujograma de repartición de insumos.......................................................121

3.2.3.4.2 Caracterización de repartición de insumos ................................................. 125

3.2.3.4.3 Indicador de repartición de insumos...................................................... 125 
3.2.3.5 Subproceso de la gestión de almacenamiento de la producción ....................126

3.2.3.5.1 Flujograma de la gestión de almacenamiento de la producción ................126

3.2.3.5.2 Caracterización de la gestión de almacenamiento de la producción ...........131

3.2.3.5.3 Indicador de la gestión de almacenamiento de la producción ....................131

3.2.3.6 Subproceso de la distribución de la producción......................................... 132

3.2.3.6.1 Flujograma de la distribución de la producción ........................................132

3.2.3.6.2 Caracterización de la distribución de la producción.................................137

3.2.3.6.3 Indicador de la distribución de la producción .........................................137

CAPÍTULO 4. VALIDACIÓN DEL MODELO ............................................................... 139

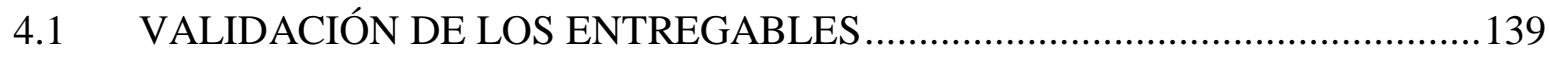

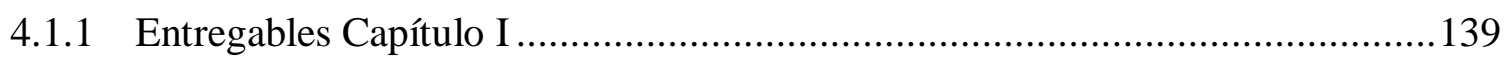

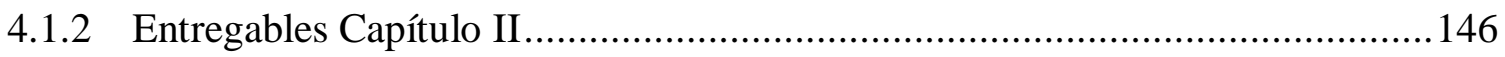

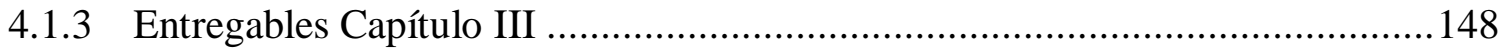

4.2 VALIDACIÓN DE LA HIPÓTESIS ESPECÍFICA …......................................150

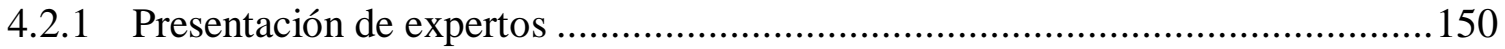

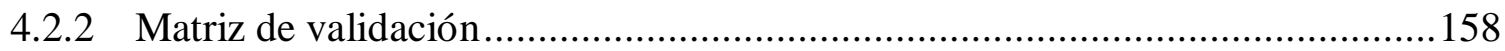

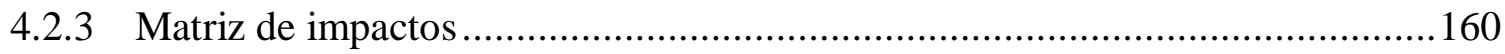

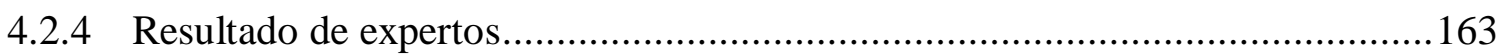

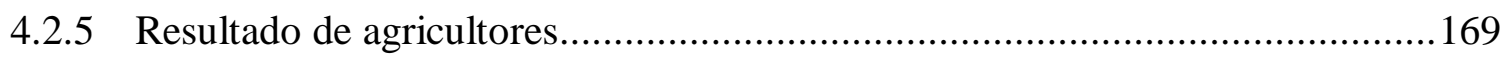

CAPÍTULO 5. CONCLUSIONES Y RECOMENDACIONES ....................................... 172

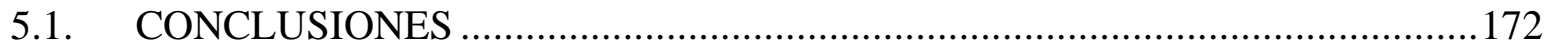

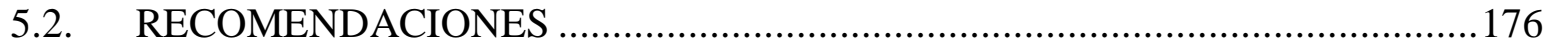

5.3. FUTURAS LÍNEAS DE INVESTIGACIÓN …............................................... 178

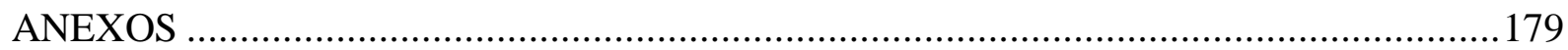

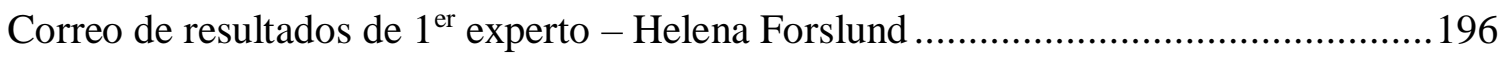

Correo de resultados de $2^{\text {do }}$ experto - Jan Olhager .................................................... 196

Correo de resultados de $3^{\text {er }}$ experto - Arnold Maltz ….............................................. 197

Correo de resultados de $4^{\text {to }}$ experto - Gülgün Alpan .................................................. 197

Correo de resultados de $5^{\text {to }}$ experto - Susan Golicic ................................................. 198

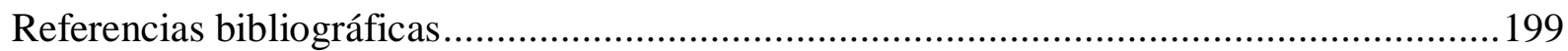




\section{ÍNDICE DE TABLAS}

Tabla 1: Criterios para definir una MYPE en el Perú ......................................................... 31

Tabla 2: Últimas proyecciones de la variación \% del PBI real..............................................47

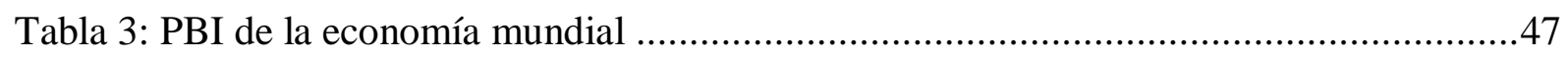

Tabla 4: PBI por Sectores Productivos del 2014 al 2017 .................................................48

Tabla 5: PEA ocupada, según rama de actividad y condición de pobreza, 2017....................50

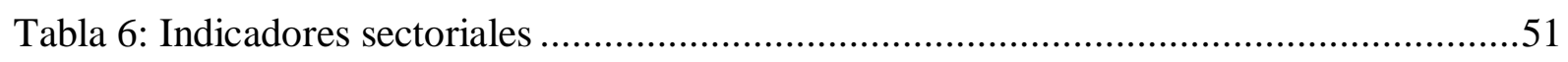

Tabla 7: Perú: Producción de frutas y nueces por región según producto, Año 2016 (toneladas)

Tabla 8: Principales exportaciones agrarias por subpartidas nacionales, Ene-Dic 2017/2016.55

Tabla 9: Perú: Precio recibido por el productor por producto según año, 2012 - 2016...........56

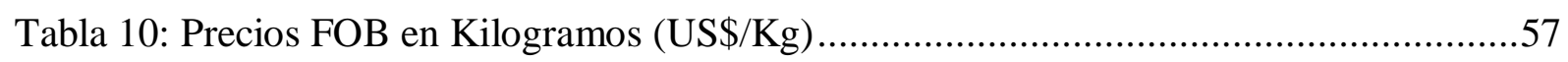

Tabla 11: Principales empresas agroexportadoras .......................................................58

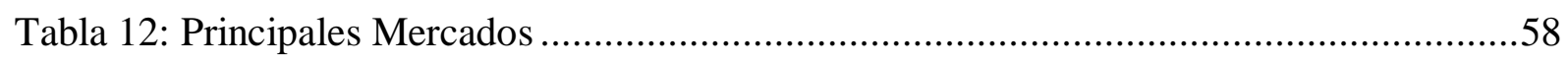

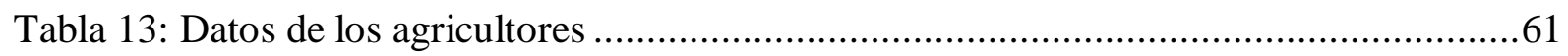

Tabla 14: Relación entre problemas y procesos................................................................91

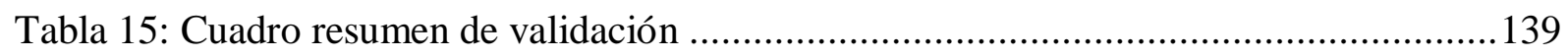

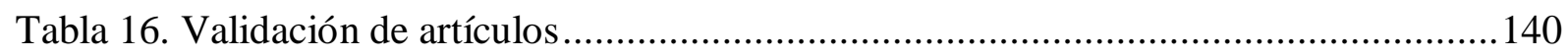

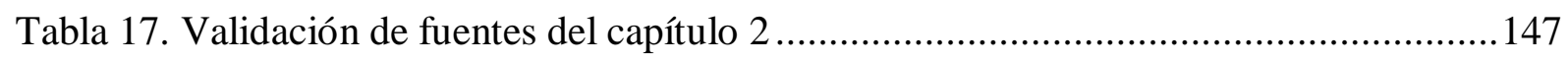

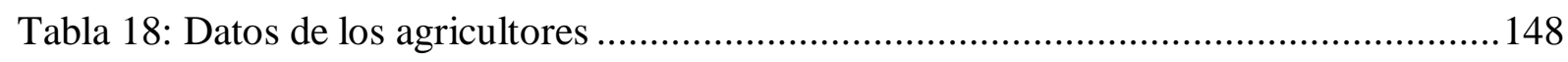

Tabla 19: Números de páginas de entregables del modelo........................................... 148

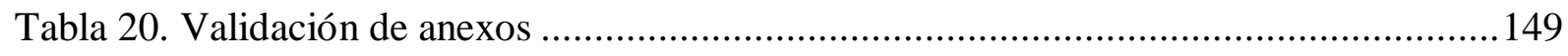

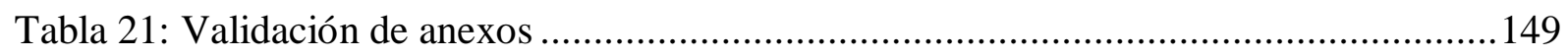

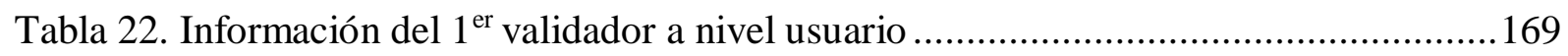

Tabla 23. Información del $2^{\text {do }}$ validador a nivel usuario ................................................ 170 


\section{ÍNDICE DE FIGURAS}

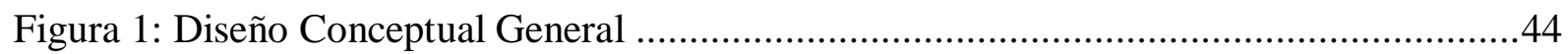

Figura 2: Tasa de crecimiento del PBI nacional y PBI agropecuario .................................49

Figura 3: Perú: Población ocupada por categoría de ocupación, según condición de pobreza, 2017

Figura 4: Evolución de la incidencia de la pobreza monetaria total, 2011-2017...................51

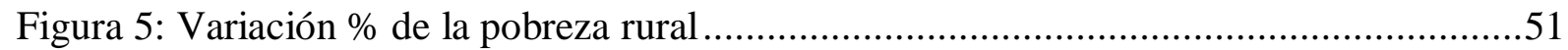

Figura 6: Perú: empresas formales, según segmento empresarial, 2015 ..............................52

Figura 7: Evolución de las MIPYMES formales, 2012-2016 ..............................................53

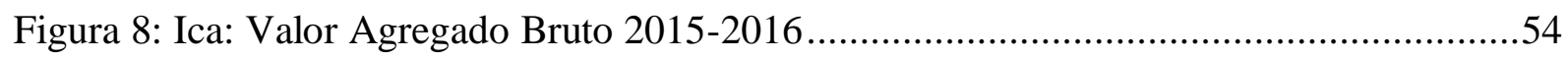

Figura 9: \% de Participación Agrícola en exportación 2017 ..................................................55

Figura 10: Mapa político del departamento de Ica......................................................61

Figura 11: Mapa político de la provincia de Pisco ...........................................................61

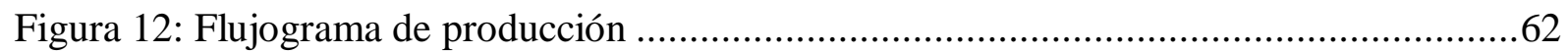

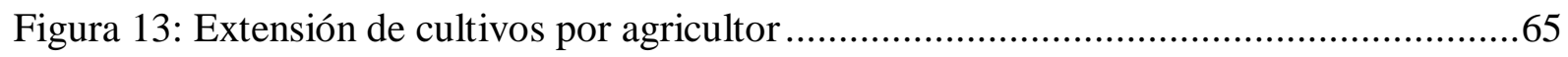

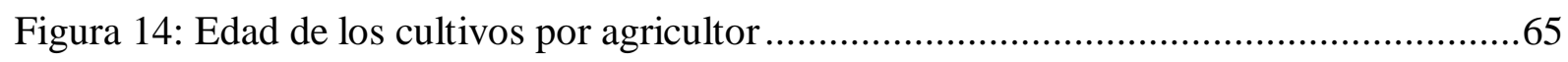

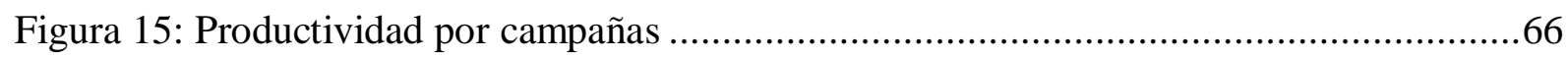

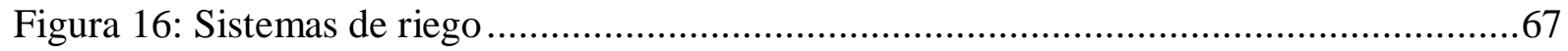

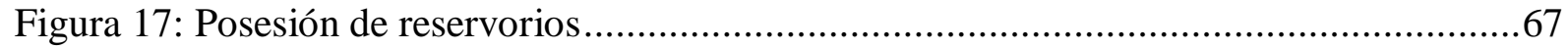

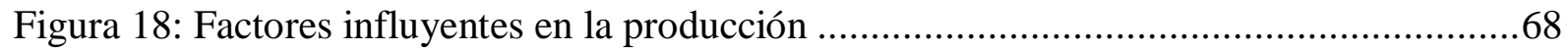

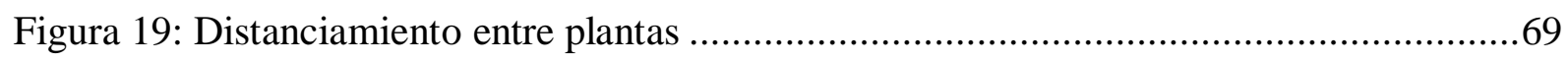

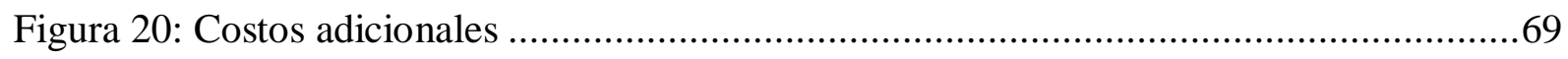

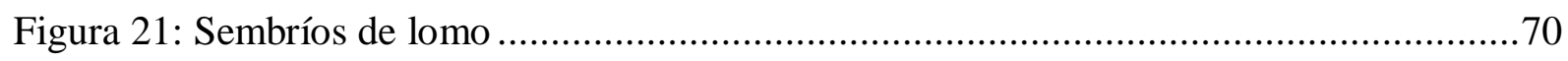

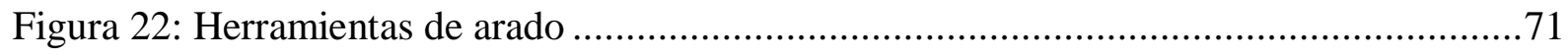

Figura 23: Beneficios por asociación según agricultores ...................................................71

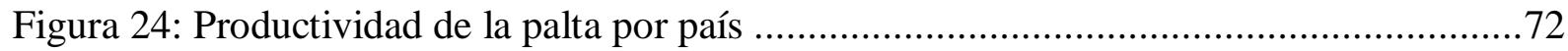

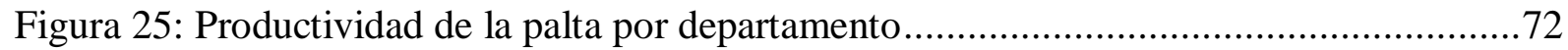

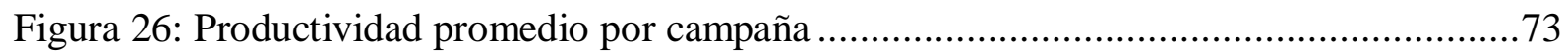

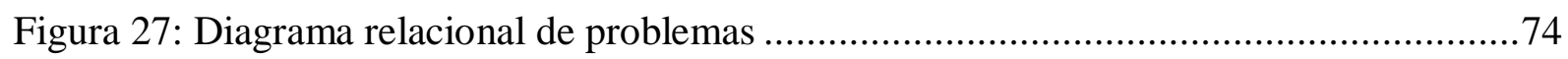

Figura 28: Factores causantes de los malestares ......................................................... 76

Figura 29: Principales problemas durante la cosecha................................................. 76

Figura 30: Factores en la estimación del costo del fruto ...................................................77 
Figura 31: Factores que evitan la buena administración de recursos ..................................77

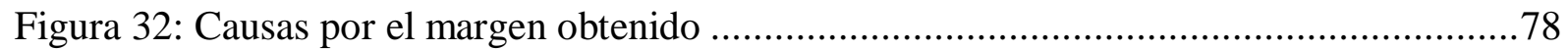

Figura 33: Factores que evitan la separación con agroexportadora ...................................78

Figura 34: Diagrama relacional de problemas con procesos ............................................. 79

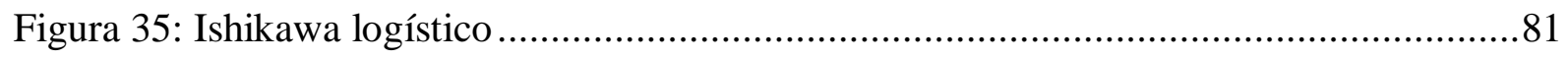

Figura 36: Principales causas de la deficiente gestión logística .........................................81

Figura 37: Diagrama causal desaprovechamiento de economías de escala ...........................82

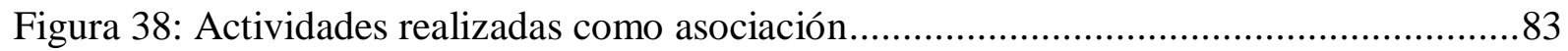

Figura 39: Diagrama causal de inexistencia de plan de inventarios.....................................84

Figura 40: Diagrama causal de inexistencia de almacenes acondicionados ..........................85

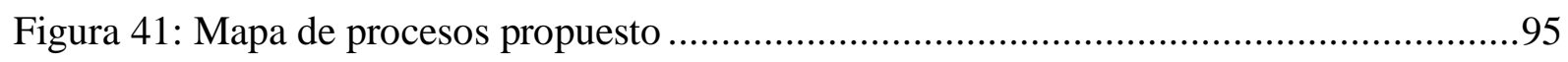

Figura 42: Flujograma del sistema básico de gestión por procesos ...................................97

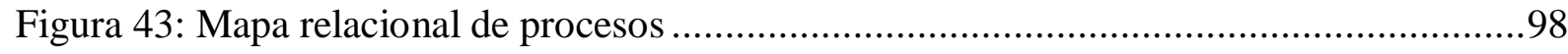

Figura 44: Diseño del proceso logístico integral....................................................... 100

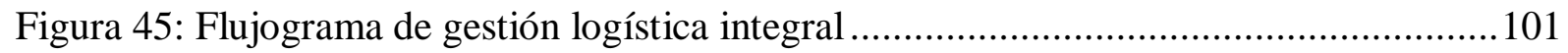

Figura 46: Mapa de entregables del Proceso de Logística....................................................103

Figura 47: Flujograma del subproceso de Inventarios.................................................. 105

Figura 48 Diagrama SIPOC del subproceso de inventarios ........................................... 108

Figura 49: Ficha técnica de exactitud en los registros de inventarios ................................. 109

Figura 50: Flujograma del subproceso de Compras ...................................................... 111

Figura 51 Diagrama SIPOC del subproceso de compras................................................114

Figura 52: Ficha técnica del indicador de porcentaje de ahorro por compras ......................115

Figura 53: Flujograma del subproceso de Almacenamiento de Insumos .............................117

Figura 54 Diagrama SIPOC del subproceso de almacenamiento de insumos ......................120

Figura 55: Ficha técnica del indicador de entregas conformes recibidas ............................121

Figura 56: Flujograma del subproceso de Repartición de Insumos ...................................122

Figura 57 Diagrama SIPOC del subproceso de Repartición de insumos ............................125

Figura 58: Ficha técnica del indicador de tiempo de distribución de insumos ......................126

Figura 59: Flujograma del subproceso de Almacenamiento de la producción ......................128

Figura 60 Diagrama SIPOC del subproceso de Almacenamiento de producción .................131

Figura 61: Ficha técnica del indicador de porcentaje de utilización de espacio por MYPE..132

Figura 62: Flujograma del subproceso de Distribución de la producción .............................134

Figura 63 Diagrama SIPOC del subproceso de Distribución de producción .......................137

Figura 64: Ficha técnica del indicador de entrega de orden completa ...............................138 
Figura 65: Cantidad de artículos según año de publicación ..............................................146

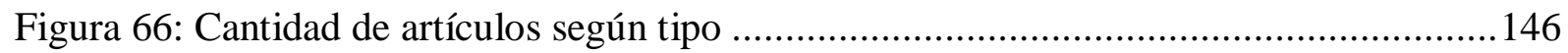

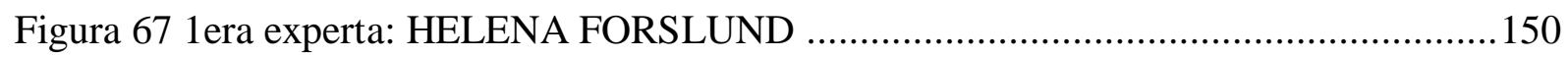

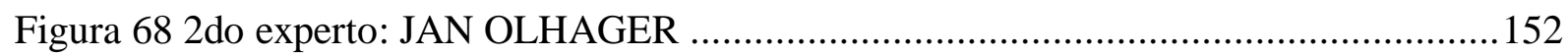

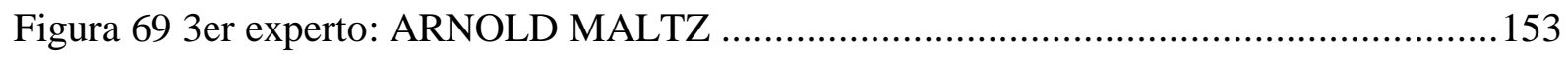

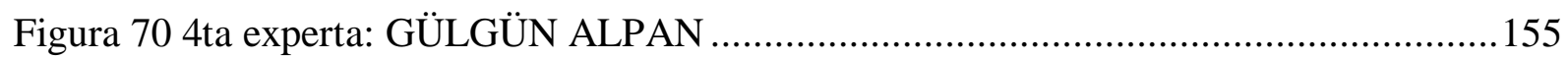

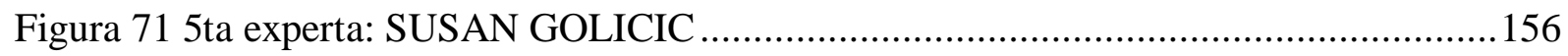

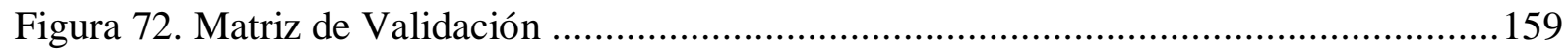

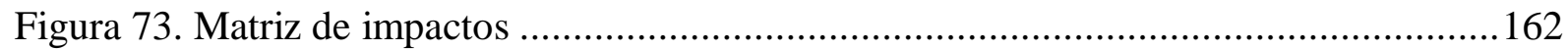

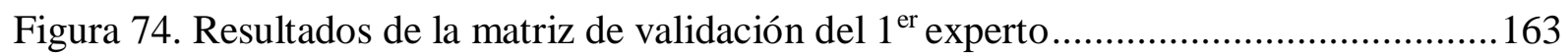

Figura 75: Resultado de la matriz de impactos del $1^{\mathrm{er}}$ experto ........................................... 164

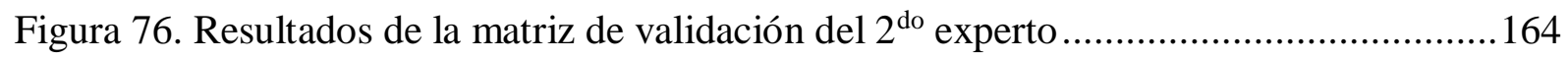

Figura 77: Resultado de la matriz de impactos del $2^{\text {do }}$ experto ............................................ 165

Figura 78: Resultados de la matriz de validación del $3^{\text {er }}$ experto ....................................... 165

Figura 79. Resultados de la Matriz de impactos del 3er experto ........................................166

Figura 80: Resultados de la matriz de validación del $4^{\text {to }}$ experto .........................................166

Figura 81. Resultados de la Matriz de impactos del $4^{\text {to }}$ experto ........................................ 167

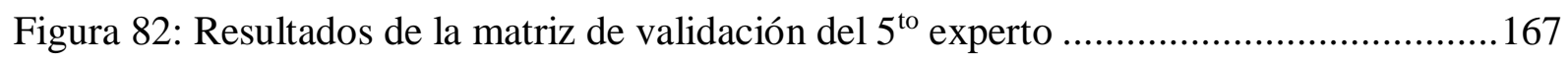

Figura 83. Resultados de la Matriz de impactos del $5^{\text {to }}$ experto ......................................... 168

Figura 84. Resultados de Validación según Expertos ...................................................... 169

Figura 85. Resultados de la matriz de validación del $1^{\mathrm{er}}$ y $2^{\text {do }}$ usuario ...............................170

Figura 86. Resultados de la Matriz de impactos del $1^{\text {er }}$ usuario .........................................171

Figura 87: Resultados de la Matriz de impactos del $2^{\text {do }}$ usuario..........................................171 


\section{INTRODUCCIÓN}

En el Perú, el sector logístico ha tenido significantes mejoras en los últimos años, una de las pruebas es el año 2013, donde Perú exportó bienes valorados en US $\$ 43,800$ millones, sin embargo, dentro de estas exportaciones se encuentran en su mayoría productos minerales dejando de lado la producción agrícola, un importante sector económico en el país. Para estos productos los costos logísticos podrían no tener impacto en la fijación del precio de exportación, pero es uno de los factores más importantes en la rentabilidad del producto. Por ello, en una economía como la peruana, mejorar la eficiencia de las cadenas logísticas de productos de exportación es esencial en la medida que Perú se trace como meta ser más competitivo en mercados regionales y globales y en cambiar la composición del portafolio de exportación para hacerlo más diversificado.

Uno de los principales problemas logísticos en Perú es el estado de las rutas de transportes, de las cuales sólo el $13 \%$ está asfaltada y hace que los costos logísticos aumenten. La falta de carreteras que hace que productores de la sierra y selva no puedan vender sus productos a precios competitivos. De hecho, el desempeño de la logística peruana se encuentra entre los escaños más bajos en comparación con otros países de ingreso medio de América Latina. En 2013, los costos logísticos agregados del Perú fueron estimados en 12.6\% del PBI, por encima de Chile (11.5\%), Brasil (11.6\%) y México (12\%).

La presente investigación tiene como principal objetivo diseñar un modelo de proceso logístico para MYPES del Perú, pertenecientes al sector agrícola de palta Hass en la irrigación Cabeza de Toro en la provincia de Pisco en el departamento de Ica en Perú. El estudio realizado abarca desde la identificación y explicación de los problemas a detalle en la cooperativa a través de un diagnóstico del sector hasta la propuesta del diseño logístico definiendo los parámetros a tomar en cuenta para su viabilidad. 


\section{CAPÍTULO 1. ESTADO DEL ARTE Y MARCO TEÓRICO}

En este capítulo se describe el soporte teórico necesario para desarrollar la presente tesis, el cual presenta el estado del arte que se basa en la revisión de la literatura sobre las relaciones entre como el crecimiento económico disminuye la pobreza, seguidamente, como el crecimiento económico afecta el PBI, asimismo, como este se refleja en el sector empresa, después, se evidencia la mejora del sector empresa cuando incrementa la productividad de las MYPES y esta mejora de productividad se genera por la gestión de los procesos. Un proceso de vital importancia dentro de esta gestión es la logística, la cual será la parte más importante de esta investigación. Además, de presentar el estado del arte se observará el marco teórico y de la misma forma casos de éxito que respaldan la investigación. Por último, se plantea la idea del modelo de solución general basado en un enfoque en procesos.

\subsection{ESTADO DEL ARTE}

En el presente capítulo se mostrará el estado del arte obtenido por la revisión de la literatura desde el enfoque de diferentes autores.

Esmaeeli y Sadighi (2017) indican que el crecimiento económico contribuye con la reducción de la pobreza, ya que la inversión en investigación agrícola puede tener gran beneficio hasta ayudar a la disminución de este factor. Por ende, son la productividad y el crecimiento de la producción a través de los cambios tecnológicos que hacen posible el éxito de dicha inversión en el sector agrícola. Los autores analizaron las consecuencias de la inversión agrícola, es decir, como esta ayuda al crecimiento económico sobre el aumento de la productividad y la reducción de la pobreza en Irán durante el año 1971-2010. El estudio llevó a demostrar que la inversión en investigación agrícola por hectárea de tierra llevaría a un aumento del $28 \%$ en la productividad agrícola durante el periodo analizado, es decir, incrementó la economía en Irán con un efecto positivo que ha ayudado a reducir la pobreza a través del uso de un modelo econométrico con ecuaciones simultáneas. No obstante, los autores señalan que no basta con la inversión para reducir la pobreza y paralelamente crezca la economía, sino que debe mejorar el funcionamiento de los servicios de extensión, así como los métodos de suministro para lograr un porcentaje de reducción elevado. 
De esta misma manera, Adrianzen (2013) en su estudio sobre la pobreza señala que la relación temporal entre el crecimiento y la pobreza no es una relación equilibrada o pronosticada. Sin embargo, un profundo análisis de los estudios sobre el tema destaca que existe una fuerte relación entre el crecimiento económico y la reducción de los niveles de pobreza. El crecimiento económico, comúnmente, se deriva en un aumento de los ingresos de los hogares y las disminuciones en la incidencia de la pobreza. El presente artículo ha evidenciado que la norma sectorial del crecimiento repercutirá en el grado de reducción de la pobreza y que el crecimiento de los puestos de trabajo contribuye a la reducción de la misma. Asimismo, el autor narra que el crecimiento en la agricultura tradicional y con bajos niveles en tecnologías puede aumentar la pobreza, mientras que el desarrollo en los sectores urbanos puede hacer que se reduzca valiosamente.

En relación con los autores de los artículos ya presentados se añade a Garrido (2013) que en su estudio demuestra que, para combatir la pobreza, el crecimiento económico es la principal política destinada a corregir esta condición. Para lograr esto el autor señala que será posible en la medida en que las dos variables básicas lo permitan, es decir, mayores tasas de crecimiento económico, con seguridad, facilitarán el objetivo de reducir la incidencia de pobreza si se mantiene la elasticidad promedio actual, de lo contrario, menores tasas de crecimiento económico raramente podrán ser solucionadas vía la elasticidad, dado que el incremento de este elemento llevaría a una mayor inversión social, el cual estaría limitado por la menor recaudación fiscal de una disminución en la actividad económica. Según el autor, este realizó un modelo de elasticidad en el que comprobó que, al calcular la relación del crecimiento económico y la pobreza, resulta que por cada punto de crecimiento económico se conseguiría disminuir los niveles de pobreza en casi 192.000 personas por año.

En adición a los estudios de los anteriores autores, Macías (2014) afirma que el ritmo de crecimiento económico influye de manera directa en los ingresos de los pobres, en otras palabras, un rápido crecimiento contribuye al éxito de una estrategia a favor de los pobres, reduce la pobreza directamente porque presenta nuevas actividades que generan ingresos y crece la demanda de alimentos y materias primas producidas por las personas que carecen de riqueza. Además, el desarrollo aumenta la disponibilidad de bienes, servicios y es generadora de empleo, ampliando los mercados, los ingresos por ventas y las opciones de consumo. Por otra parte, ayuda a reducir la pobreza indirectamente, ya que aumenta el desarrollo financiero y la creación de ahorros para apoyar la inversión y la expansión del crédito al consumo. Asimismo, la población de bajos recursos se puede beneficiar indirectamente del crecimiento mediante políticas fiscales redistributivas. En líneas generales, el autor sostiene que cuanto más 
pobre sea un país más importante es el crecimiento en la explicación de los cambios en las tasas de pobreza, hasta tal punto que se podrían justificar aumentos de la desigualdad si con ellos se logra tasas de crecimiento más altas.

En un caso más reciente, Rodríguez-Pose y Hardy (2015) aseguran que se necesita modernización para sostener el crecimiento inclusivo y profundizar el compromiso democrático en las regiones con la contribución de la disminución de la pobreza. Además, para lograr que disminuya la pobreza se debe luchar contra la falta de coordinación y responsabilidades entre distintos niveles de gobierno y las organizaciones de desarrollo.

Valdés (2015) utiliza a los indicadores como medio para evidenciar que la reducción de la pobreza tiene efectos en el crecimiento económico, es el nivel de pobreza el factor clave, dentro de las variables analizadas, que se interrelaciona con las variaciones en el nivel de crecimiento económico de un país. Además, señala que la pobreza se asoció al aumento de la riqueza de los países, al crecimiento que no solo es económico sino también que se entiende en mejorar la calidad de vida de las personas, es decir, en lograr que se viva más y mejor.

Debido a que la reducción de la pobreza fomenta el crecimiento económico, este último ayuda a la mejora del PBI, Ugne Daubarainte y Grazina Startiene (2015) realizaron un estudio sobre el impacto en la economía nacional originado por las industrias creativas, estas son organismos económicos que utilizan talentos y habilidades con el fin de generar riqueza y puestos de trabajo. Para ello, los autores seleccionaron ciertos factores que afectan estas industrias creativas, tales como la lucha contra el desempleo, el aumento del PBI, la exportación y la inclusión social, y que generan un crecimiento económico nacional. En relación con el PBI, la generación de industrias creativas genera el crecimiento de esta directamente, ya que aproximadamente 1 millón de empresas lograron una cifra igual a 402.2 mil millones de euros en sus negocios, por otro lado, se debe promover el enfoque hacia el sector de la microempresa, ya que ocupa gran parte de la economía en Lituania.

Del mismo modo, Bužinskienė y Rudytė (2014) analizan el impacto de las inversiones sobre el crecimiento económico, los autores encontraron que los principales flujos de efectivo de inversión son intangibles, educación, investigación y desarrollo de costos, quienes fomentan la participación del PBI. El artículo tiene como objetivo apoyar el impacto que generan las inversiones de crecimiento, la interconexión y el nivel de significación en el PBI. Con el fin de fortalecer la inversión en la generación de conocimiento para el crecimiento del PIB es necesario aumentar la inversión en la educación y la creación o el desarrollo de tecnologías nuevas y existentes, solo así se logrará crecer el porcentaje del PBI en un país. Asegura que es debido a esta inversión que la economía de una nación está ganando una mayor ventaja 
competitiva frente a otros países, por esta razón, las empresas deben construir sus actividades sobre la base del conocimiento para ayudar a adaptarse a las condiciones cambiantes del negocio, ya que afirma que el conocimiento es el motor de la economía no sólo de la inversión en capital físico sino también es generadora de nuevas ideas, productos, procesos, conceptos, etc. Debido a la transformación de las propiedades del conocimiento se crea valor económico, que determina el rendimiento de la productividad y la creación de nuevos conocimientos con su uso efectivo alienta el crecimiento económico de los estados.

Igualmente, Leimbach, Kriegler, et al. (2017) señala que la globalización lleva a un mayor crecimiento económico y una más fuerte convergencia entre las regiones del mundo, asegurando que el PBI crezca. En adición, promueve que, mediante el uso de un modelo de crecimiento económico para el diseño de escenarios, el diferencial entre las proyecciones del PIB está determinada por cinco factores: el factor trabajo, entrada de capital, las elasticidades del producto, crecimiento a largo plazo de la economía por la tecnológica, y la convergencia de la productividad total de los factores en las economías por debajo de la frontera tecnológica. En general, la relevancia de los factores de crecimiento del PBI es diferente entre los países en general y especialmente entre países desarrollados y en desarrollo de diferentes partes del mundo. El producto interno bruto de cada país o región es, por lo tanto, una función de factores de producción y mano de obra que se combinan con el total de los factores de productividad y elasticidades de salida de capital y mano de obra.

Si bien es cierto que la mejora del PBI se debe al crecimiento económico, cabe resaltar que la mejora del PBI fomenta el desarrollo del sector empresa. En base a Tomsik, Smutka, et al. (2015) evidencian que las oportunidades que aún no han sido trabajadas en su totalidad en África, tal como el sector empresa desarrollan un rol importante en el crecimiento económico de este país, ya que su participación en la generación del empleo y el efecto que produce en el PBI es increíble. Los autores plantean que, en muchos países, la participación de la agricultura en el PBI se ha reducido significativamente, mientras que el peso de la industria aumentó. Pero, cabe destacar que la agricultura sigue siendo un motivo considerable de oportunidades de trabajo y sobre todo una fuente de ingresos primaria para una parte relevante de la población que vive en la región. Con el aporte de este artículo, se demuestra que la mejora del PBI contribuye a la mejora del sector empresa, en gran magnitud lo es el sector de la agricultura en las naciones.

Como resultado de la mejora del sector empresa, debido al crecimiento económico y el aumento del PBI, las MYPES, quienes ocupan gran porcentaje del sector empresa, generan un mayor aumento de su productividad. Según Ndlovu, Mazvimav, et al. (2013) en el sector agrícola de 
producción de maíz en Zimbabwe en pequeños hogares de agricultores se evaluó su productividad y su eficiencia mediante métodos de cultivo basados en modelos matemáticos. A través del desarrollo de estos modelos, se ha aumentado la productividad agrícola, ya que se obtuvo ahorros en semillas y fertilizantes que utilizan. Con respecto al crecimiento económico, este sector ha aumentado su eficiencia porque en este caso los agricultores producen un $39 \%$ más en comparación con los métodos de cultivo convencionales. Asimismo, han obtenido mayores ganancias de productividades debido al uso de economías de escala. Las consecuencias de este estudio muestran incremento en el rendimiento agrícola, por ende, en el PBI nacional, pero aún existen barreras que se deben afrontar en la economía del país.

De igual manera, Fuentes, Faure, et al. (2015) en su artículo señalan que las cadenas de suministro de las MYPES de productos lácteos se caracterizan por diversificar sus explotaciones agrícolas incluidos los pequeños agricultores, permitiendo incrementar su productividad. La estructura de las cadenas de abastecimiento de productos lácteos en los países en desarrollo a menudo muestra una gran diversidad de organización, generalmente basada en la participación de los pequeños agricultores.

Asimismo, Kurczewski (2014) en su artículo "Life cycle thinking in small and medium enterprises: the results of research on the implementation of life cycle tools in Polish SMEspart 1: background and framework" destaca el uso de herramientas de gestión dentro del ciclo de vida de las MYPES, siendo las actividades económicas quienes fomentan el incremento de la productividad. El autor realizó un caso en Polonia, en el cual mostró que se dedican a diferentes negocios tratando de imitar los niveles de crecimiento que en la UE. Asimismo, destaca que la cantidad de MYPES en Polonia es mucho menor que en la UE, lo cual esparce las ganas de crecimiento en la población. De esta manera, el autor plantea que se debe apoyar a las MYPES en su desarrollo empresarial, por ejemplo, mediante la ampliación de sus horizontes más allá de los límites de su funcionamiento y la identificación de nuevas áreas de mejora y promoción de los productos y servicios que se ofrecen.

En coordinación con estos autores Dos Santos y De Barros (2014) narran acerca de la experiencia de una pequeña empresa de consultoría medioambiental y de que inclusive las más pequeñas pueden trabajar con la transparencia, la valoración de los empleados y el personal, mejorando continuamente su entorno, que reúne a socios y proveedores, la protección a los consumidores, la promoción de su comunidad, y compromiso con el bien común para así, aumentar su productividad. Como resultado, las microempresas puedan desarrollar sus actividades en armonía con los conceptos de responsabilidad social, contribuyendo a la construcción de la sostenibilidad. La falta de personal técnico y de recursos financieros puede 
ser suministrado con asociaciones de empresas de diversas áreas, cada uno de ellos puede contribuir proporcionando canales de difusión, recursos financieros, personal calificado, e información sobre los temas a tratar. Con la unión de todos estos aspectos se logrará una mayor participación de las MYPES en el país, obteniendo un mayor nivel de productividad.

Mungaray, Osuna, et al. (2015) manifiestan que el desarrollo de las micro y pequeñas empresas en la economía compensa la generación de empleo para hacerlas más productivas, ya que el auge de nuevas empresas en particular, de las pequeñas, genera oportunidades de negocio para desarrollar el talento y la creatividad empresarial. Los autores aseguran lo siguiente:

"Aun cuando su contribución productiva en términos de valor agregado es limitada, las cifras de su participación en establecimientos, empleo y autoempleo en América Latina y los países en desarrollo, permiten a este segmento empresarial mitigar los efectos de los ciclos económicos, favorecer una mejor distribución del ingreso y generar mejores condiciones de crecimiento con equidad.” (Mungaray, Osuna et al, 2015, p. 04)

Es así como el sector de la microempresa eleva su productividad; los autores señalan que la generación de microempresas se crea tanto en momentos de crecimiento económico en la cual priorizan las oportunidades que genera una economía en crecimiento, así como en épocas de crisis económica, donde surgen nuevos emprendedores que, ante la falta de opciones en el mercado laboral, buscan crear su espacio mediante la formación de una nueva empresa.

Así también, Hamann y Hernani (2013) constatan que las “micro y pequeñas empresas” forman, dentro de todo el sector empresarial, el grupo fundamental de empresas y en algunas oportunidades superan el 90\%. Estas colaboran con la creación de empleo, la generación de ingresos y a satisfacer necesidades en ciertos mercados que son poco atractivos para las grandes empresas. Además, es un medio para fomentar el desarrollo de la población y formar los futuros grandes empresarios. Es así, que la mejora de un país debe tener como uno de sus elementos estratégicos el de darle relevancia a este tipo de empresas.

Según Tello (2014), la MYPE es una de las principales fuentes de empleo, además, establece un factor relevante para la empresa al momento de resolver cuellos de botella que impiden incrementar la productividad de la misma. Asimismo, el autor asegura que el desarrollo económico de un país está directamente relacionado con el crecimiento de su PBI. Para dar este crecimiento, el país debe enfocarse en promover la investigación, la ciencia y la tecnología, ya que contribuyen al desarrollo de una nación.

Tal como afirman García (2015) el éxito de las empresas repercute en forma positiva en el desarrollo económico y en la competitividad del país. Adicionalmente, las microempresas han obtenido cada vez mayor significancia, por el hecho de que tales organizaciones tienen la 
capacidad de generar puestos de trabajo con menores requerimientos de capital, demostrando el potencial innovador para hacer frente a la flexibilidad productiva. De esta manera, el autor señala la Ley 905 de 2004: sobre la promoción del desarrollo de la micro y pequeña empresa, en donde el Artículo 1 estipula lo siguiente: "Estimular la promoción y formación de mercados altamente competitivos mediante el fomento a la permanente creación y funcionamiento de la mayor cantidad de micro, pequeñas y medianas empresas, Mipymes"

Cabe resaltar la investigación de Gomero (2015), quien manifiesta que las MYPES buscan beneficios para sus organizaciones a través de espacios económicos que les asegure el control del mercado, reducir costos, fomentar la participación tecnológica, medios que los conducirá a desarrollar su competitividad y asegurar su sostenibilidad. En base a todo esto, a largo plazo podrán observar el crecimiento de su productividad. Las MYPES, a pesar de sus deficiencias forman parte de un rol importante en el proceso de crecimiento económico del país. Si bien cierto que sus procesos productivos aún tienen que mejorar para responder a las exigencias del mercado, estas organizaciones crecen en un terreno lleno de dificultades, como el de las aperturas de los mercados; sin embargo, bajo estos difíciles escenarios aprenden a ganar fortalezas y convertirse en importantes contribuidores a la formación del PBI.

Carvalho y Costa (2014) aseguran que las microempresas en todo el mundo son consideradas como el elemento vital de las economías, ya que contribuyen a la generación de empleo, así como fomentar la competitividad en las empresas. Esta competitividad se visualiza mediante el uso de indicadores, tales como los ingresos, la satisfacción del cliente, el valor del producto, el beneficio y la productividad.

En relación con los autores señalados, según Mustafa (2016) la mejora en los sectores financiero, legal y fiscal tienen una influencia positiva en el desarrollo del sector privado. Las funciones del sector privado en diferentes ramas tales como la productividad, la restauración y el comercio lograron resultados importantes en el desarrollo económico en diferentes países del mundo, este sector constituye la mayor parte del PBI en muchos países a través del desarrollo y crea aproximadamente el $90 \%$ de las plazas de trabajo en el mundo (Banco Mundial, 2012). También en muchos países, la empresa privada genera una parte importante de los ingresos por impuestos para proporcionar servicios de educación, salud y otros públicos. El sector privado se encuentra entre las principales fuentes de crecimiento económico, ya que fomenta la creación de puestos de trabajo, la disminución de la pobreza y el aumento de los ingresos públicos.

En dirección a que la productividad empresarial aumente, según Rivera, Gligor, et al. (2016) los beneficios encontrados dentro de su investigación revelaron que, la aglomeración de empresas de logística o del sector industrial ofrecen varios beneficios claves para las empresas. 
El agrupamiento empresarial facilita los beneficios relacionados con la colaboración, la oferta de servicios de valor agregado, la movilidad profesional para la fuerza laboral logística dentro del cluster y promueve el crecimiento del empleo en múltiples niveles dentro del cluster. Los autores ofrecen una rica descripción de estos beneficios y los mecanismos que facilitan estos resultados, estos son el intercambio de conocimientos, la formación de una mano de obra, el desarrollo de una base de proveedores, entre otros.

Para lograr que la productividad aumente, la economía nacional crezca en relación con el PBI y disminuya la pobreza se debe desarrollar la gestión por procesos dentro del sector empresa en el rubro de MYPES. Como señalan Sujova y Marcinekova (2015) el enfoque basado en procesos se considera como un sistema de gestión seguro que las empresas deben optar por seguir para ser competitivas en un mercado globalizado. Durante el desarrollo de la gestión por procesos es necesario utilizar principios y métodos de gestión que aseguren un proceso continuo y optimizado. En este artículo, se muestran una serie de métodos incorporados en Eslovaquia en empresas industriales dirigidas a la medición y gestión del rendimiento en su entorno, tales como: Balanced Scorecard (BSC), Seis Sigma, Costeo Basado en Actividades (ABC), Modelo de Excelencia: Fundación Europea para la Gestión de la Calidad (EFQM), Gestión de Calidad Total (TQM), Mantenimiento Productivo Total (TPM), Kaizen, Método 5S, Normas ISO, la evaluación comparativa y el control de proceso. En conjunto, todos estos métodos de gestión al desempeñar un trabajo eficiente aumentan la productividad del sector empresa. Los resultados confirman el supuesto de que las empresas que utilizan métodos modernos de gestión de procesos han logrado alcanzar los mejores resultados de rendimiento corporativo, siendo los más empleados las normas ISO, Gestión de Calidad Total y la evaluación comparativa. Por otro lado, más del 30\% de las empresas en este estudio no aplican ningún método de gestión por procesos. A largo de la investigación, se identifica que las MYPES agrícolas deben desarrollar una gestión por procesos para estandarizar sus procesos y obtener mayor participación en el mercado global.

Según Alharithy (2015) gracias al empleo de los procesos se fomenta la diversidad de actitudes estratégicas en las organizaciones, el impacto de la alta gerencia, el pensamiento común en la gestión del conocimiento, el tamaño de las organizaciones, las actividades sectoriales y su interés por el desarrollo. Además, indica que la integración es un factor importante y que el uso de modelos opera como un marco de referencia para una organización que busca implementar y aplicar la gestión del conocimiento.

De igual forma Hrušecká (2016) sostiene que la planificación de la producción y la programación es uno de los procesos de negocios más importantes que influyen 
significativamente en el rendimiento de las empresas de fabricación, es decir, que aumenta su productividad. Si estos procesos presentaran problemas individuales y alta complejidad de la sincronización de todos los procesos empresariales que influyen en la calidad de los datos de entrada para la planificación de la producción y programación, el nivel de rendimiento empresarial sería inferior y, por ende, disminuiría la productividad.

El artículo de Da Silva, Damian, et al (2012) señala que el modelo de gestión tradicional mejora el rendimiento de los procesos y es necesario contar con un enfoque organizacional que defina los objetivos de esta. Los autores ratifican que, al ir avanzando en la gestión de los procesos, las empresas tendrán un mejor control de sus resultados, una mejor predicción de los objetivos, costos y rendimiento; lograrán ser más eficientes en el logro de sus objetivos y la mejorar la capacidad de gestión para proponer innovaciones.

Del mismo modo, Cronemyr y Danielsson (2013) sostienen que las organizaciones que se desarrollan en la gestión por procesos empiezan con un nivel muy avanzado en comparación con otras organizaciones.

Según Arellano, Carballo, et al (2013) toda organización debe establecer un plan estratégico en el que desarrolle su visión, misión y estrategias, es decir, los fines que pretende lograr a largo plazo, así como los medios a través de los cuales pretende lograr sus objetivos y metas, estos son los procesos. Adicionalmente, para asegurar el cumplimiento de estos fines a través de los procesos, se requiere la adopción de un enfoque de gestión diferente al tradicional, este es el enfoque por procesos. Este enfoque pretende que se promueva la entrega al cliente de productos y servicios de calidad, se eleve el nivel de satisfacción del cliente externo e incremente la productividad interna, así como se reduzcan costos al eliminar actividades que no generan valor agregado al cliente final.

Llanes, Isaac, et al (2014) y Torres (2014), afirman que con mejorar la integración del sistema organizacional se logra los objetivos de eficacia, eficiencia y flexibilidad planificados y la integración con la aplicación de herramientas informáticas, las etapas de planificación, operación, evaluación y mejora del proceso integrado. Asimismo, el nivel de integración hace que un cambio producido en cualquiera de los procesos produzca cambios en los demás y hasta en el sistema mismo. El beneficio del enfoque en procesos establece que "un resultado deseado se alcanza más eficientemente cuando las actividades y los resultados relacionados se gestionan como un proceso". Una gestión por procesos permite operar una organización de manera más sistemática y transparente.

Sujova, Rajnoha y Merková (2014) quienes aseguran que una de las tendencias actuales en la gestión empresarial es la implementación del enfoque en procesos a las funciones de la empresa. 
Este enfoque basado en procesos es considerado como una herramienta clave para la mejora de procesos de la organización. Asimismo, la aplicación de los principios de la gestión por procesos genera una gran cantidad de cambios con efectos positivos como una mayor competitividad, aumento de la productividad y mejor rendimiento de la empresa. El artículo trata de los resultados de la investigación cuantitativa realizada en empresas eslovacas, centrándose en el análisis de los principios, métodos y herramientas de gestión por procesos utilizados en estas empresas en la rama de procesamiento de la madera. En adición, una vía actual para evaluar el rendimiento en la compañía se basa en la medición del desempeño de los procesos de negocio conocido como gestión del rendimiento de los procesos. Esta es una identificación sistemática, una visualización, una medición, una evaluación y una mejora permanente de procesos de la empresa utilizando métodos y principios basados en el enfoque por procesos.

Para desarrollar este enfoque basado en procesos es de suma importancia realizar el levantamiento de la información. Según Cridland, Jones, et al. (2015) señalan que el uso de realizar entrevistas semi estructuradas o mixtas genera mayores beneficios que otros tipos de entrevistas. Estas vienen a ser una mezcla entre las preguntas abiertas y cerradas. Las entrevistas semiestructuradas son una de las más utilizadas en áreas de investigación. Las entrevistas semiestructuradas implican conversaciones profundas entre el investigador y el entrevistado, que tienen un propósito global motivado por los objetivos de la investigación, pero están fuertemente guiados por las percepciones, opiniones y experiencias del entrevistado. Los beneficios del uso de entrevistas semiestructuradas incluyen flexibilidad para enfocarse en temas que son significativos para los participantes, permitiendo la diversidad de percepciones en lugar de ser inhibidos por categorías de respuesta "estándar" o "esperado", y la minimización del control del investigador sobre la expresión de sus experiencias por parte de los participantes. Para desarrollar la gestión por procesos se utilizan una serie de herramientas, tales como el mapa de procesos, el flujograma, SIPOC, indicadores, Six Sigma y la lluvia de ideas como los más relevantes. Según Gao, Christensen y Kornov (2017) destacan que, como portador de información y medio de comunicación, los indicadores proporcionan una ayuda útil para la toma de decisiones en la fijación de objetivos del proceso y en el logro efectivo de las metas de la organización. Un indicador es una medida de las variables a lo largo del tiempo para describir, supervisar el entorno de referencia y para predecir los impactos (de una política / plan / programa propuestos). Por lo tanto, los indicadores son una herramienta útil en la toma de decisiones y la planificación. 
Asimismo, otra herramienta de la gestión por procesos son el diagrama SIPOC y la herramienta Six Sigma quienes a través de Mishra y Kumar (2014) identifican que el SIPOC es un acrónimo, donde los proveedores son los que suministran bienes o servicios, los insumos son los recursos, como las personas, materias primas, la información y las finanzas que se ponen en un sistema para obtener una salida deseada, el proceso convierte entradas en salidas, y, por último, se llega a los clientes de la cadena de suministro. En la revisión de la literatura, el diagrama SIPOC está construido para identificar los problemas reales en el proceso de fabricación, los clientes internos o externos, su requisito para el producto, así como, requisitos de entrada, y salidas del proceso. Por otro lado, Six Sigma es un programa centrado en el proceso que tiene como objetivo mejorarlo siguiendo una metodología sistemática basada en el SIPOC. Six Sigma es un enfoque basado en el equipo a la solución y mejora de procesos. En la búsqueda de un mejor desempeño operacional y mayor satisfacción del cliente, Six Sigma ha sido reconocida como una metodología sistemática y estructurada de los intentos de mejorar la capacidad del proceso a través de centrarse en las necesidades del cliente. Es así como los autores utilizaron el definir, medir, analizar, mejorar y controlar para integrar los aspectos humanos (cambiar la cultura, la formación y la orientación al cliente) y los aspectos del proceso (proceso de estabilidad y capacidad, la reducción de la variación) dentro de la implementación del Six Sigma.

Según Malinova y Mendling (2013) señalan que los mapas de procesos son utilizados intensivamente por las organizaciones para proporcionar una visión integral total y global de todos los procesos y las relaciones entre ellos. Estos ayudan a mejorar en la búsqueda a través de los procesos y permiten una comprensión de las operaciones de la compañía sin necesariamente entrar en profundidad del proceso. Los mapas de procesos son adoptados por las organizaciones como la base de las iniciativas de gestión por procesos en las empresas. Ellos desempeñan un papel importante en proporcionar una visión general de todos los procesos, de tal manera que el funcionamiento básico de una empresa puede entenderse sin entrar necesariamente en detalles. El mapa de procesos se centra en describir clasificaciones, relaciones y dependencias entre procesos singulares. Estos aspectos se muestran típicamente como una representación visual que sirve como medio para la comunicación básica y para una mejor comprensión de los procesos de negocio actuales.

Rolón, Chavira, et al. (2015) describen que los modelos de procesos en las empresas (BPM) tienen una amplia gama de usos, tales como soportar procesos de reingeniería, simulación o ser una base a través de la cual desarrollar sistemas para automatizar los procesos del modelo. Además, los BPM pueden ser creados o presentados utilizando muchas metodologías o lenguajes de modelado diferentes, como IDEF 0, IDEF 3, UML, UML 2.0 y BPMN. BPMN 
(Business Process Model and Notation) es un lenguaje diseñado específicamente para el modelado de procesos empresariales (organizacionales). Se ha encontrado con una aceptación general en los círculos empresariales e institucionales gracias a que ha sido concebido para ser utilizado y comprendido por cualquier tipo de funciones (directores, expertos en calidad, analistas de negocio, analistas de sistemas, ingenieros, etc.), sin necesidad de conocimientos técnicos especiales. BPMN proporciona una notación gráfica que expresa todos los aspectos de los procesos por un solo tipo de diagrama. Además, fue diseñado para cubrir muchos tipos de modelado y permite la creación de procesos de negocio de extremo a extremo. En adición, proporciona una notación gráfica mediante la cual expresar los procesos de negocio en un Business Process Diagram (BPD), basado en una técnica de diagrama de flujo adaptada para crear modelos gráficos de operaciones de procesos de negocios, permitiendo así el fácil desarrollo de diagramas simples.

Como última herramienta a presentar se destaca a la lluvia de ideas, de acuerdo con Shakir, Zaiyana, et al. (2012) aseguran que la lluvia de ideas es una serie de procedimientos (reglas) diseñados para maximizar la productividad de los grupos que participan en la generación de ideas mediante la reducción de la pérdida de producción, ya que es una de las herramientas más conocidas para el pensamiento creativo. La lluvia de ideas también se identifica como una técnica de una variedad de herramientas para generar ideas y que muchas personas pueden producir en comparación con trabajar solos.

Ahora bien, la gestión por procesos incrementa la productividad de las MYPES, pero se tiene que desarrollar cada proceso para mantener todo en equilibro y una sincronizada administración de estos estrechamente relacionados, tales procesos a analizar son: Planeamiento y Control de la producción, Seguridad, Comercial, Costos, Calidad y Logística. Este último será el desarrollado de manera profunda en toda la investigación, debido a que el proceso logístico involucra los procesos de compras, almacenamiento, inventarios y distribución. Su importancia radica en el flujo de información, flujo de materiales y flujo de capital que al optimizarse generan el crecimiento de una empresa, según señala el gerente general de GS1 Perú. De acuerdo con Kherbach y Liviu (2016) un mercado con un proceso logístico eficientemente organizado y sus instalaciones de gestión de la cadena de suministro igualmente optimizadas tienen una ventaja sobre otras economías, mientras que la mejora de la infraestructura logística puede servir como una herramienta competitiva y también es eficaz en el aumento de márgenes de ganancia. Este artículo señala como el sector empresa de Rumania se encuentra trabajando en realizas mejoras a sus procesos logísticos y, además, que la gestión de la cadena de suministro es vital para los países emergentes con el objetivo de mejorar su competitividad. 
Para lograr una eficiente gestión se debe empezar por generar la capacidad de las organizaciones para movilizar las mercaderías entre países de forma más rápida, de manera consistente y con un precio más cómodo. Los autores también señalan que: "La logística y SCM tiene tanto los efectos positivos y negativos sobre la aparición de las MYPES. Por un lado, SCM puede suministrar calidad, costo, servicio al cliente, el apalancamiento e incluso la reducción del riesgo por devolución para las MYPES. Por otra parte, se expone a las MYPES a mayores riesgos de gestión y control, al tiempo que reducen sus beneficios de diferenciación privada" (p. 05).

Asimismo, Prajogo, Oke y Olhager (2016) señalan que la integración logística afecta directamente el rendimiento de la organización, este estudio demuestra la importancia de la gestión de los procesos internos (procesos de producción) y externos (logística y cadena de suministro) de las organizaciones de forma integrada en los que la logística actúa a través de los procesos internos claves para influir en el rendimiento competitivo.

Según Mellat y Spillan (2013) la logística y la gestión de la cadena de suministro, el proceso de gestión de los flujos de material y el flujo de información, a través de la empresa y el cliente, ha sido reconocido como una parte importante de la estrategia organizacional de una empresa. Sin embargo, la integración logística sigue siendo un desafío, debido a la complejidad y la participación de múltiples organizaciones.

Del mismo modo Penteado y Chicarelli (2015) afirman que las mejores prácticas de logística están sujetas a cambios continuos que están asociados con la estructura de la cadena de suministro y las mejoras de la estrategia.

En unión con estos autores Ceniga y Sukalova (2015) aseguran que la logística es un motor clave del crecimiento económico, la creación de riqueza y empleo. Las empresas de logística y de transporte no sólo facilitan el suministro de materias primas y materiales, sino que también son cruciales cuando se trata de montaje y almacenamiento de productos, y en conseguir los productos terminados al mercado. La logística conecta a la gente y los mercados a través de una red física que es tan importante como la red virtual de Internet.

Forslund (2014) asegura que el desempeño de la logística es importante para la satisfacción del cliente y la lealtad. El artículo describe a la gestión del rendimiento de la logística entre proveedores y fabricantes como un proceso secuencial, es decir, el proceso de gestión del rendimiento. También se evidencian algunos problemas que se dan en el proceso de logística y que deben resolverse a prioridad, estos son falta de confianza; dificultades para desarrollar una cultura colaborativa; dificultades para relacionar las métricas con el valor del cliente y carecer de soporte de TI. 
El proceso de logística está conformado por cuatro sub procesos, estos son compras, almacenamiento, inventarios y transporte. Según Nair, Jayaram, et al (2015) los autores describen cómo la participación estratégica del área de compras es base para desarrollar las actividades de gestión de la oferta a través de la elección de los criterios operacionales y estrategias adecuadas. El estudio se centra en la selección de proveedores y el seguimiento de la evaluación continua del desempeño del proveedor en base a criterios operativos y estratégicos. Una combinación de la elección de los criterios de selección de proveedores adecuados y controlar el desempeño de los proveedores asegurará que el beneficio de la participación en la planificación estratégica de compras se traducirá en un mejor rendimiento de compra de los costos, la calidad, la entrega, la flexibilidad y la innovación.

Por otro lado, Huber, Klauenberg y Thaller (2015) aseguran que la creciente importancia de la logística y sus efectos en los procesos de transporte se han considerado en la modelización de la demanda de transporte de mercancías por nuevos desarrollos de modelo que incorporan varios aspectos logísticos. Los centros logísticos de transporte tienen un papel importante, especialmente en relación con la gestión y gastos de envío.

Por el lado del almacenamiento, Hedler, Alpan, et al. (2015) manifiestan que a medida que las cadenas de suministro se vuelven más complejos, la variedad de indicadores y herramientas para medir el rendimiento de los almacenes también ha aumentado. El papel estratégico de los almacenes es bien reconocido en una cadena de suministro. Debido a la creciente complejidad de las redes de logística, el análisis de rendimiento de los almacenes se ha convertido en un tema importante.

Finalmente, Salam, Panahifar, et al. (2016) detallan que en su estudio la importancia de la gestión de los inventarios asegura el nivel de servicio en una empresa. En la industria minorista competitiva de hoy en día el factor de éxito más crítico es el servicio al cliente que se indica por la disponibilidad del producto. Se argumenta que, en la industria minorista, la disponibilidad de productos es una medida importante de calidad. La decisión más importante que cada minorista tiene que hacer es, cómo maximizar el nivel de servicio manteniendo el nivel de inventario mínimo, es decir, que existe una relación directa entre el nivel de inventario y el nivel de servicio al cliente. Los resultados sugieren que el logro de un nivel de servicio receptivo depende de la gestión de una cadena de suministro eficiente además de las reducciones de costos logísticos. Los resultados también revelan el efecto del nivel de inventario en el nivel de servicio. 
En general, el desarrollo del proceso logístico y sus subprocesos dentro de las MYPES es de suma importancia debido a que, gestiona e integra todos los procesos de la organización para una mejor participación en el mercado.

\subsection{CASOS DE ÉXITO}

\subsubsection{Caso de éxito $\mathrm{N}^{\circ} 1$ : Estudio de 2 empresas de servicios de Brasil}

El estudio se realizó en dos empresas que operan en el sector de servicios en varias regiones de Brasil, y el criterio para la selección de estas empresas fueron las organizaciones de los sectores de servicios que han crecido y están haciendo grandes cambios en su modelo de gestión, las decisiones y las acciones pertinentes relevante para la propuesta de este trabajo y también para facilitar el acceso a los encuestados. Las dos compañías han crecido en los últimos cinco años y ha iniciado proyectos para promover BPM. Por lo tanto, la selección de las empresas se basa en un crecimiento rápido, los cambios en la gestión de los procesos relacionados y la necesidad de gestionar los procesos para mantener el nivel de calidad de los servicios.

Una de las empresas estudiadas ha estado en funcionamiento durante 40 años y el otro es una empresa relativamente joven que ha operado en el mercado durante siete años, sin embargo, ambos son de buena reputación y conocidas en el segmento debido al nivel de la calidad del trabajo y la dedicación a su servicio.

Se ha dictado seminarios, cursos, presentación de casos prácticos y visitas a empresas que han implementado BPM sugerida para el aprendizaje organizacional, e implican no sólo la fuerza laboral de la organización, sino también los clientes, proveedores y socios.

Asimismo, señalan que tener documentados todos los procesos que se ejecutan en una empresa supone elaborar una serie de documentación, la cual tienen que estar revisando constantemente, dado que "la empresa es un ser vivo" y los procesos van cambiando con el tiempo.

\subsubsection{Caso de éxito $\mathrm{N}^{\circ} 2$ : Pequeña empresa mexicana de productos de maíz}

En este caso de éxito según Arellano, Carballo, et al (2013) la empresa bajo estudio gestionaba los procesos de manera informal, es decir, en base a la experiencia del personal que tenía a cargo. Aun cuando sus productos han sido aceptados desde hace aproximadamente 26 años, los autores dedujeron que los procesos y la administración ha sido controlada; sin embargo, no se conoce con certeza qué tan eficiente y maduros son estos, por lo que plantean como objetivo determinar el nivel de madurez de los procesos de la empresa productora de tostadas para 
identificar propuestas de mejora que promuevan posicionarla en un nivel superior. El análisis de madurez de procesos facilita identificar puntos débiles que pueden obstaculizar el proceso de madurez sostenido de la empresa.

La finalidad del proyecto propuesto por los autores es diseñar un método que permita el procesamiento de la información de manera automatizada, utilizando tecnología disponible, y teorías usadas en programación de sistemas de información. De esta manera, al optimizar todo se mejorará las deficiencias de la organización.

Como resultado de esta investigación, los procesos claves obtuvieron un 32\% de cumplimiento, mientras que los procesos estratégicos solo un 15\%, dejándolos de lado. En general, el porcentaje de cumplimiento de los procesos organizacionales es de un $24 \%$.

En términos de gestión organizacional la empresa tiene definida su misión y visión, pero el personal no la conoce. Por otro lado, la organización no ha establecido su planeación estratégica, solo ha planeado a nivel departamental y operativo. Además, la organización tiene identificadas las normas y reglamentos sobre el cuidado del personal, pero no se han implementado sistemas de gestiones integrales de seguridad y salud. Por último, se cuenta con poca documentación.

La mejor solución para estos problemas es la gestión por procesos desarrollado a través del concepto de madurez, el cual permite incorporar una métrica para definir la madurez de los sistemas, y realizar un seguimiento entre los diferentes niveles de madurez propuestos por los modelos mostrados en el artículo.

\subsubsection{Caso de éxito $\mathrm{N}^{\circ}$ 3: Empresas de Eslovaquia}

Los resultados de la investigación cuantitativa primaria en Eslovaquia empresas industriales confirman la hipótesis de que las empresas que utilizan métodos modernos de gestión de procesos empresariales han alcanzado los mejores resultados de rendimiento corporativo representado por el retorno indicador sobre recursos propios (ROE). Los métodos de gestión de procesos más utilizados en las empresas de fabricación eslovaca son las normas ISO, Gestión de Calidad Total y la evaluación comparativa.

Por otra parte, más de 30\% de las empresas que no usan la gestión por procesos desconocen que para alcanzar valores más altos de ROE es posible mediante el uso de los principios de gestión por procesos y métodos modernos, especialmente en las empresas de producción en masa. Por otra parte, se confirmó la relevancia entre el nivel de aplicación de gestión de procesos y el nivel alcanzado de ROE en las empresas eslovacas implementando los procesos internos a nivel cualitativo superior, quienes tienen mayores valores de indicador de ROE. 
Algunos hallazgos mencionados llegan a la conclusión de que las empresas eslovacas en objetivo de lograr un mayor rendimiento corporativo deben prestar atención a la gestión de los procesos internos utilizando las modernas concepciones y métodos de gestión por procesos y orientado al cliente para ser más competitivas.

\subsubsection{Caso de éxito $\mathrm{N}^{\circ} 4$ : Empresas de fabricación Checa}

La investigación en el logro de beneficios esperados de una avanzada tecnología implementada para planificación y programación en la fabricación de empresas Checa demostraron que el nivel de su rendimiento es inferior al 75\%. La consecuente cualitativa entrevista basada en la investigación mostró que las principales razones de este hecho son problemas individuales y alta complejidad de la sincronización de todos los procesos empresariales que influyen en la calidad de los datos de entrada para la planificación de la producción y programación.

Los resultados de las actividades de investigación, presentados en el artículo, mostraron que la tecnología avanzada y el alto nivel de gestión de procesos son dos condiciones inseparables para la planificación y programación de la producción eficiente y el logro de los resultados esperados en forma de alto rendimiento de todo el sistema de producción.

Por lo tanto, en los próximos pasos de la investigación, un modelo de sistema simple de los factores clave que afectan planificación y programación fue creado como un modelo básico para la formulación del modelo matemático abstracto complejo. El método de evento-B fue elegida para crear el modelo matemático formal basado en la obligación prueba debido a su simplicidad en el uso de refinamientos y la máxima fiabilidad.

\subsubsection{Caso de éxito $\mathrm{N}^{\circ}$ 5: Empresa pesquera Sancti Spíritus "PESCASPIR"}

Pérez, De la Cruz \& Marrero (2015) trabajaron con la empresa pesquera Sancti Spíritus "PESCASPIR". Dentro de las estrategias de la empresa, no se consideraban estrategias en enfoque de procesos para garantizar la efectividad de los mismos, tampoco indicadores que permitan el control y seguimiento de los procesos. Por otra parte, el incumplimiento de requisitos de calidad generaba devoluciones y en oportunidades no se cumplía con la demanda de productos pesqueros.

El estudio estuvo orientado a la mejora de procesos. La investigación consistió en desarrollar procedimientos que permitan la coordinación y organización de los procesos, teniendo en cuenta la definición de responsables, documentación e interrelaciones. El estudio consistió en seis etapas: La formación del equipo, la familiarización con la situación actual de la 
organización en lo que refiere a procesos, identificación y clasificación de los procesos, interrelaciones de los procesos, documentación y diseño de los procesos; por último, implantación, seguimiento y control. Se obtuvieron como entregables el mapa de procesos de la empresa PESCASPIR, la ficha de indicadores, y la ficha del subproceso de Picadillo de pescado congelado.

Al implementar lo propuesto por los autores, se obtuvieron como resultados una organización panorámica de los procesos, lo cual le permitió a la empresa el poder comprender y relacionar las interacciones y funciones de cada proceso. Adicional a ello, la ficha del subproceso de picadillo de pescado dio paso a la recopilación de información necesaria para la precisión de la actividad, y consiguió el realizar seguimiento para futuras mejoras.

\subsection{MARCO TEÓRICO}

En esta parte se realizará una investigación acerca de términos que ayudarán a una mejor comprensión del trabajo de investigación.

\subsubsection{Pobreza}

Según Carlos Parodi (2012) uno de los indicadores más relevantes para medir el desarrollo del bienestar es el nivel de pobreza de un país. En el caso de Perú, se utiliza el término de pobreza monetaria para calcular la pobreza "oficial”. De acuerdo con el INEI (2016) se considera como pobres monetarios a las personas que habitan en hogares cuyo presupuesto per cápita es escaso para obtener una canasta básica de alimentos y otros aspectos como la vivienda, vestido, educación, salud, transporte, entre otros. Se considera que son pobres extremos aquellas personas que forman parte de hogares cuyos gastos per cápita son inferiores a los de la pobreza monetaria. La medición monetaria utiliza el gasto como indicador de bienestar, el cual está compuesto no solo por las compras sino también por el autoconsumo, el auto suministro, los pagos en especies, las transferencias de otros hogares y las donaciones públicas. Asimismo, una línea de la pobreza es un límite, que indica el costo de una canasta básica. Por ende, aquellos, cuya capacidad de gasto es menor que la línea, son considerados pobres.

Según el Banco Mundial (2015), en base a la información recaudada, menciona "En la actualidad aún hay casi 1000 millones de personas que subsisten con menos de $\$ 1,25$ al día" En efecto, Esmaeeli y Sadighi (2017) indican que el crecimiento económico contribuye con la reducción de la pobreza, ya que la inversión en investigación agrícola e industrial puede tener gran beneficio hasta ayudar a la disminución de este factor. 


\subsubsection{Crecimiento económico y PBI}

En relación con el crecimiento económico, según el Instituto Peruano de Economía (2016) esta se define como la variación porcentual en forma positiva del producto bruto interno (PBI) de una economía en un tiempo determinado, dado que parte de este crecimiento puede deberse al aumento de la población, sugieren utilizar la variación del PBI per cápita como medida del crecimiento económico. Asimismo, entre los principales factores que determinan este crecimiento destacan la productividad y la acumulación de capital. Por el lado de la productividad de los factores se refiere al desarrollo de procesos más eficientes para producir bienes y servicios; sin embargo, por el lado de la acumulación de capital se refiere al aumento de recursos de capital, lo que incluye capital físico como la infraestructura y los bienes de capital, y, capital humano como las competencias de la fuerza laboral.

De acuerdo con Carlos Parodi (2014) el crecimiento económico significa producir más y se mide a partir de la tasa de variación porcentual con respecto del año previo, mientras que el PBI es el valor de mercado de todos los bienes y servicios finales producidos en una economía durante un período de tiempo; siendo así, cuando el PBI aumenta significa que se produce más. Sin embargo, el aumento en el PBI es solo un medio y no un fin en sí mismo. El fin de cualquier estrategia es el desarrollo, es decir, el aumento en la calidad de vida de los habitantes de un país. Crecer es producir más, desarrollar es mejorar la calidad de vida.

\subsubsection{MYPES}

\subsubsection{Definición}

De acuerdo con Yamakawa, Del Castillo, et al. (2010) se define a la Micro y Pequeña Empresa (MYPE) como la unidad económica formada por una persona natural o jurídica, bajo cualquier modo de organización o gestión empresarial observada en la legislación vigente, que tiene como objeto desarrollar actividades de extracción, transformación, producción, comercialización de bienes o prestación de servicios. Las MYPES se caracterizan por ser una empresa que es propia y operada por una persona individual, una familia, o un grupo de personas de ingresos relativamente bajos, cuyos propietarios son quienes tienen la única decisión sobre los precios, productos, mercados y otras variables. Estas constituyen una importante fuente de ingresos para la familia (unidad básica social), convirtiéndose así en un componente importante de la economía local. 


\subsubsection{Características de MYPES}

Las características de las MYPES se basan en el número de trabajadores y el nivel de ventas, es decir, la microempresa abarca de 1 a 10 trabajadores y/o tiene un monto de ventas anuales hasta el monto máximo de 150 unidades impositivas tributarias (UIT). Por otro lado, la pequeña empresa abarca de 1 a 100 trabajadores y/o un monto de ventas anuales de 150 hasta 1700 UIT. La siguiente figura resume los aspectos considerados para definir a la MYPE en términos de número de trabajadores, ventas brutas anuales y organización empresarial. (Yamakawa, Del Castillo, et al., 2010, pp. 30)

Tabla 1: Criterios para definir una MYPE en el Perú

\begin{tabular}{cccc}
\hline Tipo de empresa & Trabajadores (N) & $\begin{array}{c}\text { Ventas Brutas Anuales } \\
(\text { VBA }) \text { en UIT }\end{array}$ & Organización \\
\hline Microempresas & $1<=\mathrm{N}<=10$ & VBA $<=150$ UI & $\begin{array}{c}\text { Persona natural o } \\
\text { jurídica }\end{array}$ \\
Pequeña empresa & $1<=\mathrm{N}<=100$ & 150 UIT $<$ VBA $<=1700$ & $\begin{array}{c}\text { Persona natural o } \\
\text { jurídica }\end{array}$ \\
\hline
\end{tabular}

Fuente: Ley MYPE, Elaboración: Yamakawa, et al. (2014)

En el contexto de características comerciales y administrativas estas incluyen que la administración sea independiente, es decir manejada por sus propios dueños, su incidencia en el mercado no es tan significativa, y su área de operación es relativamente pequeña, sobre todo local. Las MYPES tienen escasa o nula preparación en el trabajo, tanto en el ámbito productivo como en el administrativo, y no suelen utilizar técnicas de gestión. Como utilizan poco personal dependen en gran magnitud de la mano de obra familiar. Además, no cuentan con mucha mano de obra fija o estable.

\subsubsection{Tipos de MYPES}

Según el Ministerio de la Producción (PRODUCE) (2011) se evidencian tres tipos de MYPES, estos son Nuevos Emprendimientos, Microempresa de subsistencia y Micro y pequeña empresa de acumulación. En el primer caso, las MYPES de nuevos emprendimientos han surgido por iniciativas concebidas por un enfoque de oportunidad; los emprendedores son personas que buscan su autorrealización y la generación de sus propios ingresos, también apuntan a la innovación, a la creatividad y a un cambio en su calidad de vida. Asimismo, asume riesgos y condiciones de trabajo dificultosas, por otro lado, se observan dos enfoques, el primero de ellos es el enfoque de oportunidad en donde las personas presentan un alto nivel educativo, cuentan con relaciones comerciales cuyos clientes son empresas y se centran en sectores económicos 
dinámicos. El segundo enfoque es el de necesidad donde se asocian personas de bajo nivel educativo, se instalan en sectores tradicionales tales como los artesanos, productores agrarios, trabajadores independientes, entre otros. Además, la inversión es pequeña y su cliente final es el usuario. En segundo caso, el otro tipo de MYPE es la Microempresa de Subsistencia que son unidades económicas sin capacidad de generar utilidades, lo cual perjudica y pone en peligro su capital, por ende, no requieren de mayor exigencia de transformación. El ultimo tipo de MYPE es el de Acumulación, ya que se enfoca en la capacidad de generación de utilidades que le permita mantener y desarrollar su capital con el cual inició y también poder invertir en el crecimiento de la MYPE.

\subsubsection{Problemas recurrentes en las MYPES}

Tal como afirman Yamakawa, Del Castillo, et al. (2010) las dificultades que se observan en las MYPES se centran en acceso al mercado, financiamiento, innovación y transferencia tecnológica, capacitación y asesoría, capacidad gerencial, informalidad, cultura y conocimiento, participación individual, y desarticulación empresarial.

Uno de los mayores problemas de las MYPES es su dificultad de acceder al mercado. También, la imposibilidad de las MYPES de contar con el capital financiero adecuado para incrementar su productividad se constituye en un obstáculo importante para su desarrollo. El hecho de desarrollar las capacidades empresariales personales es un requerimiento esencial que pasa por el análisis de la propia experiencia y de la competencia. Además, el acceso a tecnologías actualizadas es otro de los factores críticos para que las pequeñas empresas mejoren sus procesos de producción y gestión y sean competitivas.

\subsubsection{Asociatividad}

\subsubsection{Definición}

Según Vergara, Morelos, et al. (2012) la asociatividad empresarial es una estrategia que potencia que permite tener una ventaja competitiva respecto a otras empresas, mediante la identificación de objetivos y metas comunes de MYPES de igual o similar actividad económica, para afrontar la evolución del entorno. Además, los integrantes pueden decidir su independencia jurídica y autonomía gerencial y son ellos quienes voluntariamente deciden trabajar conjuntamente en sinergia con los otros participantes para tener mayor efectividad en el logro de objetivos comunes. 
En el Perú, la asociatividad para las MYPES constituye una herramienta importante respecto a la gestión estratégica, desarrollando esta característica es posible generar ventajas competitivas que traigan beneficios para las MYPES, para poder realizar esto es necesario desarrollar relaciones de confianza que permitan a las MYPES trabajar de forma conjunta modificando sus rutinas y generando un aprendizaje continuo.

Los beneficios que se busca al realizar una asociatividad entre MYPES es buscar la disminución de costos al realizar compras de manera conjunta, mayor poder de negociación frente a compradores, acceso a mercados que demandan mayores volúmenes y mejorar las capacitación y procesamiento de la información del mercado.

\subsubsection{Tipos de la Asociatividad}

De acuerdo con la Guía de Asociatividad del Comercio Exterior (2013) existen 10 tipos de asociatividad, estos son:

1. Subcontratación: Son relaciones verticales entre los distintos eslabones de la cadena de valor. En muchos casos, se trata de pequeñas o medianas empresas que orientan su producción a clientes grandes.

2. Alianzas Estratégicas: Son relaciones horizontales entre empresas que compiten en el mercado, pero que se unen y cooperan en ciertas actividades, como pueden ser investigación y desarrollo, compras, comercialización, entre otras.

3. Distritos Industriales: Son empresas regionales de una rama de la industria que se complementan mutuamente y cooperan de manera intensiva para fortalecer la competitividad de la aglomeración.

4. Núcleos Empresariales: Son equipos de trabajo formados por empresarios del mismo rubro, o de rubros diferentes con problemas en común, que se unen para compartir experiencias y buscar soluciones en conjunto.

5. Redes de Servicio: Son grupos de personas de una misma profesión, pero con diferentes especialidades, o un conjunto de instituciones que organizan un equipo de trabajo interdisciplinario para cubrir integralmente las necesidades de potenciales clientes.

6. Pools de Compras: Son grupos de empresas que necesitan adquirir productos o servicios similares y se reúnen con el objeto de aumentar el poder de negociación frente a los proveedores.

7. Grupos de Exportación: Varias empresas de un mismo sector se agrupan para encarar juntas un proyecto de exportación. Cuentan con un coordinador quienes les va guiando en el trazado de una estrategia que le permita al grupo colocar sus productos en el exterior. 
8. Cluster: Similar a las cadenas de valor, pero los actores están concentrados geográficamente y están interconectados en una actividad productiva particular. Comprende no sólo empresas, sino también instituciones que proveen servicios de soporte empresarial.

9. Joint Venture: Una nueva sociedad, constituida por dos o más empresas con personalidad jurídica independiente, que realiza una actividad empresarial a las estrategias competitivas de las empresas propietarias. Esta forma de cooperación implica la aportación de fondos, tecnología, personal, bienes industriales, capacidad productiva o servicios.

10. Consorcio: Es cuando dos o más personas se asocian para participar en forma activa y directa en un determinado negocio o empresa, con el propósito de obtener un beneficio económico. Los consorcios se pueden formalizar legalmente sin que las empresas pierdan su personería jurídica, pero con una gerencia común.

\subsubsection{Productividad}

\subsubsection{Definición}

De acuerdo con Webb (2013) la productividad es la relación entre lo producido y los medios empleados. Este concepto está relacionado con la eficiencia. Según el INEI la productividad promedio del sector MYPES en el Perú es 1.4. Esto representa que para producir 14 unidades se necesitan 10 unidades de consumo intermedio. Así pues, la productividad se define como el uso eficiente de recursos tales como el trabajo, capital, tierra, materiales, energía, información en la producción de diversos bienes y servicios. Una productividad mayor significa la obtención de más con la misma cantidad de recursos, o el logro de una mayor producción en volumen y calidad con el mismo insumo.

\subsubsection{Factores influyentes en la productividad}

Dentro de los factores internos, Webb (2013) asegura que quienes están sujetos a un control, se encuentran el producto donde la productividad del factor producto significa el grado en que el producto satisface las exigencias de la producción, la productividad de la planta y el equipo se puede mejorar prestando atención a la utilización, la antigüedad, la modernización, el costo, la inversión, el equipo producido internamente, el mantenimiento y la expansión de la capacidad, el control de los inventarios, la planificación y el control de la producción, etc. Otro factor es la tecnología, ya que la innovación tecnológica constituye una fuente importante de aumento de la productividad. Incluso un pequeño esfuerzo por reducir el consumo de materiales y energía puede producir notables resultados. Entre los factores externos cabe mencionar las 
políticas estatales y los mecanismos institucionales; la situación política, social y económica; el clima económico; la disponibilidad de recursos financieros, energía, agua, medios de transporte, comunicaciones y materias primas. Esos factores afectan a la productividad de la empresa individual, pero las organizaciones afectadas no pueden controlarlos activamente.

\subsubsection{Productividad Agrícola}

Según el Instituto Interamericano de Ciencia Agrícolas (2013) cuando se analiza la productividad de un campo cultivado, se debe diferenciar entre la productividad biológica o primaria y productividad económica o agrícola. Lo primero hace referencia a la cantidad total de materia orgánica que la vegetación o campo cultivado produce incluyendo tallos, raíces, entre otros. Mientras que la productividad agrícola se refiere a la producción del órgano de importancia económica, esta se mide generalmente por la cantidad cultivada del fruto sembrado por hectárea de cultivo.

\subsubsection{Gestión por procesos}

\subsubsection{Definición}

De acuerdo con la Norma Internacional UNE-EN ISO 9000:2015 “cualquier actividad, o conjunto de actividades, que utiliza recursos para transformar elementos de entrada en resultados, puede considerarse un proceso". "Para que las organizaciones operen de manera eficaz, tienen que identificar y gestionar numerosos procesos interrelacionados y que interactúan. A menudo el resultado de un proceso constituye directamente el elemento de entrada del siguiente proceso. La identificación y gestión sistemática de los procesos empleados en la organización y, en particular, las interacciones entre tales procesos, se conoce como "enfoque basado en procesos". Una metodología de mejora para la gestión efectiva de las organizaciones es la gestión por procesos. Los procesos han pasado de ser individualmente y aisladamente a tener un tipo de gestión sistemática. Se ha pasado de la gestión de procesos a la gestión por procesos. Esta gestión se da de manera horizontal lo que permite al flujo de trabajo cruzar barreras entre diferentes unidades funcionales. Con esta herramienta se unifican los enfoques hacia las principales metas y objetivos de la organización.

\subsubsection{Ventajas}

Las ventajas de la gestión por procesos que se obtienen en todas las organizaciones con la implementación de la gestión de acuerdo con Mallar Miguel (2011) son que esta aporta una nítida visión global de la organización y de sus relaciones internas. En segundo lugar, la 
organización gestionada por procesos tiene más flexibilidad que una basada en jerarquías. En tercer lugar, dado que los procesos son transversales y afectan a diferentes unidades organizativas, se favorecen las interrelaciones entre las personas. En cuarto lugar, se establecen responsables de cada proceso. Todas las personas de la organización conocen su rol en cada uno de los procesos y saben cómo contribuyen a alcanzar los objetivos de la organización. En quinto lugar, permite que no se trabaje de manera aislada, buscando solo el beneficio de una parte de la organización, sino buscando el beneficio común.

Permite una optimización del uso de los recursos y, en consecuencia, una reducción y optimización de los costos operativos y de gestión. En sexto lugar, los procesos se miden; se establecen objetivos e indicadores para cada uno de ellos. En séptimo lugar, entre las medidas que se analizan es muy importante el grado de satisfacción del cliente. La organización se orienta así a satisfacer las necesidades de los clientes. Por último, se promueve la mejora continua de los procesos. Se detectan ineficiencias, debilidades organizativas, cuellos de botella y errores de manera rápida y metódica, reduciendo los riesgos.

\subsubsection{Herramientas}

\subsubsection{1. $\quad \underline{\text { Mapa de Procesos }}$}

Según Malinova y Mendling (2013) señalan que los mapas de procesos son utilizados intensivamente por las organizaciones para proporcionar una visión integral total y global de todos los procesos y las relaciones entre ellos. Estos ayudan a mejorar en la búsqueda a través de los procesos y permiten una comprensión de las operaciones de la compañía sin necesariamente entrar en profundidad del proceso. Los mapas de procesos son adoptados por las organizaciones como la base de las iniciativas de gestión por procesos en las empresas. Ellos desempeñan un papel importante en proporcionar una visión general de todos los procesos, de tal manera que el funcionamiento básico de una empresa puede entenderse sin entrar necesariamente en detalles. El mapa de procesos se centra en describir clasificaciones, relaciones y dependencias entre procesos singulares. Estos aspectos se muestran típicamente como una representación visual que sirve como medio para la comunicación básica y para una mejor comprensión de los procesos de negocio actuales.

\subsection{Flujograma BPMN}

Rolón, Chavira, et al. (2015) describen que los modelos de procesos en las empresas (BPM) tienen una amplia gama de usos, tales como soportar procesos de reingeniería, simulación o ser una base a través de la cual desarrollar sistemas para automatizar los procesos del modelo. 
Además, los BPM pueden ser creados o presentados utilizando muchas metodologías o lenguajes de modelado diferentes, como IDEF 0, IDEF 3, UML, UML 2.0 y BPMN. BPMN (Business Process Model and Notation) es un lenguaje diseñado específicamente para el modelado de procesos empresariales (organizacionales). Se ha encontrado con una aceptación general en los círculos empresariales e institucionales gracias a que ha sido concebido para ser utilizado y comprendido por cualquier tipo de funciones (directores, expertos en calidad, analistas de negocio, analistas de sistemas, ingenieros, etc.), sin necesidad de conocimientos técnicos especiales. BPMN proporciona una notación gráfica que expresa todos los aspectos de los procesos por un solo tipo de diagrama. Además, fue diseñado para cubrir muchos tipos de modelado y permite la creación de procesos de negocio de extremo a extremo.

\subsubsection{3. $\quad \underline{\text { Indicadores }}$}

Según Gao, Christensen y Kornov (2017) destacan que, como portador de información y medio de comunicación, los indicadores proporcionan una ayuda útil para la toma de decisiones en la fijación de objetivos del proceso y en el logro efectivo de las metas de la organización. Un indicador es una medida de las variables a lo largo del tiempo para describir, supervisar el entorno de referencia y para predecir los impactos (de una política / plan / programa propuestos). Por lo tanto, los indicadores son una herramienta útil en la toma de decisiones y la planificación.

\subsubsection{4. $\quad \underline{\text { SIPOC }}$}

Según Charma (2014) el diagrama SIPOC se utiliza para categorizar las entidades interactúan con cada proceso, dividiendo el alcance en segmentos convenientes. Es una herramienta para identificar problemas que, ayudarán a definir el alcance de oportunidades de mejora, asegurará que el enfoque de la oportunidad de mejora esté alineado con los requerimientos de mayores niveles del cliente.

Dentro de los beneficios del SIPOC se puede encontrar la identificación de deficiencias en los requerimientos, identificación de proveedores y clientes, determinación de la métrica correcta para verificar los requerimientos del cliente.

\subsubsection{5. $\quad \underline{\text { Procedimientos }}$}

De acuerdo con Arias (2012) un procedimiento es una forma específica de llevar a cabo una actividad o un proceso. Los procedimientos se expresan en documentos que contienen el objeto y el campo de aplicación de una actividad; qué debe hacerse y quién debe hacerlo; cuándo, 
dónde y cómo se debe llevar a cabo; qué materiales, equipos y documentos deben utilizarse; y cómo debe controlarse y registrarse.

\subsubsection{Gestión Logística}

\subsubsection{Definición}

De acuerdo con Monterroso (2015), la logística es un término que frecuentemente se asocia con la distribución y transporte de productos terminados; sin embargo, ésa es una apreciación parcial de la misma, ya que la logística se relaciona con la administración del flujo de bienes y servicios, desde la adquisición de las materias primas e insumos en su punto de origen, hasta la entrega del producto terminado en el punto de consumo.

De esta forma, todas aquellas actividades que involucran el movimiento de materias primas, materiales y otros insumos forman parte de los procesos logísticos, al igual que todas aquellas tareas que ofrecen un soporte adecuado para la transformación de dichos elementos en productos terminados: las compras, el almacenamiento, la administración de los inventarios, el mantenimiento de las instalaciones y maquinarias, la seguridad y los servicios de planta.

Según Council of Supply Chain of Management Professionals, CSCMP anteriormente conocido como Council of Logistics Management, CLM) "La Logística es aquella parte de la gestión de la Cadena de Suministro que planifica, implementa y controla el flujo -hacia atrás y adelantey el almacenamiento eficaz y eficiente de los bienes, servicios e información relacionada desde el punto de origen al punto de consumo con el objetivo de satisfacer los requerimientos de los consumidores". (CSCMP: 2008)

La logística es "el movimiento de los bienes correctos en la cantidad adecuada hacia el lugar correcto en el momento apropiado" (Franklin: 2004)

Las actividades logísticas deben coordinarse entre sí para lograr mayor eficiencia en todo el sistema productivo. Por dicha razón, la logística no debe verse como una función aislada, sino como un proceso global de generación de valor para el cliente, esto es, un proceso integrado de tareas que ofrezca una mayor velocidad de respuesta al mercado, con costos mínimos.

\subsubsection{Logística Integral}

Según Cano, et al. (2015) aseguran que un modelo de gestión logística para MYPES debe ser diferente a los modelos para grandes empresas, debido al lenguaje, la estructura, la cultura, la capacitación y los recursos tecnológicos y económicos bajo la cual actúan. Por ende, el modelo de logística integral busca el equilibrio de la estructura de la cadena de valor y de lograr una 
interacción y operación eficiente de las áreas involucradas en forma que las actividades proyecten la creación de valor en las empresas. De esta manera, se define la logística integral como el control del flujo de materiales desde la fuente de aprovisionamiento hasta situar el producto en el punto de venta de acuerdo con los requerimientos del cliente. Es así, que los procesos que forman parte de la logística integral son el proceso de inventario, abastecimiento, almacenamiento, producción y distribución, así como la aplicación de herramientas que mejorarán el desempeño logístico en la MYPE. La Asociación Europea de Logística (E.L.A.) define a la logística integral como la organización, planificación, control y ejecución del conjunto de actividades de aprovisionamiento, transporte, manipulación, elaboración y distribución de los productos, con el fin de satisfacer los requerimientos de costos e inversión de capital mínimos.

\subsubsection{Gestión de compras}

Según la Universidad Nacional de Luján (2014) toda empresa necesita adquirir recursos para la realización de sus operaciones. La gestión de compras es el conjunto de actividades a realizar en la empresa para satisfacer esa necesidad de la forma más eficiente. Es un proceso por el cual se adquieren bienes, insumos, activos, para las operaciones de una empresa. La práctica de una correcta gestión de compras asegura que la empresa tenga los mejores proveedores para abastecer los mejores productos y servicios, al mejor valor total.

Asimismo, señala que la función de compras "tiene por objetivo adquirir los bienes y servicios que la empresa necesita, garantizando el abastecimiento de las cantidades requeridas en términos de tiempo, calidad y precio." La Logística del aprovisionamiento se ocupa del proceso de adquisición y almacenamiento de productos que pueden ser materias primas, materiales, partes, piezas, entre otros, desde los proveedores hasta el comienzo del proceso productivo en empresas productivas. El aprovisionamiento, abarca tres áreas: Compras, almacenamiento y gestión de inventarios. La gestión del aprovisionamiento implica la toma de decisiones que contribuyan al logro de un eficiente y eficaz funcionamiento del sistema logístico. Las compras como función empresarial presentan un carácter más restringido y tiene por objeto adquirir los bienes y servicios que la empresa necesita, garantizando el abastecimiento de las cantidades requeridas en términos de tiempo, calidad y precio.

"Pero para lograr una gestión de compras eficiente debe quedar bien identificada la cadena de suministros de la entidad. Para lograrlo, las empresas deben involucrar en su estrategia, el tránsito por un camino de tres etapas: la integración funcional de cada área de la organización, la integración interna entre las áreas funcionales formando una cadena de suministro interna y 
la integración externa entre los proveedores, la cadena de suministro interna y los clientes" (Cristopher, 2010).

\subsubsection{Gestión de inventarios}

La Universidad Nacional de Luján (2014), afirma que la gestión de inventarios es un punto determinante en el manejo estratégico de toda organización. Las tareas correspondientes a la gestión de un inventario se relacionan con la determinación de los métodos de registro, los puntos de rotación, las formas de clasificación y los modelos de inventario, determinados por los métodos de control. Los objetivos fundamentales de la gestión de inventarios son reducir al mínimo "posible" los niveles de existencias y asegurar la disponibilidad de existencias (producto terminado, producto en curso, materia prima, insumo, etc.) en el momento justo. Los inventarios, aunque carecen de generación de valor agregado para las organizaciones permiten de una $\mathrm{u}$ otra manera proporcionar una disponibilidad de los bienes y servicios prestados por ellas además de asegurar la continuidad de los procesos que realiza la misma.

Según ESAN (2016), existen muchos mecanismos para llevar el control de inventarios, entre ellos: inventarios físicos, inventarios en tránsito (inventarios en el proceso de adquisición y entrega), inventarios comprometidos e inventarios teóricos. Un inadecuado del manejo de los inventarios produciría exceso, desperdicio y variabilidad del stock. Tener una buena gestión en la administración de los almacenes y el control de los inventarios da a la empresa la posibilidad de tener sus procesos funcionando como un reloj suizo, manejando, preservando y custodiando sus activos.

\subsubsection{Gestión de almacenamiento}

La gestión de almacenes comprende diversas actividades necesarias para mantener, custodiar y suministrar el producto requerido por los clientes. Dichas operaciones corresponden a manipulaciones de los productos para su adaptación a los requisitos fijados por los clientes, transportes internos y externos, preparación de pedidos, reposición de existencias, inventarios de seguridad, gestión de los documentos originados como consecuencia del movimiento de las mercancías, etc. (Universidad Nacional de Luján, 2014, pp.59). Sirve como centro regulador del flujo de mercancías entre la disponibilidad y la necesidad de fabricantes, comerciantes y consumidores.

Según la Universidad Nacional de Luján (2014) se muestran a continuación, decisiones básicas dentro de la gestión de almacenes. En primer lugar, se debe decidir el número de almacenes y su tamaño. Seguidamente, elegir las localizaciones para los almacenes. En tercer lugar, elegir 
el tipo y nivel de mecanización. La primera decisión es si utilizar almacenes en propiedad, alquilados o almacenes ajenos. Algunos productos requieren almacenes especializados como los productos congelados. Otra decisión fundamental es el nivel de automatización de los almacenes. Actualmente podemos disponer de almacenes totalmente automatizados. Aunque en ocasiones resulta más rentable un nivel intermedio de automatización. En cuarto lugar, establecer la organización y los procedimientos concretos de gestión. En quinto lugar, el número de almacenes depende de varios factores. Un factor fundamental es el costo y la duración de los transportes. La mejora de las comunicaciones y la eliminación de fronteras dentro de la Unión Europea han facilitado concentrar en un menor número de grandes almacenes automatizados las operaciones. Otros factores fundamentales se relacionan con las características del producto y del mercado. En sexto lugar, la localización de los almacenes se decide analizando los costos de los diversos emplazamientos alternativos y teniendo como restricción fundamental el tiempo máximo de respuesta a los pedidos de los clientes. Por último, el sistema de organización. Se hace preciso decidir el número de empleados de los almacenes, seleccionarlos, formarlos y asignarles responsabilidades. Un aspecto importante en los almacenes es la distribución en planta, es decir, cómo se reparten por la superficie del almacén los distintos productos.

\subsubsection{Gestión del transporte}

Del mismo modo, la Universidad Nacional de Luján (2014) enfatiza que el transporte es por excelencia uno de los procesos fundamentales de la estrategia logística de una organización, este componente es de atención prioritaria en el diseño y la gestión del sistema logístico de una compañía, dado que suele ser el elemento individual con mayor ponderación en el consolidado de los costos logísticos de la mayoría de las empresas. Algunos factores a tomar en consideración para la gestión del transporte son en primer lugar, los sistemas de transporte utilizados, es decir si se utiliza camiones, trenes, barcos, aviones y la combinación de los mismos. Naturalmente el sistema elegido afecta a los costos, el tiempo de respuesta a los clientes e incluso en la imagen de la empresa. En segundo lugar, si se tienen camiones propios o se contrata los servicios de empresas de transportes ajenos. En tercer lugar, la organización del sistema de transporte y la gestión de la información. La adecuada coordinación de todo el sistema integrado de transporte es fundamental para llevar los productos a los consumidores en el momento adecuado al menor coste posible. En cuarto lugar, el establecimiento de las rutas. Diversos programas informáticos ayudan al establecimiento de rutas para los camiones de reparto. Así como los procesos por los cuales se formulan los pedidos y se realizan los envíos. 
Por último, los costos de la distribución podemos decir que están determinados por cuatro factores claves independientemente de los sistemas de costeo a utilizar, tales como el producto y los canales de comercialización, el valor del producto, el tamaño de la organización y el nivel de servicio.

\subsubsection{Indicadores logísticos}

Según Polanco Isaac (2012), algunos indicadores logísticos para tener en cuenta son:

- Duración de los inventarios: es el número de días en que se consumiría los stocks disponibles de un material a los niveles de consumo promedio de la institución.

- Quiebres de inventario: frecuencia de casos en que una institución se queda sin inventario de un material que se mantiene en bodega.

- Tiempo de ciclo de compras: tiempo que transcurre entre que se solicita la compra de un material y que este es recibido en bodegas.

- Tiempo de despacho de la orden de compra: tiempo que transcurre entre que se solicita la compra de un material y se despacha al proveedor la orden de compra respectiva.

- Cantidad de peticiones de oferta enviadas: corresponde al número de proveedores a los cuales se envía una petición de oferta para los procesos de cotización

- Cantidad de ofertas recibidas: corresponde al número de ofertas o cotizaciones recibidas en un proceso de compra.

- Indicadores de satisfacción de usuarios: corresponden a una calificación de la calidad de servicio percibida por los clientes internos del área de adquisiciones, normalmente considera distintos ámbitos.

- Indicadores de evaluación de proveedores: corresponden a una evaluación de la calidad de servicio entregada por los proveedores. Normalmente se asocia a una clasificación de los proveedores.

\subsubsection{Marco Normativo}

\subsubsection{Ley de Promoción y Formalización de la Micro y Pequeña Empresa - Ley} 30056

La ley 30056 afirma que "La presente Ley tiene por objeto la promoción de la competitividad, formalización y desarrollo de las micro y pequeñas empresas para incrementar el empleo sostenible, su productividad y rentabilidad, su contribución al Producto Bruto Interno, la ampliación del mercado interno y las exportaciones, y su contribución a la recaudación 
tributaria." Se especifican los lineamientos generales sobre las relaciones con los diversos stakeholders del negocio y el papel que cada uno desempeña dentro del desarrollo mencionado.

\subsubsection{Codex STAN 197-1995}

Según la norma Codex Stan 197-1995 aplica a las variedades comerciales de palta obtenidos de Persea americana Mill., de la familia Lauraceae, que habrán de suministrarse frescos al consumidor, después de su acondicionamiento y envasado." El código CODEX se utiliza como medio de protección de la salud de los consumidores y para la garantía de comportamientos correctos en el mercado internacional de los alimentos y coordinar todos los trabajos internacionales sobre normas alimentarias.

\subsubsection{Procedimiento: Certificación Fitosanitaria de Palta (Persea americana) Variedad Hass destinada a la exportación}

Según la certificación Fitosanitaria de la Palta, esta se encarga de asegurar la eficacia del proceso de Certificación Fitosanitaria de frutas frescas de palta de la variedad Hass, destinadas a la exportación." Dado a que el objetivo del proyecto es la exportación del producto de parte de los mismos productores se deben cumplir con los requisitos. La certificación fitosanitaria presenta el paso a paso del proceso, lo que ayuda a los productores a producir un producto que cumpla con los requisitos de este procedimiento y sea más fácil acceder a la certificación para la exportación.

\subsubsection{4. $\quad$ NTP 011-018 2012}

De acuerdo con la Norma Técnica de la Palta (2012) esta establece los requisitos mínimos de calidad que deben cumplir las paltas de los diversos cultivares de Persea americana Mill de la familia de las Lauraceae, que habrán de suministrarse frescas al consumidor, después de su acondicionamiento y envasado. Se excluyen los frutos partenocárpicos y las paltas destinadas a la elaboración industrial." Para la estandarización de los procesos es necesario conocer el producto. También en el proceso de exportación es necesario conocer los requisitos fundamentales que debe tener la palta para asegurar su calidad. 


\subsection{MODELO DE SOLUCIÓN}

Figura 1: Diseño Conceptual General

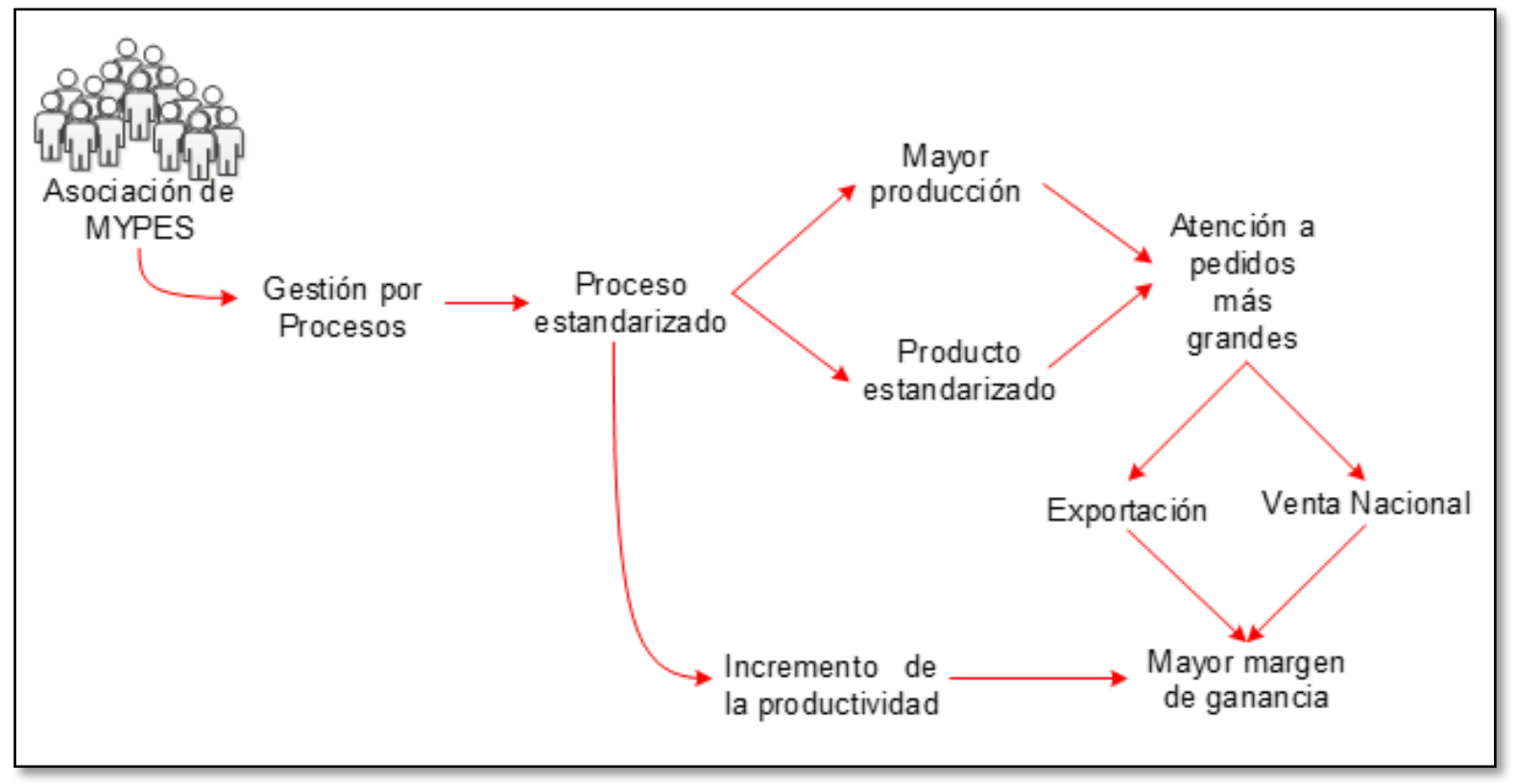

Elaboración: Propia

En la actualidad, las MYPES agrícolas pierden oportunidades al trabajar solo por su propia cuenta, incluso teniendo muy cercano empresas similares, debido que al ser entre micro y pequeñas empresas su producción, margen de ganancia y productividad son muy bajas, ya que dependen de un intermediario para poder llevar su producto al cliente final, no solo la empresa exportadora sino que en la mayoría de las ocasiones estos dependen también de un acopiador que recolecta los productos de varios campos, los combina con otros y así puede brindárselo a la empresa exportadora, quien necesita de un gran cantidad de producto para poder sustentar los costos de exportación.

Ante este escenario la respuesta rápida sería eliminar al acopiador de la cadena de suministro e ir directamente con la empresa exportadora o incluso con el cliente final; sin embargo esto no fácil, ya que según Yamakawa, et al. (2010) las MYPES enfrentan diversos desafíos como por ejemplo incumplimiento de estándares de calidad, producción muy baja, falta de clientes potenciales, desconocimiento de los costos incurridos en el proceso, poca planificación de la producción y sobre todo el hecho que están acostumbrados a no realizar las actividades que el acopiador y la exportadora se encargan como por ejemplo, como manipular el producto hasta que llegue al cliente final.

Según Hrusecka (2016), todas las deficiencias mencionadas se pueden solucionar mediante la gestión por procesos, considerando los procesos de calidad, costos, comercial, planeamiento y control de producción, seguridad industrial y logística. La creación de los macroprocesos 
mencionados no es sencilla, esto se profundizará en el trabajo de cada uno de los integrantes del equipo de investigación, sin embargo, a continuación, se explicará cómo es que se llega a lograr lo que se quiere gracias a la gestión por procesos.

En primer lugar, según Arellano, et al. (2013) las MyPES empiezan a trabajar juntas, claramente las que tienen el mismo producto final, de esta manera se apoyan entre sí, dejan de ser competencia y aprovechan los beneficios de compartir los recursos y la sabiduría ganada con la experiencia; al mismo tiempo, empieza la estandarización de los procesos de la producción del fruto, en este caso la palta Hass, esto requiere de mucho disposición y esfuerzo de parte de los agricultores ya que es un proceso largo, considerando que se necesita que todos las MyPES unidas lo apliquen para poder crecer juntas como asociación. Una vez que se logra tener procesos estandarizados se obtienen productos iguales, no solo en tipo de fruta sino en tiempo de cosecha, tamaño y sobre todo en calidad del fruto, esto permitirá poder unir la producción y así poder venderlo a mejores postores. Al mismo tiempo se logrará una producción mucho mayor, ya que las mermas deben haber disminuido con todo el conocimiento ganado a través del aprendizaje descrito. Teniendo mayor producción como asociación se puede garantizar la eliminación de la necesidad de un acopiador, ya que se puede satisfacer pedidos más grandes e incluso dependiendo de la magnitud del crecimiento se puede empezar a gestionar la exportación de los productos. Con mayor oferta se puede acudir tanto a la venta en mercados o supermercados nacionales y sobre todo a la exportación a Estados Unidos y países europeos; con cualquiera de estas opciones lo que se busca es incrementar el margen de ganancia y poco a poco ir invirtiendo en más mejoras para la asociación e incentivar nuevos integrantes a involucrarse en el mismo fruto. Teniendo un incremento de producción y del margen de ganancia se puede decir que se logró una elevación de la productividad de la asociación y por lo tanto de cada una de las MYPES.

En general, se resume la idea de que el crecimiento económico reduce la pobreza, de igual manera, esta mejora el PBI, al mejorar este indicador mejora el sector empresa y, por ende, las MYPES, es este grupo específico se logra aumentar la productividad a través de la gestión por procesos y si se aplica un sistema de gestión con enfoque en procesos se aumentará la productividad. De esta manera, este primer capítulo sirve de base para la realización de los posteriores capítulos, pues se generalizan los conceptos tanto para el diagnóstico del sector, diagnóstico de los procesos que serán identificados más adelante, así como el respaldo hacia el diseño del modelo tanto general como específico. 


\section{CAPÍTULO 2. METODOLOGÍA DE LA INVESTIGACIÓN Y DIAGNÓSTICO}

En este capítulo se describe la situación actual del sector agrícola como de la cooperativa, el funcionamiento general y el desarrollo de la gestión logística realizada con el fin de identificar el problema, esto es resultado de un elaborado análisis a partir de la información ofrecida por las personas que han tomado parte en el proceso de investigación. No solo se describen las actividades realizadas por los agricultores sino también se analizan cada aspecto de estos con el fin de encontrar la problemática principal de la asociación y así poder proponer una solución que ayude mejorar su situación actual.

La amplia pluralidad y diversidad de la información recabada ha permitido realizar un exhaustivo contraste de los análisis, que ha revertido en un mayor enriquecimiento y precisión de este diagnóstico, y que finalmente se presenta como una caracterización de las principales problemáticas.

\subsection{DESCRIPCIÓN DEL SECTOR}

Según el Ministerio de Economía y Finanzas (MEF), los “Indicadores” brindan una clara idea de cómo se encuentran los diferentes elementos u objetos en relación con algún aspecto de la realidad que nos interesa conocer. Estos pueden ser números, gráficos, hechos, opiniones o percepciones que señalen condiciones o situaciones específicas. Como el objetivo de la fundamentación es explicar por qué se ha tomado al sector agrícola de palta Hass como tema de investigación, se hará uso de los indicadores más relevantes de la economía del Perú, tales como el PBI, índice de pobreza y la situación de la MYPES.

En el ámbito económico, como principal indicador se tiene al PBI, el crecimiento económico de un país.

En la Tabla N², se observa que el Perú se encuentra en la segunda posición para el 2017 dentro de América Latina, seguido de México con una variación del PBI de solo 2.0\% (0.5\% menor respecto al resultado del país). También, América Latina y el Caribe registraron en el 2017 un crecimiento económico de $1.3 \%$; mientras que para el 2018 mejorarían a un $2.0 \%$. 
Tabla 2: Últimas proyecciones de la variación \% del PBI real

\begin{tabular}{lccccc}
\hline & $\mathbf{2 0 1 5}$ & $\mathbf{2 0 1 6}$ & $\mathbf{2 0 1 7}$ & $\mathbf{2 0 1 8}$ & $\mathbf{2 0 1 9}$ \\
\hline América Latina y el Caribe & 0.1 & -0.7 & 1.3 & 2.0 & 2.8 \\
América del Sur & -1.3 & -2.3 & 0.7 & 1.7 & 2.5 \\
América Central & 4.7 & 3.8 & 3.7 & 3.9 & 4.0 \\
América Latina & & & & & \\
$\quad$ Perú & 3.3 & 4.0 & 2.5 & 3.7 & 4.0 \\
Colombia & 3.1 & 1.9 & 1.8 & 2.7 & 3.3 \\
Argentina & 2.5 & -2.4 & 2.9 & 2.0 & 3.2 \\
Chile & 2.3 & 1.6 & 1.5 & 3.4 & 3.3 \\
$\quad$ México & 2.6 & 2.2 & 2.0 & 2.3 & 3.0 \\
$\quad$ Brasil & -3.8 & -3.5 & 1.0 & 2.3 & 2.5 \\
$\quad$ Venezuela & -6.2 & -12.0 & -14.0 & -15.0 & -6.0 \\
\hline Fuente: FMI (Fondo monetario internacional), Perspectivas de la economía mundial (informe WEO) & & & &
\end{tabular}

En términos comparativos con los otros países de América Latina, el Perú lidera este ranking con una variación del PBI de 3.3\% en el 2015, 4.0\% en el 2016; sin embargo, una segunda posición en el 2017 con $2.5 \%$ y se estima que para el 2018 alcance $3.7 \%$ del PBI real debido a su desempeño económico.

Tabla 3: PBI de la economía mundial

\begin{tabular}{lccccc}
\hline \multicolumn{5}{c}{ VARIACIONES PORCENTUALES ANUALES A PRECIOS CONSTANTES } \\
\hline \multicolumn{1}{c}{ PAÍSES } & $\mathbf{2 0 1 5}$ & $\mathbf{2 0 1 6}$ & $\mathbf{2 0 1 7}$ & $\mathbf{2 0 1 8}$ & $\mathbf{2 0 1 9}$ \\
Economía mundial & $\mathbf{3 . 4}$ & $\mathbf{3 . 2}$ & $\mathbf{3 . 7}$ & $\mathbf{3 . 9}$ & $\mathbf{3 . 9}$ \\
Economías avanzadas & $\mathbf{2 . 1}$ & $\mathbf{1 . 7}$ & $\mathbf{2 . 3}$ & $\mathbf{2 . 3}$ & $\mathbf{2 . 2}$ \\
Estados Unidos & 2.6 & 1.5 & 2.3 & 2.7 & 2.5 \\
Japón & 1.1 & 0.9 & 1.8 & 1.2 & 0.9 \\
Zona Europea & 2.0 & 1.8 & 2.4 & 2.2 & 2.0 \\
Economías emergentes y en desarrollo & $\mathbf{4 . 3}$ & $\mathbf{4 . 4}$ & $\mathbf{4 . 7}$ & $\mathbf{4 . 9}$ & $\mathbf{5 . 0}$ \\
Asia emergente y en desarrollo & 6.8 & 6.4 & 6.5 & 6.5 & 6.6 \\
China & 6.9 & 6.7 & 6.8 & 6.6 & 6.4 \\
India & 8.0 & 7.1 & 6.7 & 7.4 & 7.8 \\
Rusia & -2.8 & -0.2 & 1.8 & 1.7 & 1.5 \\
América Latina y El Caribe & $\mathbf{0 . 1}$ & $\mathbf{- 0 . 7}$ & $\mathbf{1 . 3}$ & $\mathbf{1 . 9}$ & $\mathbf{2 . 6}$ \\
Brasil & -3.8 & -3.5 & 1.0 & 2.3 & 2.5 \\
México & 2.6 & 2.2 & 2.0 & 2.3 & 3.0 \\
Perú & $\mathbf{3 . 3}$ & $\mathbf{4 . 0}$ & $\mathbf{2 . 5}$ & $\mathbf{3 . 7}$ & $\mathbf{4 . 0}$ \\
\hline
\end{tabular}


En la Tabla $\mathrm{N}^{\circ} 3$, se muestra una comparación entre las economías avanzadas tales como Estados Unidos, Japón y Zona Europea con variaciones porcentuales de 2.3\%, $1.8 \%$ y $2.4 \%$ del PBI en el año 2017 respectivamente. En el caso de los países asiáticos como China, India y Rusia, estos representan 6.8\%, 6.7\% y 1.8\% del PBI en el 2017 correspondientemente. Por otro lado, en el Perú se evidencia una baja en el PBI nacional, ya que ha ido ascendiendo desde el 2014 hasta el 2016 que obtuvo un porcentaje igual a 4.0\%, pero un decremento en el año 2017 con una variación del PBI nacional de $2.5 \%$.

Dentro de los sectores productivos, el sector agropecuario avanzó 2,62\% por el incremento de la producción agrícola, siendo este PBI junto al PBI de la pesca quienes aumentaron con respecto a su año anterior. El Perú debe enfocarse en incrementar el porcentaje de participación de PBI agrícola. Además, de las ocho actividades económicas realizadas en el país dentro de la tabla, el sector agropecuario se ubica en la cuarta posición con un valor de $2.6 \%$, implicando que otros rubros den un paso al frente antes de la agricultura tal como se muestra en la Tabla $\mathrm{N}^{\circ} 4$.

Tabla 4: PBI por Sectores Productivos del 2014 al 2017

\begin{tabular}{lcccc}
\hline \multicolumn{1}{r}{ SECTOR ECONÓMICO } & $\mathbf{2 0 1 4}$ & $\mathbf{2 0 1 5}$ & $\mathbf{2 0 1 6}$ & $\mathbf{2 0 1 7}$ \\
\hline PBI & $\mathbf{2 . 4}$ & $\mathbf{3 . 3}$ & $\mathbf{4 . 0}$ & $\mathbf{2 . 5}$ \\
Agropecuario & 1.3 & 3.1 & 2.5 & 2.6 \\
Pesca & -28.7 & 18.2 & -9.0 & 4.7 \\
Minería e Hidrocarburos & -1.6 & 8.4 & 12.6 & 3.2 \\
Manufactura & -1.1 & -0.9 & -0.6 & -0.3 \\
Electricidad y agua & 5.2 & 6.6 & 7.7 & 1.1 \\
Construcción & 1.8 & -5.3 & -2.5 & 2.2 \\
Comercio & 1.9 & 3.1 & 2.8 & 1.1 \\
Otros servicios & 4.1 & 4.4 & 4.2 & 3.8 \\
\hline Fuente: Banco Central de Reserva del Perí. Elaboración: MINAGRI-DGESEP-DSEP & & & &
\end{tabular}

Si bien es cierto que el PBI agrícola ha crecido en comparación con el año 2014, no obstante, este puede seguir en aumento dándole prioridad al sector agrícola.

En la Figura $\mathrm{N}^{\circ}$ 2, el PBI agropecuario, durante el periodo 2012-2017, presenta un comportamiento cíclico, con un lapso de bajo crecimiento (problemas climáticos, sequias, heladas, lluvias intensas) y periodos de alto crecimiento (debido al aumento de la producción y productividad). En adición, a partir de los años 2015 en adelante tanto el PBI nacional como el PBI agropecuario han mostrado que ambos presentan un comportamiento inverso, es decir, que en 2017 el PBI nacional ha descendido en comparación con el año anterior, mientras que el PBI agropecuario ha aumentado en comparación con el 2016. 
Figura 2: Tasa de crecimiento del PBI nacional y PBI agropecuario

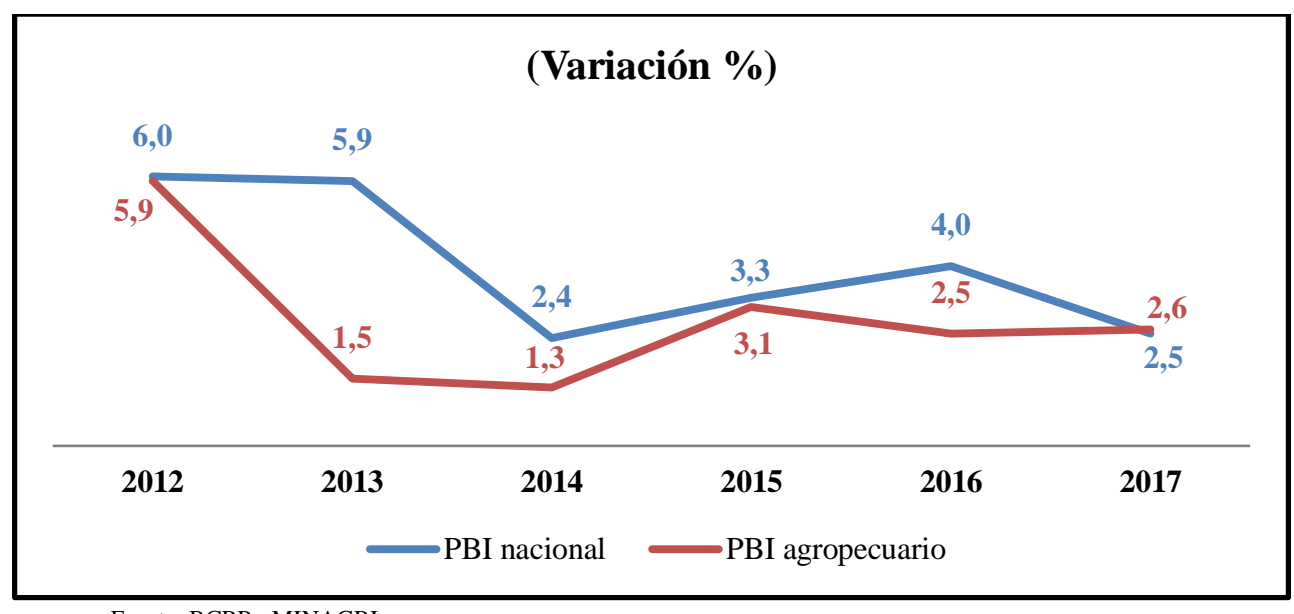

Después de observar el comportamiento del PBI, se procederá a demostrar en qué situación se encuentra la población económicamente activa (PEA) y el índice de pobreza.

En la Figura $\mathrm{N}^{\circ} 3$, se puede identificar las categorías de ocupación según sus condiciones de pobreza en el año 2017, con lo cual se obtiene como resultado que la población con menos recursos económicos del país participa en el mercado laboral como trabajadores independientes, ya que no cuentan con contratos ni tampoco figuran en planilla. Mientras que, el $47.8 \%$ de la población ocupada no pobre se dedica como persona asalariada (obreros y empleados).

Figura 3: Perú: Población ocupada por categoría de ocupación, según condición de pobreza, 2017

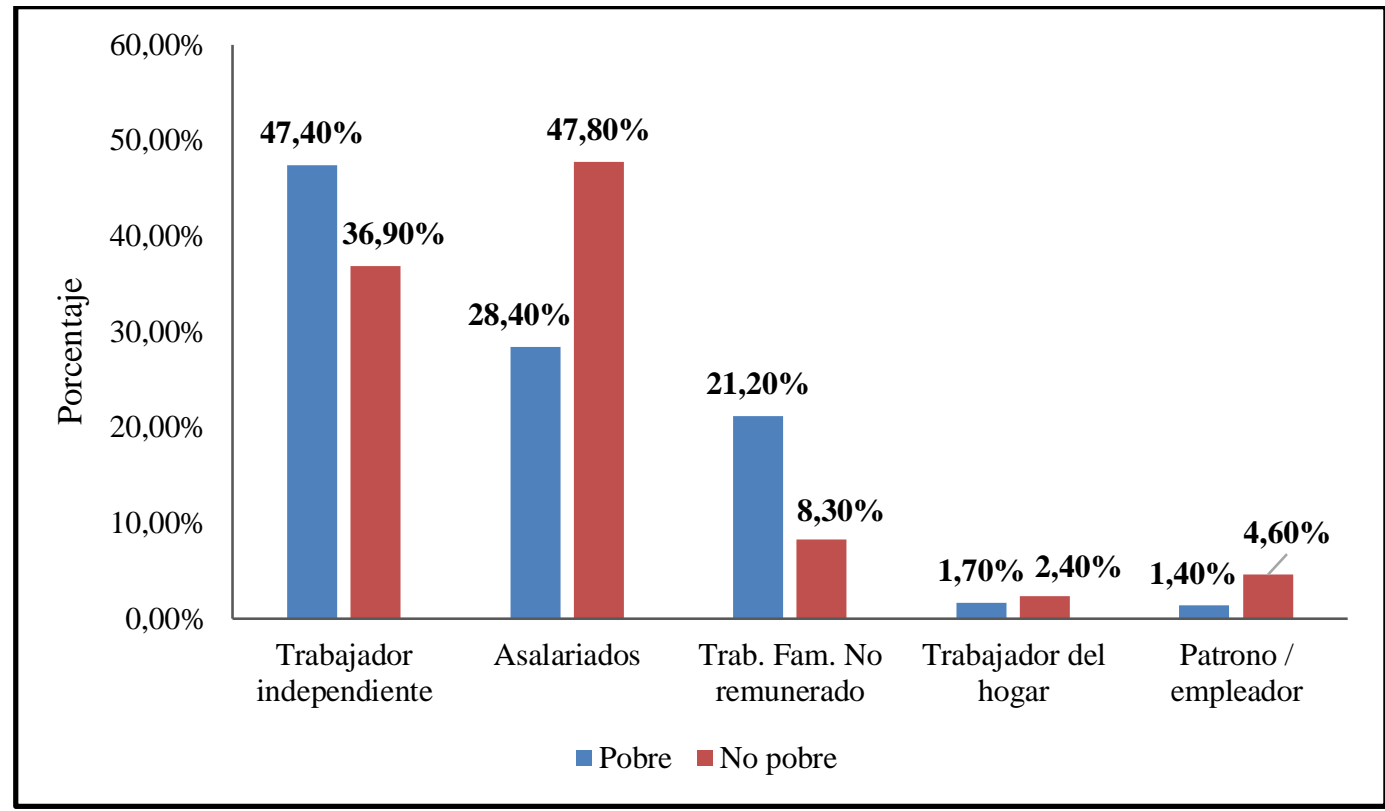

Fuente: Instituto Nacional de Estadística e Informática (INEI)

Del total de la PEA (Población económicamente activa), el sector agropecuario, pesca y minería a nivel nacional emplean al 55.3\% de la población pobre y ocupa al 79.9\% de la población muy 
pobre tal como se muestra en la Tabla $\mathrm{N}^{\circ} 5$. Esto demuestra que las familias con menos recursos económicos son las que se dedican al rubro de la agricultura.

En efecto, Esmaeeli y Sadighi (2017) indican que el crecimiento económico contribuye con la reducción de la pobreza, ya que la inversión en investigación agrícola puede tener gran beneficio hasta ayudar a la disminución de este factor. Por ende, son la productividad y el crecimiento de la producción a través de los cambios tecnológicos que hacen posible el éxito de dicha inversión en el sector agrícola.

Tabla 5: PEA ocupada, según rama de actividad y condición de pobreza, 2017

\begin{tabular}{lccc}
\hline \multicolumn{1}{c}{ RAMA DE ACTIVIDAD } & POBRE & $\begin{array}{c}\text { POBRE } \\
\text { EXTREMO }\end{array}$ & NO POBRE \\
\hline Total & 100.0 & 100.0 & 100.0 \\
Agricultura/pesca/minería & 55.3 & 79.9 & 20.8 \\
Manufactura & 7.9 & 4.6 & 9.6 \\
Construcción & 4.6 & 2.7 & 5.6 \\
Comercio & 12.3 & 4.5 & 20.6 \\
Transportes y comunicaciones & 5.8 & 2.1 & 8.5 \\
Servicios & 14.2 & 6.2 & 34.8 \\
\hline
\end{tabular}

Fuente: Instituto Nacional de Estadística e Informática (INEI)

Según el INEI en el año 2017, el 21,7\% de la población del país, que equivale en cifras absolutas a 6 millones 906 mil personas, se encontraban en situación de pobreza, es decir, tenían un nivel de gasto inferior al costo de la canasta básica de consumo compuesto por alimentos y no alimentos. Al comparar estos resultados con el nivel obtenido en el año 2016, se observa que la pobreza aumentó en 1,0 punto porcentual que equivale a 375 mil personas pobres, más que en el año 2016 tal como se muestra en la Figura $\mathrm{N}^{\circ} 4$.

Según el Ministerio de Agricultura (2017), el agro es un sector importante para el crecimiento económico y la reducción de la pobreza rural en el Perú, la cual equivale a 44.4\% del total de la población tal como se evidencia en la Figura $\mathrm{N}^{\circ} 5$, siendo tres veces más que en el área urbana (15,1\%). Al comparar con el año 2016, la pobreza aumentó en 1,2 puntos porcentuales en el área urbana, en tanto, el área rural lo hizo en 0,6 punto porcentual.

Por otro lado, si bien es cierto que la población con altos índices de pobreza se dedica a la agricultura, el sector agrícola contribuye con ocupar a más de 3,800 (miles de personas) de la PEA, aporta el $5.3 \%$ al PBI global y también, el $15.8 \%$ de las exportaciones, tal como lo expresa la Tabla $\mathrm{N}^{\circ} 6$. 
Figura 4: Evolución de la incidencia de la pobreza monetaria total, 2011-2017

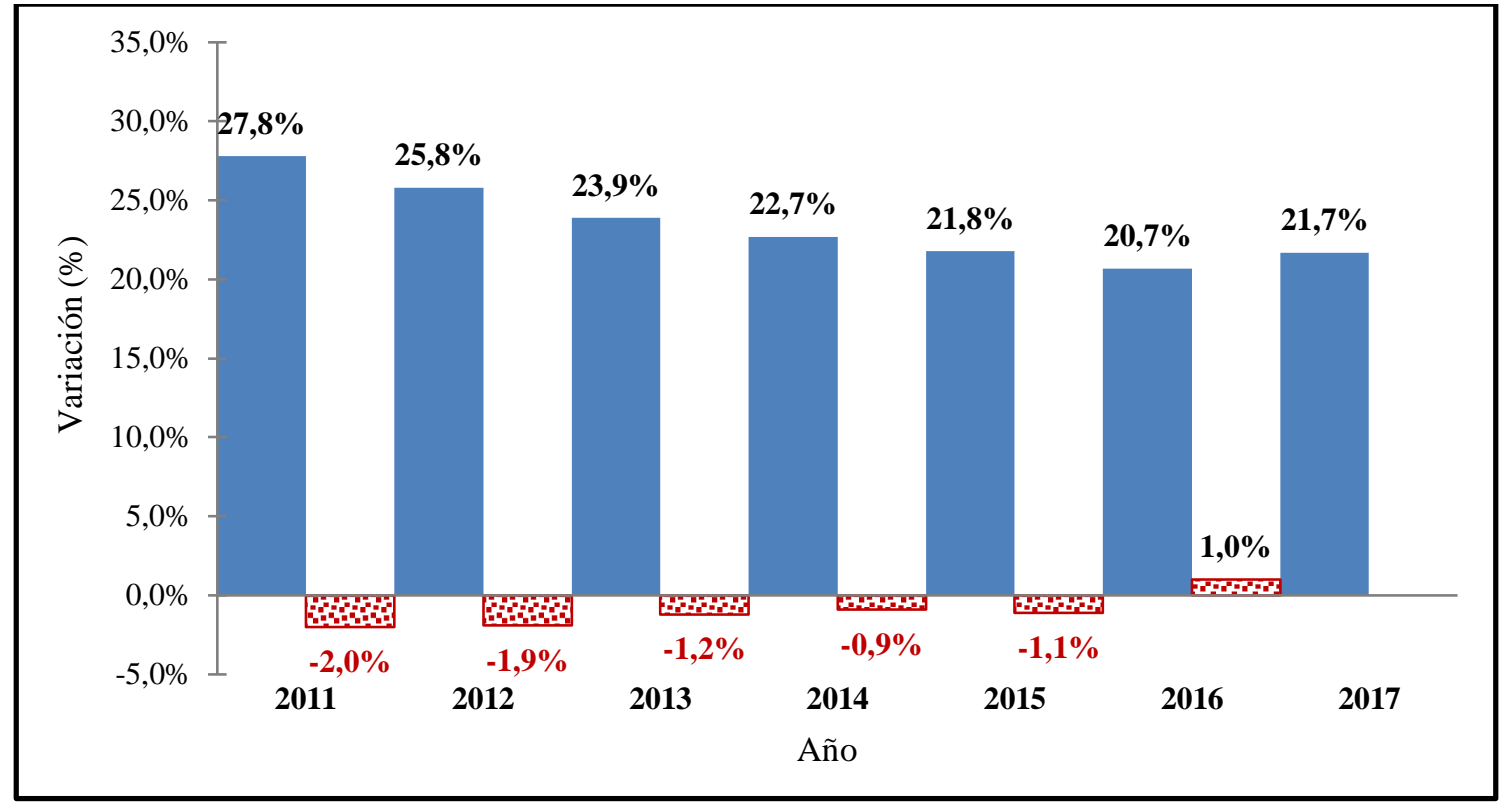

Fuente: Instituto Nacional de Estadística e Informática (INEI)

Figura 5: Variación \% de la pobreza rural

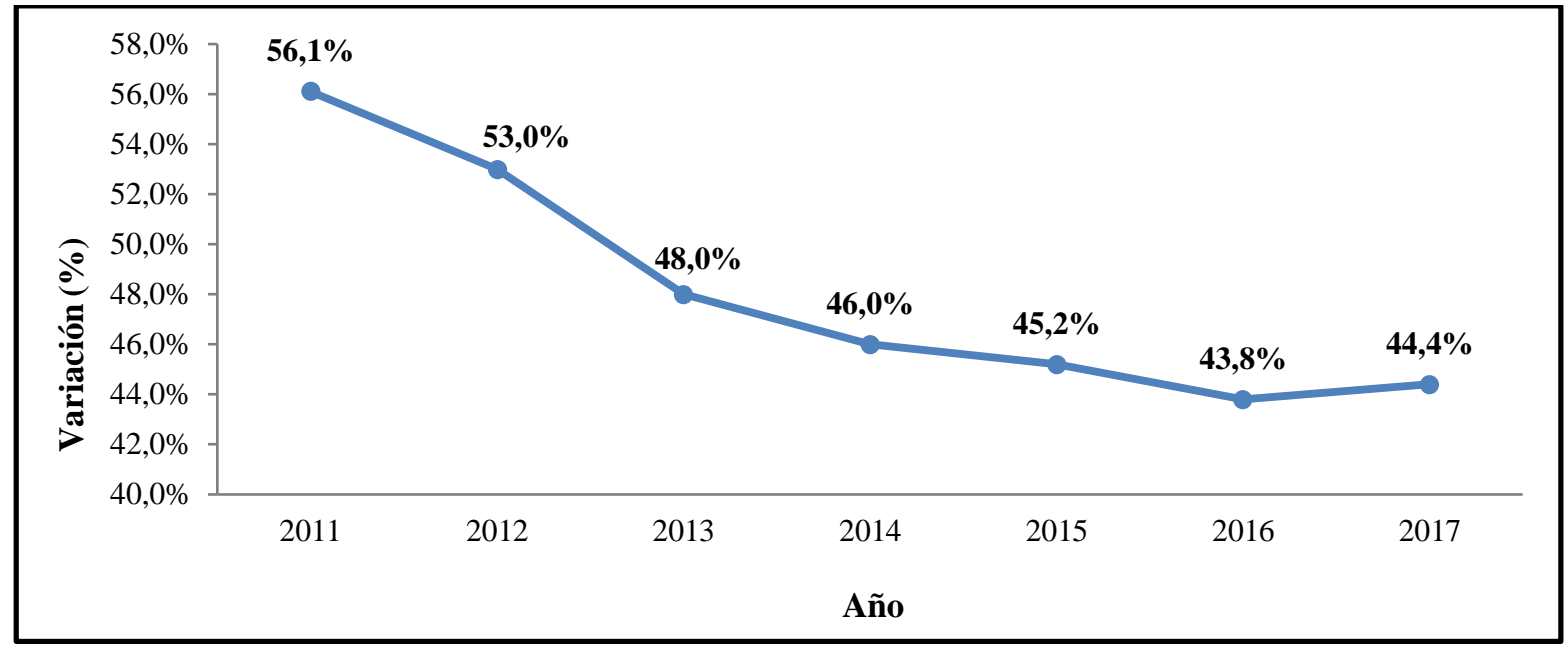

Fuente: Ministerio de Agricultura (MINAGRI). Elaboración: Propia

Tabla 6: Indicadores sectoriales

\begin{tabular}{lccccc}
\hline \multicolumn{1}{c}{ INDICADORES SECTORIALES } & $\mathbf{2 0 1 1}$ & $\mathbf{2 0 1 2}$ & $\mathbf{2 0 1 3}$ & $\mathbf{2 0 1 4}$ & $\mathbf{2 0 1 5}$ \\
\hline Crecimiento exportación & 6.5 & 6.0 & 5.9 & 2.4 & 3.3 \\
Crecimiento PBI agropecuario & 29.5 & 0.0 & -9.7 & -8.1 & -13.2 \\
Participación del agro en PBI nacional & 4.1 & 5.9 & 1.5 & 1.9 & 2.8 \\
Crecimiento agroexportaciones & 40.6 & -7.0 & -0.4 & 19.8 & -0.3 \\
Participación en exportaciones totales & 10.3 & 9.6 & 10.6 & 13.8 & 15.8 \\
PEA Ocupada en el sector agropecuario & 25.2 & 24.2 & 24.0 & 24.2 & - \\
Pobreza rural & 56.1 & 53.0 & 48.0 & 46.0 & 45.2 \\
\hline Fuente: SUNAT, BCRP. INEI, MINAGRI-DGESEP-DSEP. Elaboración: MINAGRI-DGESEP-DSEP & & &
\end{tabular}


PRODUCE (2015), señala que el número de Mipyme ha crecido a un ritmo anual promedio de 7,6\% entre 2007 y 2015. Este crecimiento guarda relación con el avance de la economía, el cual fue en promedio 5,3\% en el mismo periodo. Durante el periodo 2007-2015, la tasa de variación fue positiva, alcanzando el máximo en 2013 con un incremento de 12,9\% en el número de empresas respecto del 2012, cabe resaltar que en el 2013 el crecimiento de la economía peruana fue de $5,9 \%$.

Figura 6: Perú: empresas formales, según segmento empresarial, 2015

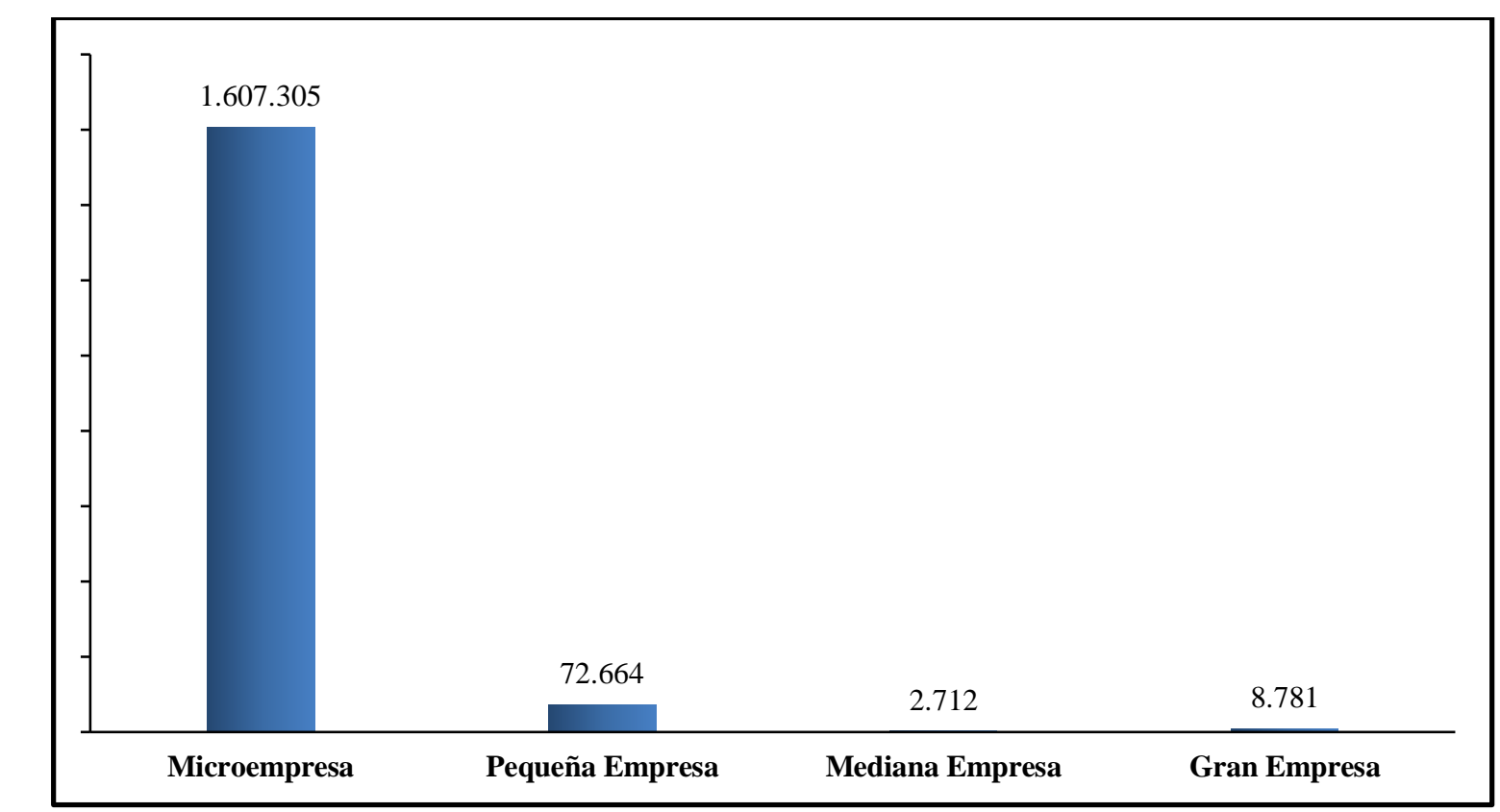

Fuente: SUNAT (2014). Elaboración: PRODUCE - Dirección de Estudios Económicos de Mype e Industria

En la Figura $\mathrm{N}^{\circ} 6$, se observa que son las microempresas las que ocupan el $95 \%$ del total de MIPYMES en el país, lo cual genera mayor empleo y crecimiento económico nacional.

En la siguiente Figura $\mathrm{N}^{\circ} 7$, se observa que el rubro con mayor crecimiento ha sido el sector de la Microempresa, seguidamente la pequeña empresa y, por último, sin ningún notable desarrollo la mediana empresa. En consecuencia, es en el sector de la Microempresa donde se centra el mayor porcentaje de desarrollo nacional. 
Figura 7: Evolución de las MIPYMES formales, 2012-2016

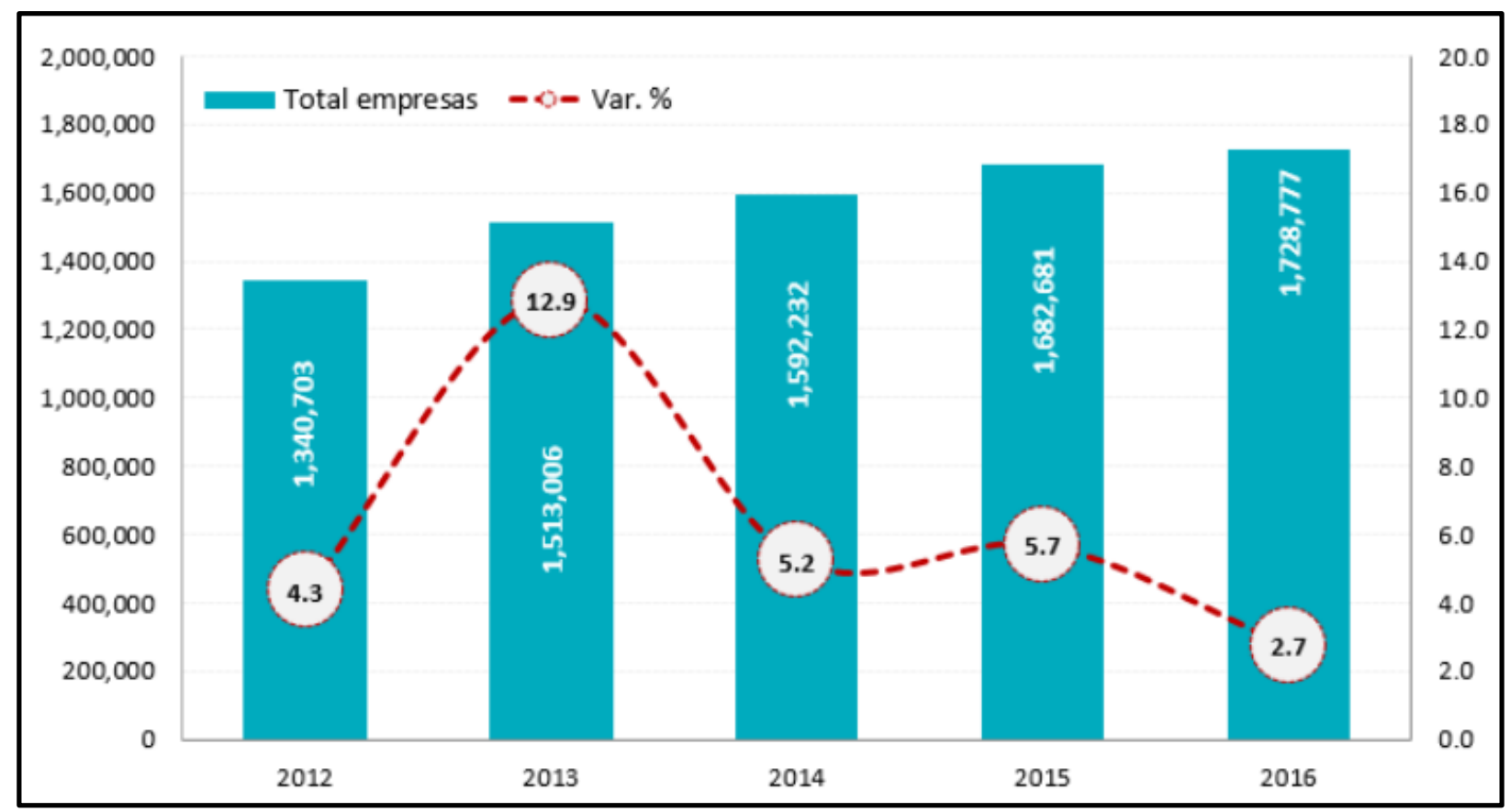

Fuente: SUNAT (2017). Elaboración: PRODUCE - Dirección de Estudios Económicos de Mype e Industria (DEMI)

En términos generales, una vez presentado la variación del PBI y como su crecimiento influye en el desarrollo económico, y que el mayor porcentaje de población pobre trabaja en el sector agrícola, se ha elegido a este sector por las oportunidades de crecimiento que muestra y que puede llevar a generar un mayor incremento del PBI y de la productividad del sector agro.

En la Tabla $N^{\circ}$, el departamento de Ica ocupa el tercer lugar en producir palta Hass en los años 2015 y 2016 con un valor de 56,6 y 57,0 miles de toneladas respectivamente, entonces cabe la posibilidad de aumentar esta cifra y llegar a ser un departamento con mayor producción a la par de La Libertad y Lima. 
Tabla 7: Perú: Producción de frutas y nueces por región según producto, Año 2016 (toneladas)

\begin{tabular}{lr}
\hline \multicolumn{1}{c}{ REGIÓN } & PALTA \\
\hline Nacional & $\mathbf{4 5 5} 394$ \\
Amazonas & 1051 \\
Áncash & 20456 \\
Apurímac & 3795 \\
Arequipa & 12579 \\
Ayacucho & 5219 \\
Cajamarca & 4510 \\
Callao & 0 \\
Cusco & 7861 \\
Huancavelica & 729 \\
Huánuco & 2833 \\
Ica & 57049 \\
Junín & 34128 \\
La Libertad & 178272 \\
Lambayeque & 8278 \\
Lima & 92070 \\
Lima Metropolitana & 1820 \\
Loreto & 3453 \\
Madre de Dios & 491 \\
Moquegua & 6156 \\
Pasco & 2384 \\
Piura & 7025 \\
Puno & 2469 \\
San Martín & 301 \\
Tacna & 377 \\
Tumbes & 0 \\
Ucayali & 2087 \\
\hline
\end{tabular}

Fuente: SIEA

Figura 8: Ica: Valor Agregado Bruto 2015-2016

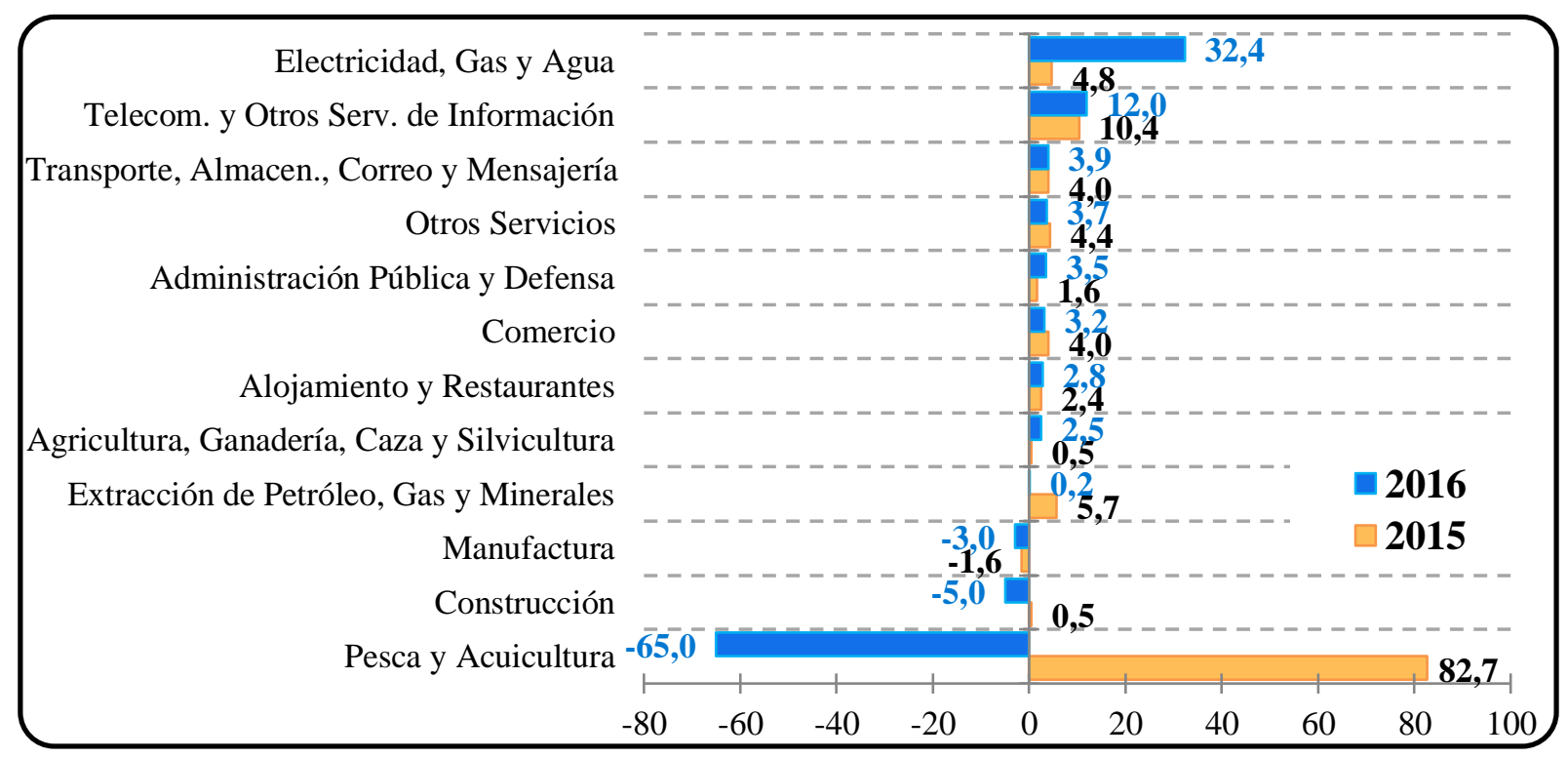

Fuente: INEI (2017) 
Asimismo, en la Figura $\mathrm{N}^{\circ}$, el sector agrícola tuvo una variación en $2.5 \%$ al valor agregado bruto en la región Ica en el año 2016, siendo esta actividad la tercera en generar crecimiento para esta región con $13.1 \%$ de su VAB.

Tal como veremos en la Tabla $\mathrm{N}^{\circ} 8$, la palta ocupa el $3^{\text {er }}$ lugar como producto de exportación con un ingreso FOB, en comparación al cierre del año 2016, en (+46.4\%). De esta manera, los productos estrella que destacaron durante el 2017 fueron la palta y el arándano. Asimismo, en la Figura $\mathrm{N}^{\circ}$ se observa que la palta posee un porcentaje de participación en el mercado igual a $9.28 \%$ en el valor total de las agroexportaciones del año 2017, posicionando al país como segundo proveedor mundial de este fruto, según MINAGRI.

Tabla 8: Principales exportaciones agrarias por subpartidas nacionales, Ene-Dic 2017/2016

\begin{tabular}{|c|c|c|c|c|c|c|c|}
\hline \multirow[b]{2}{*}{$\begin{array}{l}\text { Subpartida } \\
\text { Nacional }\end{array}$} & \multirow[b]{2}{*}{ Descripción } & \multicolumn{3}{|c|}{ Masa Neta (t) } & \multicolumn{3}{|c|}{ Valor FOB (Miles USD) } \\
\hline & & 2016 & $2017^{r}$ & $\begin{array}{c}\text { Variación } \\
2017 / 2016\end{array}$ & 2016 & $2017^{r}$ & $\begin{array}{c}\text { Variación } \\
2017 / 2016\end{array}$ \\
\hline \multicolumn{5}{|c|}{$\overline{T \text { TOTAL }}$} & 5789936 & 6255420 & $\overline{8,0}$ \\
\hline 0901119000 & Café sin tostar ni descafeinar & 239312 & 244523 & 2,2 & 756240 & 705409 & $-6,7$ \\
\hline "0806100000 & Uvas frescas & 285559 & 268182 & $-6,1$ & 646318 & 651212 & 0,8 \\
\hline "0804400000 & Paltas frescas & 194098 & 247192 & 27,4 & 396583 & 580399 & 46,4 \\
\hline 0709200000 & Espárragos frescos & 123292 & 115143 & $-6,6$ & 420019 & 409147 & $-2,6$ \\
\hline 0810400000 & Arándanos frescos & 27240 & 43007 & 57,9 & 237120 & 360942 & 52,2 \\
\hline ₹309909000 & Preparaciones para alimento animal & 152051 & 214773 & 41,3 & 160311 & 225121 & 40,4 \\
\hline Г0804502000 & Mangos frescos & 157069 & 162652 & 3,6 & 197739 & 191671 & $-3,1$ \\
\hline 0803901100 & Bananas tipo "Cavendish Valery" & 202037 & 202728 & 0,3 & 152186 & 148619 & $-2,3$ \\
\hline 1801001900 & Cacao en grano, entero o partido, crudo & 57324 & 54311 & $-5,3$ & 183479 & 131718 & $-28,2$ \\
\hline \multirow[t]{2}{*}{1008509000} & Quinua & 44339 & 51850 & 16,9 & 103001 & 121565 & 18,0 \\
\hline & Otros & 1668250 & 1800462 & 7,9 & 2536939 & 2729616 & 7,6 \\
\hline
\end{tabular}

Fuente: SUNAT

Figura 9: \% de Participación Agrícola en exportación 2017

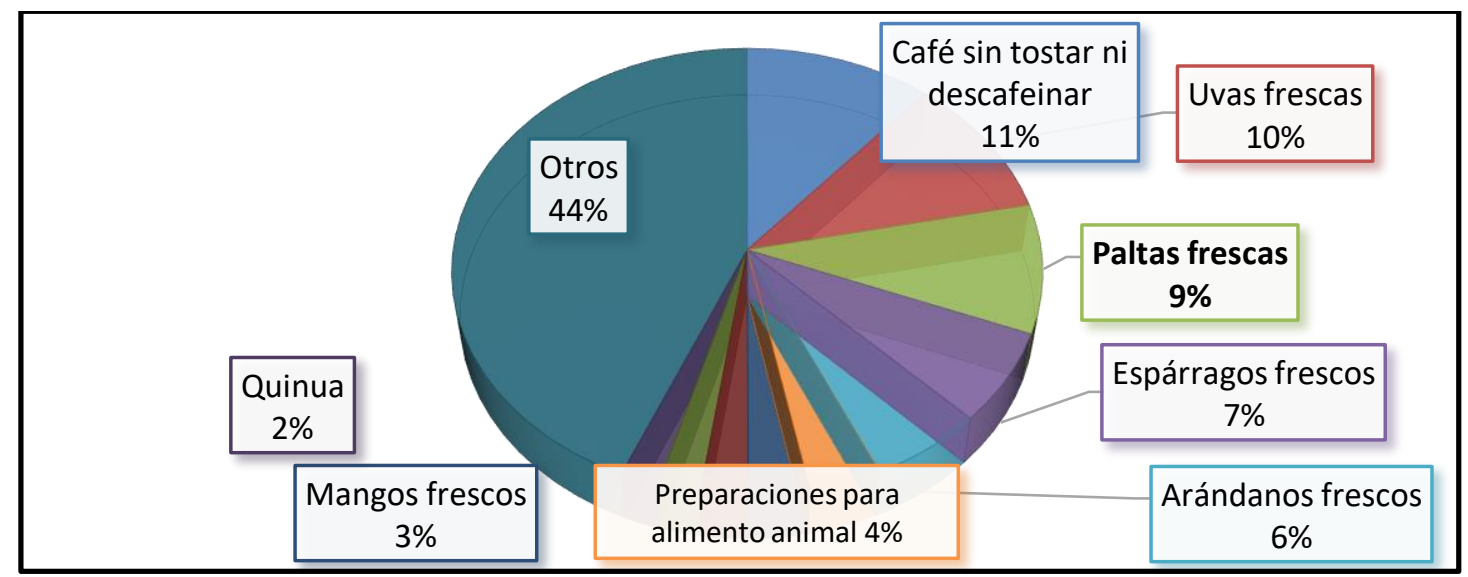

Fuente: SUNAT

Por lo tanto, se llega a la propuesta de aumentar esta participación en el mundo a través de las asociaciones agrícolas de palta Hass, quienes representan al sector de la MYPES. El objetivo es obtener una mayor participación en la exportación agrícola. Esta participación agrícola se verá reflejada en una mayor productividad de las asociaciones en la producción de palta Hass. 
Al ser microempresas, le venden a una agroexportadora evitando de esta manera la exportación por cuenta propia, por ende, un menor margen de ganancia.

Tabla 9: Perú: Precio recibido por el productor por producto según año, 2012 - 2016

\begin{tabular}{|c|c|c|c|c|c|c|c|}
\hline Producto & 2012 & 2013 & 2014 & 2015 & 2016 & $\begin{array}{c}\text { Var. \% } \\
2012-2016\end{array}$ & $\begin{array}{c}\% \\
2016 / 2015\end{array}$ \\
\hline \multicolumn{8}{|l|}{ Cereales } \\
\hline Trigo & 1317 & 1374 & 1449 & 1505 & 1567 & 4,5 & 4,1 \\
\hline Maiz amarillo duro & 833 & 879 & 904 & 899 & 992 & 4,5 & 10,3 \\
\hline Maiz amiláceo & 2133 & 2285 & 2282 & 2146 & 2338 & 2,3 & 8,9 \\
\hline Maiz morado & 1221 & 1246 & 1261 & 1231 & 1617 & 7,3 & 31,4 \\
\hline Arroz con cascarilla & 887 & 871 & 1093 & 1095 & 1152 & 6,8 & 5,3 \\
\hline Sorgo grano & 560 & 660 & 750 & 580 & 598 & 1,6 & 3,1 \\
\hline Cebada grano & 1081 & 1164 & 1231 & 1222 & 1240 & 3,5 & 1,4 \\
\hline Avena grano & 1363 & 1488 & 1695 & 1499 & 1630 & 4,6 & 8,8 \\
\hline Quinua & 3881 & 6293 & 7875 & 4906 & 3986 & 0,7 & $-18,8$ \\
\hline Kiwicha & 3591 & 3664 & 6644 & 4312 & 3484 & $-0,8$ & $-19,2$ \\
\hline Cañihua & 3082 & 3991 & 4974 & 5238 & 4136 & 7,6 & $-21,0$ \\
\hline \multicolumn{8}{|l|}{ Hortalizas } \\
\hline Espárrago & 2798 & 3053 & 2652 & 3764 & 4195 & 10,6 & 11,4 \\
\hline Col & 653 & 672 & 712 & 741 & 773 & 4,3 & 4,3 \\
\hline Coliflor & 746 & 780 & 831 & 840 & 1011 & 7,9 & 20,3 \\
\hline Brocoli & 805 & 928 & 1023 & 1035 & 1121 & 8,6 & 8,3 \\
\hline Lechuga & 636 & 753 & 800 & 735 & 834 & 7,0 & 13,4 \\
\hline Espinaca & 741 & 832 & 894 & 935 & 1012 & 8,1 & 8,3 \\
\hline Alcachofa & 1417 & 1586 & 2172 & 1658 & 2263 & 12,4 & 36,5 \\
\hline Acelga & 737 & 826 & 861 & 908 & 993 & 7,7 & 9,3 \\
\hline Culantro & 522 & 614 & 618 & 671 & 683 & 7,0 & 1,8 \\
\hline Perejil & 559 & 582 & 595 & 619 & 694 & 5,6 & 12,1 \\
\hline \multicolumn{8}{|l|}{ Frutas y nueces } \\
\hline Palta & 2047 & 1846 & 2008 & 2265 & 2618 & 6,3 & 15,6 \\
\hline Banano y plátano & 1922 & 494 & 487 & 521 & 583 & $-25,8$ & 11,8 \\
\hline Dátil & 1022 & 1044 & 1124 & 1207 & 1502 & 10,1 & 24,4 \\
\hline Higo & 1274 & 1456 & 1684 & 1724 & 2196 & 14,6 & 27,4 \\
\hline Mango & 901 & 295 & 542 & 1027 & 555 & $-11,4$ & $-46,0$ \\
\hline Guayaba & 344 & 378 & 433 & 497 & 605 & 15,2 & 21,8 \\
\hline Papaya & 790 & 556 & 605 & 721 & 764 & $-0,8$ & 5,9 \\
\hline Piña & 540 & 584 & 630 & 678 & 707 & 6,9 & 4,3 \\
\hline Maracuyá & 785 & 1072 & 1357 & 922 & 1096 & 8,7 & 18,9 \\
\hline Granadilla & 2062 & 2023 & 1850 & 1667 & 1656 & $-5,3$ & $-0,6$ \\
\hline Tumbo & 683 & 662 & 638 & 682 & 691 & 0,3 & 1,3 \\
\hline Chirimoya & 2158 & 2310 & 2362 & 2471 & 2751 & 6,3 & 11,3 \\
\hline
\end{tabular}

Fuente: SIEA

Como evidencia de que la agroexportadora es quien obtiene más utilidades en comparación con una asociación de agricultores se muestra la Tabla $\mathrm{N}^{\circ} 9$ y Tabla $\mathrm{N}^{\circ} 10$, a través de una relación entre el precio de chacra por kilo de palta que obtiene el agricultor con una diferencia del precio FOB que se le paga en el exterior a la empresa agroexportadora (Tabla 10). 
Tabla 10: Precios FOB en Kilogramos (US\$/Kg)

\begin{tabular}{lrr}
\hline \multicolumn{1}{c}{ MES } & $\mathbf{2 0 1 6}$ & $\mathbf{2 0 1 7}$ \\
\hline Enero & 1.80 & 1.91 \\
Febrero & 1.89 & 2.03 \\
Marzo & 2.00 & 2.18 \\
Abril & 1.90 & 2.15 \\
Mayo & 1.87 & 2.30 \\
Junio & 2.06 & 2.39 \\
Julio & 2.16 & 2.49 \\
Agosto & 2.41 & 2.58 \\
Septiembre & 2.47 & 2.45 \\
Octubre & 1.76 & 1.94 \\
Noviembre & 2.92 & 3.27 \\
Diciembre & 2.06 & 1.90 \\
\hline
\end{tabular}

Fuente: SUNAT

En la Tabla $\mathrm{N}^{\circ}$, se muestra que el productor agrícola ha recibido en el año 2016: S/. 2.62 por kilo de palta. Mientras que en la Tabla $\mathrm{N}^{\circ} 10$, el precio promedio de venta al extranjero de palta en el 2017 es de 7.47 soles por kilo.

La diferencia económica entre la empresa agroexportadora y el precio en chacra es de S/4.85 por kilo de palta en promedio.

Si bien es cierto, que este monto se dirige a procesos posteriores a la cosecha, pero también queda un buen porcentaje de ganancia para las agroexportadoras. Además, las pequeñas asociaciones no cuentan con un contrato fijo con la agroexportadora y es esta última la que solo cosecha el producto cuando lo desea y sin cantidad específica, mientras que las asociaciones no reciben ningún beneficio, por ende, es posible que estas crezcan y lleguen a exportar por cuenta propia a través de la gestión por procesos.

Asimismo, en la Tabla $N^{\circ} 11$ se observa que son las empresas grandes quienes tienen un mayor porcentaje de participación en la exportación tal como Camposol S.A. y Avocado Packing Company S.A.C. con $14 \%$ cada una en el mercado exportador. 
Tabla 11: Principales empresas agroexportadoras

\begin{tabular}{lcc}
\hline \multicolumn{1}{c}{ EMPRESA } & $\mathbf{\% V a r}$ & $\mathbf{\%}$ Part. \\
& $\mathbf{1 7 - 1 6}$ & $\mathbf{1 7}$ \\
\hline CAMPOSOL S.A. & $124 \%$ & $14 \%$ \\
AVOCADO PACKING COMPANY S.A.C. & $274 \%$ & $14 \%$ \\
SOCIEDAD AGRICOLA DROKASA S.A. & $-11 \%$ & $10 \%$ \\
CONSORCIO DE PRODUCTORES DE FRUTA S.A. & $25 \%$ & $5 \%$ \\
AGRICOLA CERRO PRIETO S.A.C. & $-16 \%$ & $5 \%$ \\
VIRU S.A. & $214 \%$ & $5 \%$ \\
CAMET TRADING S.A.C. & $4 \%$ & $4 \%$ \\
CORPORACION FRUTICOLA DE CHINCHA S.A.C. & $1 \%$ & $3 \%$ \\
ASR TRADING SOCIEDAD ANONIMA CERRADA & $664 \%$ & $2 \%$ \\
Otras Empresas (169) & - & $25 \%$ \\
\hline
\end{tabular}

Fuente: SUNAT

Tabla 12: Principales Mercados

\begin{tabular}{lccc}
\hline \multicolumn{1}{c}{ MERCADO } & $\begin{array}{c}\mathbf{\% V a r} \\
\mathbf{1 7 - 1 6}\end{array}$ & $\begin{array}{c}\mathbf{\%} \text { Part. } \\
\mathbf{1 7}\end{array}$ & $\begin{array}{c}\text { FOB-17 (miles } \\
\text { US\$) }\end{array}$ \\
\hline Países Bajos & $28 \%$ & $36 \%$ & 208726.51 \\
Estados Unidos & $134 \%$ & $30 \%$ & 175066.55 \\
España & $14 \%$ & $15 \%$ & 89219.91 \\
Reino Unido & $37 \%$ & $10 \%$ & 60474.01 \\
China & $195 \%$ & $2 \%$ & 13489.44 \\
Chile & $-20 \%$ & $2 \%$ & 10006.17 \\
Japón & $351 \%$ & $2 \%$ & 9243.88 \\
Hong Kong & $16 \%$ & $1 \%$ & 5362.18 \\
Costa Rica & $-32 \%$ & $1 \%$ & 4961.93 \\
Otros Países (26) & - & $2 \%$ & 9234.69 \\
\hline
\end{tabular}

Fuente: SUNAT. Elaboración: SIICEX (Sistema Integrado de Información de Comercio Exterior)

Para lograr esta exportación de manera libre, existe un tratado con la unión europea que permite venderles productos peruanos. El tratado es "Acuerdos comerciales del Perú" que va a consolidar el tratamiento preferencial que la UE otorga bajo el SGP-Plus. Las negociaciones 
con la Unión Europea pretenden alcanzar un Acuerdo de Libre Comercio, a fin de consolidar la presencia del Perú en el primer mercado para las exportaciones agropecuarias. Es un mercado de elevada capacidad adquisitiva y que está integrado por 28 países calificados de desarrollados. Es un mega mercado de enorme potencialidad" (MINAGRI, 2015, p.34). Los principales países donde se exportó palta en el 2017 son Países Bajos y Estados Unidos con índices de participación de $36 \%$ y $30 \%$ respectivamente (Tabla $\mathrm{N}^{\circ} 12$ ).

Tal como se evidencia en las figuras y tablas mostradas, es posible la exportación de palta Hass a través de las pequeñas asociaciones. Para ello será necesario el uso de la gestión por procesos, ya que de esa manera estos se estandarizarán, se obtendrá mayor confianza para cumplir con pedidos grandes y, por ende, lograr la exportación.

\subsection{DISEÑO DE INVESTIGACIÓN}

\subsubsection{Tipo de investigación}

Según el libro Metodología de la Investigación 6ta edición se hallaron los siguientes tipos de investigación.

\section{- Según la intervención del investigador: Experimental}

La investigación es experimental ya que se han recolectado los datos desde cero, es decir, aparte de las fuentes secundarias, el equipo ha recurrido a fuentes primarias como entrevistas profundas.

\section{- Según la planificación de la toma de datos: Prospectivo}

Prospectivo porque el equipo busca una solución desde la causa raíz y no solo en los resultados, esto busca tener resultados a futuro y a mayor relevancia.

- Según el número de ocasiones que se mide: Longitudinal

En nuestro caso, se han realizado las mediciones en más de una ocasión y sobre todo a más de un agricultor de la Irrigación Cabeza de Toro del departamento Ica, Perú.

\section{- Según el número de variables de interés: Analítico}

El trabajo es analítico, ya que, a diferencia de la descriptiva, no se va a realizar solo un diagnóstico del sector, sino también se presentará una propuesta de gestión. Además, se utilizará más de dos variables, las cuales son mencionadas posteriormente en el presente documento.

- Según manejo de la información: Cuantitativo 
En este caso es cuantitativa debido a la utilización de magnitudes numéricas las cuales sirven como herramientas para realizar el diagnóstico. (Hernández, Fernández y Baptista, 2014).

\subsubsection{Pregunta de investigación}

¿Cómo incrementar la productividad de las MyPES agrícolas productoras de palta Hass a través de la gestión por procesos en la Irrigación Cabeza de Toro del departamento de Ica, Perú?

Con esta investigación se apoyará a la Asociación Agro Inka a incrementar su productividad mediante una mejora en su gestión llegando así a la estandarización de sus actividades y la interacción de sus procesos. El incremento de la productividad, toneladas por hectárea, influirá en el incremento de las ganancias de la asociación.

\subsubsection{Levantamiento de información}

Una vez decidido el sector agrícola de las paltas Hass en la Irrigación Cabeza de Toro se optó por el diseño del experimento para la obtención de información del sector.

Aparte del uso de las fuentes secundarias se utilizaron entrevistas semiestructuradas en las cuales se pidió a los mismos agricultores explicar de qué trata todo el proceso de producción de paltas Hass, dando así a conocer cada característica que ellos consideran importante y sobre todo las dificultades que atraviesan el día a día y realizaremos preguntas puntuales si lo consideramos necesario para la investigación. La utilización de las entrevistas semiestructuradas fue debido a la mayor posibilidad de extracción de información que brinda este método ya que permite al agricultor explayarse y brindar todos los detalles que ellos consideran importantes y especificarlo mediante las preguntas cerradas para obtener información considerada necesaria por el equipo de investigación no ha sido mencionada por los entrevistados.

Con respecto al tamaño de muestra, no fue necesario el cálculo de esta ya que la población del sector es de trece agricultores y estadísticamente no se puede trabajar con una muestra menor a treinta, por lo tanto, se procedió a realizar un censo.

La asociación Agro Inka posee hectáreas en la irrigación Cabeza de Toro ubicada en el distrito de Independencia, provincia Pisco, Ica, Perú. 
Figura 10: Mapa político del departamento de Ica

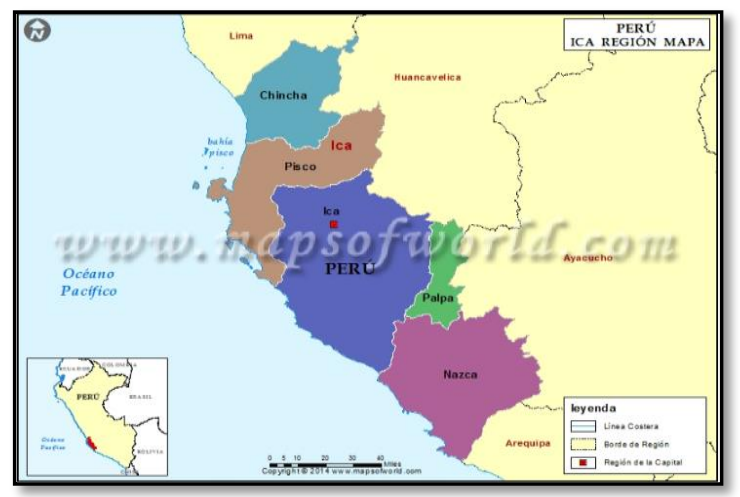

Fuente: Mapas del mundo

Figura 11: Mapa político de la provincia de Pisco

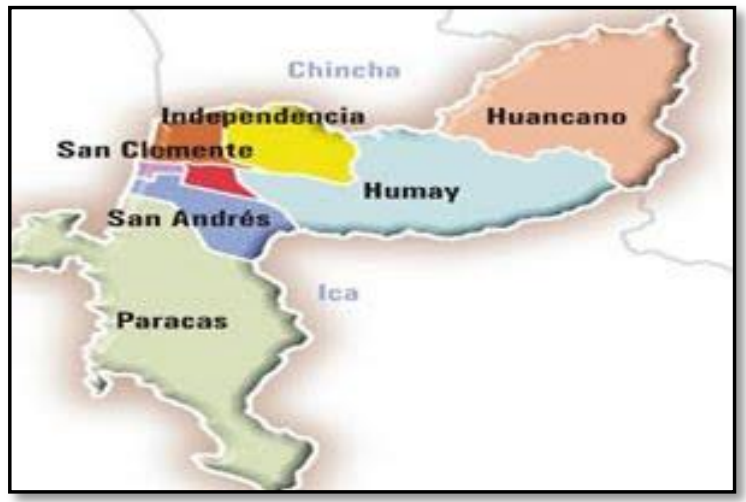

Fuente: Mapas del mundo

La relación de agricultores es la siguiente:

Tabla 13: Datos de los agricultores

\begin{tabular}{clc}
\hline $\mathbf{N}^{\mathbf{0}}$ & \multicolumn{1}{c}{ NOMBRE } & DNI \\
\hline $\mathbf{1}$ & EUGENIO PABLO CORAHUA MUÑANTE & 9079029 \\
$\mathbf{2}$ & CIRILO ALEJANDRO UCULMANA ESPIRITU & 22278571 \\
$\mathbf{3}$ & JOSE LUIS HUAYRA MELGAR & 22274094 \\
$\mathbf{4}$ & MARCIAL ANTONIO PALOMINO VALDEZ & 2178512 \\
$\mathbf{5}$ & GUILLERMO ANTONIO PORRAS YATACO & 22280692 \\
$\mathbf{6}$ & NORMA ELIZABETH JIMENEZ LOAYZA & 22299375 \\
$\mathbf{7}$ & RAFAEL JOSE NEYRA PUNTRIANO & 22280444 \\
$\mathbf{8}$ & GABINO JULIÁN GERONIMO ALARCÓN & 22278914 \\
$\mathbf{9}$ & WILMER IVÁN ALBERTIS MOREYRA & 43312736 \\
$\mathbf{1 0}$ & GLORIA SIHUAS QUIJAITE & 22252504 \\
$\mathbf{1 1}$ & FRANCISCO JESUS CARTAGENA ESPINO & 21827045 \\
$\mathbf{1 2}$ & ANGEL EDUARDO SOTO HUAMAN & 22278599 \\
$\mathbf{1 3}$ & CARMEN JULIA MEJÍA ESPÍRITU & 22281951 \\
\hline Fuente: Elaboración propia
\end{tabular}




\subsection{DIAGNÓSTICO}

\subsubsection{Diagnóstico de las actividades realizadas}

Para la obtención de la palta se requieren cuatro actividades las cuales se evidencian en el siguiente flujograma.

Figura 12: Flujograma de producción

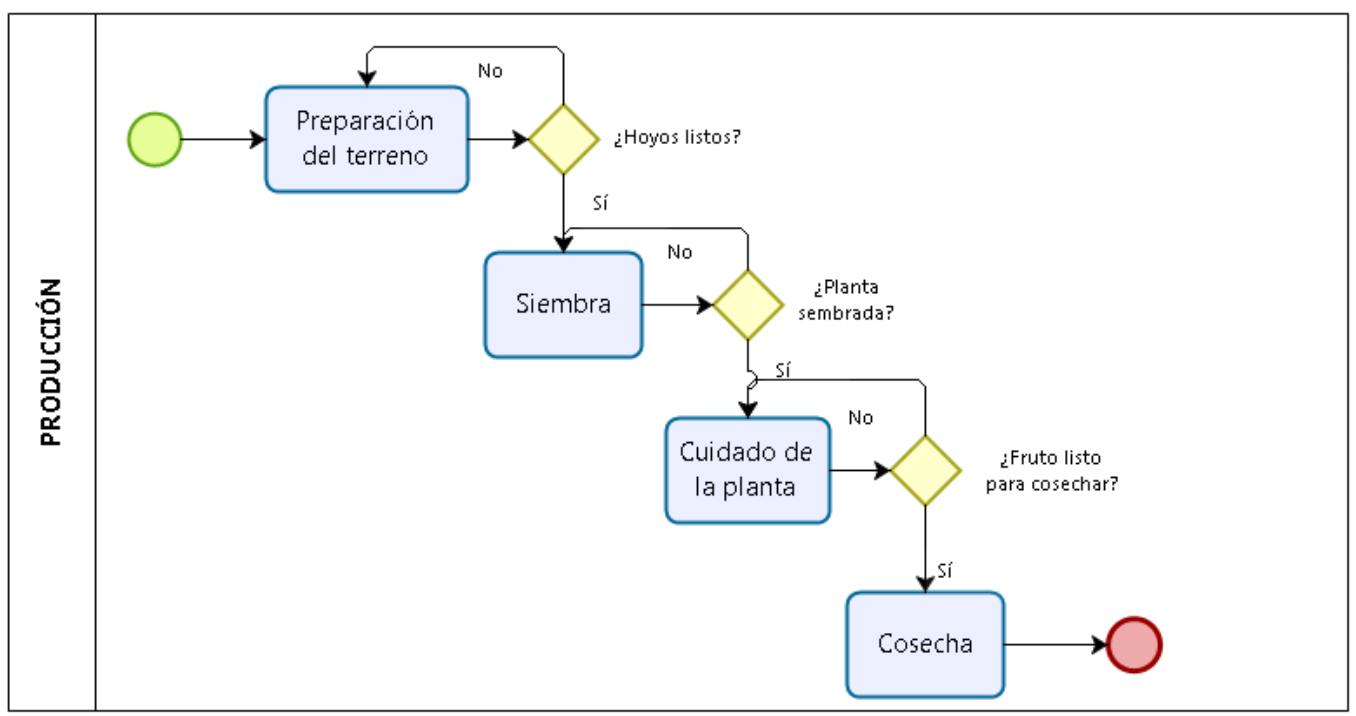

Fuente: Entrevistas realizadas. Elaboración: propia

\subsubsection{Preparación de terreno}

Como primer paso se limita el terreno a destinar para el cultivo de la palta y la elección del distanciamiento entre cada planta, en el caso de los agricultores entrevistados la mayoría utiliza $3 \times 5$, teniendo 3 metros entre cada planta y cinco entre cada línea. Después, se contrata el personal necesario para cavar los huecos para cada planta, la medida promedio es de un metro de diámetro con un metro de profundidad. Esta tarea tiene un costo de S/. 1.00/ hueco.

Una vez se tienen los huecos bien realizados se vierten distintos componentes al suelo los cuales servirán como nutrientes y asegurarán un crecimiento ideal a la planta. Los insumos requeridos en este paso son compus, $50 \mathrm{~kg}$, cal, $30 \mathrm{~kg}$, nitrógeno (nitrato de amonio), fósforo (fosfato diamónico) y potasio (sulfato de potasio), los últimos 3 insumos los entrega la agroexportadora. La colocación se realiza de forma manual, dependiendo del dueño del campo se procede a contratar personal pagando S/.55 por día trabajado, tener cuenta que con 3 personas se podría cubrir hasta 2 hectáreas en un solo día; por otro lado, otros agricultores prefieren realizarlo ellos mismos ya que no confían en el correcto cumplimiento con las proporciones de parte de personas externas. 
Durante este proceso se debe humedecer la tierra constantemente y posteriormente cerrar el hueco con tierra dejando aproximadamente medio metro de profundidad donde se debe colocar una combinación de abono y tierra.

\subsubsection{Siembra}

Cuando ya se tiene el hueco listo se procede a la compra de las plantas, aproximadamente S/. 1.30 cada una y por instalación se genera un costo de S/. 55/día por persona, considerando que dos pueden cubrir 1 hectárea en un día.

Al plantar se cierra el hueco con la combinación de tierra y abono, además, se coloca una vara con la finalidad de brindar sostén a la planta, esta se cambia o retira de acuerdo con el crecimiento de la planta, según juicio de los agricultores o recomendación de parte del técnico. Otro punto que tratar es la libreta de tiempo que manejan, donde apuntan los siguientes puntos:

- Fecha de sembrío

- Fecha de abonamiento

- Fecha de aplicación de foliares

- Fecha y duración de las plagas

- Qué abonos se utilizan

Aparte de los puntos mencionados también apuntan todo aquello requerido por el técnico, sobre todo en los primeros dos años, sin embargo, no todos tienen esta práctica.

\subsubsection{Cuidado de la planta}

Esta actividad es constante, a diferencia de las anteriores que se culminan después de un cierto tiempo, ya que la planta requiere de abono por lo menos una vez cada año e insecticidas y foliares cada tres meses con el fin de evitar las enfermedades como la mosca blanca, la arañita roja y el hongo que ataca desde la raíz de la planta. Cabe recalcar que estos insumos no los brinda la agroexportadora, ellos lo adquieren de forma independiente, lamentablemente cada agricultor realiza sus compras de forma separada generando un costo mayor por flete y desperdiciando la oportunidad de conseguir descuentos por economías de escala.

Con respecto a la instalación, los agricultores también utilizan diferentes métodos de aplicación, desde manual, a caballo y máquinas, esta elección varía con respecto a la edad de sus cultivos, el distanciamiento de las plantas y al capital disponible. 


\subsubsection{Cosecha}

Esta actividad no la realizan los agricultores de la asociación Agro Inka ya que es la agroexportadora quien lleva el personal necesario para la cosecha y la selección del fruto. A continuación, se describirá las actividades correspondientes.

Para empezar, se toma una muestra de tres paltas por cada agricultor con el fin de analizar el porcentaje de la materia seca, una vez se obtiene más de $22 \%$ se procede a cosechar.

Se manejan dos tiempos de corte, el primero es dos semanas después de haber aprobado la prueba de materia seca, y se llevan solo los frutos que califiquen como el primer calibre, con un peso mayor igual a 160 gr. Por este los agricultores reciben $\$ 1.30 / \mathrm{kg}$. El segundo corte se lleva a cabo después de un mes llevándose todo el fruto del campo sin importar su peso recibiendo $\$ 1.00 / \mathrm{kg}$. Estos también se llevan los frutos con defectos visibles ya que, aunque no son calidad de exportación se utilizan en la agroindustria.

Finalmente, el fruto es recogido en javas, $25 \mathrm{~kg}$ por cada una, dentro de camiones, según la agroexportadora lo vea conveniente, ha habido ocasiones en las cuales ha sido necesario más de cuatro días de cosecha para abarcar todas las hectáreas de la asociación mientras que en la cosecha 2017 se pudo terminar en día y medio el primer corte. Con respecto al destino final, los agricultores no tienen certeza de a qué país se exporta sin embargo tienen conocimiento de la duración del viaje, 18 días.

\subsubsection{Identificación de la problemática}

Después de realizar las entrevistas semiestructuradas a los agricultores mencionados anteriormente se pudo obtener la siguiente información.

Unos de los datos más importantes son la extensión del cultivo, hectáreas, y la edad de este de cada agricultor ya que de esto depende la producción que estos pueden llegar a obtener. 
Figura 13: Extensión de cultivos por agricultor

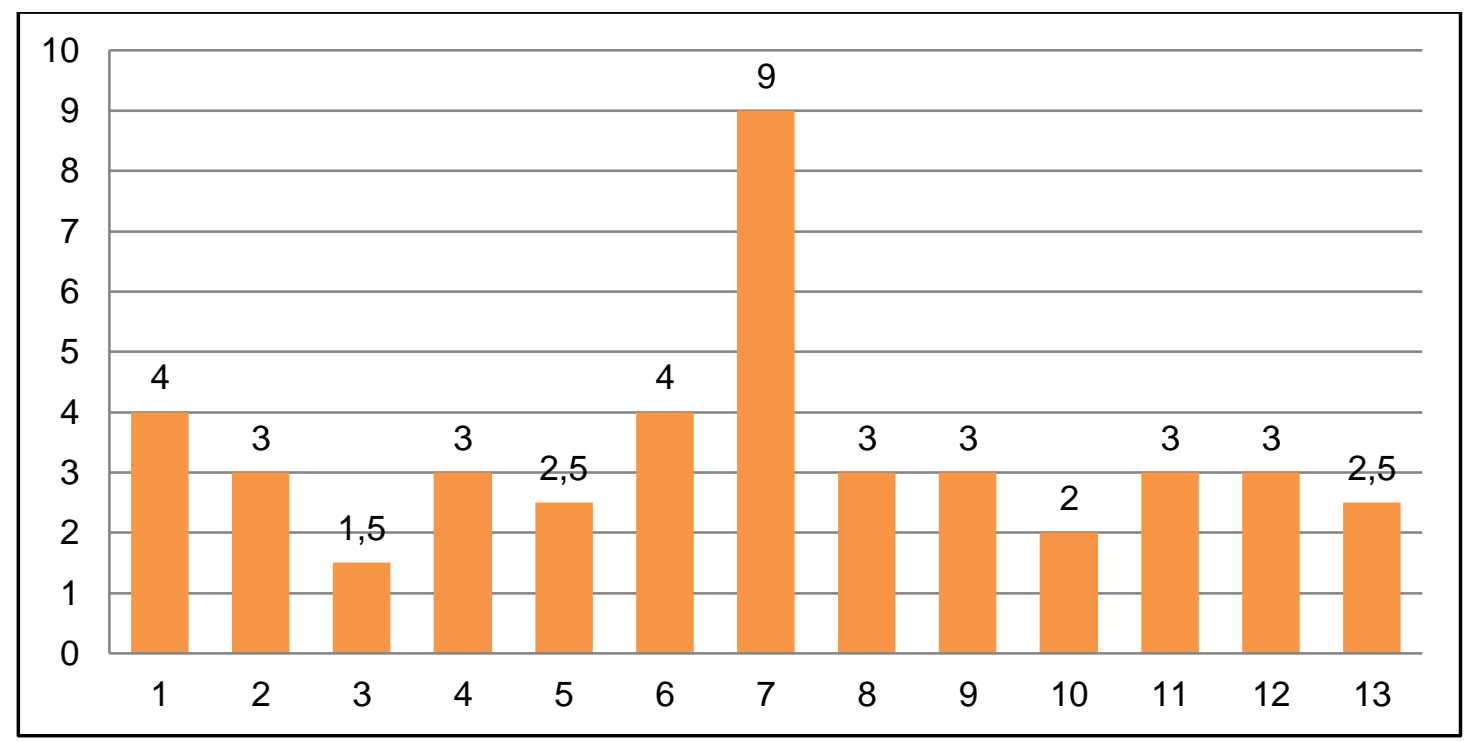

Fuente: Entrevistas realizadas. Elaboración: Propia

Figura 14: Edad de los cultivos por agricultor

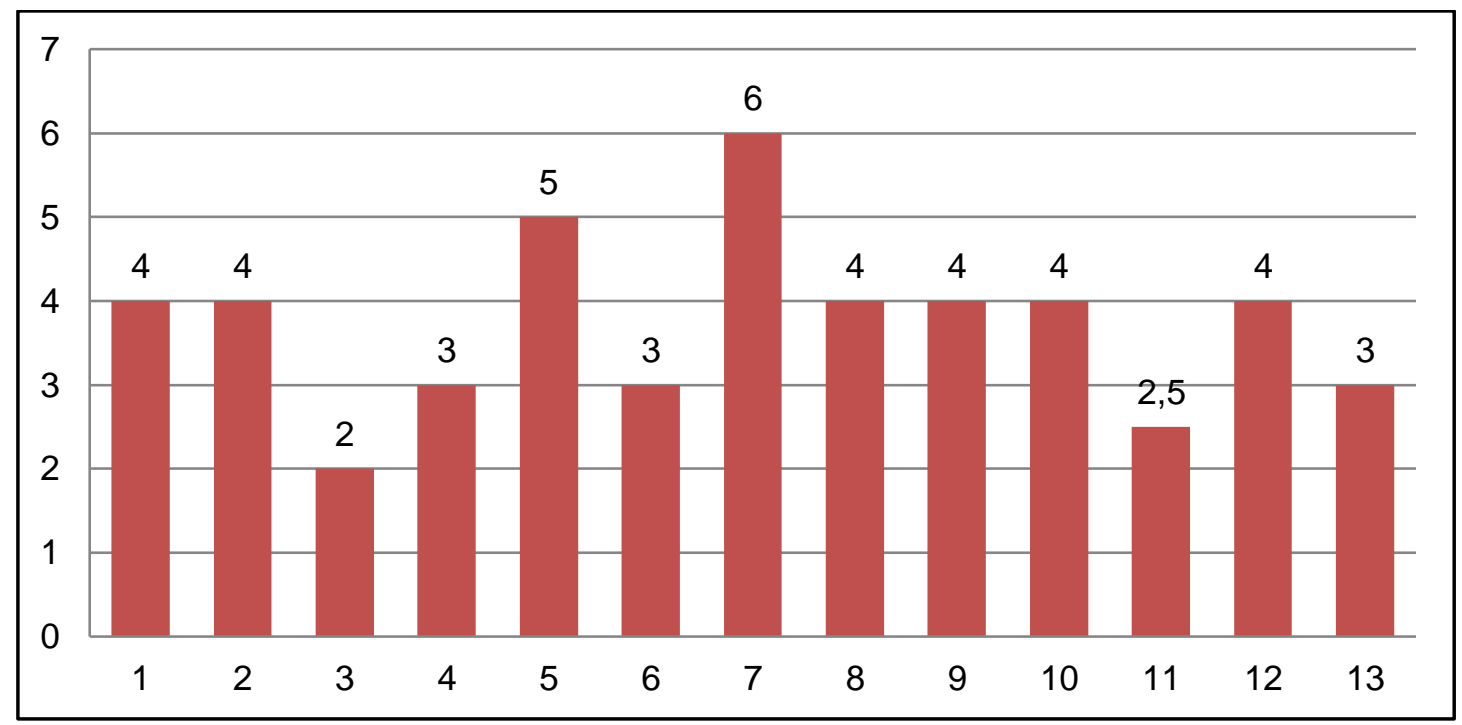

Fuente: Entrevistas realizadas. Elaboración: Propia

La edad promedio es de 3.3 años mientras que la extensión promedio es de 3.7 hectáreas, sin embargo, se puede observar que muchos de los agricultores rodean los 4 años de edad mientras que el agricultor $\mathrm{N}^{\circ} 7$ tiene 6 años, esto se debe a la iniciativa del señor Aldo Romero quien realizó el cambio y gracias a sus ganancias, mayores a las del algodón y del maíz, otros agricultores de la zona se animaron a involucrarse en el cultivo de la palta Hass.

También se puede observar la diferencia con respecto a la extensión del cultivo con respecto a los otros agricultores, en su caso la mayoría de su campo está constituido por palta Hass mientras que los demás por miedo al cambio destinaron alrededor del 50\% de su terreno. Cabe 
recalcar que hoy en día alrededor del $60 \%$ quisiera agrandar su cultivo de palta Hass pero no es posible por su limitado capital.

Por otro lado, se tiene la cosecha obtenida en la campaña 2016, 2017 y la estimada para el 2018. La cosecha del 2017 es muy escasa, esto se debe a las pésimas condiciones afrontadas por el efecto climatológico Niño Costero la cual generó una sequía que generó muchas pérdidas de frutos e inclusive de plantas, por eso solo se ve una producción hasta de 3 toneladas.

Figura 15: Productividad por campañas

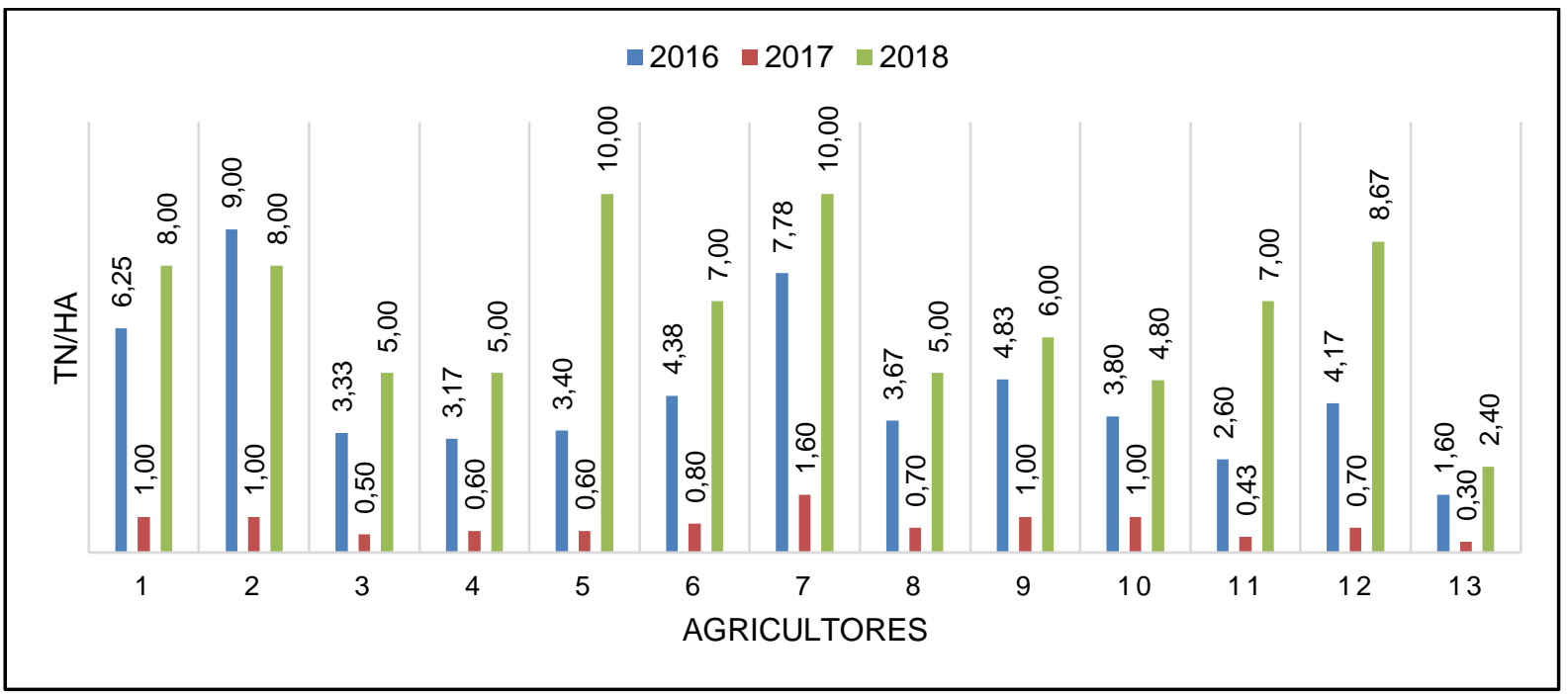

Fuente: Entrevistas realizadas. Elaboración: Propia

Es importante resaltar que en la irrigación Cabeza de Toro la palta fue uno de los pocos cultivos que sobrevivió a la falta de agua, el algodón y el maíz se perdieron por completo dejando sin ganancias a los agricultores de la zona.

Por otro lado, la cosecha del 2018 es un panorama totalmente distinto, en este caso se solicitó a los agricultores que nos mencionen su estimado para el próximo año, 2018, en un escenario ideal, sin complicaciones ambientales como en este año. Se puede observar la prominente diferencia entre la campaña 2016 y 2017, esto pudo haberse prevenido, sin embargo, fue la falta de planificación quien los condujo a tales resultados, ya que en su momento SENAMI informó del posible incidente de sequía, pero los agricultores al no tener conocimientos de cómo contrarrestar este caso y al no confiar en la información brindada, hicieron caso omiso al aviso.

Con respecto al sistema de riego, se tienen dos opciones dentro de los agricultores, tecnificado, un sistema eléctrico que consta con tuberías subterráneas las cuales realizan un riego por goteo el cual consigue el agua de un reservorio, y por gravedad, gracias a los canales de la irrigación 
Cabeza de Toro se distribuyen el agua por turnos y gracias a la gravedad y al caudal las plantas se pueden regar.

Figura 16: Sistemas de riego

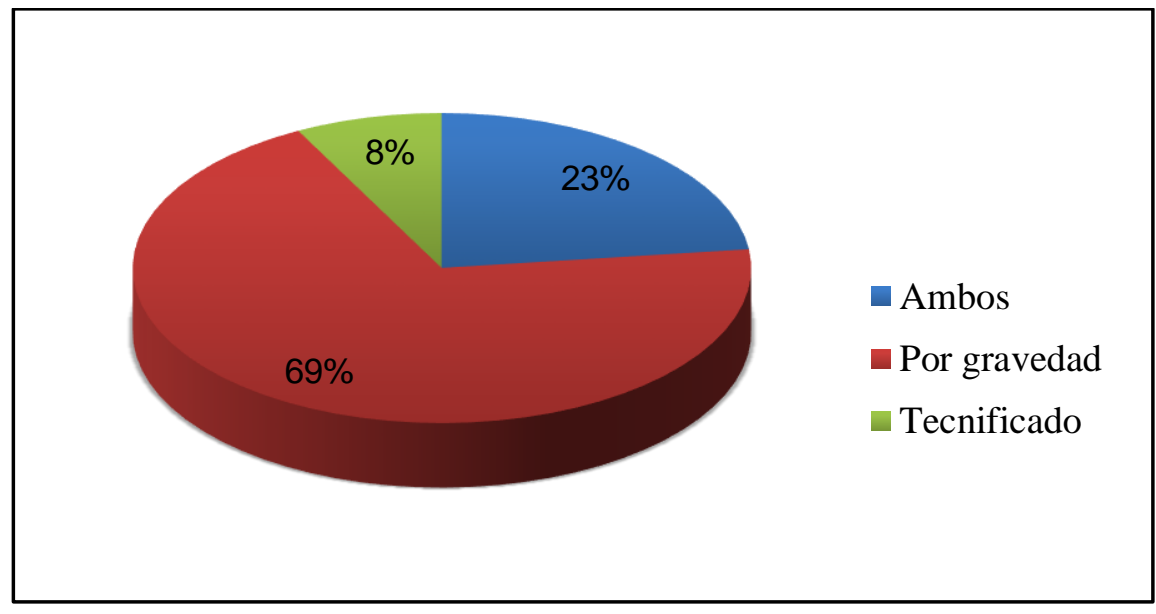

Fuente: Entrevistas realizadas. Elaboración: Propia

Con respecto a las ventajas, los agricultores solo conocen las opiniones de los técnicos quienes aseguran que el sistema tecnificado es mejor, sin embargo, gracias a la experiencia de la sequía ellos mismos han llegado a la conclusión de la necesidad de ambos sistemas para un correcto crecimiento de la planta ya que el riego por gravedad genera un desarrollo de las raíces mucho mejor que el tecnificado pero con el riego tecnificado se aprovecha mejor el agua, se puede mantener un reservorio y también se puede aplicar los nutrientes por las tuberías.

Tres agricultores confesaron que están esperando obtener capital en la siguiente campaña con el fin de financiar un reservorio y la instalación de un sistema tecnificado, un agricultor sí tiene sistema tecnificado pero el reservorio está dañado por lo que no se puede usar y otro no tiene sistema tecnificado, pero sí reservorio, espera poder conseguir el capital suficiente para seguir con las mejoras.

Figura 17: Posesión de reservorios

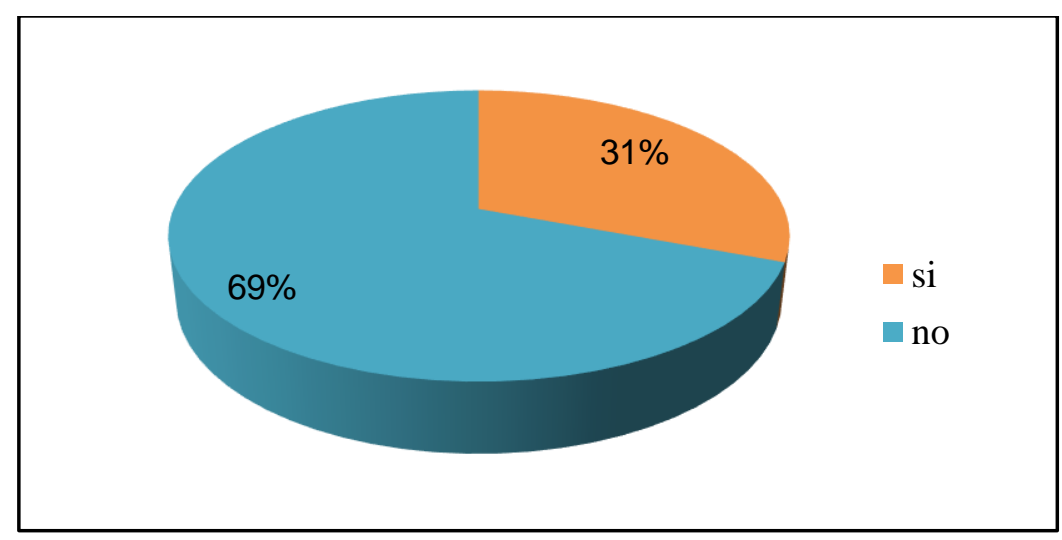

Fuente: Entrevistas realizadas. Elaboración: Propia 
Continuando con el análisis, se consultó a los agricultores cuáles son los factores más importantes para obtener una buena producción de palta Hass y estos fueron los resultados. Figura 18: Factores influyentes en la producción

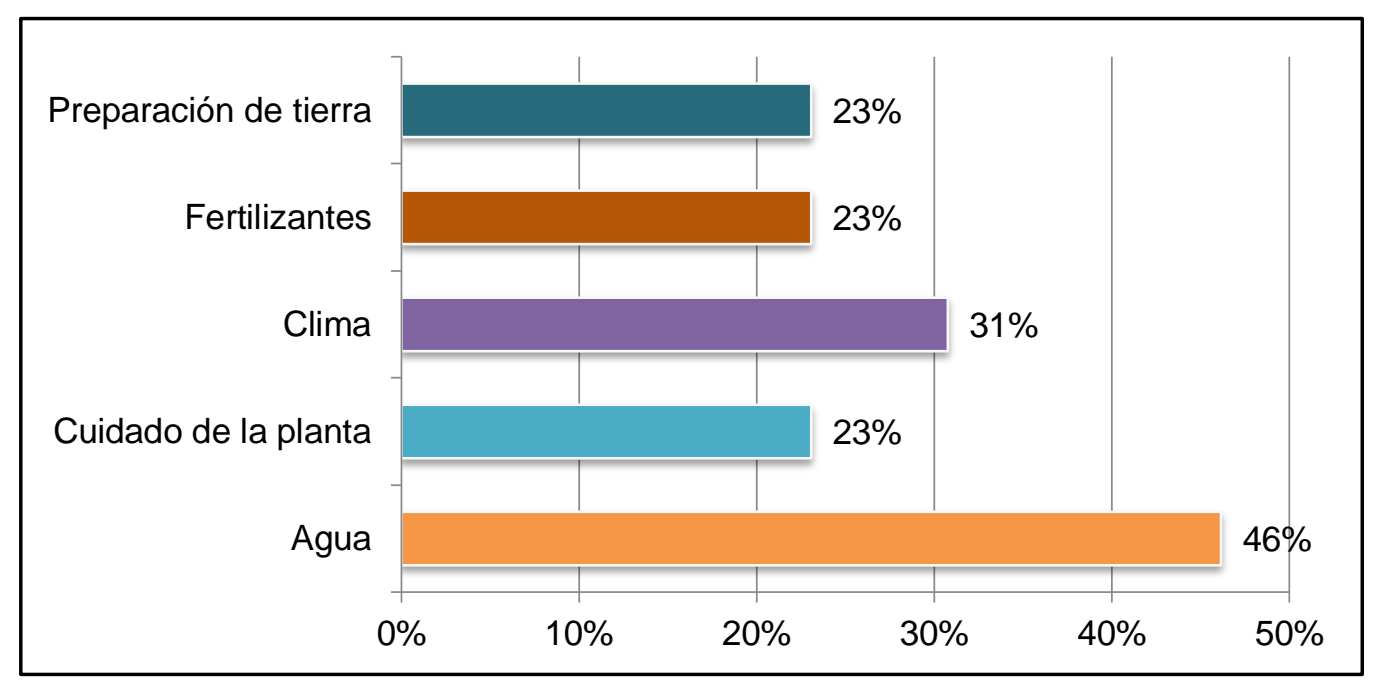

Fuente: Entrevistas realizadas. Elaboración: Propia

En la gráfica se muestra el porcentaje de agricultores que consideró cada factor importante para la producción de la palta. Como se puede observar, un $46 \%$ considera al abastecimiento de agua un factor influyente y el $31 \%$ considera que es el clima, sin embargo, no se puede manipular ninguno de estos dos factores por lo que se tratará de abarcar la preparación de la tierra y el cuidado de la planta.

Con respecto a la preparación de la tierra, se identificaron varios valores para el distanciamiento de las plantas lo cual genera una alteración en la producción ya que, aunque dos agricultores tengan la misma extensión de terreno no tendrán la misma cantidad de plantas, estas no aprovecharán de la misma manera los nutrientes de la tierra, el consumo de por hectáreas tampoco será lo mismo lo cual dificulta poder estimar un precio por hectárea para cada campaña.

Con respecto al distanciamiento entre plantas, se puede apreciar que, aunque los valores no se diferencian mucho sí hay conjugaciones distintas teniendo un $38 \%$ con $5 \times 3,5$ metros entre cada planta y 3 metros entre cada línea. 
Figura 19: Distanciamiento entre plantas

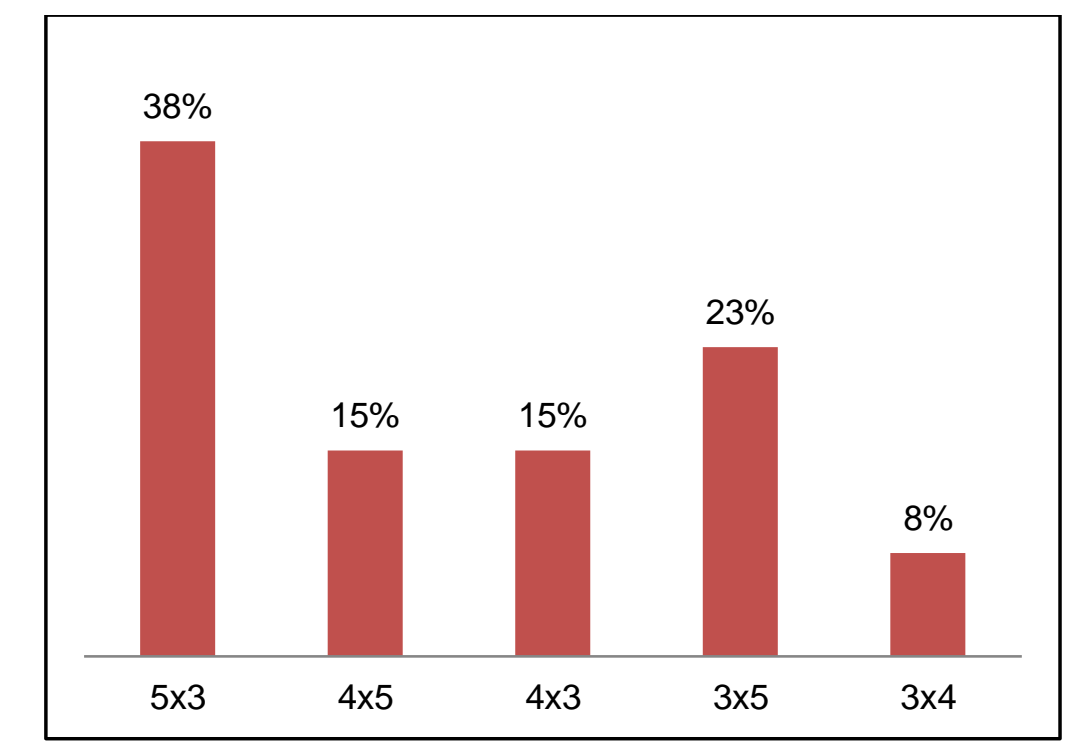

Fuente: Entrevistas realizadas. Elaboración: Propia

Cabe recalcar que estos distanciamientos fueron recomendados por un técnico agrícola a quien los miembros de la asociación acuden ante cualquier consulta.

Como ya se había mencionado, el costo por insumos varía con respecto a cada agricultor, esto se debe a las diferencias ya mencionadas, la diferente cantidad de plantas por hectárea y claro, la diferencia de extensión de terreno entre cada uno.

Figura 20: Costos adicionales

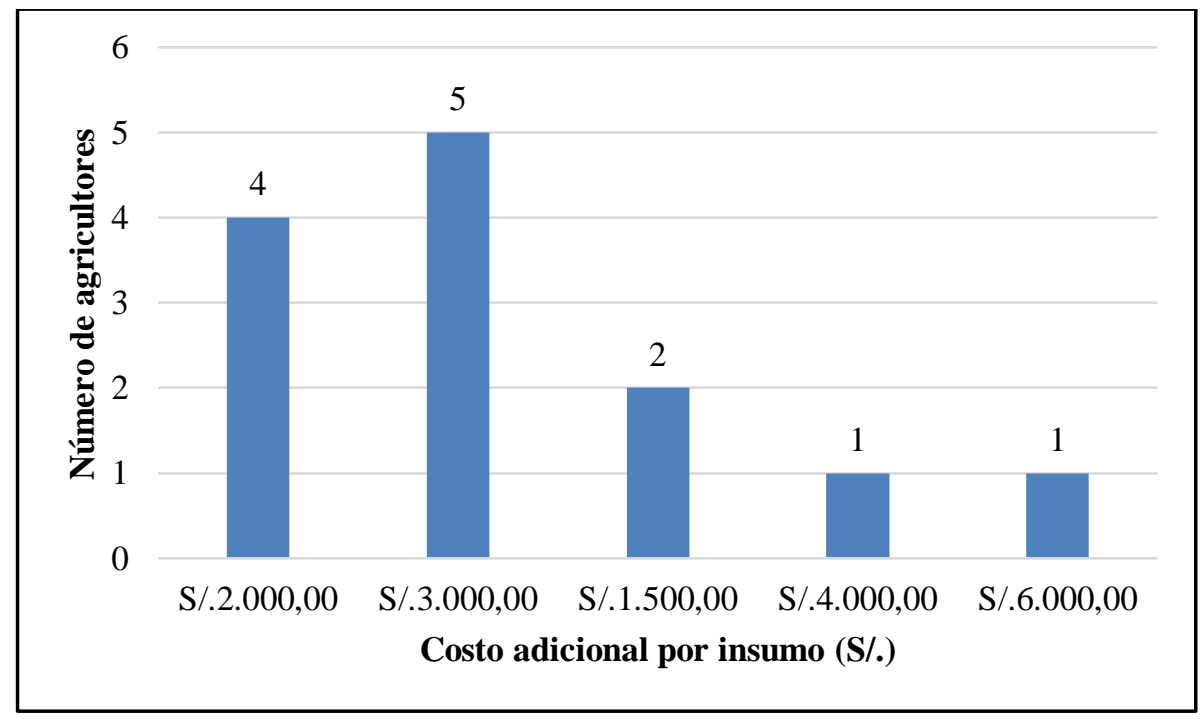

Fuente: Entrevistas realizadas. Elaboración: Propia

Dentro de los costos adicionales se encuentra la adquisición de todos los insumos que la agroexportadora no les brinda como por ejemplo pesticidas, foliares y fungicidas. Otra razón por la cual los gastos son tan altos es el desaprovechamiento de las economías de escalas, es 
decir aprovechar pedidos más grandes con el fin de obtener mejores precios y reducir los costos de transporte, esto solo lo realizan dos agricultores dentro de los 13 miembros de la asociación. Dejando de lado los costos incurridos por la asociación, en los primeros dos años del cultivo la planta no produce, lo cual deja al agricultor sin ningún tipo de ingreso, ante esto se puede optar por diferentes cultivos, llamados sembríos de lomo ya que como el palto no ocupa gran lugar se puede sembrar entre planta y planta. Se puede observar que los cultivos más sobresalientes, el maíz y el algodón, esto se debe a la costumbre de la zona. Es importante recordar que estos cultivos deben de durar máximo 2 años y medio ya que a esta edad el palto necesita de mayor espacio tanto en sus raíces como en sus ramas.

Otras ventajas de realizar estos sembríos adicionales son la limpieza del terreno ya que esto previene la acumulación de la hierba mala y el fortalecimiento del terreno en caso no se haya trabajado en este anteriormente.

Figura 21: Sembríos de lomo

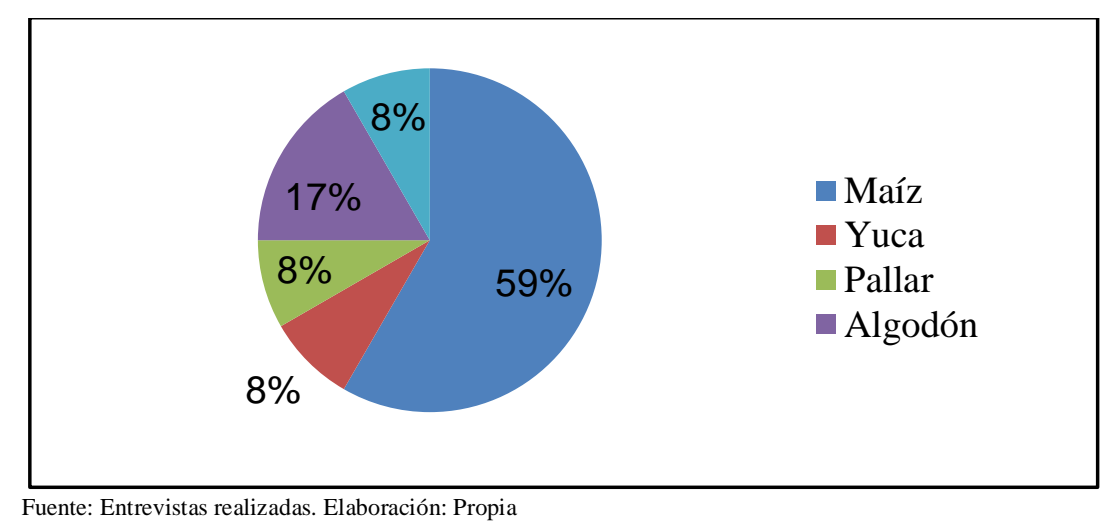

Con respecto a la limpieza del terreno y el arado, los agricultores también lo realizan de manera diferente, con máquina, de forma manual y con la ayuda de un caballo teniendo una mayoría en el uso de maquinaria; cabe resaltar que los diferentes tipos de aplicaciones se debe a las diferentes edades del cultivo y al distanciamiento de las plantas ya que estos permiten el paso de una máquina sin deteriorar el cultivo. 
Figura 22: Herramientas de arado

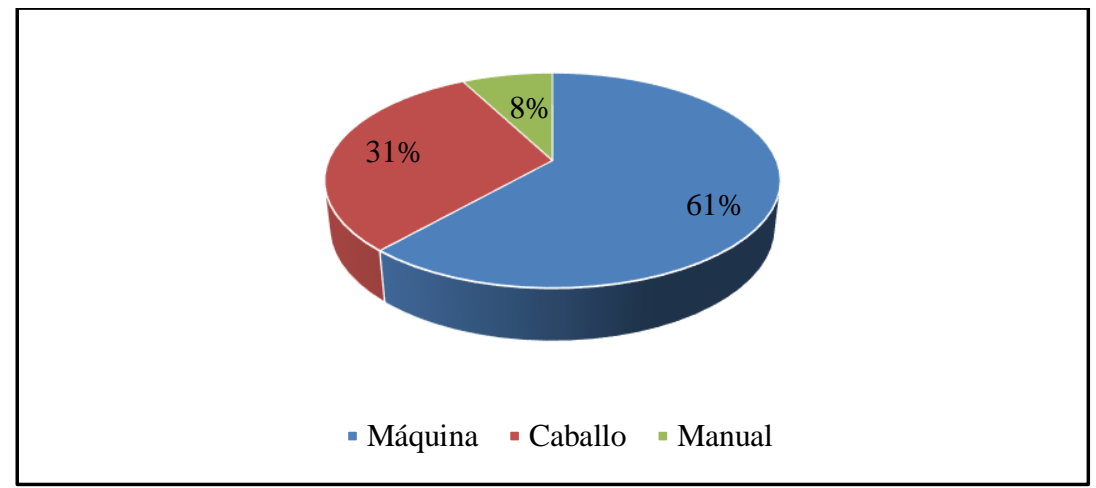

Fuente: Entrevistas realizadas. Elaboración: Propia

Otro punto que tratar es el seguimiento que realizan los agricultores a los cultivos, con el fin de poder obtener la certificación Global GAP, se realiza la libreta de tiempo anteriormente mencionada, sin embargo, no todos lo hacen, solo el 38\% de los agricultores.

Finalmente, se preguntó a los agricultores si conocían los beneficios de pertenecer a una asociación y la respuesta fue la siguiente.

Figura 23: Beneficios por asociación según agricultores

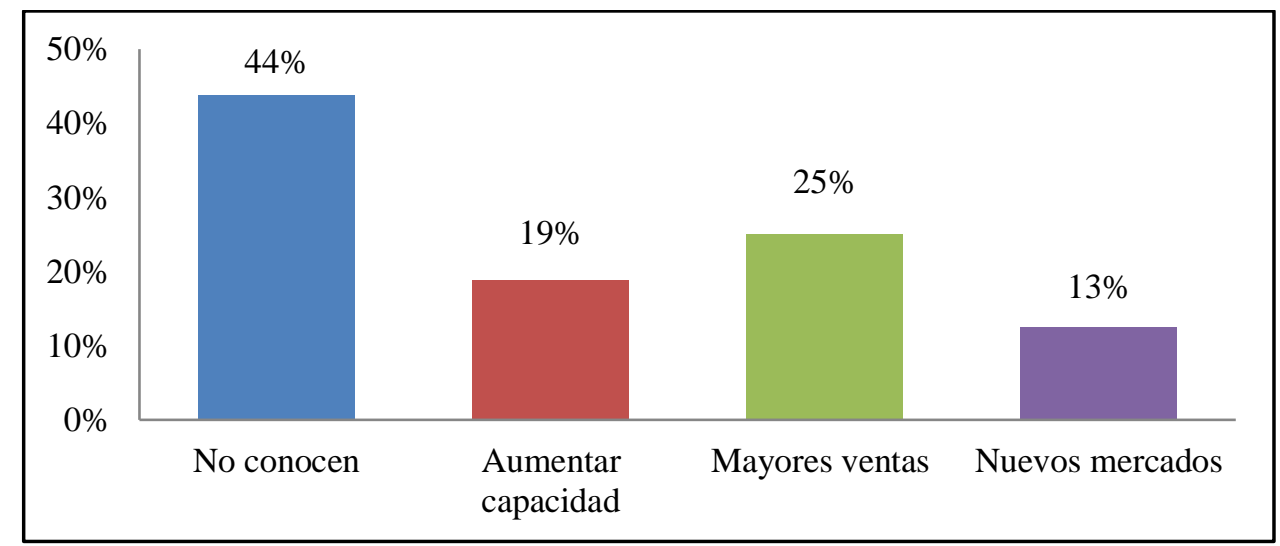

Fuente: Entrevistas realizadas. Elaboración: Propia

La respuesta más recibida fue "no sé" teniendo el $44 \%$ y teniendo como segundo puesto a "mayores ventas" lo cual es entendible ya que es lo que realmente buscaban ya que individualmente no podrían venderle a una agroexportadora. En el tercer lugar tenemos "aumentar la capacidad", lo cual va de la mano con lo anterior, aunque también refleja la capacidad de negociación con sus clientes al ser una oferta mucho más atrayente. Finalmente tenemos a "nuevos mercados" lo cual muestra el poco interés de poder salir de las limitaciones en las que se encuentran. 
Después de recaudar y evaluar la información adquirida, se procedió a analizar las productividades promedio del Perú, Ica y otros países, con el fin de tener un nivel de referencia para diagnosticar la situación actual del rendimiento de los agricultores.

Figura 24: Productividad de la palta por país

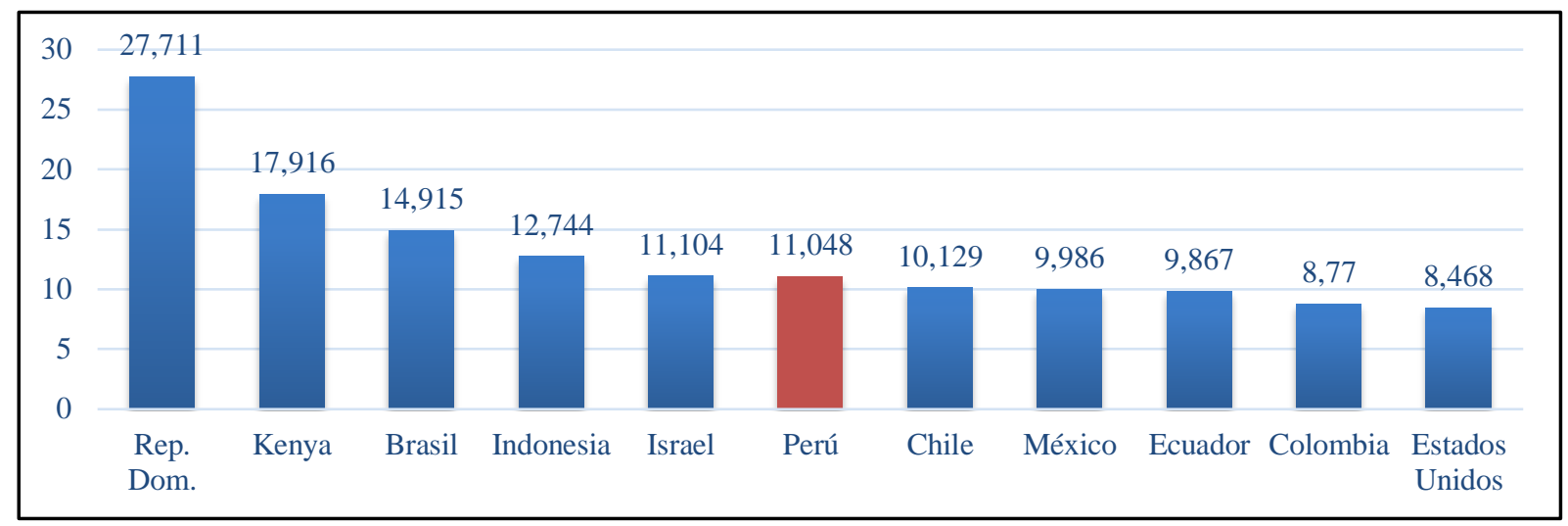

Fuente: Agraria.pe. Elaboración: Propia

Figura 25: Productividad de la palta por departamento

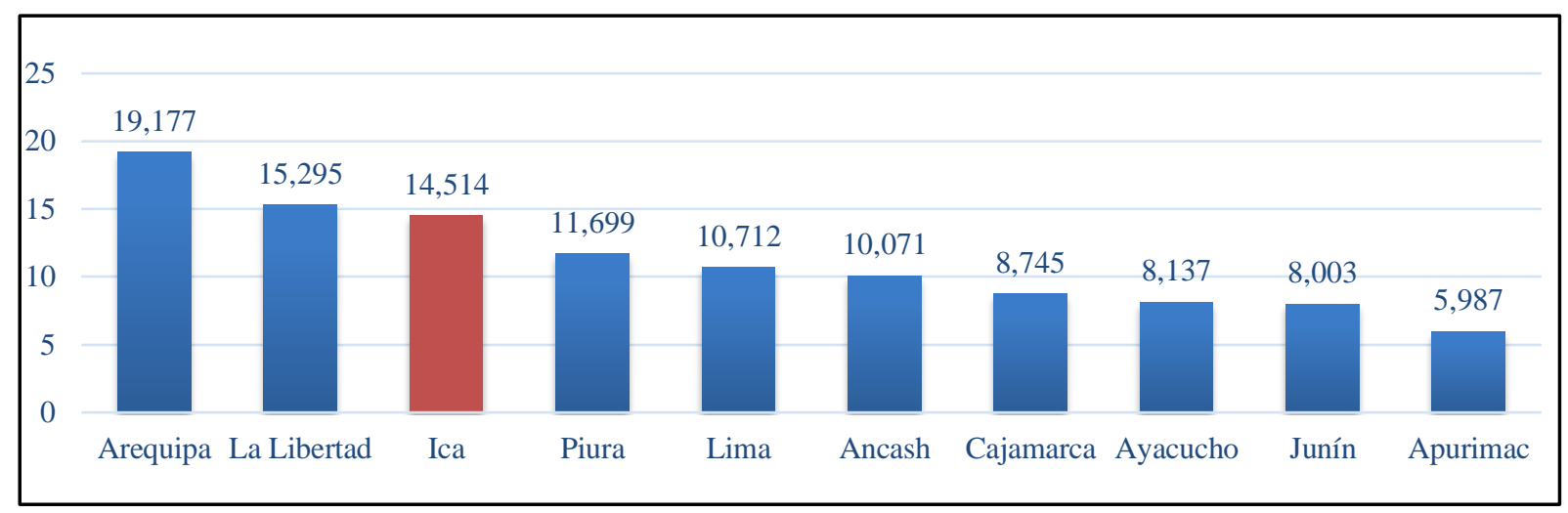

Fuente: Agraria.pe. Elaboración: Propia

Como se puede observar, entre los países productores de palta, Perú se encuentra en el sexto lugar con la productividad promedio de $11.05 \mathrm{tn} / \mathrm{ha}$ y el departamento de Ica se encuentra en el tercer puesto a nivel nacional con una productividad promedio de $14.51 \mathrm{tn} / \mathrm{ha}$. 
Figura 26: Productividad promedio por campaña

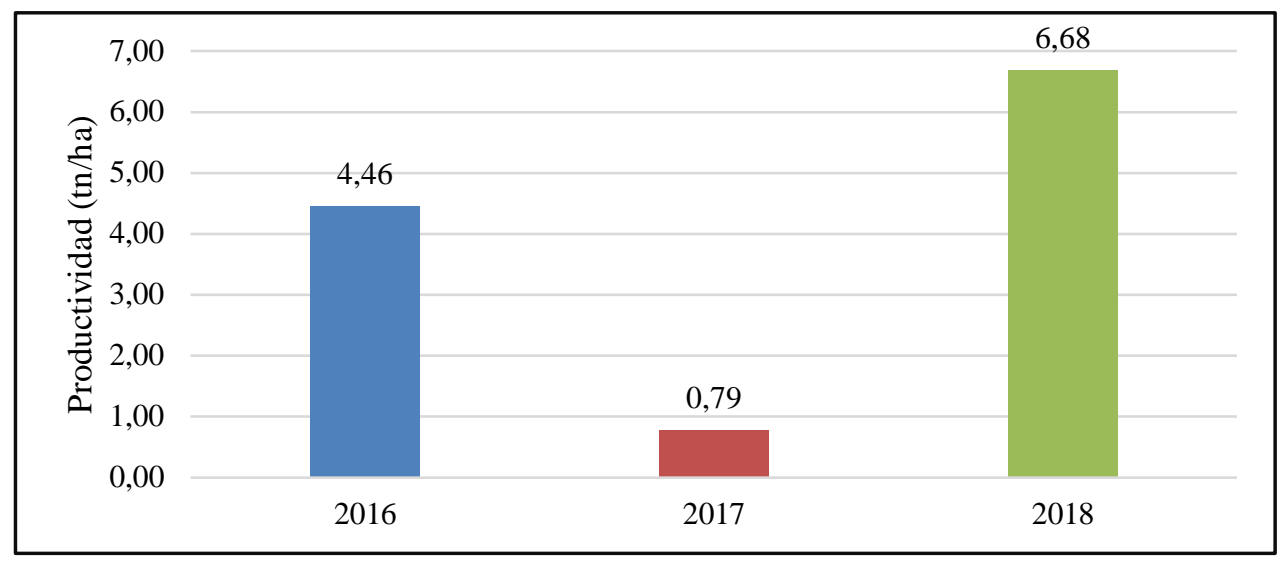

Fuente: Entrevistas realizadas. Elaboración: Propia

Para culminar con la comparación se presenta la productividad promedio de la asociación de las campañas de 2016, 2017 y la estimada para el 2018 las cuales son 4.46 tn/ha, 0.79 tn/ha y $6.68 \mathrm{tn} / \mathrm{ha}$ para a campaña respectivamente. Con estos datos, se llega a la conclusión de que los agricultores obtuvieron una productividad muy por debajo de la media tanto a nivel nacional como por departamento, lo cual significa que uno de los grandes problemas de la asociación es la baja productividad. 
Figura 27: Diagrama relacional de problemas

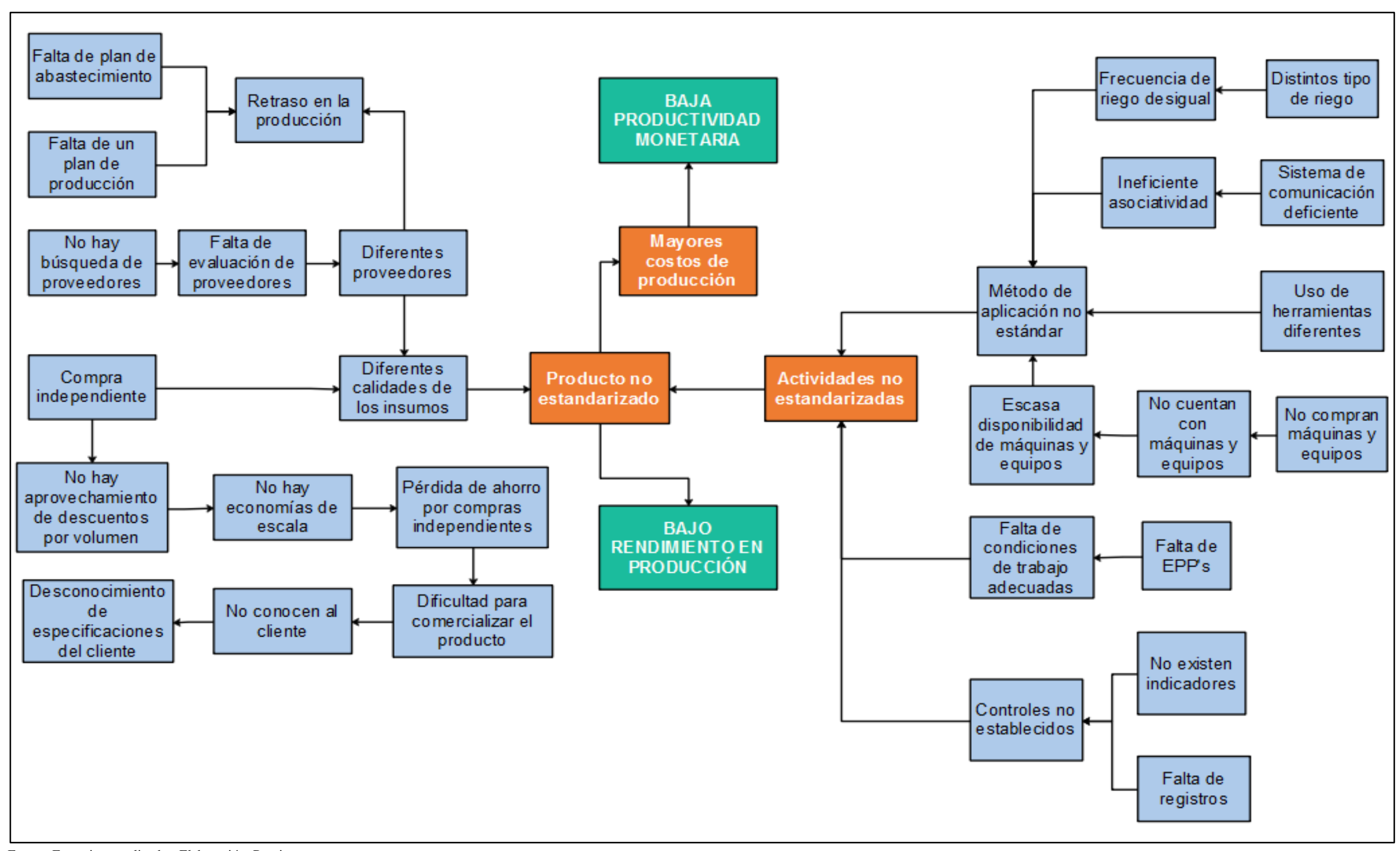

Fuente: Entrevistas realizadas. Elaboración: Propia 
Gracias a los gráficos mostrados anteriormente, se pudieron identificar varios problemas en la asociación y al interrelacionarlos se pudo un obtener el diagrama en la Figura 25.

En el diagrama se pueden identificar tres problemas principales que afectan directamente a la baja productividad de los agricultores:

\section{- Actividades no estandarizadas}

Dentro de estas actividades se encuentran la aplicación de los insumos como el abono, los foliares, los pesticidas, nutrientes, etc., la frecuencia de riego, esto se debe al diferente tipo de abastecimiento de agua por cada agricultor, no solo por el sistema de riego ya mencionado sino también por la cercanía a la fuente de agua, la periodicidad de controles, como ya se había mencionado, no todos llevan la libreta de tiempo por lo que en caso de necesidad de análisis de algún problema de parte del técnico este no puede ayudar de la mejor manera por la falta de información relevante lo cual nos lleva a lo siguiente, la falta de indicadores, como no tienen un estándar al cual deben alcanzar estos piensan que realizan las actividades de la mejor forma sin embargo se llevan con la sorpresa de una menor productividad o menores ganancias al finalizar la campaña cuando asisten a las reuniones de la asociación, lo cual también los lleva a lo siguiente, la ineficiente asociatividad, lastimosamente cada vez se reúnen menos y menos personas asisten lo cual vuelve poco efectivas las reuniones ya que pierden la retroalimentación que deberían de tener.

\section{- Mayores costos de producción}

En este caso lo más influyente es la compra independiente que causa desaprovechamiento de descuentos por cantidad, sobre costo de transporte de insumos, etc. El hecho de tener mayores costos de producción genera mayor dificultad para poder exportar ya que una vez se empiecen a encargar de los procesos logísticos estos también necesitarán de una gran inversión la cual deberá ser sustentada con el margen ganado con la eliminación de la agroexportadora entre el cliente final y los agricultores.

\section{- Producto no estandarizado}

Obtener diferentes características en el fruto genera la baja productividad ya que con respecto a esto se reciben las ganancias teniendo una diferente de $\$ 0.30 / \mathrm{kg}$. Estas diferencias se deben a la diferenciación entre las cantidades usadas para los cultivos lo cual refleja la falta de un plan de abastecimiento y de producción para toda la asociación, sin mencionar que no utilizan los mismos proveedores entonces se corre el riesgo de no utilizar una calidad consistente para la nutrición de la planta. 
Además, como parte de las entrevistas semi estructuradas, se formularon las siguientes preguntas con el fin de obtener información considerada necesaria por el equipo de investigación.

Figura 28: Factores causantes de los malestares

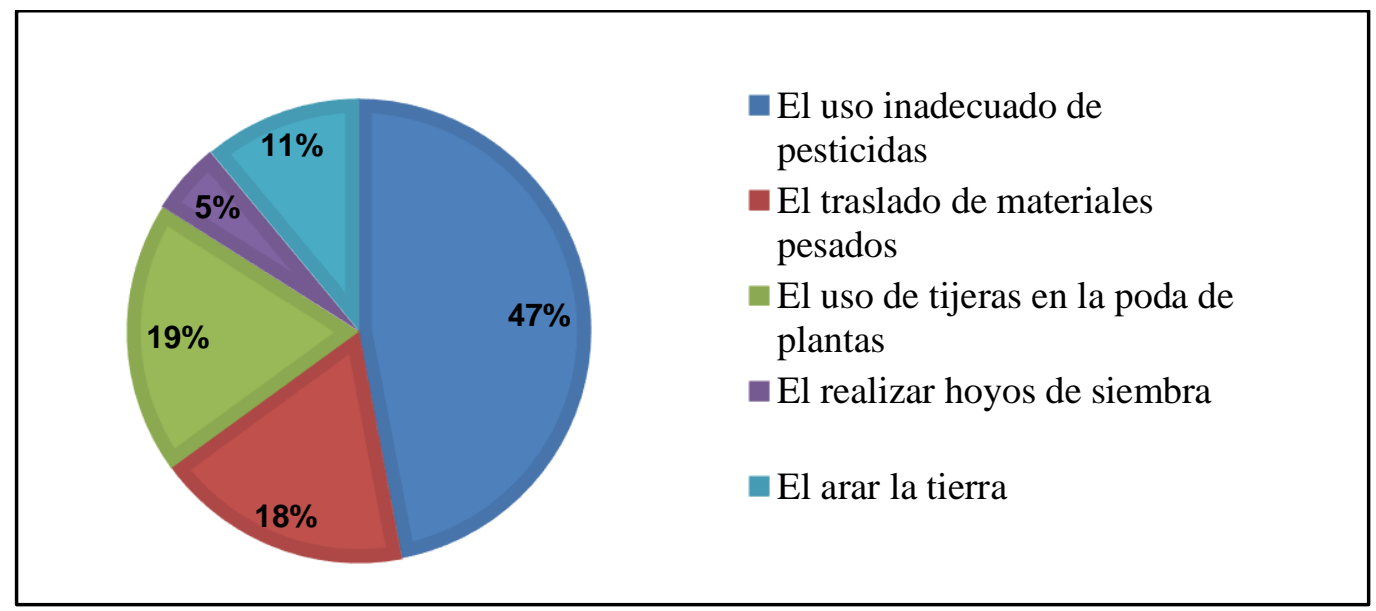

Fuente: Entrevistas realizadas. Elaboración: Propia

La razón por la cual se consultó las causas de los malestares es el bajo rendimiento de parte de los operarios en campo debido a dolores de cabeza, espalda, cintura, etc. Como resultado, $47 \%$ de los agricultores comentaron que el uso inadecuado de los pesticidas es la causa principal de las dolencias, como segundo puesto se tuvo el uso de tijeras en la poda ya que en ocasiones se provocan accidentes manuales y como tercer puesto se tiene el traslado de materiales lo cual se debe a la forma en la cual se cargan los sacos de insumos.

Figura 29: Principales problemas durante la cosecha

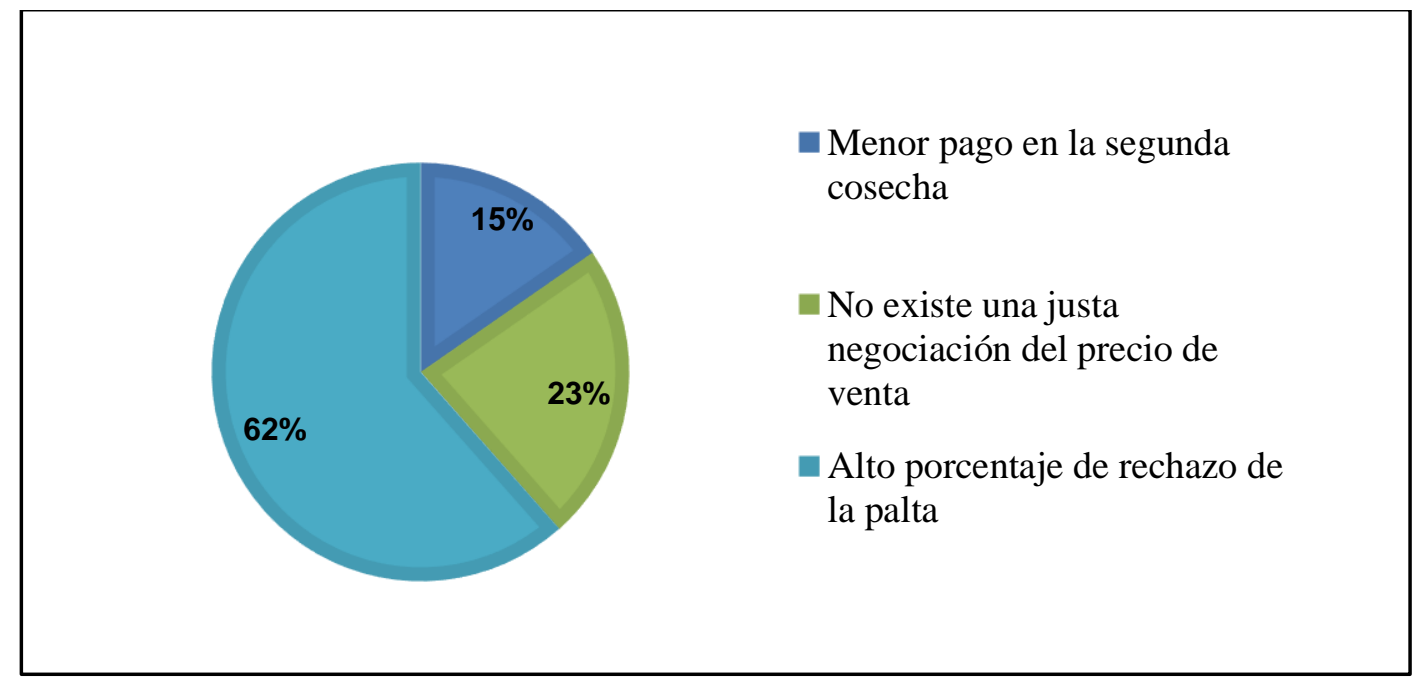

Fuente: Entrevistas realizadas. Elaboración: Propia

Gracias a la segunda pregunta, se obtuvo como resultado que, dentro de la asociación, el 62\% se queja del alto porcentaje de rechazo de la palta el cual es de $46 \%$ en promedio en el primer corte generando así menores ingresos para los agricultores ya que el pago en el segundo corte 
es \$0.3 menor. Otro motivo de desagrado es la nula negociación entre ellos y la agroexportadora con respecto a precio de venta lo cual les brinda cierta incertidumbre en las ganancias futuras. Otro punto importante para el equipo de investigación fue el desconocimiento de costo del producto, solo algunos de los agricultores podían brindar valores aproximados sin embargo no se encontraban seguros de los valores.

De acuerdo con los resultados, $46 \%$ de los agricultores no guardan registros de sus actividades mientras que el $31 \%$ no identifica los costos incurridos y el $23 \%$ desconoce la inversión que realizan para los diferentes requerimientos.

Figura 30: Factores en la estimación del costo del fruto

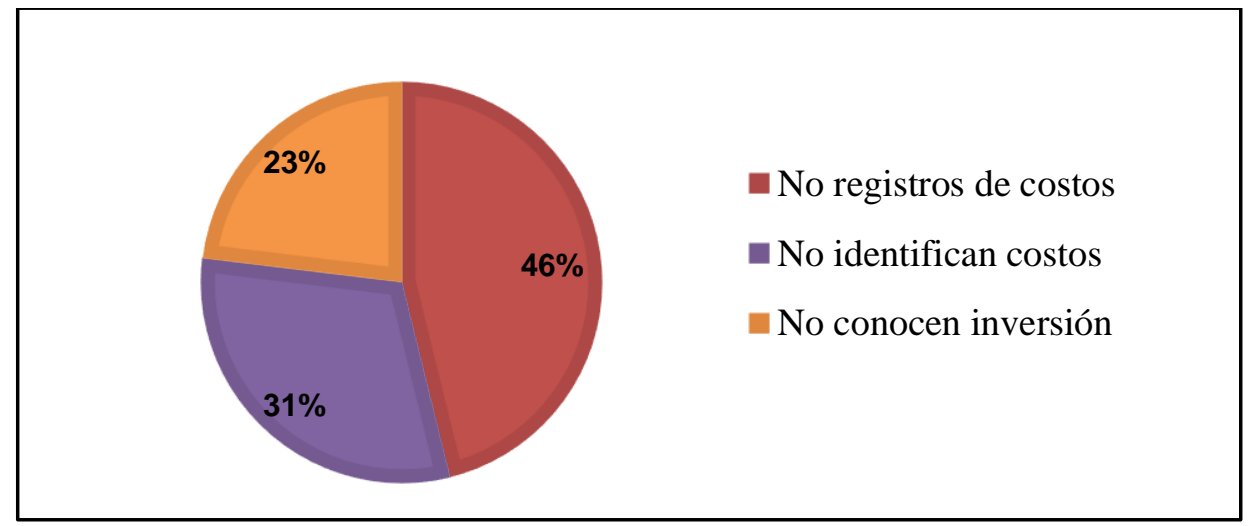

Fuente: Entrevistas realizadas. Elaboración: Propia

Como ya se mencionó, no tienen conocimiento de todos los requerimientos necesarios para la producción lo cual genera en ocasiones problemas de desabastecimiento. Según los resultados la principal causa es la insuficiente coordinación y disposición de los elementos de producción ya que no existe una evaluación y planificación previa de los requerimientos.

Figura 31: Factores que evitan la buena administración de recursos

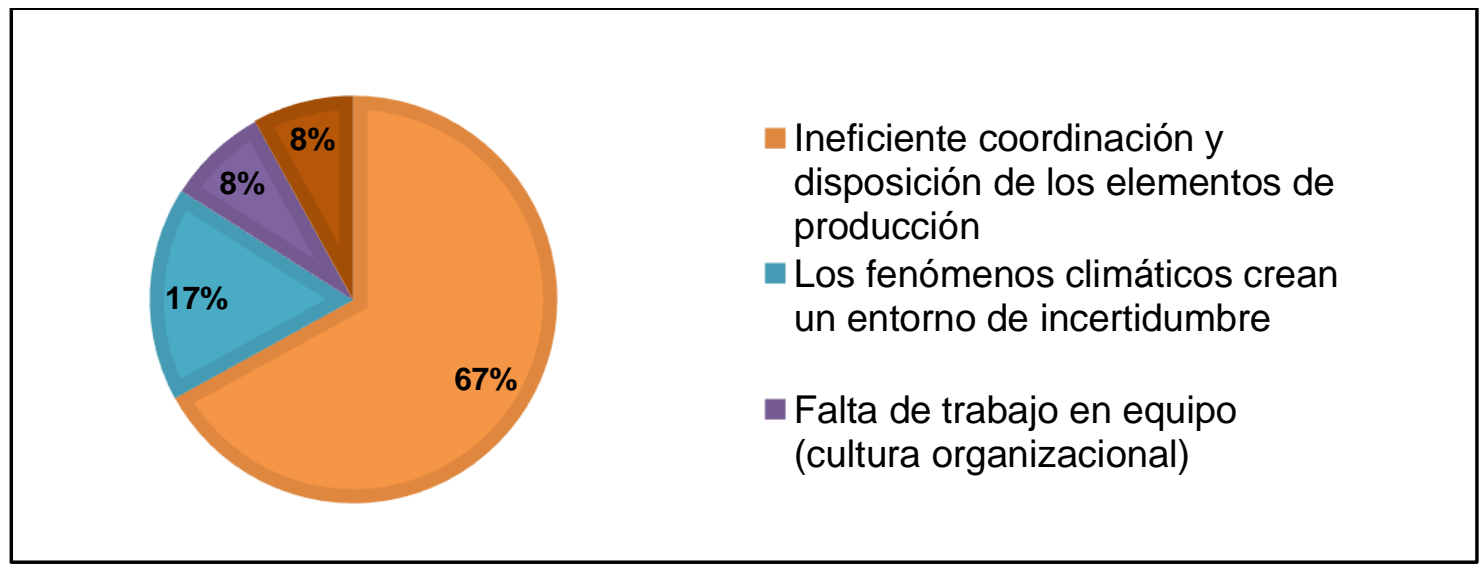

Fuente: Entrevistas realizadas. Elaboración: Propia

Anteriormente se mencionó la incapacidad de negociación del precio del cultivo, esto genera un bajo margen de ganancia, se consultó las causas de esto en particularmente y como resultado el $69 \%$ de los agricultores sentían limitados para poder ingresar a nuevos mercados, sobre todo 
internacionales mientras que el $23 \%$ consideran que se debe a lo ya mencionado, la incapacidad de negociación y finalmente el $8 \%$ la falta de ayuda del gobierno con respecto a financiamientos y proyectos agrícolas.

Figura 32: Causas por el margen obtenido

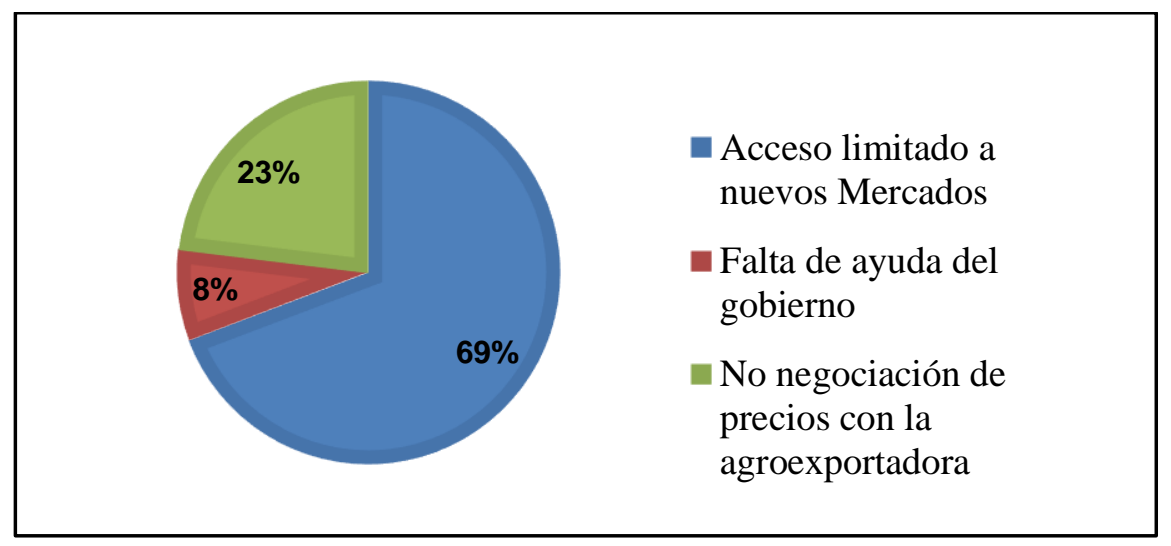

Fuente: Entrevistas realizadas. Elaboración: Propia

Figura 33: Factores que evitan la separación con agroexportadora

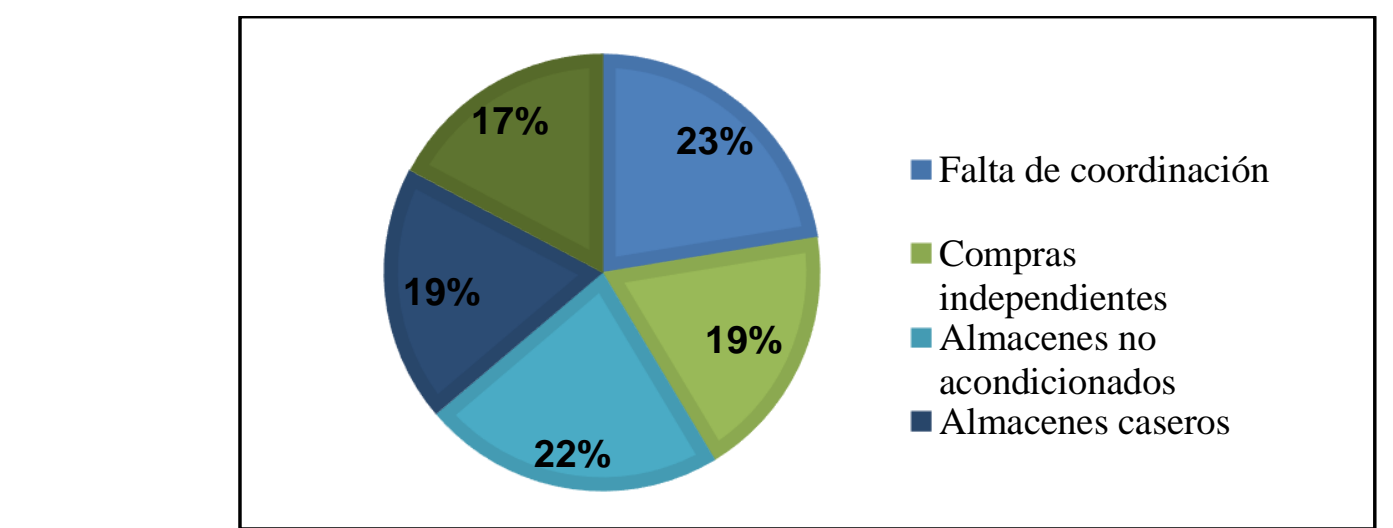

Fuente: Entrevistas realizadas. Elaboración: Propia

Finalmente, debido a las quejas mencionadas acerca de la relación con la agro exportadora con la cual trabajan actualmente se consultó cuáles son las razones por lo cual no se pueden desligarse de esta y como principal respuesta, con $23 \%$, se tuvo la falta de coordinación entre los 13 agricultores para poder gestionar pedidos de alto volumen y poder negociar con los clientes finales, mientras que con $22 \%$ se mencionó la falta de almacenes preparados para poder sostener la producción y poder comprar los insumos por volumen lo cual nos lleva a las compras independientes que obtuvo un $19 \%$ y finalmente la falta de planificación de las compras realizadas con $17 \%$. 
Figura 34: Diagrama relacional de problemas con procesos

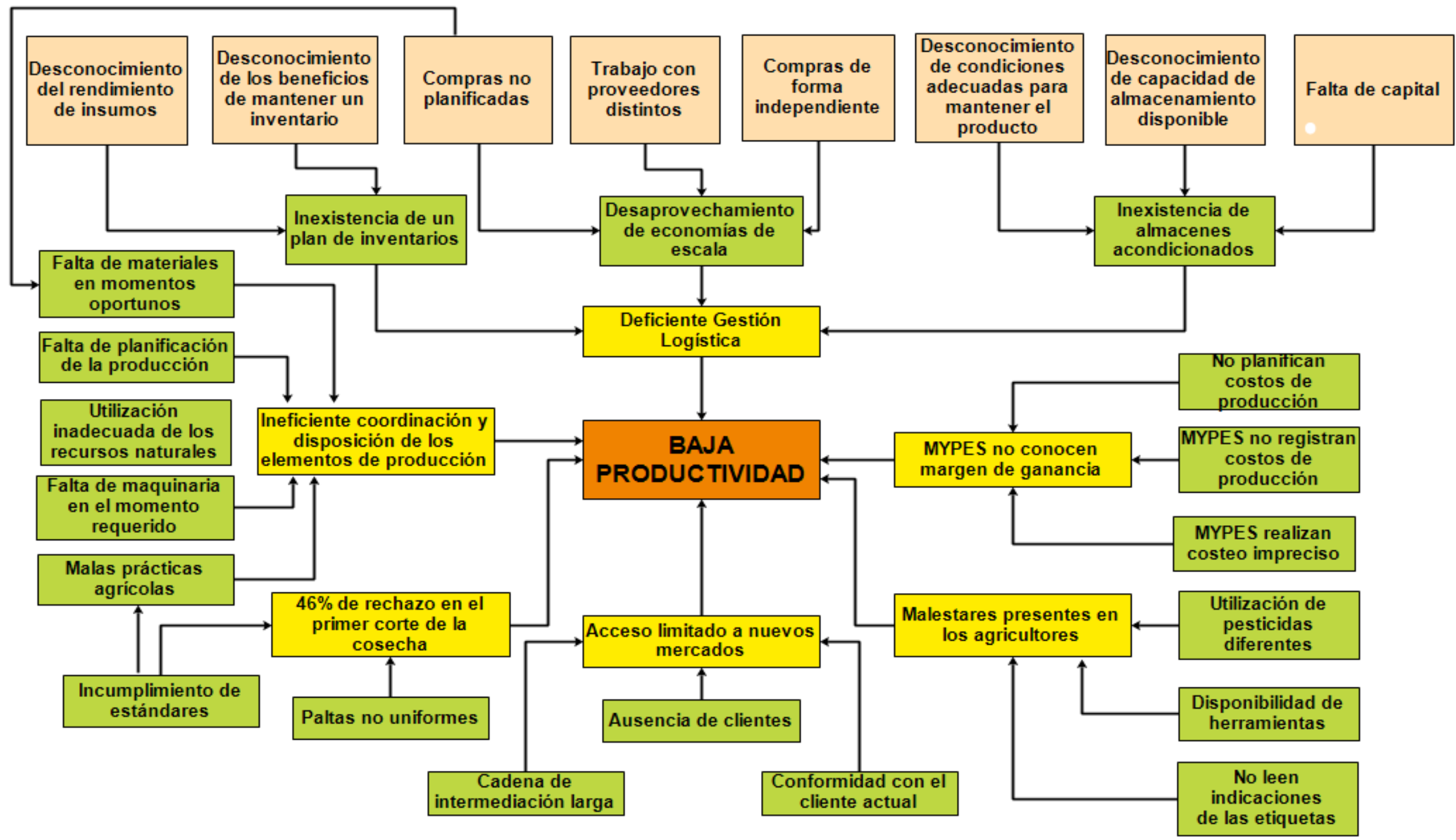

Fuente: Entrevistas realizadas. Elaboración: Propia 
Todos los resultados mencionados se relacionaron con el problema principal encontrados anteriormente, la baja productividad, y se relacionó con el proceso correspondiente que podría mejorar la situación. (Figura 32)

Gracias a todo el análisis realizado se llegó a la conclusión de la necesidad del diseño de seis procesos diferentes e interconectados:

- Planeamiento y control de producción

- Gestión de calidad

- Gestión logística

- Seguridad industrial y salud ocupacional

- Gestión comercial

- Gestión de costos

Debido a esto se armó el equipo de investigación donde se abarcarían los procesos mencionados, pero en diferentes proyectos de investigación, llevando eso a nuestra elección, gestión logística.

\subsubsection{Diagnóstico de la gestión logística}

Dentro del diagnóstico realizado, gracias a los factores que atan a la asociación con la agroexportadora se encontró como principal problema la deficiente gestión logística, a partir de esto se investigaron las causas de este mediante el método 6'sM teniendo en cuenta materiales, métodos, mano de obra, medición, medio ambiente y maquinaria con el fin de abarcar todos los puntos posibles teniendo como resultados la inexistencia de almacenes acondicionados, de plan de inventarios y el desaprovechamiento de economías de escala. 
Figura 35: Ishikawa logístico

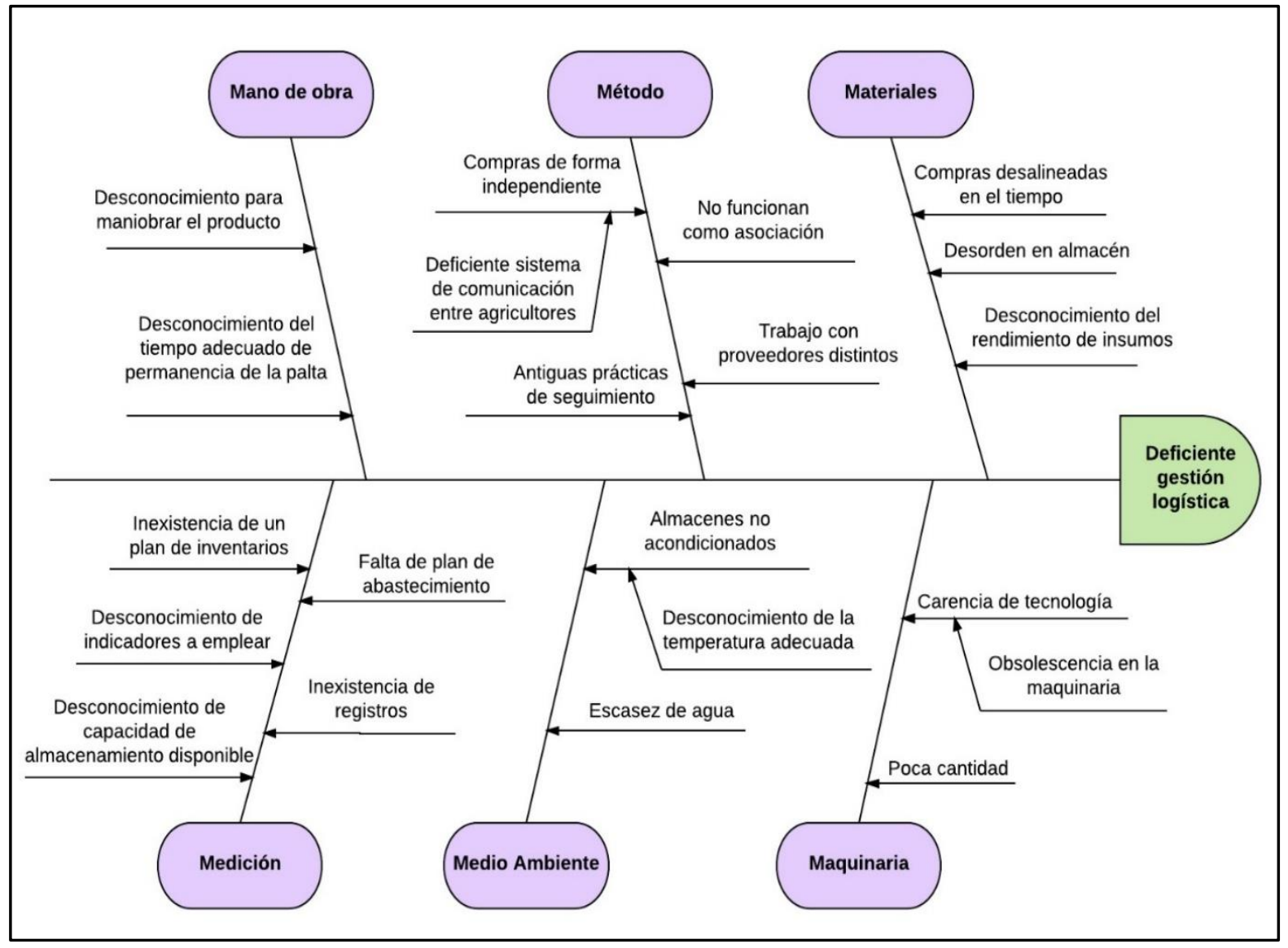

Fuente: Entrevistas realizadas. Elaboración: Propia

Figura 36: Principales causas de la deficiente gestión logística

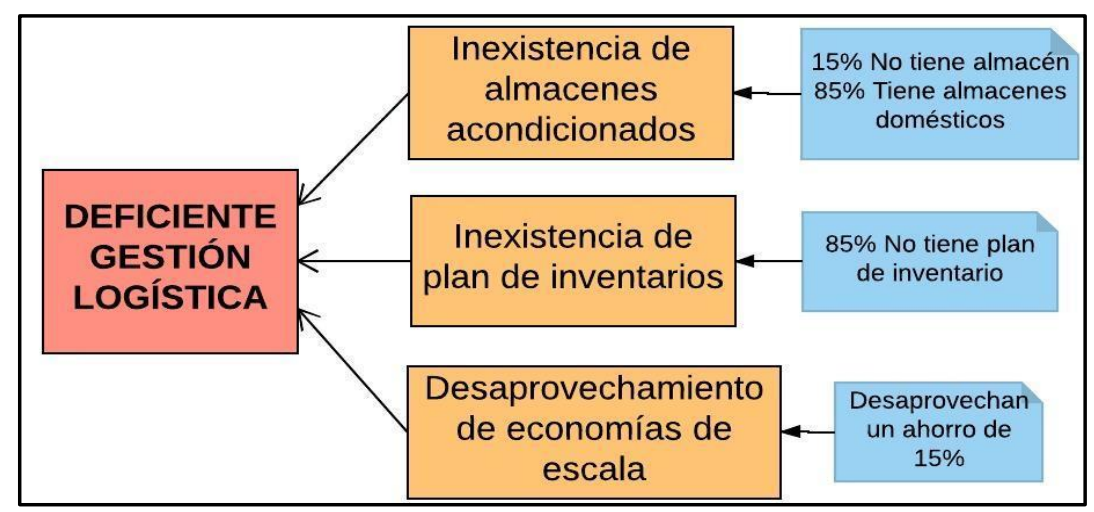

Fuente: Entrevistas realizadas. Elaboración: Propia

Después de analizar las principales causas encontradas se optó por dividir el diagnóstico logístico en tres diferentes subprocesos compras, inventarios y almacén para poder profundizar y poder encontrar las causas raíces de cada uno. 


\subsubsection{Compras}

Figura 37: Diagrama causal desaprovechamiento de economías de escala

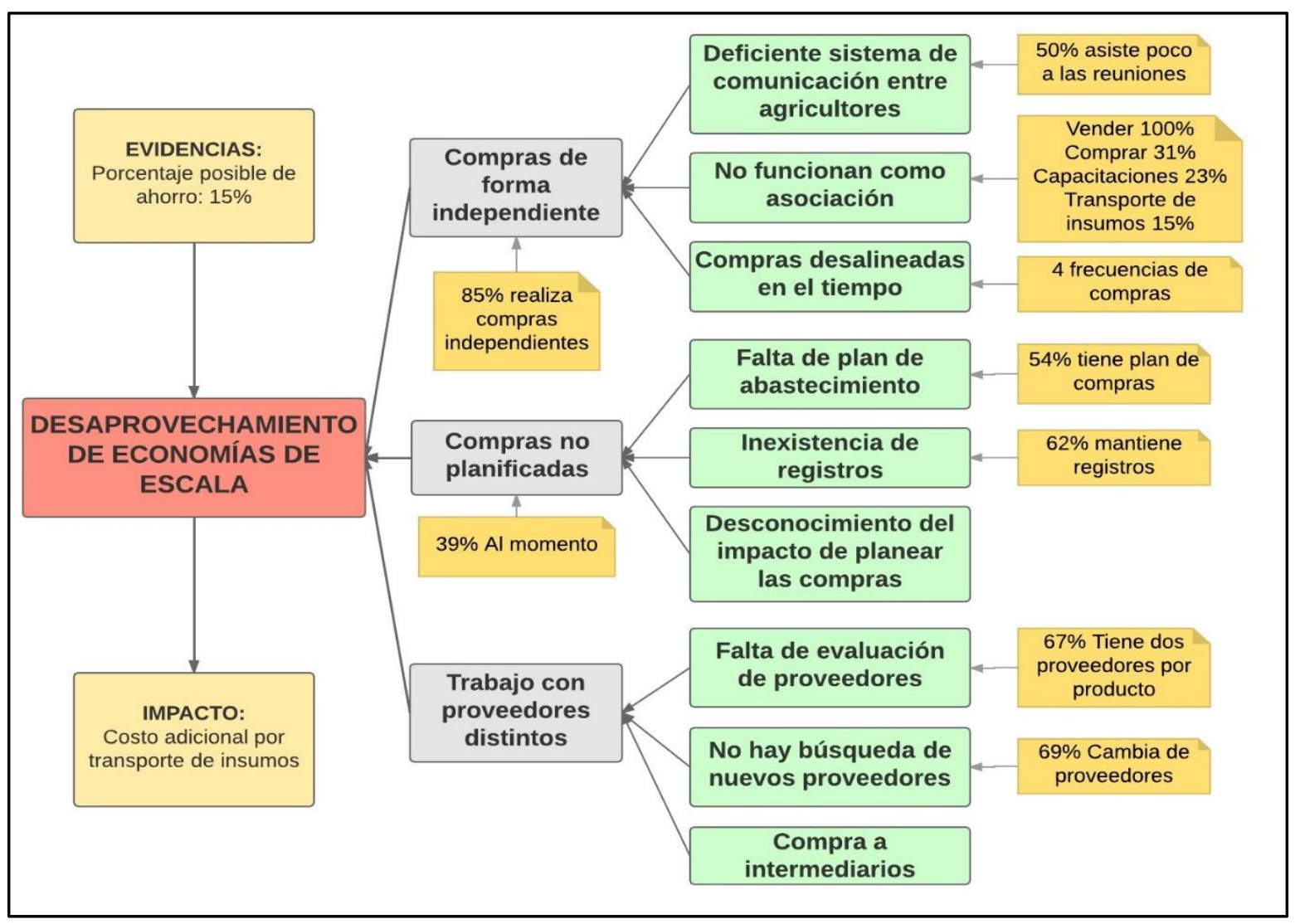

Fuente: Entrevistas realizadas. Elaboración: Propia

El principal problema del subproceso Compras es el desaprovechamiento de economías de escala lo cual tiene como consecuencia la pérdida de oportunidad de ahorrar hasta el $15 \%$ de sus gastos y a la vez incurrir en costos de transporte en exceso ya que se emiten pedidos por separados generando así un costo de flete por cada uno. Esto nos lleva a la primera causa encontrada, compras de forma independiente, $85 \%$ de los agricultores lo realizan, esto es debido a la escasa comunicación entre agricultores quienes organizan reuniones para poder contrarrestar esto sin embargo solo aproximadamente la mitad de los agricultores asiste, además, muchas de las actividades necesarias en cada campaña no la realizan como asociación una prueba de esto es que solo el $31 \%$ de los agricultores realizan compras conjuntas, $15 \%$ paga el transporte de sus insumos en conjunto. Finalmente, los agricultores realizan sus compras en frecuencias diferentes, pudiendo ser cada 2, 3, 4 y 6 meses teniendo como mayor porcentaje la compra cada 2 meses con $54 \%$ de incidencia entre los agricultores. 
Figura 38: Actividades realizadas como asociación

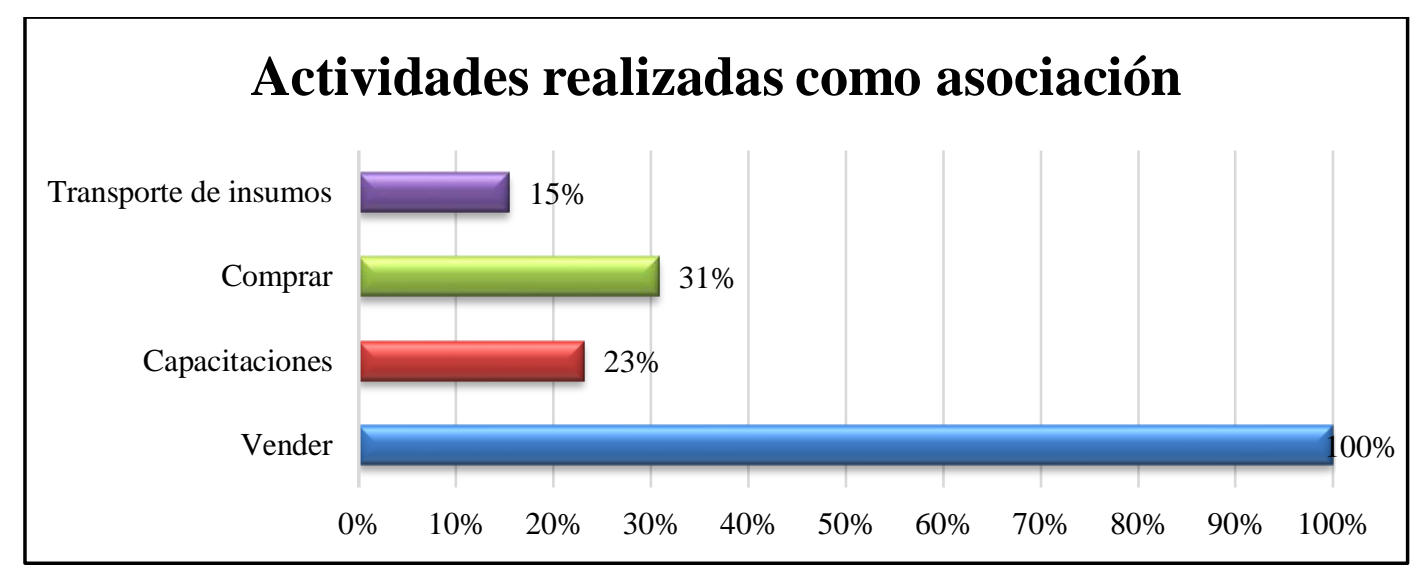

Fuente: Entrevistas realizadas. Elaboración: Propia

La segunda causa encontrada es la realización de compras no planificadas ya que $39 \%$ de los agricultores compran al momento ya que no planifican sus requerimientos con tiempo esto se debe a la falta de un plan de abastecimiento, esto sucede en 54\% de los agricultores. Además, esto se debe a la inexistencia de registros en el $38 \%$ de los agricultores, cabe recalcar que los agricultores no registran todos los datos necesarios, más bien solo los básicos solicitados por el técnico agrónomo los cuales no abarcan los precios de los insumos ni fechas de las compras. Finalmente, se realizan compras no planificadas ya que desconocen el impacto y los beneficios de la planificación en compras.

La tercera causa es el trabajo con proveedores distintos entre los trece agricultores de la asociación ya que cada uno trabajo por su cuenta y no realizan evaluaciones lo cual también se refleja gracias a la falta de búsqueda de nuevos proveedores, se conforman con los aquellos que se dirigen a los campos a ofrecer su producto y algunas veces para evitar el transporte aceptan $\mathrm{y}$ adquieren de esta manera sus insumos.

Con respecto a los productos que deben ir a conseguirlos por su cuenta, van a distribuidores cercanos, lo cual les quita la oportunidad de aprovechar los precios y las calidades de otras empresas y a la vez los obliga a incurrir en el costo de transporte desde la tienda hasta su campo, nos comentaron el costo de S/. 1/saco. 


\subsubsection{Inventarios}

Figura 39: Diagrama causal de inexistencia de plan de inventarios

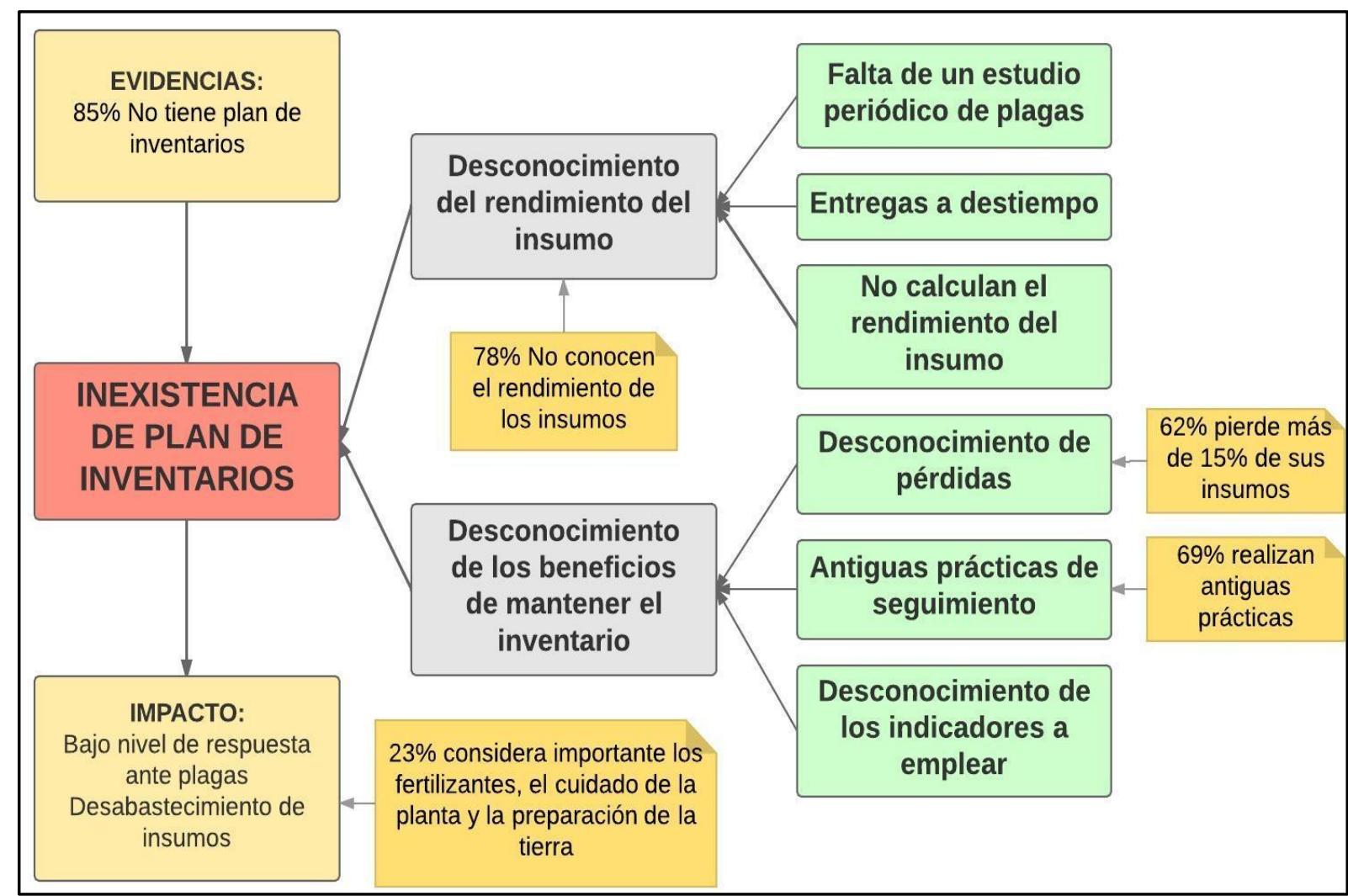

Fuente: Entrevistas realizadas. Elaboración: Propia

Dentro del subproceso inventarios, el principal problema encontrado fue la inexistencia de un plan de inventarios, $85 \%$ de los agricultores, esto los conduce a un bajo nivel de respuesta ante las plagas ya que tienen desabastecimiento de los pesticidas e insecticidas, y al mismo tiempo genera demoras en las actividades de producción ya que no se tienen los insumos disponibles para el cuidado de la planta.

La principal causa de no poder planificar un inventario es el desconocimiento del rendimiento de los insumos lo cual está ligado con el desconocimiento de un estudio de periodicidad de las plagas, sobre todo con los pesticidas e insecticidas, ya que no son conscientes de cuantas plagas van a afrontar durante la campaña y terminan comprando al momento cuando la plaga ya se encuentra deteriorando la planta.

La segunda causa es el desconocimiento de los beneficios de mantener el inventario ya que no son conscientes de las pérdidas exacta por desabastecimiento tanto a nivel de producción como monetariamente, se asume que las pérdidas son por factores climatológicos y por lo tanto no se podrían evitar. Además, se realizan antiguas prácticas agrícolas lo cual conlleva a un seguimiento básico de los cultivos, esto se evidencia ya que solo el $31 \%$ de los agricultores están siguiendo las buenas prácticas agrícolas. Al mismo tiempo, como no se realizan las buenas 
prácticas agrícolas no conocen los indicadores adecuados que deben emplear, y en la mayoría de los casos no calculan ningún indicador logístico.

\subsubsection{Almacén}

Figura 40: Diagrama causal de inexistencia de almacenes acondicionados

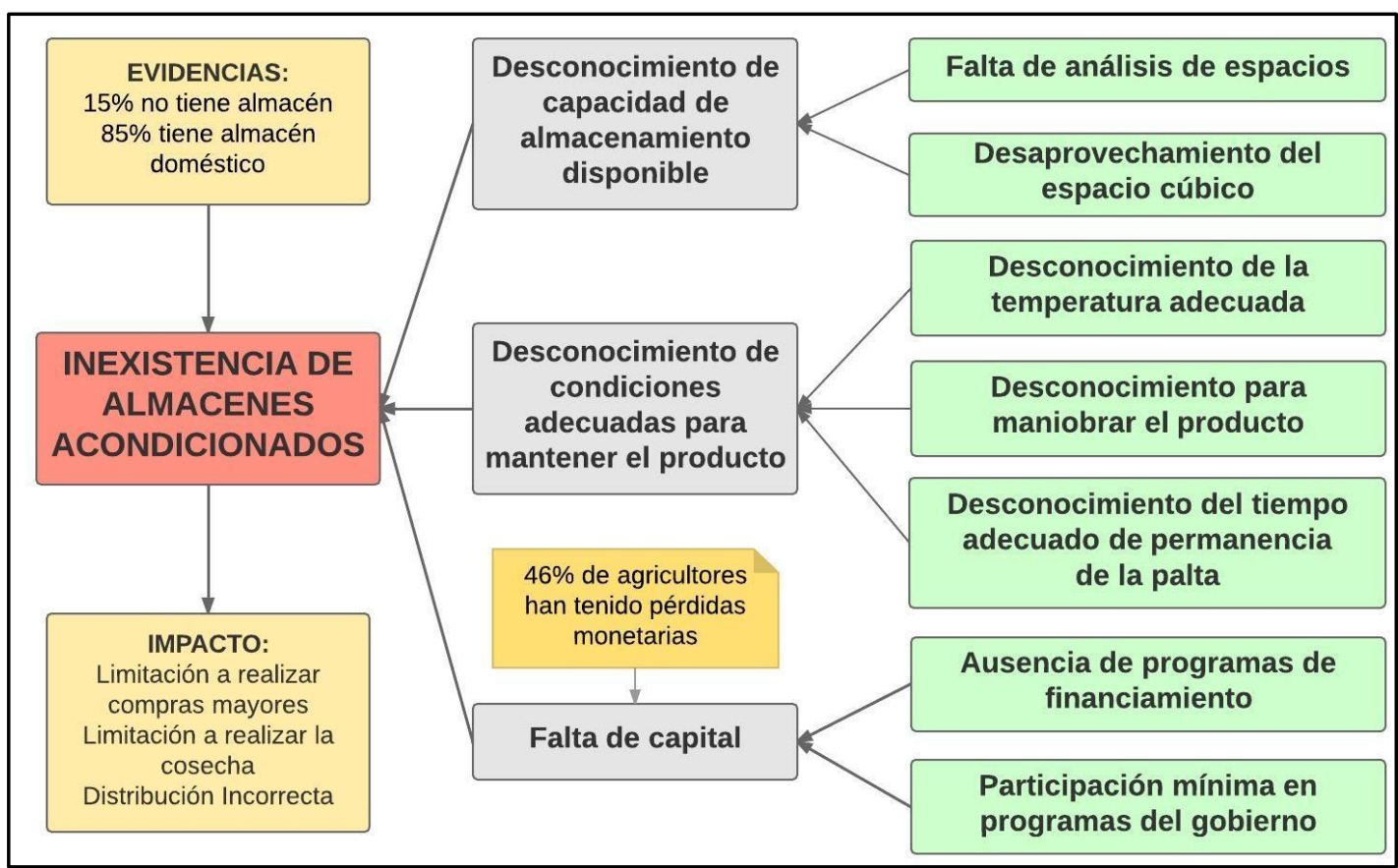

Fuente: Entrevistas realizadas. Elaboración: Propia

Este caso, el principal problema es la inexistencia de almacenes acondicionados ya que no poseen un almacén en común para la asociación y los pertenecientes a cada agricultor son ambientes dentro de sus hogares, esto sucede en toda la asociación a excepción de una quien no tiene ningún lugar destinado para el almacenamiento de sus insumos lo cual la obliga a comprar de forma exacta y por consiguiente al momento en casos de inconvenientes.

La primera causa encontrada es el desconocimiento de la capacidad de almacenamiento que poseen, como se comentó anteriormente, destinan un ambiente de sus hogares y no realizan las medidas correspondientes para realizar un análisis de espacios, esto junto a la falta de inversión en muebles de almacenamiento tiene como consecuencia el desaprovechamiento del espacio cúbico.

Además, los agricultores mencionaron como plan a futuro poseer un almacén en conjunto para poder realizar compras en volumen, sin embargo, no tenían claro la ubicación, la capacidad posible y las condiciones que debería tener el almacén, lo cual nos lleva a la segunda causa encontrada. Esto se debe al desconocimiento de datos específicos de almacenamiento del fruto como por ejemplo la temperatura a mantener una vez cosechada, el tiempo de permanencia máximo antes de poder entregarlo a un operador logístico y las maneras de almacenar el fruto. 
Finalmente, comentaron la falta de capital, no solo por las pérdidas de la campaña 2017 donde 47\% de los agricultores tuvieron pérdidas monetarias en vez de ganancias, sino también por la ausencia de programas de financiamiento y la poca ayuda del gobierno para el sector agrícola en la zona.

\subsection{ALCANCE}

El trabajo presentado presenta un diagnóstico del sector agrícola de la palta Hass y brinda una propuesta de gestión logística a un alcance de diseño ya que se planteará todos los puntos pertinentes para su creación, sin embargo, no se llegará a implementarlo.

Para este trabajo se tendrán los siguientes entregables:

- Mapa General de Procesos del sistema básico de gestión para la palta Hass.

- Mapa Específico de Subprocesos de Logística.

- Flujograma de subprocesos de Logística.

- Procedimientos de sub procesos propuestos.

- Fichas de indicadores logísticos

\subsection{OBJETIVO}

\subsubsection{General}

Diseñar un proceso conjunto que ayude a incrementar la productividad del sector agrícola de la palta Hass del departamento Ica, Perú a través del análisis de las áreas de compras, transporte, almacén e inventarios.

\subsubsection{Específicos}

- Diseñar un proceso que permita transportar los frutos de la manera más rápida y menos costosa.

- Realizar un diagnóstico sobre los objetivos y la situación actual del sector en las áreas compras e inventarios.

- Diseñar una propuesta para el manejo de las áreas transporte y almacén.

- Definir una propuesta para concretar la óptima interacción de las áreas compras, transporte, almacén e inventarios.

- Incrementar la participación en la cadena de suministro de la palta Hass que ellos mismo producen. 


\subsection{HIPÓTESIS}

La implementación y uso de un proceso logístico con la visión de gestión por procesos, incrementará la productividad del sector agrícola de la palta Hass a través del crecimiento del margen de ganancia bruta gracias a los precios de exportación.

\subsection{VARIABLES DE INVESTIGACIÓN}

\subsubsection{Compras}

- Cantidad necesaria de materia prima.

- Cantidad necesaria de insumos.

- Mínimo costo de adquisición de insumos.

- Tiempo de pago a proveedores.

- Tiempo de entrega de los pedidos.

\subsubsection{Inventarios}

- Espacio disponible en almacenes.

- Periodos de reposición de insumos.

- Cantidad de materiales que salen al mes.

- Cantidad de materiales que entran al mes.

\subsubsection{Transporte}

- Cantidad de medios de transporte necesarios.

- Capacidad de volumen de cada unidad de transporte.

- Capacidad de peso de cada unidad de transporte.

- Tiempo de transporte del campo a los puntos de acopio.

- Distancia de transporte del campo a los puntos de acopio.

- Diferencia de tiempo con respecto al tiempo de transporte.

- Número de rutas disponibles

\subsubsection{Almacén}

- Capacidad de volumen de los almacenes.

- Temperatura de almacenaje.

- Medidas del empaque.

- Tiempo de atención a unidades de transporte. 
Para concluir el capítulo, se identificaron distintos problemas que afectaban la productividad de la asociación y como resultados se identificó la necesidad de diseñar un sistema básico de gestión por procesos, considerando planificación y control de producción, gestión de calidad, gestión de costos, gestión de seguridad y salud ocupacional, gestión comercial y gestión logística, en el cual se enfocó en profundizar el análisis con el fin de poder obtener todos los datos necesarios para brindar una propuesta logística amoldada a la asociación Agro Inka de tal manera que los pueda ayudar a incrementar su productividad, sus ganancias y sus posibilidades de mejora. 


\section{CAPÍTULO 3. PROPUESTA DE SOLUCIÓN}

El presente capítulo describe el diseño de la propuesta realizada para la cooperativa "Agro Inka". Después de obtener la información sobre las problemáticas, se plantea el desarrollo de un sistema básico de gestión por procesos, el cual incluye el mapa de procesos propuesto, en donde se observan los procesos analizados, además, el flujograma general donde interactúan todos los procesos y el mapa relacional donde se visualizan los entregables de cada proceso, así como, sus entradas y salidas. Por otro lado, se plantea el diseño del proceso de logística propuesto para resolver el problema de la deficiente gestión logística a través del desarrollo de seis subprocesos que se relacional entre sí. Para cada subproceso se ha realizado un flujograma, un procedimiento sobre sus actividades, se ha diseñado formatos para los mismos, la caracterización del subproceso a través de un SIPOC tortuga y, por último, la ficha del indicador que sirve para medir el desempeño del subproceso.

\subsection{PROPUESTA DE SOLUCIÓN BASADA EN LA GESTIÓN POR PROCESOS}

A continuación, se realizará el desarrollo de la propuesta general en base a la gestión por procesos. Dicha propuesta se encuentra constituida por el desarrollo de los objetivos, en donde se identifica cual es el propósito de este, asimismo, un mapa de procesos sugerido para tener una visión clara acerca de todas las actividades que aportan valor a la organización, en adición, el flujograma del sistema básico de gestión, en el cual se observa la interacción de los procesos analizados y, por último, el mapa relacional de procesos, donde se contempla los entregables de los diferentes procesos.

\subsubsection{Objetivos}

\subsubsection{Objetivos de la propuesta general}

- Manejar a las actividades de la organización mediante la interacción de sus procesos a través de la estandarización con el establecimiento de procedimientos y formatos que permitan mantener en equilibrio la cooperativa y aumentar su productividad económica y en rendimiento. 
- Identificar todas y cada una de las actividades que realiza la cooperativa de manera ordenada y secuencial mediante el mapa de procesos, donde se obtiene un panorama claro de aquellas actividades que generen valor a la empresa.

- Conocer el funcionamiento de los procesos examinados y como estos interactúan entre sí hasta cumplir con el pedido del cliente potencial final a través del flujograma del sistema de gestión.

- Establecer las entradas y salidas de todos los procesos mediante el mapa relacional para conseguir un resultado, y que a su vez satisfaga los requerimientos de los clientes.

\subsubsection{Objetivos de cada proceso}

- La gestión comercial busca acceder a nuevos mercados y fidelizar a los clientes, cumpliendo con los requerimientos acordados previamente.

- La gestión de calidad e inocuidad mejora la calidad del producto y de la organización a través del establecimiento de procesos estandarizados.

- La gestión de planeamiento y control de la producción busca hacer más productiva a la cooperativa mediante el aumento de la producción a realizar en un determinado tiempo a través de la programación de sus actividades y un mejor control de ellas.

- La gestión logística busca proveer a la organización de los recursos necesarios para su operación, asimismo, realizar entregas conformes a las expectativas del cliente a través del desarrollo de todos sus subprocesos.

- La gestión de seguridad y salud ocupacional identifica los riesgos y peligros que generan los malestares hacia los agricultores, para así prevenirlos y trabajar de manera más cómoda en base al manual de gestión de SSO.

- La gestión de costos busca establecer el presupuesto y evaluar los costos realizados en relación con lo planificado, para así, tomar acciones frente a un desbalance.

\subsubsection{Mapa General de procesos propuesto}

La investigación se realizó en la irrigación "Cabeza de Toro" en Ica, Perú, donde, a través de entrevistas semiestructuradas, se obtuvieron resultados del problema experimentado por la cooperativa "AgroInka" realizada por 13 agricultores con baja productividad monetaria y en rendimiento de la producción de palta Hass. De esta manera, Perú posee una productividad promedio de 11,05 ton/ha a nivel mundial y el departamento de Ica ocupa el tercer lugar a nivel nacional con una productividad promedio de 14,51 ton/ha. En comparación, la productividad promedio de las cooperativas en el 2016, 2017 y 2018 es de 4.46ton/ha, 0.79ton/ha y 6.68ton/ha, 
respectivamente. Con estos datos, concluimos que los agricultores lograron una productividad por debajo del promedio a nivel nacional y departamental, lo que significa que uno de los principales problemas de la cooperativa es la baja productividad. Este problema se debe a actividades no estandarizadas, mayores costos de producción y un producto no estandarizado. Asimismo, al efectuarse las entrevistas se obtuvieron los siguientes resultados:

Tabla 14: Relación entre problemas y procesos

\section{Problema}

El uso inadecuado de pesticidas en $47 \%$ de productores

$46 \%$ de rechazo de la palta durante el primer corte

No se registran los costos

Ineficiente coordinación y disposición de los elementos de producción en el $67 \%$ de los planificadas y controles

Al causar malestares a los agricultores genera que trabajen con dificultad y que disminuyan su tiempo productivo

Poseen una pérdida económica de $11 \%$ aproximadamente

No tienen un registro de costos; por lo tanto, al no calcularlos desconocen cuanto invertir o cuanto gastar

agricultores
Acceso limitado a nuevos
mercados para gestionar pedidos

$\begin{array}{ll}\text { Aumento de gastos por compras no } & \text { Planeamiento y } \\ \text { planificadas y controles } & \text { Control de la } \\ & \text { Producción }\end{array}$

Cadenas de intermediación muy largas que generan márgenes de ganancia bajos.

Gestión Comercial

Al no contar con un plan de inventarios, comprar de forma independiente y no contar con almacenes acondicionados Gestión Logística Gestión de Seguridad y salud ocupacional Gestión de Calidad e Inocuidad

Gestión de Costos Producción generan altos costos logísticos.

Fuente: Entrevistas realizadas. Elaboración: Propia

De acuerdo con los diferentes problemas evidenciados en el capítulo anterior que afectan a la baja productividad de la cooperativa basados en los resultados obtenidos en las encuestas y, por otro lado, tomando los principios de la gestión por procesos, se realizó el mapa de procesos, el cual incluye los procesos estratégicos, claves y de soporte. El primer tipo de procesos brinda los lineamientos y directrices para toda la cooperativa de acuerdo con los objetivos, las estrategias y políticas que se presenten dentro de la asociación, de igual manera, los procesos claves generan valor al cliente final y son críticos para el éxito del negocio y, por último, los 
procesos de soporte entregan los recursos necesarios para cumplir con los requerimientos del cliente.

Seguidamente, se muestra una descripción de cada proceso:

\section{- Toma de Decisiones}

Proceso estratégico que define los objetivos de la organización, tales como el tipo de mercado al cual dirigirse, estándares, normas y beneficios, así como, la misión, visión, estrategias y políticas de la organización. Este proceso se comunica directamente con la Gestión Comercial, debido a que ambos comparten información, como el mercado a ingresar y los requerimientos del cliente.

\section{- Gestión Comercial}

Este proceso toma el papel de intermediario entre el mercado y la cooperativa, ya que se encarga de difundir los requerimientos del cliente y dar lineamientos a los demás procesos para asegurar que se cumplan mencionados requerimientos. De la misma manera, gestión comercial incluye actividades para captar a nuevos clientes mediante el acceso a nuevos mercados y fidelizar clientes, realizando un seguimiento a la distribución de los pedidos desde que salen del almacén hasta su posterior entrega al cliente final.

\section{- Gestión de Calidad e Inocuidad}

Este proceso se encarga de definir estándares de calidad del producto a través de los requerimientos del mercado, así como de las normas técnicas. Del mismo modo, asegura el cumplimiento de todas las especificaciones dentro de la organización. Por otro lado, mantiene al producto libre de contaminantes y daños que atenten contra la salud. Para llevar a cabo el proceso de Calidad, esta necesita de seguimientos, controles, así como, auditorías para garantizar el desempeño de la gestión.

\section{- Planificación y Control de la Producción}

Este proceso es clave, ya que genera valor al cliente, debido a que al desarrollar un planeamiento y control de la producción se puede optimizar el uso de los recursos a través de un seguimiento y mejoras por medio de planes. Además, permite manejar en forma eficiente la adquisición de materiales e insumos para el proceso de producción, la programación y control de la producción, la utilización adecuada de los recursos naturales, la planificación de la maquinaria y el desarrollo de las buenas prácticas agrícolas por los agricultores. Asimismo, se mantendrán registros de las actividades productivas realizadas e indicadores que servirán como entrada al subproceso de mejora del proceso. 


\section{- Producción}

El proceso de producción es clave, ya que es vital para el core business de la cooperativa. En este proceso se producen las paltas de acuerdo con los lineamientos del proceso comercial y programas e inspecciones del proceso de planeación y control de la producción. Es así como, el proceso de producción sigue las etapas de preparación de tierra, siembra, cosecha y embalaje de las paltas ya producidas. Este proceso no es desarrollado por el grupo de investigación, ya que los agricultores tienen establecidas sus actividades de producción, es decir, tienen experiencia y conocimiento sobre el cuidado de la planta, la siembra y todas las actividades necesarias para producir la palta Hass. Cada MYPE tiene su propio método de trabajo sobre sus tierras.

\section{- Distribución}

El proceso de distribución es clave, debido a que sin este no se podría entregar el pedido internacional o local al cliente. Las entregas requieren ser puntuales y al menor tiempo posible o por lo menos estar dentro de lo pactado. Asimismo, en el proceso de distribución existe un seguimiento por parte del proceso Comercial hacia el operador logístico, quien se encarga de los procedimientos aduaneros y de la salida del producto hasta el país destino. Dentro de la distribución es el operador logístico quien se encarga de la entrega del producto hasta el puerto, mientras que es el agricultor quien se encarga de la entrega del pedido desde el almacén hacia el operador.

\section{- Gestión Logística}

Este proceso define un conjunto de actividades para llevar a cabo el core business de la cooperativa, es decir, brinda apoyo hacia los procesos claves y estratégicos quienes agregan valor a la organización. El proceso de logística es de soporte, debido a que sin ello no serían posibles los otros procesos. Este se encuentra agrupado por el subproceso de compras, inventarios, almacenamiento y, asimismo, la distribución. En el caso de las compras, se encarga del abastecimiento de insumos y otros materiales requeridos por el agricultor; de igual manera, dentro de la gestión de los inventarios se verifican las existencias mediante un control y a su vez se analiza la cantidad de pedido de insumos que debe solicitarse. Por otro lado, en el almacén se despachan los productos requeridos por el agricultor y, asimismo, se prepara el pedido para luego ser entregado hacia el operador logístico y llegar hasta el cliente final. Por último, la distribución se encarga de transportar los insumos hacia los agricultores, así como, la producción hasta su destino. 


\section{- Gestión de Seguridad y Salud Ocupacional}

Este proceso identifica los requerimientos de EPP's que necesiten los agricultores para ejecutar las diferentes actividades hasta realiza el manual de SSO, el plan de contingencia y la matriz IPER para evitar accidentes e incidentes laborales que pudieran ocurrir en la cooperativa.

\section{- Gestión de Costos}

Este proceso se encarga de elaborar el presupuesto de costos y con información brindada por los otros procesos adquirir el margen de ganancia de la cooperativa. Asimismo, permite llevar un control de los costos de producción de las MYPES mediante registros e indicadores. Por último, calcula el costo unitario del producto y analiza el resultado del presupuesto ante lo real y lo planificado, así como las oportunidades de mejora en caso existan variaciones.

Se presenta el mapa de procesos propuesto en la figura №39.

\subsubsection{Flujograma del sistema básico de gestión propuesto}

Los procesos analizados interactúan entre sí de manera constante desde que se recibe un pedido hasta que es entregado al cliente final. El proceso general parte de la Gestión Comercial, en donde se realiza la búsqueda de clientes con la información del mercado y los lineamientos de mercados potenciales para así planificar las ventas, una vez realizado esto se tienen los objetivos, los cuales ingresan al proceso de Gestión de Calidad con lo que se definen los estándares basados en normas técnicas y en los requerimientos del mercado, es decir, estos estándares son la traducción de los requisitos del cliente seleccionado. Una vez con los estándares se evalúan los riesgos en la producción mediante una matriz IPER y se establece un manual de seguridad y salud ocupacional, asimismo, se realiza el seguimiento a la producción y al proceso en conjunto, con lo cual tanto el manual como el seguimiento de calidad se dan durante el proceso de producción. 
Figura 41: Mapa de procesos propuesto

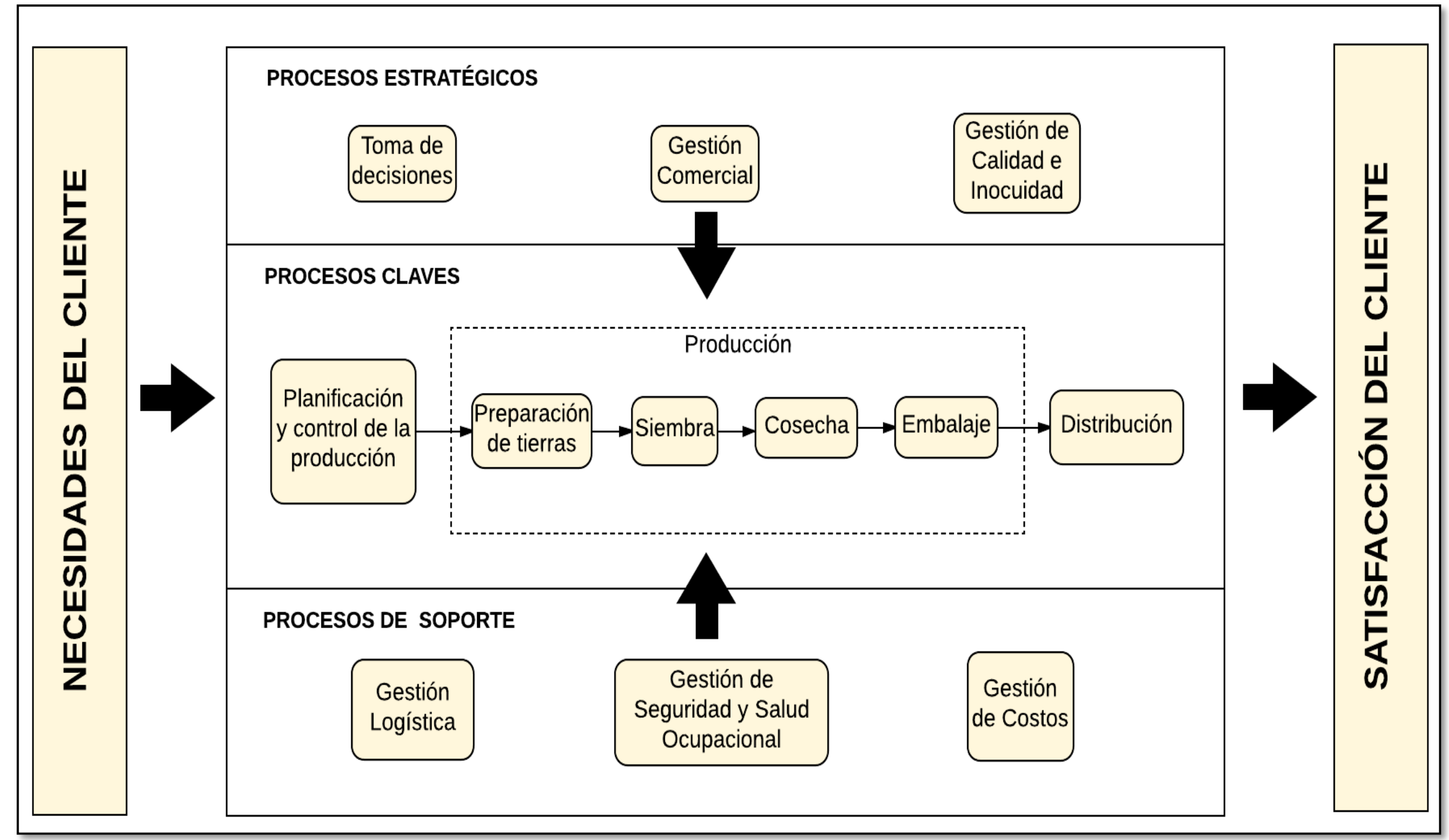

Fuente: Elaboración propia 
De igual modo, paso previo a la producción es el de su planificación a través de un informe de disponibilidad y data histórica de producción de donde sale un informe de oferta que busca ofrecer la cantidad disponible a los clientes identificados por la Gestión Comercial. Ahora bien, finalizada la etapa de planificación se requiere de la cantidad de insumos necesaria para la producción, para obtener la compra de esta cantidad se debe primero buscar proveedores, evaluar y seleccionarlos, dicha compra está basada en el plan de compras, el cual es respaldado por el proceso de costos a través del presupuesto, entonces si el costo de la compra es aprobado se emite la orden de compras al proveedor seleccionado y posteriormente su recepción, dicha recepción se da en almacén, el cual mediante un control de los inventarios se verifican las existencias y se asignan los insumos para empezar la producción. Durante el proceso de producción se lleva a cabo un control, donde se obtiene un informe de producción real anual y un registro de producción, luego de finalizado este proceso se realiza la cosecha, entonces, una vez recolectadas las paltas estas se llevan al almacén en donde se espera por la orden del pedido, que se tiene cuando se realiza la venta y posteriormente, se distribuyen hacia el operador logístico, quien es el encargado de entregar el pedido al cliente final. Es en esta parte donde Gestión Comercial realiza un seguimiento y controla los pedidos a ser entregados hasta que estén en manos del cliente final. Por otro lado, al finalizar la producción anual o por campaña, con el informe de fin de año productivo, se realizan las mejoras de producción obteniéndose un plan de mejora de PCP. Asimismo, la Gestión de Costos con los registros de las compras efectuadas calcula y evalúa el costo de producción. En caso este sea diferente al obtenido por el presupuesto se plantean las oportunidades de mejora. Finalmente, es así como se realiza la secuencia de actividades de todo el proceso a través de la gestión por procesos. A continuación, se presenta el flujograma del sistema básico de gestión propuesto en la figura $\mathrm{N}^{\circ} 40$ : 
Figura 42: Flujograma del sistema básico de gestión por procesos

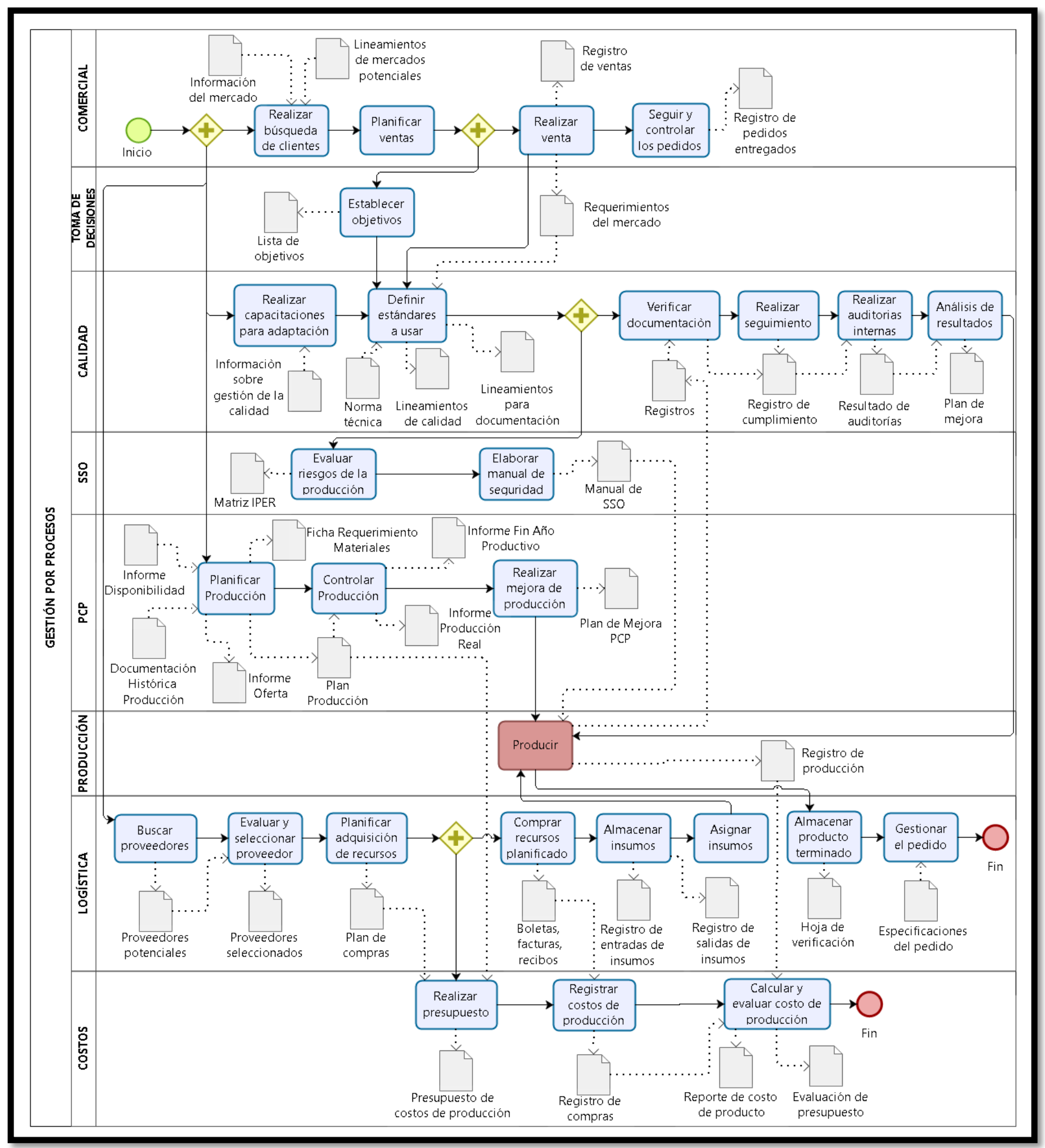

Fuente: Elaboración propia

\subsubsection{Mapa relacional de procesos}

A continuación, se mostrarán las entradas y las salidas de todos los procesos en la figura $\mathrm{N}^{\circ} 41$ : 
Figura 43: Mapa relacional de procesos

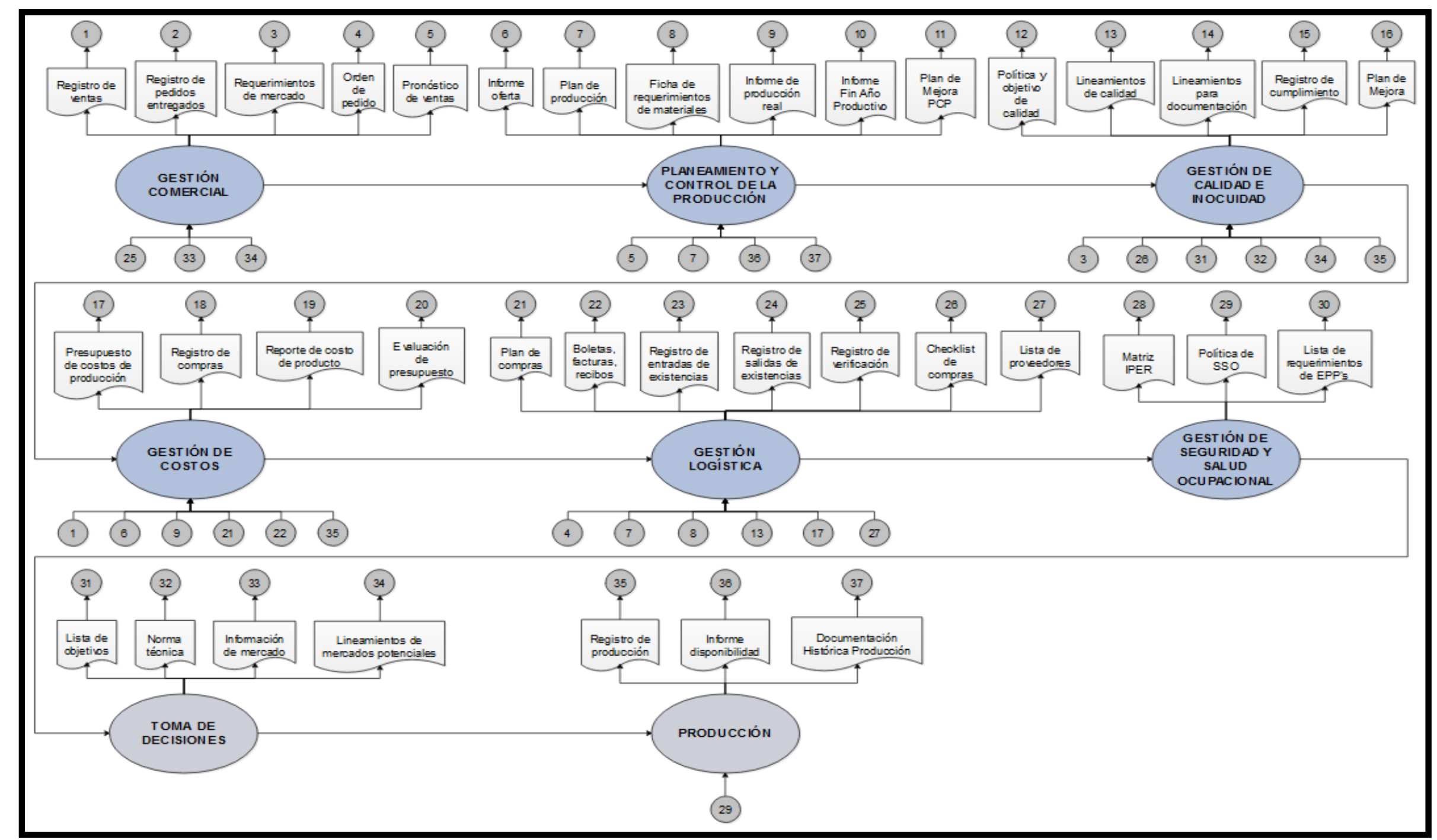

Fuente: Elaboración propia 


\subsection{PROPUESTA DE SOLUCIÓN DE LA GESTIÓN LOGÍSTICA INTEGRAL}

Cómo se evidenció en el capítulo anterior, existen tres principales causas que generan una deficiente gestión logística, estas son el desaprovechamiento de las economías de escala, la falta de un plan de inventarios, así como, la inexistencia de almacenes acondicionados. Por ello, al no contar con un proceso estandarizado que forme parte sus actividades como asociación genera que trabajen de manera independiente sin conocer los beneficios que adquieren al trabajar en conjunto. De esta forma, a continuación, se planteará la propuesta de solución del proceso de logística integral, el cual empieza con el diseño de la propuesta, asimismo, la secuencia de actividades a través del flujograma, y, por último, el desarrollo de cada subproceso con su respectivo flujo, caracterización e indicador para medir el desempeño del subproceso.

\subsubsection{Diseño de la gestión logística integral}

En la figura $\mathrm{N}^{\circ} 42$, se observa el diseño del proceso logístico integral, el cual se divide en cuatro subprocesos, tales como el subproceso de compras, inventarios, almacén y distribución. La logística integral es un enfoque que permite la gestión de una empresa, a partir del flujo de material e información, haciendo énfasis en los proveedores y los clientes. Dentro de la propuesta de gestión de compras, se realizará un procedimiento en el cual se definan los pasos para realizar las compras desde que se selecciona al proveedor hasta obtener un cronograma de entregas. Por otro lado, en la gestión de inventarios se controlan las existencias ya sea de insumos, materiales y hasta de producción. Asimismo, se ejecuta un plan de compras donde se detalla la cantidad y el tiempo a comprar los insumos para realizar la producción. De igual manera, dentro de la propuesta de Almacenamiento se recepciona los insumos o la producción, se establece la cantidad asignada de insumos para cada MYPE, además, se almacenan y ubican las compras, y con respecto a los pedidos de producción, estos se atienden. 
Figura 44: Diseño del proceso logístico integral

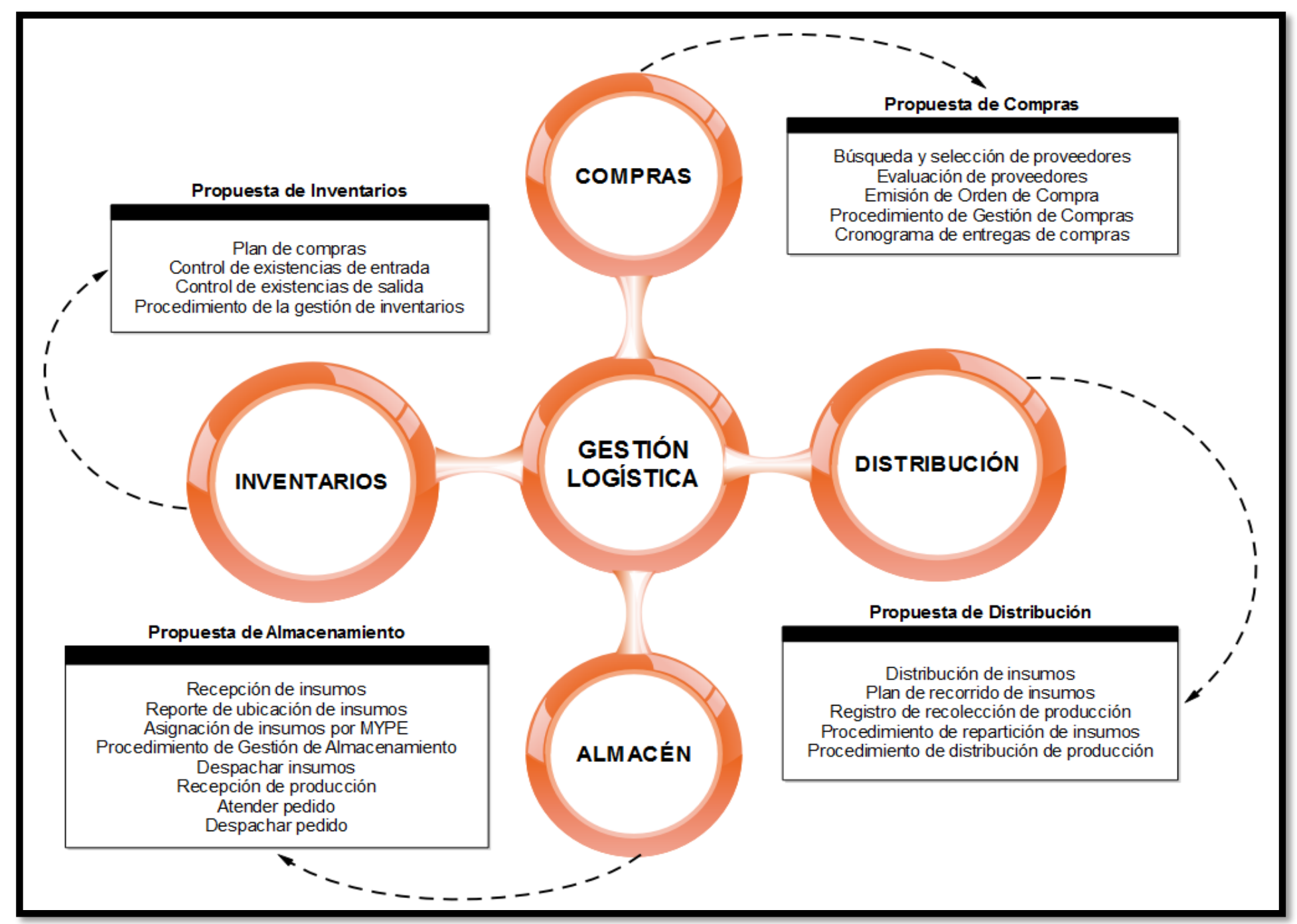

Fuente: Elaboración propia 
Por último, dentro de la propuesta de distribución, en el caso de los despachos de los insumos asignados para cada MYPE, se realizará un plan de recorrido que optimice el traslado de los requerimientos de los agricultores, es decir, buscar rutas más cortas con un menor tiempo de empleo. Por otro lado, cuando la producción este cosechada se realiza un registro de recolección y se transporta la producción hacia el almacén y posteriormente, hacia el operador logístico.

\subsubsection{Flujograma de la gestión logística integral}

En la figura $\mathrm{N}^{\circ} 43$, se aprecia el flujograma de todo el proceso logístico tanto de entrada como de salida dentro de la cooperativa.

Figura 45: Flujograma de gestión logística integral

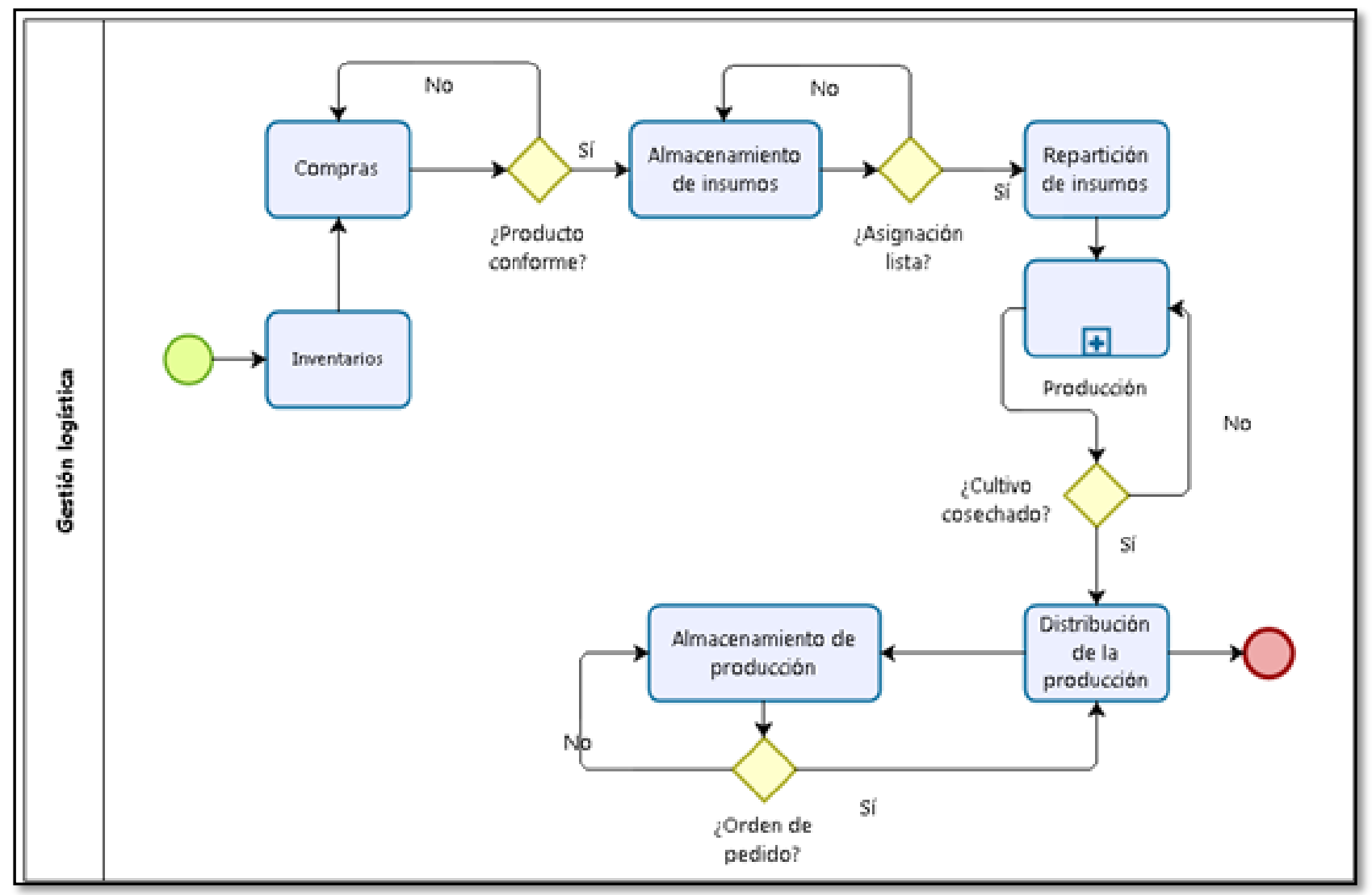

Fuente: Elaboración propia

El proceso logístico integral empieza con el subproceso de inventarios, en donde llega un boletín de pedido por parte de producción, con el cual inventario se encarga de revisar si hay stock disponible o no en el almacén, en caso no se cuenta con stock disponible se analiza la cantidad a comprar con el ingreso del plan de producción por parte de PCP y con una salida del plan de compras en donde se observa la cantidad y el tiempo a realizar la compra. Este plan ingresa al subproceso de compras, específicamente a la actividad de buscar proveedores, ya que posteriormente se realiza un análisis y selección de proveedores con respecto a la cantidad 
solicitada por el agricultor y la capacidad de respuesta del proveedor, luego de seleccionado el proveedor, si se aprueba por costos entonces se acuerda la fecha de entrega del pedido hasta su recepción, en caso no es aprobado se elige otro proveedor.

Posteriormente, para la recepción de la mercadería, si el producto es conforme entonces se almacena y si es defectuoso se rechaza y se elige a otro proveedor. Ya en el almacén de insumos, los productos se guardan según ubicación designada, asimismo, si existe una asignación lista de reparto por MYPE entonces se distribuyen los insumos y si todavía no hay un requerimiento se mantiene en el almacén. Para la repartición de insumos este se realiza identificando la ruta más corta y el orden de entrega por MYPE.

De esta manera, con los insumos entregados a los agricultores empieza la producción hasta la etapa de cosecha. En ese momento, el subproceso de distribución de producción traslada las paltas cosechadas hacia el almacén. Dentro de este, se guardan las paltas e ingresa una orden de pedido brindada por la Gestión Comercial; por lo tanto, se prepara el pedido y se espera al subproceso de distribución de la producción para entregar el mismo al operador logístico, con lo cual da fin a la cadena de actividades de la gestión logística y sus subprocesos.

Asimismo, no solo los subprocesos logísticos trabajan entre sí, sino que también existen relacionales con los otros procesos dentro del sistema de gestión. En consecuencia, en seguida se evidenciará los entregables, es decir, la entradas y salidas del proceso de logística hacia los otros procesos en la figura $\mathrm{N}^{\circ} 44$.

Los subprocesos anteriormente descritos que forman parte del flujograma logístico también reciben documentos de otros procesos, tal es el caso del subproceso de inventarios quien recibe la lista de requerimientos de EPP's por parte de la Gestión de Seguridad y Salud Ocupacional para que se realicen las compras de los mismos, de igual manera, recibe el plan de producción por parte de PCP para definir las cantidades de compra, asimismo, recibe la ficha de requerimientos de materiales así como la lista de requerimiento de calidad por parte de Gestión de Calidad. El subproceso de Compras toma el presupuesto brindado por la Gestión de Costos para evaluar la aceptación de un proveedor.

Por último, el subproceso de almacenamiento de la producción recibe la orden de pedido por parte de Gestión Comercial para gestionar el mismo hasta su despacho. Por otro lado, el subproceso de Compras le ofrece a Gestión de Calidad el check list de compras en donde se evidencia si dichas compras están dentro de los estándares de calidad. Igualmente, el mismo subproceso le brinda a la Gestión de Costos el plan de compras y las boletas, facturas y recibos para la siguiente elaboración de su presupuesto. 
Finalmente, el subproceso de Distribución de la Producción le entrega a la Gestión Comercial el registro de verificación en donde se muestra la cantidad aceptada por el operador logístico.

Figura 46: Mapa de entregables del Proceso de Logística

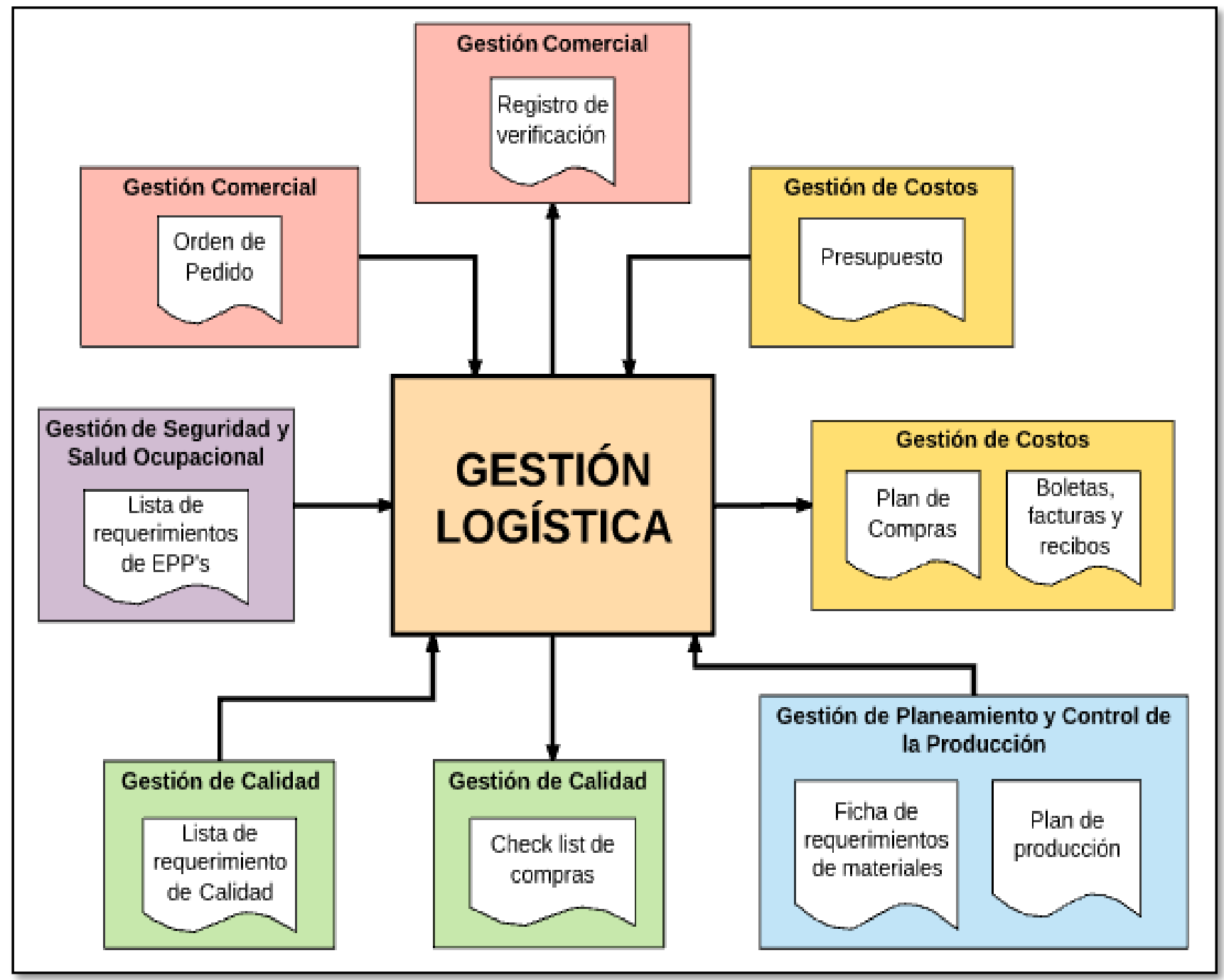

Fuente: Elaboración propia

\subsubsection{Desarrollo de subprocesos de la gestión logística}

A continuación, se muestra el desarrollo de los seis subprocesos identificados como propuesta de solución.

\subsubsection{Subproceso de la gestión de inventarios}

\subsection{Flujograma de la gestión de inventarios}

En la figura $\mathrm{N}^{\circ} 45$, se observa la secuencia de actividades del subproceso de inventarios, quien da inicio a todo el proceso logístico. De esta manera, a través de la lista de requerimientos 
de EPP's entregada por el subproceso de evaluación de riesgos dentro del proceso de SSO, la lista de requerimientos de Calidad entregada por el subproceso de definición de estándares y la ficha de requerimientos de materiales brindado por el subproceso de planificación de la producción se reciben los requerimientos para una revisión de stock en el almacén sobre los productos que se están solicitando; de esta forma, si hay suficiente stock entonces se realizan anotaciones contables obteniéndose un registro de existencias y una base de datos física sobre los inventarios.

Por otro lado, en caso no haya insumos disponibles para la producción se analiza la cantidad requerida a través del plan de producción que entrega el subproceso de planificación de la producción que forma parte del proceso de planeamiento y control de la producción, con lo cual se genera el plan de compras donde se detalla la cantidad a comprar, así como, el tiempo de abastecimiento de los insumos u otros materiales.

Cabe resaltar que el subproceso de inventarios es de entrada, es decir, se encarga de manejar las actividades hasta antes de la producción, es decir maneja los niveles de insumos, materiales u otros para empezar la producción de las paltas, posteriormente, en el subproceso de almacenamiento de la producción se especificará a los inventarios de producción, ya que ambos subprocesos están relacionados.

De esta manera, luego de analizar el flujograma de este subproceso, se presenta el $\boldsymbol{P}$ LOG-01. Procedimiento de la gestión de inventarios donde se describe cada actividad con un responsable de su desarrollo, así como las condiciones básicas para que se lleve a cabo el subproceso, los documentos a consultar que brindan los otros procesos, el objetivo del procedimiento, la responsabilidad y el alcance, algunas definiciones para una mejor comprensión del procedimiento y, por último, la sección de registros, los cuales son formatos que se plantearán de las salidas del flujograma y que serán presentados en la parte de anexos para ser aplicados dentro de la cooperativa. 
Figura 47: Flujograma del subproceso de Inventarios

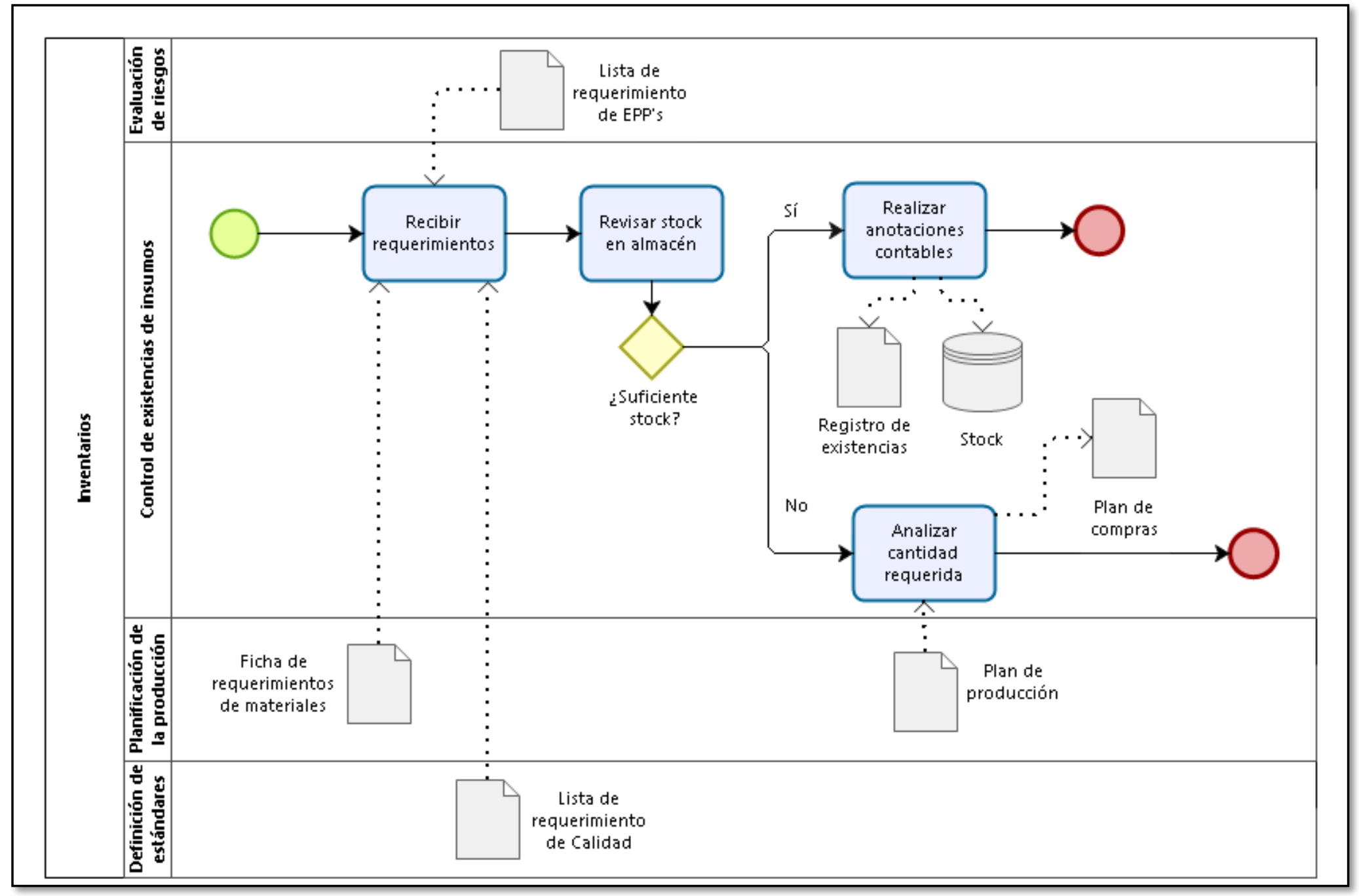

Fuente: Elaboración propia 


\begin{tabular}{|l|c|c|}
\hline PROCEDIMIENTO DE INVENTARIOS & CÓDIGO: & PÁGINA: \\
& P-LOG-0 1 & 1 de 2 \\
\hline
\end{tabular}

\section{OBJETIVO}

El presente procedimiento establece las acciones a realizar para mantener un inventario tanto de insumos como de producción.

\section{RESPONSABILIDAD Y ALCANCE}

El presente procedimiento es administrado por la Cooperativa, en especial por el presidente de la asociación, e incluye los pasos a seguir desde la revisión de stock, el registro entradas y salidas y la realización del plan de compras.

\section{DOCUMENTOS A CONSULTAR}

* Lista de requerimientos de EPP's

* Plan de producción

\section{DEFINICIONES}

* Stock: Productos disponibles en almacén

* SSO: Gestión de Seguridad y Salud Ocupacional

* PCP: Planificación y control de producción.

\section{CONDICIONES BASICAS}

5.1. Se debe tener el plan de producción con los insumos necesarios para toda la campaña con la especificación de las cantidades correspondientes para cada MyPE.

5.2. Se debe tener la lista de requerimientos de EPP's.

5.3. El conteo de los productos en stock debe estar actualizado.

\section{DESARROLLO DEL PROCEDIMIENTO}

\begin{tabular}{|l|c|}
\hline \multicolumn{1}{|c|}{ Actividad } & Responsable \\
\hline EVALUACIÓN DE RIESGOS & \\
\hline $6.1 \quad$ Elaborar la lista de requerimientos de EPP's. & SSO \\
\hline PRODUCCIÓN & Producción \\
\hline $6.2 . \quad$ Brindar boletín de pedido. & \\
\hline
\end{tabular}

\begin{tabular}{|c|c|c|}
\hline GENERADO POR: & REVISADO Y APROBADO POR: & FECHA DE EMISIÓN \\
Gestión Logística & Presidente de la Cooperativa & $22 / 06 / 2017$ \\
\hline
\end{tabular}




\begin{tabular}{|l|c|c|}
\hline PROCEDIMIENTO DE INVENTARIOS & CÓDIGO: & PÁGINA: \\
& P-LOG-0 1 & 2 de 2 \\
\hline
\end{tabular}

\begin{tabular}{|c|c|}
\hline INVENTARIOS & \multirow[b]{2}{*}{ Inventarios } \\
\hline $\begin{array}{l}\text { 6.3. Recibir requerimientos. } \\
\text { 6.3.1. Revisar los requerimientos. } \\
\text { 6.3.2. Comparar con requerimientos anteriores para identificar } \\
\text { alguna anomalía. } \\
\text { 6.3.3. Sintetizar todos los pedidos en una sola lista de } \\
\text { requerimientos. } \\
\text { 6.3.4. Verificar el dato de la fecha en la cual se requiere el } \\
\text { producto. }\end{array}$ & \\
\hline $\begin{array}{l}\text { 6.4. Revisar stock en almacén } \\
\text { 6.4.1. Verificar los productos que se encuentran en almacén } \\
\text { 6.4.2. Verificar el estado de los productos } \\
\text { 6.4.3. } \quad \text { Comunicar cantidad exacta de stock disponible }\end{array}$ & Inventarios \\
\hline $\begin{array}{l}\text { 6.5. Realizar anotaciones contables } \\
\text { 6.5.1. En caso haya suficientes productos se actualiza el registro } \\
\text { de existencias }\end{array}$ & Inventarios \\
\hline PLANIFICACIÓN DE INVENTARIOS & \\
\hline 6.6. Brindar plan de producción & PCP \\
\hline $\begin{array}{l}\text { 6.7. Analizar cantidad requerida } \\
\text { 6.7.1. Comparar stock disponible y requerimientos } \\
\text { Armar el plan de compras siguiendo el formato } \boldsymbol{F} \text {-LOG-01. Plan de } \\
\text { compras } \\
\text { 6.7.2. Analizar el tiempo de entrega necesario para poder cumplir } \\
\text { con los plazos establecidos. } \\
\text { 6.7.3. Distribuir la llegada de los productos de tal manera que no } \\
\text { se sobre sature el almacén cuando los proveedores despachen sus } \\
\text { mercaderías. } \\
\text { 6.7.4. Brindar el resultado a Compras. }\end{array}$ & Inventarios \\
\hline
\end{tabular}

\section{REGISTROS}

* F-LOG-01. Plan de compras

* F-LOG-02. Registro de existencias

\section{ANEXOS}

No hay anexos para este documento.

\begin{tabular}{|c|c|c|}
\hline GENERADO POR: & REVISADO Y APROBADO POR: & FECHA DE EMISIÓN \\
Gestión Logística & Presidente de la Cooperativa & $22 / 06 / 2017$ \\
\hline
\end{tabular}




\subsection{Caracterización de la gestión de inventarios}

La herramienta del SIPOC se utiliza para la caracterización de procesos, en este caso identifica las principales actividades del subproceso de inventarios. Las entradas que ingresan al subproceso son las listas de requerimientos de SSO, PCP y de Calidad, así como, el plan de producción de PCP. Del mismo modo, las salidas son el plan de compras destinado para Compras, el registro de existencias destinado para Inventarios y una base de datos física sobre el nivel de stock. Asimismo, las actividades del proceso empiezan desde la recepción del requerimiento de insumos, materiales, continua con la revisión de disponibilidad de stock en almacén y, por último, analiza la cantidad requerida para evaluar la futura compra. En adición, los controles establecidos surgen de los factores críticos analizados y de la misma forma, los recursos identificados son los útiles de escritorio, cuadernos para realizar los formatos y calculadora para las operaciones.

Figura 48 Diagrama SIPOC del subproceso de inventarios

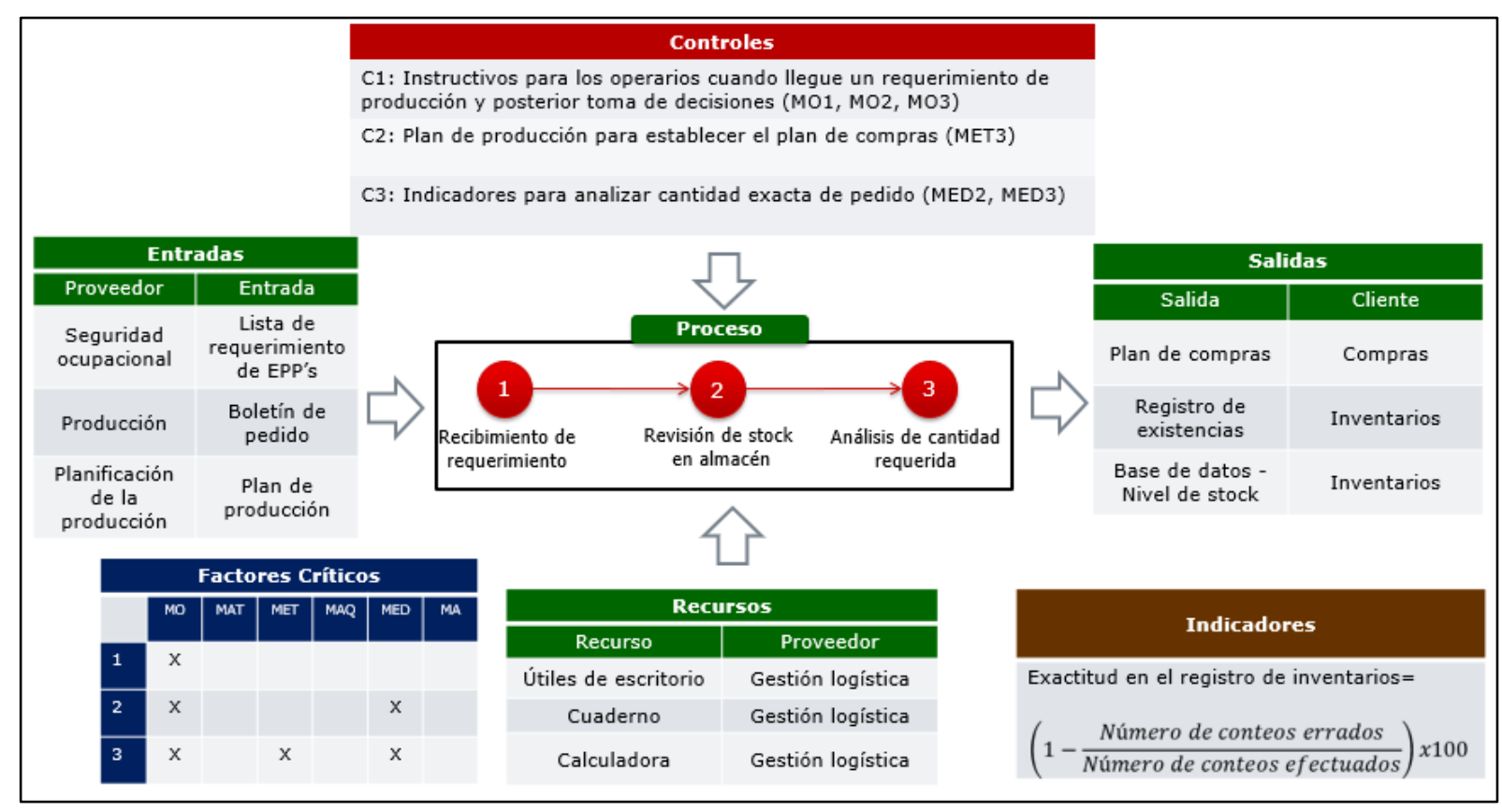

Fuente: Elaboración propia

\subsection{Indicador de la gestión de inventarios}

El indicador para medir la gestión de los inventarios es el ERI, es decir, la exactitud del registro de inventarios, ya que demuestra la precisión con la que se cuentan las existencias de manera física con respecto a las entradas registradas por el almacén a la entrega de cada compra. Según la Réplica de la Revista Énfasis Logística de México para ser considerado eficiente se debe contar con la exactitud de inventario (ERI) en un 95\%, llegar al máximo nivel de exactitud es clasificada una fantasía logística, así entonces, la gestión de los procesos minimiza el margen 
de error, pero no lo elimina. A continuación, la ficha del indicador IN-LOG-01. Exactitud en el registro de inventarios.

Figura 49: Ficha técnica de exactitud en los registros de inventarios

\begin{tabular}{|c|c|c|}
\hline EXACTITUD EN EL REGISTRO DE INVENTARIOS & $\begin{array}{c}\text { CÓDIGO: } \\
\text { IN-LOG-01 }\end{array}$ & $\begin{array}{c}\text { PÁGINA: } \\
1 \text { de } 1\end{array}$ \\
\hline
\end{tabular}

1. Nombre:

Exactitud en el registro de inventarios

\section{Objetivo:}

Identificar la precisión del conteo de los inventarios de manera física comparado con los registros de existencias para determinar pérdidas o faltantes de inventario.

3. Fórmula de Cálculo:

$$
E R I=\left(1-\frac{\text { Número de conteos errados }}{\text { Número de conteos efectuados }}\right) \times 100
$$

4. Nivel de Referencia:

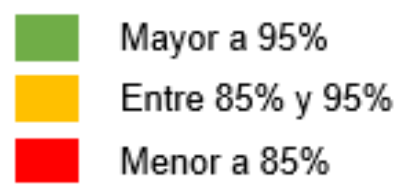

Un incremento en el valor del indicador refleja una mejora en el resultado.

5. Responsable de Gestión:

Encargado de inventarios

6. Fuente de Información:

Registro de existencias

Nivel de inventario

7. Frecuencia de Medición:

Cada fin de mes

8. Frecuencia de Reporte:

Cada fin de mes

9. Responsable del Reporte:

Encargado de inventarios

10. Usuarios:

Inventarios

11. Observaciones:

\begin{tabular}{|c|c|c|}
\hline GENERADO POR: & REVISADO Y APROBADO POR: & FECHA DE EMISIÓN \\
Gestión Logística & Presidente de la Cooperativa & $22 / 06 / 2017$ \\
\hline
\end{tabular}

Fuente: Elaboración propia 


\subsubsection{Subproceso de gestión de compras}

\subsection{Flujograma de la gestión de compras}

En la figura $\mathrm{N}^{\circ} 48$, se observa la secuencia de actividades del subproceso de compras, este empieza con el ingreso del plan de compras hacia la búsqueda de proveedores, el cual es una salida del subproceso de inventarios, la búsqueda se realiza a partir de los proveedores de los fundos o de proveedores directos de los productores de insumos, ya que se busca evitar contratar a los distribuidores de los insumos de los alrededores de la cooperativa.

Luego de buscar a los proveedores, ingresa un check list de criterios para analizar a los proveedores y posteriormente, ingresa el presupuesto brindado por compras para la selección del proveedores, si es aprobado por costos entonces se acuerda la fecha de entrega del pedido, en cambio si no es aprobado se busca otro proveedor, luego de acordar la fecha, se emite el pedido al proveedor a través de una orden de compra, luego de entregada dicha orden se notifican las compras hacia el proceso de costos y hacia al subproceso de almacenamiento de insumos. Al proceso de costos se le brinda el informe de compras donde se detallan los costos de las compras y las cantidades compradas, mientras que al subproceso de almacenamiento se le presenta el cronograma de entregas de todas las compras, para que se mantenga un orden en los pedidos y se disponga de espacio para el ingreso de los mismos.

De esta manera, luego de analizar el flujograma de este subproceso, se presenta el $\boldsymbol{P}$ - LOG-02. Procedimiento de la gestión de compras donde se describe en forma detallada cada actividad, así como cada parte del procedimiento. 
Figura 50: Flujograma del subproceso de Compras

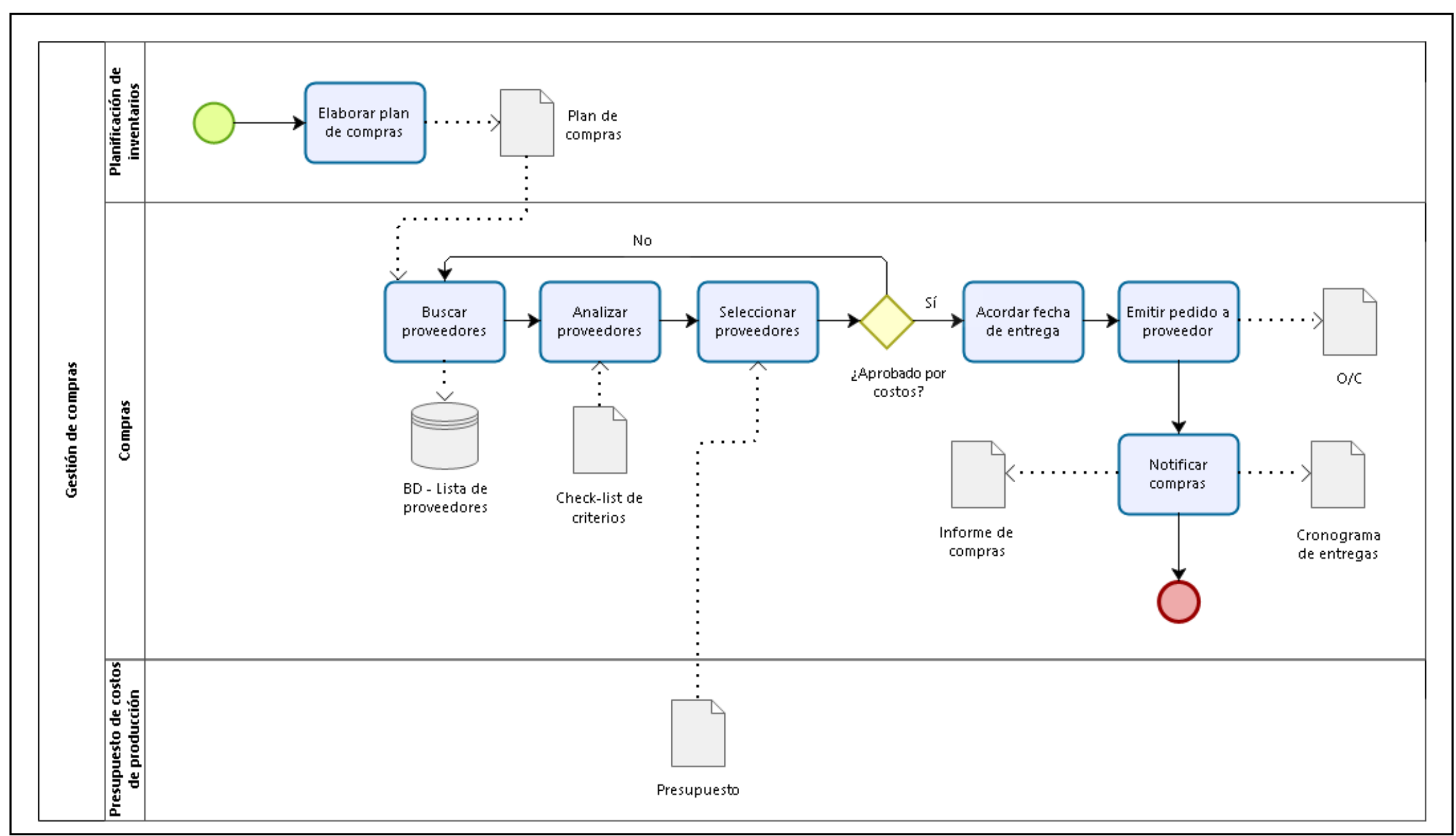

Fuente: Elaboración propia 


\begin{tabular}{|l|c|c|}
\hline PROCEDIMIENTO DE COMPRAS & CÓDIGO: & PÁGINA: \\
& P-LOG-02 & 1 de 2 \\
\hline
\end{tabular}

\section{OBJETIVO}

El presente procedimiento establece las acciones a realizar para las compras de los insumos, materiales $\mathrm{u}$ otros requerimientos por parte de los agricultores.

\section{RESPONSABILIDAD Y ALCANCE}

El presente procedimiento es administrado por la Cooperativa, en especial por el presidente de la asociación, e incluye los pasos a seguir desde que se busca al proveedor hasta que se notifican las compras al área de almacén.

\section{DOCUMENTOS A CONSULTAR}

* Plan de compras

\section{DEFINICIONES}

N/A

\section{CONDICIONES BASICAS}

5.1. Se debe tener clara la fecha de entrega de los productos.

5.2. Se debe tener claro las cantidades necesarias a comprar establecidas por el plan de compras.

\section{DESARROLLO DEL PROCEDIMIENTO}

\begin{tabular}{|l|c|}
\hline \multicolumn{1}{|c|}{ Actividad } & Responsable \\
\hline PLANIFICACIÓN DE INVENTARIOS & Inventarios \\
\hline 6.1. Elaborar plan de compras & \\
\hline COMPRAS & \\
\hline 6.2. Buscar proveedores: & \\
6.2.1. Identificar proveedores que trabajan con los fundos de la zona. \\
6.2.2. Contactar a los proveedores \\
6.2.3 Entregar requerimiento a proveedor & \multirow{2}{*}{ Compras } \\
\hline 6.3. Analizar proveedores & \\
6.3.1 Establecer criterios de selección & \\
6.3.2. Aplicar criterios seleccionados en los proveedores & \\
6.3.3. Comparar respuestas a criterios entre proveedores & \\
\hline 6.4. Seleccionar proveedores & \\
6.4.1 Seleccionar al proveedor con mejor promedio & \\
\hline
\end{tabular}

\begin{tabular}{|c|c|c|}
\hline GENERADO POR: & REVISADO Y APROBADO POR: & FECHA DE EMISIÓN \\
Gestión Logística & Presidente de la Cooperativa & $22 / 06 / 2017$ \\
\hline
\end{tabular}




\begin{tabular}{|l|c|c|}
\hline PROCEDIMIENTO DE COMPRAS & CÓDIGO: & PÁGINA: \\
& P-LOG-02 & 2 de 2 \\
\hline
\end{tabular}

\begin{tabular}{|l|l|}
\hline 6.5. Acordar fecha de entrega & \\
6.5.1 Fijar método de pago & \\
6.5.2. Aprobación por costos \\
6.5.3. Si aprueba se continua con el proceso, de lo contrario se \\
elige a otro proveedor. & \\
\hline 6.6. Emitir pedido a proveedor & \\
6.6.1 Realizar O/C para el proveedor & \\
6.6.2 Entregar O/C a proveedor & \\
6.7. Notificar compras & \\
6.7.1 Se comunica a almacén sobre las fechas de entrega de & \\
las compras. & \\
\end{tabular}

\section{REGISTROS}

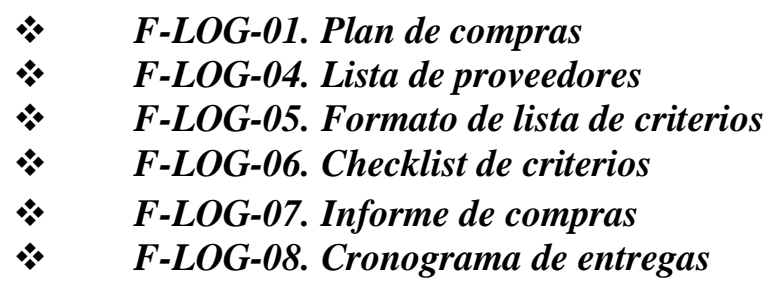

\section{ANEXOS}

No hay anexos para este documento.

\begin{tabular}{|c|c|c|}
\hline GENERADO POR: & REVISADO Y APROBADO POR: & FECHA DE EMISIÓN \\
Gestión Logística & Presidente de la Cooperativa & $22 / 06 / 2017$ \\
\hline
\end{tabular}




\subsection{Caracterización de la gestión de compras}

Las entradas que ingresan al subproceso de compras son el plan de compras, a partir de la gestión de inventarios, el presupuesto para la selección del proveedor analizado y el checklist de criterios para evaluar al posible proveedor. Del mismo modo, las salidas son la lista de proveedores que se remite a compras, la $\mathrm{O} / \mathrm{C}$ destinada al proveedor, el informe de compras para la gestión de Costos y el cronograma de entregas para el subproceso de almacenamiento de insumos. Asimismo, las actividades del proceso empiezan desde la selección del proveedor hasta que la compra se lleve a cabo a través de la orden de compra y posterior entrega del cronograma. En adición, los controles establecidos surgen de los factores críticos analizados y de la misma forma, los recursos identificados son los útiles de escritorio, cuadernos para realizar los formatos, calculadora para las operaciones y un celular para contactar a los proveedores.

Figura 51 Diagrama SIPOC del subproceso de compras

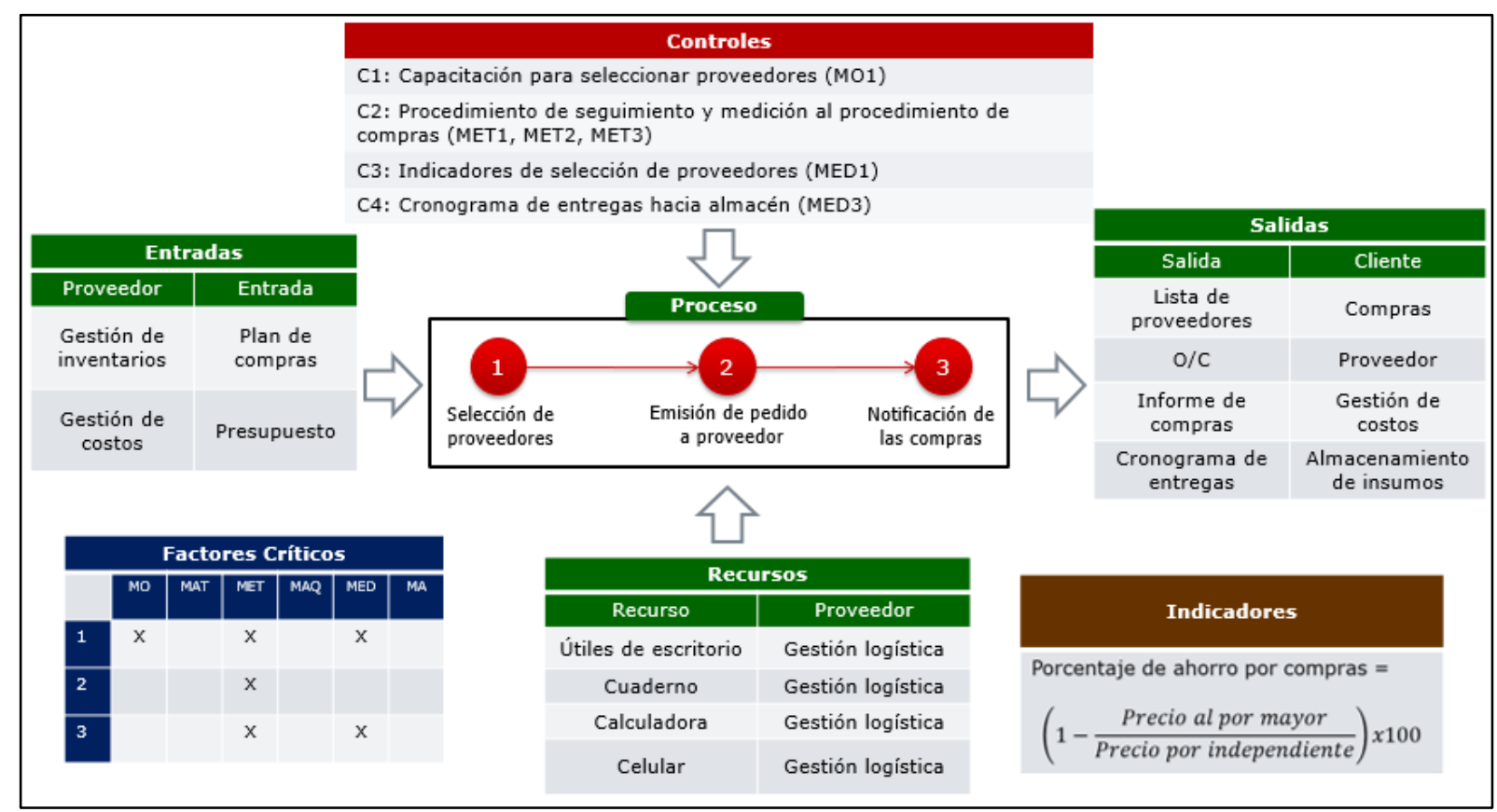

Fuente: Elaboración propia

\subsection{Indicador de la gestión de compras}

El indicador para medir la gestión de las compras es el porcentaje de ahorro en compras, es decir, se compara el saldo de los pagos realizados en compras de manera conjunta sobre el saldo de los pagos realizados de manera independiente, este indicador se presenta una vez cada campaña, debido a que es cuando se analizan los precios de los diferentes proveedores. Lo ideal es que este indicador sea mayor a $15 \%$ de ahorro, debido a que, tendría gran impacto sobre los costos invertidos en compras. Este indicador es respaldado por IV Jornada Técnica de la CTCL 
llevada a cabo en el 2013. A continuación, la ficha del indicador IN-LOG-02. Porcentaje de

\section{ahorro en compras.}

Figura 52: Ficha técnica del indicador de porcentaje de ahorro por compras

\begin{tabular}{|c|c|c|c|}
\hline \multicolumn{2}{|c|}{ PORCENTAJE DE AHORRO POR COMPRAS } & $\begin{array}{l}\text { CÓDIGO: } \\
\text { IN-LOG-01 }\end{array}$ & $\begin{array}{l}\text { PÁGINA: } \\
1 \text { de } 1\end{array}$ \\
\hline \multicolumn{4}{|c|}{ Porcentaje de ahorro por compras } \\
\hline \multicolumn{4}{|c|}{$\begin{array}{l}\text { 2. Objetivo: } \\
\text { Identificar el beneficio económico de las compras en conjunto para la decisión de la } \\
\text { orden de compra. }\end{array}$} \\
\hline \multicolumn{3}{|c|}{ Porcentaje de ahorro por compras $=\left(1-\frac{\text { Precio }}{\text { Precio po }}\right.$} & $x 100$ \\
\hline \multicolumn{4}{|c|}{$\begin{array}{l}\text { Mayor a } 15 \% \\
\text { Entre } 5 \% \text { y } 15 \% \\
\text { Menor a } 5 \%\end{array}$} \\
\hline \multicolumn{4}{|c|}{ Un incremento en el indicador indica una mejora en el resultado. } \\
\hline \multicolumn{4}{|c|}{$\begin{array}{l}\text { 5. Responsable de Gestión: } \\
\text { Encargado de compras }\end{array}$} \\
\hline \multicolumn{4}{|c|}{$\begin{array}{l}\text { 6. Fuente de Información: } \\
\text { Informe de compras }\end{array}$} \\
\hline \multicolumn{4}{|c|}{$\begin{array}{l}\text { 7. Frecuencia de Medición: } \\
\text { Cada vez realizada una compra }\end{array}$} \\
\hline \multicolumn{4}{|c|}{$\begin{array}{l}\text { 8. Frecuencia de Reporte: } \\
\text { Cada vez realizada una compra }\end{array}$} \\
\hline \multicolumn{4}{|c|}{$\begin{array}{l}\text { 9. Responsable del Reporte: } \\
\text { Encargado de compras }\end{array}$} \\
\hline \multicolumn{4}{|l|}{$\begin{array}{l}\text { 10. Usuarios: } \\
\text { Compras }\end{array}$} \\
\hline \multicolumn{4}{|l|}{ 11. Observaciones: } \\
\hline $\begin{array}{l}\text { GENERADO POR: } \\
\text { Gestión Logística }\end{array}$ & $\begin{array}{l}\text { REVISADO Y APROBADO POR: } \\
\text { Presidente de la Cooperativa }\end{array}$ & $\begin{array}{r}\text { FECHA DE } \\
22 / 06 /\end{array}$ & MISIÓN \\
\hline
\end{tabular}




\subsubsection{Subproceso de gestión de almacenamiento de insumos}

\subsection{Flujograma de la gestión de almacenamiento de insumos}

En la figura $\mathrm{N}^{\circ} 51$, se observa la secuencia de actividades del subproceso de almacenamiento de insumos, este empieza con el ingreso del cronograma de entregas para la recepción de mercadería, luego, se inspecciona si el producto es conforme según los lineamientos del proceso de Gestión de Calidad, entonces si el producto no es conforme se devuelve al proveedor y se emite una hoja de devolución.

En cambio, si se acepta el pedido se registran las entradas al almacén, luego se guardan los insumos en el almacén, en donde sale un reporte de ubicación de insumos y de manera secuencial ingresa a través de planificación de la producción una ficha de requerimientos de materiales, la cual es necesaria para asignar los insumos a cada MYPE, es decir, se analiza la cantidad que se le entregará a cada agricultor.

Después de haber repartido la cantidad se le entregan los insumos al subproceso de repartición de insumos para distribuirlos, finalizando con un registro de salidas de insumos que queda como documento dentro del almacén para un conteo sobre los niveles de inventarios.

De esta manera, luego de analizar el flujograma de este subproceso, se presenta el P-LOG-03. Procedimiento de la gestión de almacenamiento de insumos donde se describe todas las actividades realizadas por este subproceso, así como los responsables, el objetivo, el alcance, es decir, hasta donde abarca este procedimiento, las condiciones básicas para que se pueda realizar el correcto funcionamiento del procedimiento y los documentos de salida que controlan los procesos y su desempeño. 
Figura 53: Flujograma del subproceso de Almacenamiento de Insumos

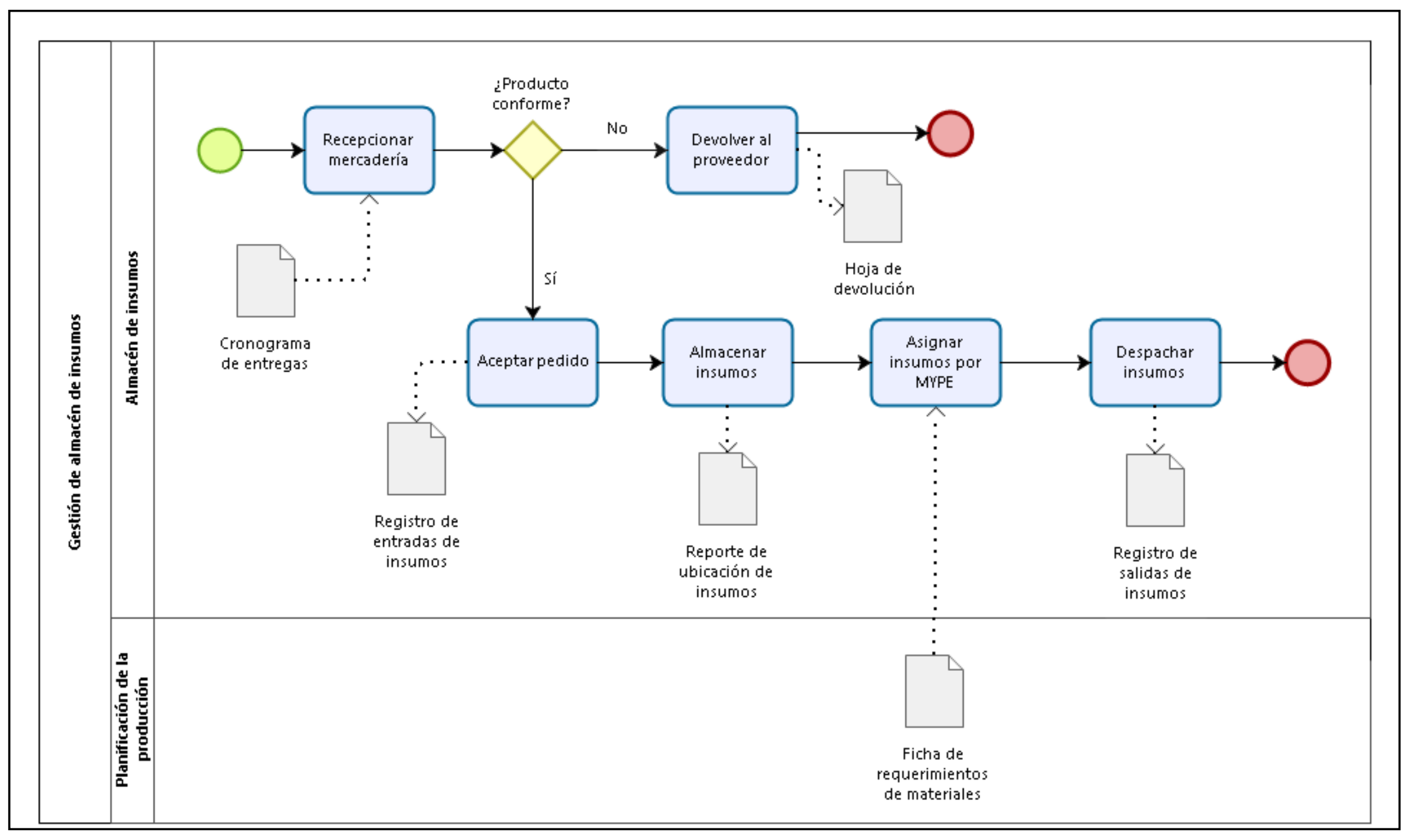

Fuente: Elaboración propia 


\section{OBJETIVO}

El presente procedimiento establece las acciones a realizar para almacenar los insumos y su conservación.

\section{RESPONSABILIDAD Y ALCANCE}

El presente procedimiento es administrado por la Cooperativa, en especial por el presidente de la asociación, e incluye los pasos a seguir desde que se recepciona la mercadería hasta que se despachan los insumos para su posterior distribución.

\section{DOCUMENTOS A CONSULTAR}

* Cronograma de entregas

* Ficha de requerimiento de materiales

\section{DEFINICIONES}

N/A

\section{CONDICIONES BÁSICAS}

5.1. Se debe tener un almacén en conjunto que se encuentre acondicionado según los estándares de calidad.

\section{DESARROLLO DEL PROCEDIMIENTO}

\begin{tabular}{|c|c|}
\hline Actividad & Responsable \\
\hline GESTIÓN DE ALMACÉN DE INSUMOS & \\
\hline $\begin{array}{l}\text { 6.1 Recepcionar mercadería } \\
\text { 6.1.1 Con base en el cronograma de entregas, podrá observar } \\
\text { el día y hora estimada de la llegada de la mercadería. } \\
\text { 6.1.2 Al llegar la mercadería debe presentarse ante el vendedor para } \\
\text { establecer la conformidad o no de la entrega } \\
\text { 6.1.3. Se realiza un control de calidad del pedido }\end{array}$ & \multirow{3}{*}{ Almacén } \\
\hline $\begin{array}{l}\text { 6.2. Devolver al proveedor } \\
\text { 6.2.1. En caso se rechace el pedido por incidencias en la calidad del } \\
\text { insumo o problemas en el nivel de servicio, se deberá establecer una } \\
\text { hoja de devolución. Caso contrario, se acepta el pedido. }\end{array}$ & \\
\hline $\begin{array}{l}\text { 6.3. Aceptar pedido } \\
\text { 6.3.1. Se emite la orden de ingreso de la mercadería al almacén. } \\
\text { 6.3.2. Se mantiene un registro de entradas de insumos al almacén. }\end{array}$ & \\
\hline
\end{tabular}

\begin{tabular}{|c|c|c|}
\hline GENERADO POR: & REVISADO Y APROBADO POR: & FECHA DE EMISIÓN: \\
Gestión Logística & Presidente de la Cooperativa & $22 / 06 / 2017$ \\
\hline
\end{tabular}




\begin{tabular}{|c|c|c|}
\hline PROCEDIMIENTO DE ALMACÉN DE INSUMOS & CÓDIGO: & PÁGINA: \\
P- LOG-03 & 2 de 2 \\
\hline
\end{tabular}

\begin{tabular}{|c|c|}
\hline 6.4 & $\begin{array}{l}\text { Almacenar insumos } \\
\text { 6.4.1 Se debe colocar la mercadería detrás de la que ya existe en el } \\
\text { almacén. } \\
\text { 6.4.2 Los productos más pesados deberán colocarse en la parte } \\
\text { inferior de los estantes. } \\
\text { 6.4.3. Se debe ubicar cada insumo según orden alfabético. } \\
\text { 6.4.4. Cada producto debe tener un control de las entradas y salidas } \\
\text { de la mercancía en el almacén de insumos. }\end{array}$ \\
\hline 6.5 & $\begin{array}{l}\text { Asignar insumos por MYPE } \\
\text { 6.5.1. A través de la ficha de requerimientos de materiales, se } \\
\text { establece la cantidad que debe ser entregada para cada agricultor. }\end{array}$ \\
\hline & $\begin{array}{l}\text { Despachar insumos } \\
\text { 6.6.1. Entregar la cantidad asignada de insumos a } \\
\text { distribución para luego ser entregado a cada agricultor. }\end{array}$ \\
\hline
\end{tabular}

\section{REGISTROS}

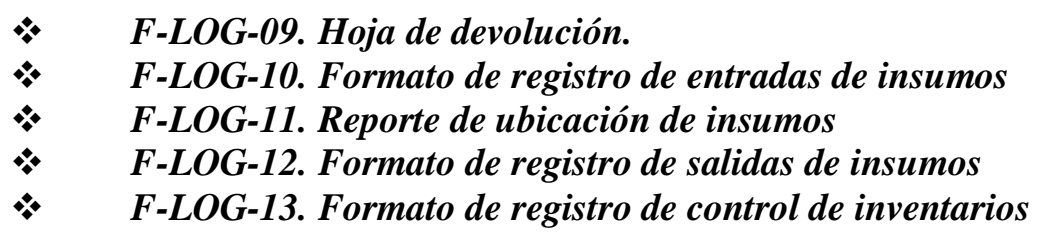

\section{ANEXOS}

No hay anexos para este documento.

\begin{tabular}{|c|c|c|}
\hline GENERADO POR: & REVISADO Y APROBADO POR: & FECHA DE EMISIÓN: \\
Gestión Logística & Presidente de la Cooperativa & $22 / 06 / 2017$ \\
\hline
\end{tabular}




\subsection{Caracterización de la gestión de almacenamiento de insumos}

Las entradas que ingresan al subproceso de almacenamiento de insumos son el cronograma de entregas que es brindado por el subproceso de compras y la ficha de requerimientos de materiales por parte de la planificación de la producción, la cual sirve para definir la cantidad a entregar a cada MYPE sobre las compras. Del mismo modo, las salidas son la hoja de devolución en caso el producto no es conforme, el registro de entradas de insumos una vez que se recepciona la mercadería, el reporte de ubicación de insumos, el cual sirve para el almacenamiento ordenado de las compras y el registro de salidas de insumos para el posterior despacho. Asimismo, las actividades del proceso empiezan desde la recepción de la mercadería hasta el despacho hacia producción. Además, los recursos son los útiles de escritorio, cuadernos, calculadora y una pizarra para realizar la ubicación de los insumos.

Figura 54 Diagrama SIPOC del subproceso de almacenamiento de insumos

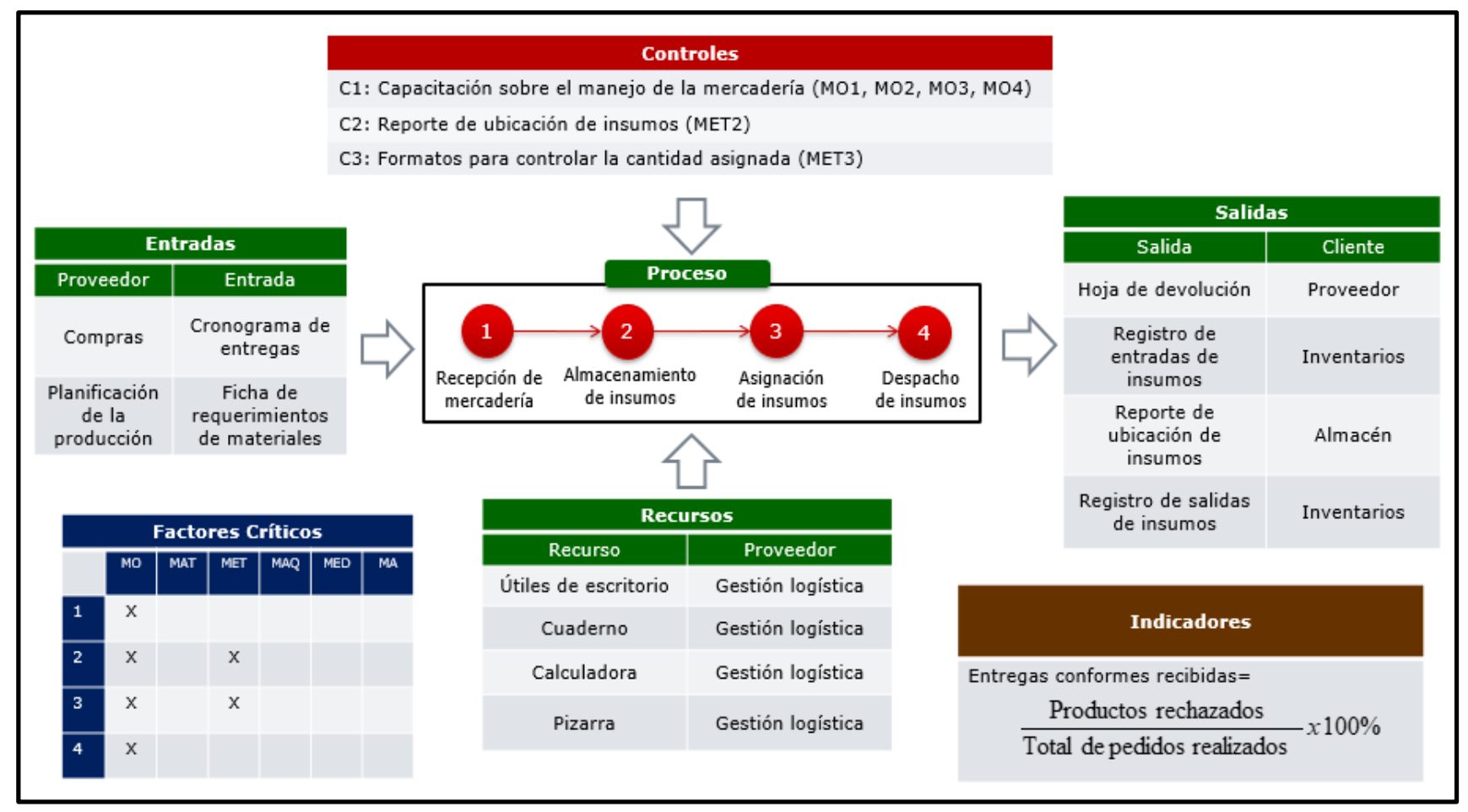

Fuente: Elaboración propia

\subsection{Indicador de la gestión de almacenamiento de insumos}

El indicador para medir la gestión del almacenamiento de insumos es sobre el porcentaje de entregas conformes recibidas, es decir, se compara la cantidad de productos rechazados al momento de la inspección de calidad en la recepción de insumos sobre el total de pedidos realizados, dentro de la cooperativa en la actualidad se rechaza alrededor del 15\% de productos, mientras que en los fundos y otras empresas organizadas el porcentaje de rechazo es de $5 \%$. Asimismo, según la Colombiana de Salud el porcentaje de rechazo aceptado es de un valor 
menor a $10 \%$, por ende, lo aceptable para la cooperativa es que el porcentaje de rechazo sea menor a 8\%. A continuación, la ficha del indicador IN-LOG-03. Entregas conformes recibidas.

Figura 55: Ficha técnica del indicador de entregas conformes recibidas

\begin{tabular}{|c|c|c|c|}
\hline \multicolumn{2}{|c|}{ ENTREGAS CONFORMES RECIBIDAS } & $\begin{array}{l}\text { CÓDIGO: } \\
\text { IN- LOG-03 }\end{array}$ & $\begin{array}{c}\text { PÁGINA: } \\
1 \text { de } 1\end{array}$ \\
\hline \multicolumn{4}{|c|}{ Porcentaje de entregas conformes recibidas } \\
\hline \multicolumn{4}{|c|}{$\begin{array}{l}\text { 2. Objetivo: } \\
\text { Reducir la cantidad de productos rechazados que impiden el proceso de producción. }\end{array}$} \\
\hline \multicolumn{4}{|c|}{ Entregas conformes recibidas $=\frac{\text { Cantidad productos rechazados }}{\text { Total de pedidos realizados }} \times 100 \%$} \\
\hline \multicolumn{4}{|c|}{$\begin{array}{l}\text { Menor a } 8 \% \\
\text { Entre } 8 \% \text { y } 13 \% \\
\text { Mayor } 13 \%\end{array}$} \\
\hline \multicolumn{4}{|c|}{ Un decremento en el valor del indicador indica una mejora en el resultado. } \\
\hline \multicolumn{4}{|c|}{$\begin{array}{l}\text { 5. Responsable de Gestión: } \\
\text { Responsable de almacén }\end{array}$} \\
\hline \multicolumn{4}{|c|}{$\begin{array}{l}\text { 6. Fuente de Información: } \\
\text { Cronograma de entregas }\end{array}$} \\
\hline \multicolumn{4}{|c|}{$\begin{array}{l}\text { 7. Frecuencia de Medición: } \\
\text { Cada recepción de una compra }\end{array}$} \\
\hline \multicolumn{4}{|c|}{$\begin{array}{l}\text { 8. Frecuencia de Reporte: } \\
\text { Después de la recepción de compra }\end{array}$} \\
\hline \multicolumn{4}{|c|}{$\begin{array}{l}\text { 9. Responsable del Reporte: } \\
\text { Responsable de almacén }\end{array}$} \\
\hline \multicolumn{4}{|l|}{$\begin{array}{l}\text { 10. Usuarios: } \\
\text { Almacén }\end{array}$} \\
\hline \multicolumn{4}{|l|}{ 11. Observaciones: } \\
\hline $\begin{array}{l}\text { GENERADO POR: } \\
\text { Gestión Logística }\end{array}$ & $\begin{array}{l}\text { REVISADO Y APROBADO POR: } \\
\text { Presidente de la Cooperativa }\end{array}$ & $\begin{array}{r}\text { FECHA DE } \\
22 / 06\end{array}$ & $\begin{array}{l}\text { EMISIÓN: } \\
2017\end{array}$ \\
\hline
\end{tabular}

Fuente: Elaboración propia

\subsubsection{Subproceso de repartición de insumos}

\subsection{Flujograma de repartición de insumos}

En la figura $\mathrm{N}^{\mathrm{0} 54}$, se observa la secuencia de actividades del subproceso de repartición de insumos, este empieza con el cálculo de las rutas donde se obtiene el plan de recorrido, una vez con el plan de recorrido, el cual optimiza los tiempos de entrega y detalla el orden de entrega a cada MYPE, se procede a distribuir los insumos.

Una vez que el encargado del almacén reparta los insumos, este emite una verificación de entrega donde se señala la cantidad y la hora a las que fueron aceptadas y posteriormente, lo entrega al almacén para llevar un control. 
De esta manera, luego de analizar el flujograma de este subproceso, se presenta el $\boldsymbol{P}$ LOG-04. Procedimiento de la gestión de repartición de insumos donde se describe todas las actividades realizadas, así como los responsables, el objetivo, el alcance, es decir, hasta donde abarca este procedimiento, las condiciones básicas para que se pueda realizar el correcto funcionamiento del procedimiento y los documentos de salida que controlan los procesos y su desempeño.

Figura 56: Flujograma del subproceso de Repartición de Insumos

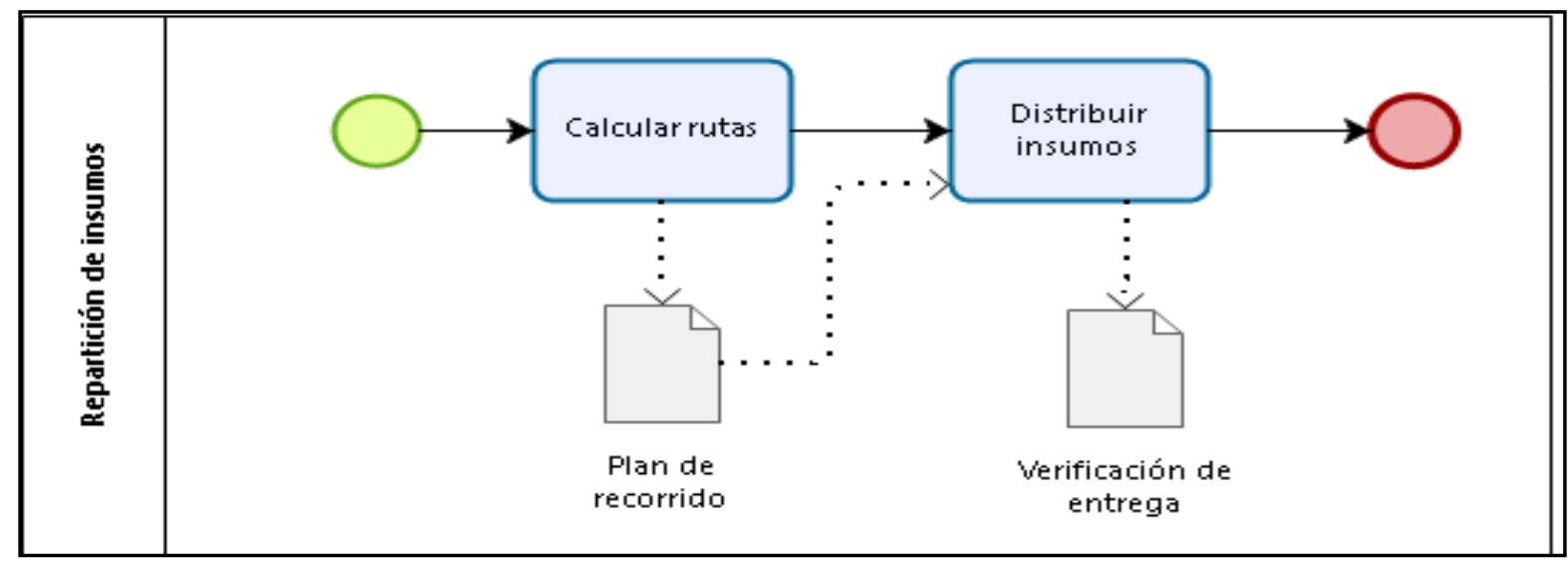

Fuente: Elaboración propia 


\section{OBJETIVO}

El presente procedimiento establece las acciones a realizar para la repartición de insumos.

\section{RESPONSABILIDAD Y ALCANCE}

El presente procedimiento es administrado por la Cooperativa, en especial por el presidente de la asociación.

\section{DOCUMENTOS A CONSULTAR}

* Plan de producción

\section{DEFINICIONES}

N/A

\section{CONDICIONES BASICAS}

7.1. Se debe tener clara la asignación de productos para cada MyPE. Esto se debe encontrar en el plan de producción.

7.2. La repartición de insumos se realiza desde el almacén en común, este proceso no transporta productos desde el proveedor hasta el almacén.

7.3. Todos los productos ya deben encontrarse listos para cargar a las unidades de transporte responsables.

\section{DESARROLLO DEL PROCEDIMIENTO}

\begin{tabular}{|c|c|}
\hline Actividad & Responsable \\
\hline REPARTICIÓN DE INSUMOS & \\
\hline $\begin{array}{l}\text { 6.8. Calcular rutas } \\
\text { 6.8.1. Identificar cantidades requeridas para cada MyPE según lo } \\
\text { diga el plan de producción. } \\
\text { 6.8.2. Identificar el peso total a transportar por cada MyPE } \\
\text { 6.8.3. Trazar rutas posibles según se pueda combinar los pedidos. } \\
\text { 6.8.4. Comparar tiempos y distancias requeridas } \\
\text { 6.8.5. Elegir la cual necesite menores viajes y tome menor tiempo. } \\
\text { 6.8.6. Comunicar a encargado de transporte }\end{array}$ & Transporte \\
\hline
\end{tabular}

\section{GENERADO POR:}

Gestión Logística

\section{REVISADO Y APROBADO POR:}

Presidente de la Cooperativa
FECHA DE EMISIÓN

$22 / 06 / 2017$ 


\begin{tabular}{|l|l|}
\hline 6.9. & Distribuir insumos \\
6.9.1. Cargar productos según sea destinado el viaje & \\
correspondiente. & \\
6.9.2. Verificar estado de los productos & \\
6.9.3. Verificar la estabilidad de los productos para evitar que se \\
deterioren en camino. \\
6.9.4. Transportar los insumos \\
6.9.5. Entregar los insumos al responsable de cada MyPe \\
6.9.6. Solicitar la firma del encargado para asegurar la \\
verificación de entrega. \\
6.9.7. Regresar a almacén por el siguiente viaje. \\
6.9.8. Culminar cuando todos los insumos se encuentren en su \\
destino final.
\end{tabular}

\section{REGISTROS}

* F-LOG-14. Plan de recorrido

* F-LOG-15. Verificación de entrega de insumos

\section{ANEXOS}

No hay anexos para este documento.

\section{GENERADO POR:}

Gestión Logística

\section{REVISADO Y APROBADO POR:}

Presidente de la Cooperativa
FECHA DE EMISIÓN

$22 / 06 / 2017$ 


\subsection{Caracterización de repartición de insumos}

La entrada que ingresa al subproceso de repartición de insumos es el plan de recorrido, el cual detalla la cantidad, el orden, la ubicación y el tiempo que deben ser entregados los insumos hacia las MYPES. Del mismo modo, la salida de la primera actividad es el plan de recorrido que se utiliza para el despacho, así como, la verificación de entrega después de realizado la aceptación del pedido por parte de los agricultores. Asimismo, las actividades del proceso empiezan con el cálculo de las rutas y su posterior, distribución. En adición, los controles establecidos surgen de los factores críticos analizados y de la misma forma, los recursos identificados son los útiles de escritorio, cuadernos, calculadora para las operaciones, las unidades de transporte para realizar las entregas, un celular para mantener informada a la cooperativa sobre el proceso de distribución y combustible para el uso del transporte.

Figura 57 Diagrama SIPOC del subproceso de Repartición de insumos

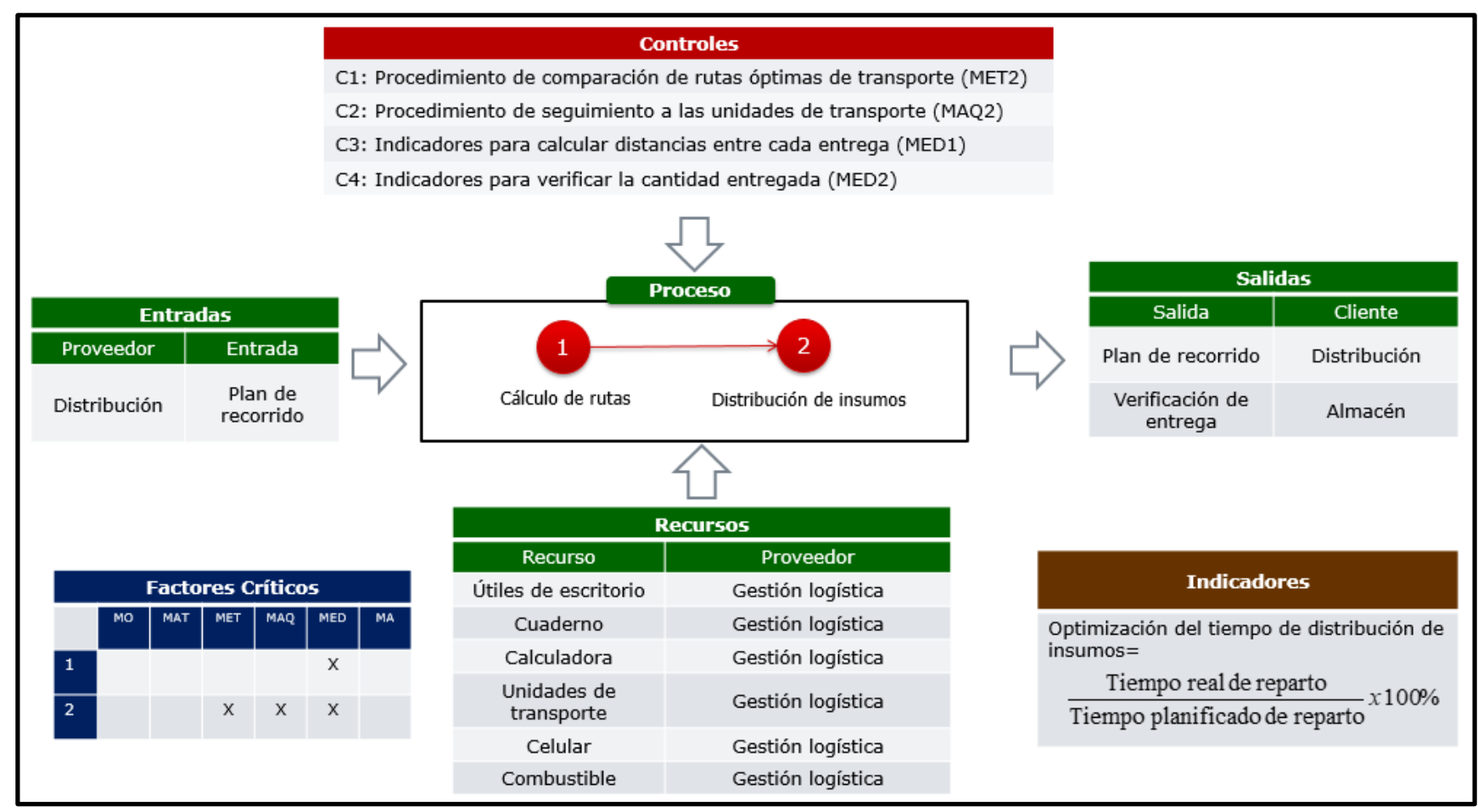

Fuente: Elaboración propia

\subsection{Indicador de repartición de insumos}

Este indicador es para comparar el tiempo real de reparto sobre el tiempo planificado. La importancia es resguardada por la tesis Indicadores de Gestión para Empresas Agrícolas y Ganaderas de la Universidad de la Salle ubicada en Bogotá. El valor aceptable es cuando el porcentaje es menor a $80 \%$, es decir, que llegan dentro de lo estimado. A continuación, la ficha del indicador IN-LOG-04. Tiempo de distribución de insumos. 
Figura 58: Ficha técnica del indicador de tiempo de distribución de insumos

\begin{tabular}{|c|c|c|}
\hline TIEMPO DE DISTRIBUCIÓN DE INSUMOS & CODIGO & PAGINA \\
& IN-LOG-04 & 1 de 1 \\
\hline
\end{tabular}

\begin{tabular}{|c|c|c|}
\hline \multicolumn{3}{|c|}{ Tiempo de distribución de insumos } \\
\hline \multicolumn{3}{|c|}{$\begin{array}{l}\text { 2. Objetivo: } \\
\text { Identificar la certeza de la estimación de los tiempos de distribución para futuras } \\
\text { consideraciones tener valores más cercanos a la realidad. }\end{array}$} \\
\hline \multicolumn{3}{|c|}{ Tiempo de distribución de insumos $=\frac{\text { Tiempo real de reparto }}{\text { Tiempo planificado de reparto }} \times 100$} \\
\hline \multicolumn{3}{|c|}{$\begin{array}{l}\text { Menor a } 80 \% \\
\text { Entre } 80 \% \text { y } 130 \% \\
\text { Mayor a } 130 \%\end{array}$} \\
\hline \multicolumn{3}{|c|}{ Un incremento refleja la deficiente estimación del tiempo de recorrido. } \\
\hline \multicolumn{3}{|c|}{$\begin{array}{l}\text { 5. Responsable de Gestión: } \\
\text { Encargado de distribución de insumos }\end{array}$} \\
\hline \multicolumn{3}{|c|}{$\begin{array}{l}\text { 6. Fuente de Información: } \\
\text { Plan de recorrido }\end{array}$} \\
\hline \multicolumn{3}{|c|}{$\begin{array}{l}\text { 7. Frecuencia de Medición: } \\
\text { Después de cada reparto }\end{array}$} \\
\hline \multicolumn{3}{|c|}{$\begin{array}{l}\text { 8. Frecuencia de Reporte: } \\
\text { Después de cada campaña }\end{array}$} \\
\hline \multicolumn{3}{|c|}{$\begin{array}{l}\text { 9. Responsable del Reporte: } \\
\text { Encargado de repartición de insumos }\end{array}$} \\
\hline \multirow{2}{*}{\multicolumn{3}{|c|}{$\begin{array}{l}\text { 10. Usuarios: } \\
\text { Repartición de insumos } \\
\text { Producción } \\
\text { 11. Observaciones: }\end{array}$}} \\
\hline & & \\
\hline $\begin{array}{l}\text { GENERADO POR: } \\
\text { Gestión Logística }\end{array}$ & $\begin{array}{l}\text { REVISADO Y APROBADO POR: } \\
\text { Presidente de la Cooperativa }\end{array}$ & $\begin{array}{l}\text { FECHA DE EMISION } \\
22 / 06 / 2017\end{array}$ \\
\hline
\end{tabular}

Fuente: Elaboración propia

\subsubsection{Subproceso de la gestión de almacenamiento de la producción}

\subsection{Flujograma de la gestión de almacenamiento de la producción}

En la figura $\mathrm{N}^{\circ} 57$, se observa la secuencia de actividades del subproceso de gestión de almacenamiento de la producción, este empieza con el ingreso de un plan de distribución de la producción, es decir, en dicho plan se ubica la producción en el almacén de acuerdo con el calibre de la palta, asimismo, al guardar las paltas según calibre se genera un registro de entradas 
de producción, el cual sirve para llevar un control de lo ingresado donde se espera que la misma cantidad ingresada sea la de salida.

Posteriormente, al ingresar la orden de pedido por parte de gestión Comercial se prepara el pedido a ser atendido y se despacha en donde sale un registro de salidas de producción, así como, una base de datos física sobre el stock que queda para la siguiente entrega. Además, se le entrega una guía de remisión al subproceso de distribución de la producción para llevar el pedido hacia el operador logístico.

De esta manera, luego de analizar el flujograma de este subproceso, se presenta el P-LOG-05.

Procedimiento de almacenamiento de la producción donde se describe todas las actividades realizadas, así como los responsables, el objetivo, el alcance, es decir, hasta donde abarca este procedimiento, las condiciones básicas para que se pueda realizar el correcto funcionamiento del procedimiento y los documentos de salida que controlan los procesos y su desempeño. 
Figura 59: Flujograma del subproceso de Almacenamiento de la producción

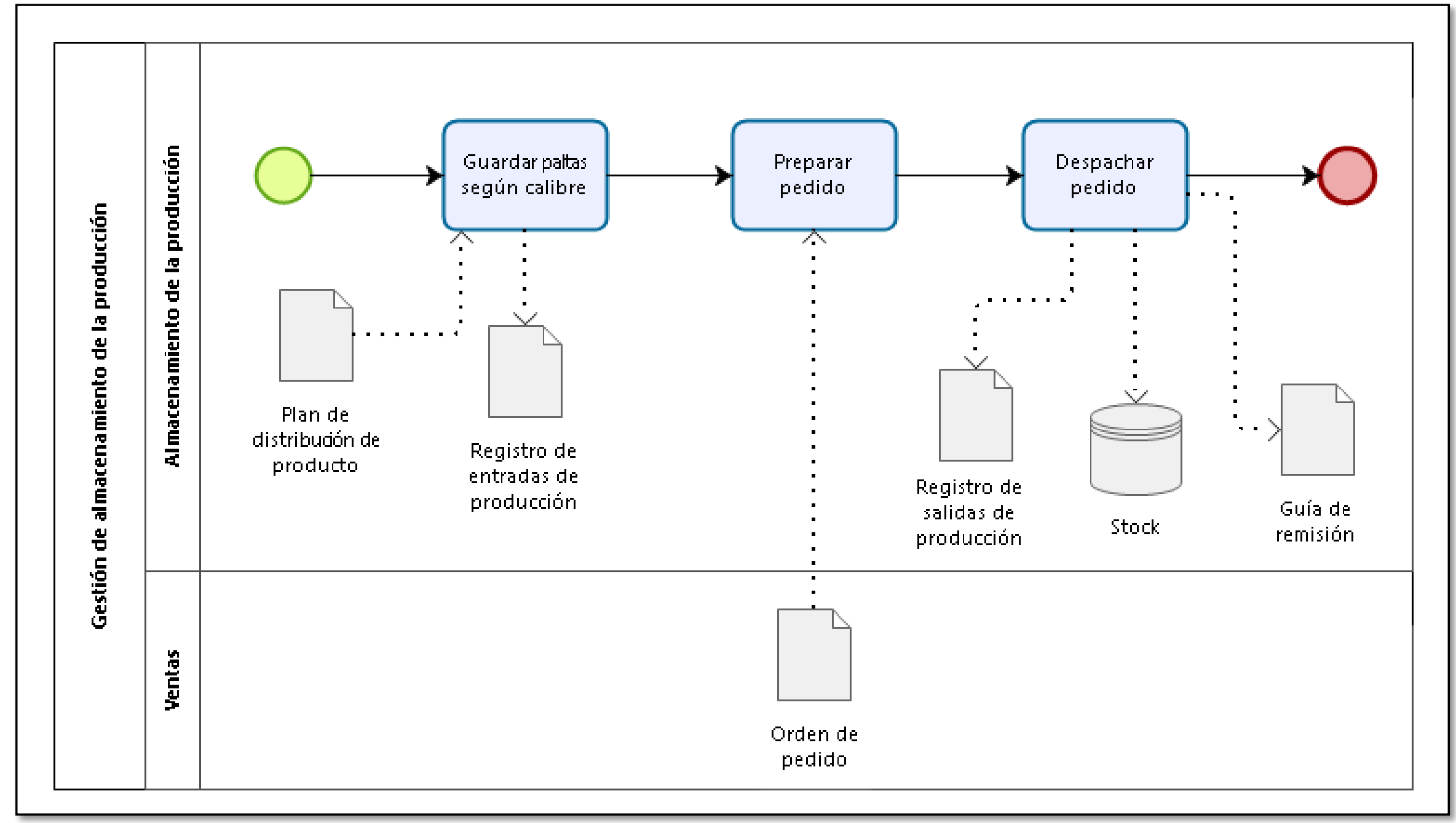

Fuente: Elaboración propia 


\begin{tabular}{|c|c|c|}
\hline $\begin{array}{c}\text { PROCEDIMIENTO DE ALMACENAMIENTO DE LA } \\
\text { PRODUCCIÓN }\end{array}$ & $\begin{array}{c}\text { CÓDIGO: } \\
\text { P- LOG-05 }\end{array}$ & \begin{tabular}{c} 
PÁGA 2 \\
\hline
\end{tabular}
\end{tabular}

\section{OBJETIVO}

El presente procedimiento establece las acciones a realizar para almacenar la producción y preparar el pedido a ser entregado posteriormente.

\section{RESPONSABILIDAD Y ALCANCE}

El presente procedimiento es administrado por la Cooperativa, en especial por el presidente de la asociación, e incluye los pasos a seguir desde que se guardan las paltas según el calibre hasta que se tiene el pedido listo para ser transportado hacia el operador logístico.

\section{DOCUMENTOS A CONSULTAR}

* Orden de pedido

* Plan de distribución de producto

\section{DEFINICIONES}

* Clasificar: Identificar el producto según el calibre

\section{CONDICIONES BÁSICAS}

5.1. Se debe tener un almacén en conjunto que se encuentre acondicionado según los estándares de calidad para almacenar el producto hasta que ingresa una orden de pedido.

5.2. Se debe tener espacio físico en el almacén para preparar el pedido.

\section{DESARROLLO DEL PROCEDIMIENTO}

\begin{tabular}{|c|c|}
\hline Actividad & Responsable \\
\hline GESTIÓN DE ALMACÉN DE PRODUCCIÓN & \\
\hline $\begin{array}{l}\text { 6.1. Guardar paltas según calibre } \\
\text { 6.1.1. Con base en el plan de distribución de producto, se almacenan } \\
\text { las paltas de acuerdo con el calibre que tengan. } \\
\text { 6.1.2. Se empezará por el calibre de } 170 \text { gr, el cual es el más solicitado } \\
\text { y posteriormente, se guardará estante tras estante en jabas de } 20 \mathrm{~kg} \text {. } \\
\text { según el orden de importancia del calibre. } \\
\text { 6.1.3. Luego de haber guardado las paltas, se obtendrá un registro de } \\
\text { entradas de producción. } \\
\text { 6.1.4. El tiempo de guardado de las paltas es menor a una semana, } \\
\text { debido a que según el plan de cosecha las paltas se cosechan cuando ya } \\
\text { está por solicitarse el pedido. }\end{array}$ & \multirow[t]{2}{*}{$\begin{array}{l}\text { Almacén de } \\
\text { producción }\end{array}$} \\
\hline $\begin{array}{l}\text { 6.2 Preparar pedido } \\
\text { 6.2.1. Con la llegada de la orden de pedido, se prepara el pedido. } \\
\text { 6.2.2. Se analiza la cantidad solicitada y se separa en el almacén lo que } \\
\text { se enviará a exportar. Se guarda en jabas de } 20 \mathrm{~kg} \text {. }\end{array}$ & \\
\hline
\end{tabular}

\begin{tabular}{|c|c|c|}
\hline GENERADO POR: & REVISADO Y APROBADO POR: & FECHA DE EMISIÓN: \\
Gestión Logística & Presidente de la Cooperativa & $22 / 06 / 2017$ \\
\hline
\end{tabular}




6.3 Despachar pedido
6.3.1. Se colocan los pedidos en las afueras del almacén esperando al
vehículo para realizar la distribución.
6.3.2. Aquí se emite un registro de salidas de producción.
6.3.3. Luego, se verifica el nivel de stock en la base de datos física.
6.3.4. Para dar salida al camión se emite una guía de remisión que debe
ser entregada al transportista.

\section{REGISTROS}

* F-LOG-16. Plan de distribución de producto

* F-LOG-17. Formato de registro de entradas de producción

* F-LOG-18. Formato de registro de salidas de producción

* F-LOG-19. Formato de base de datos de producción

* F-LOG-20. Formato de guía de remisión

\section{ANEXOS}

No hay anexos para este documento.

GENERADO POR:

Gestión Logística
REVISADO Y APROBADO POR:

Presidente de la Cooperativa
FECHA DE EMISIÓN:

$22 / 06 / 2017$ 


\subsection{Caracterización de la gestión de almacenamiento de la producción}

Las entradas que ingresan al subproceso de almacenamiento de la producción es el plan de distribución del producto, quien lo genera el mismo subproceso, el cual sirve para ordenar la producción según su calibre y la orden de pedido por Gestión Comercial para preparar el pedido del cliente final. Del mismo modo, las salidas son el registro de entradas de producción, el registro de salidas de producción, la base de datos que muestra el nivel de stock, todos estos emitidos para el subproceso de inventarios y la guía de remisión con la que el subproceso de distribución realiza la entrega al operador logístico. Asimismo, las actividades del proceso empiezan con el almacenamiento de las paltas y termina con el pedido listo para ser entregado. Los recursos identificados son los útiles de escritorio, cuadernos y la calculadora para las operaciones.

Figura 60 Diagrama SIPOC del subproceso de Almacenamiento de producción

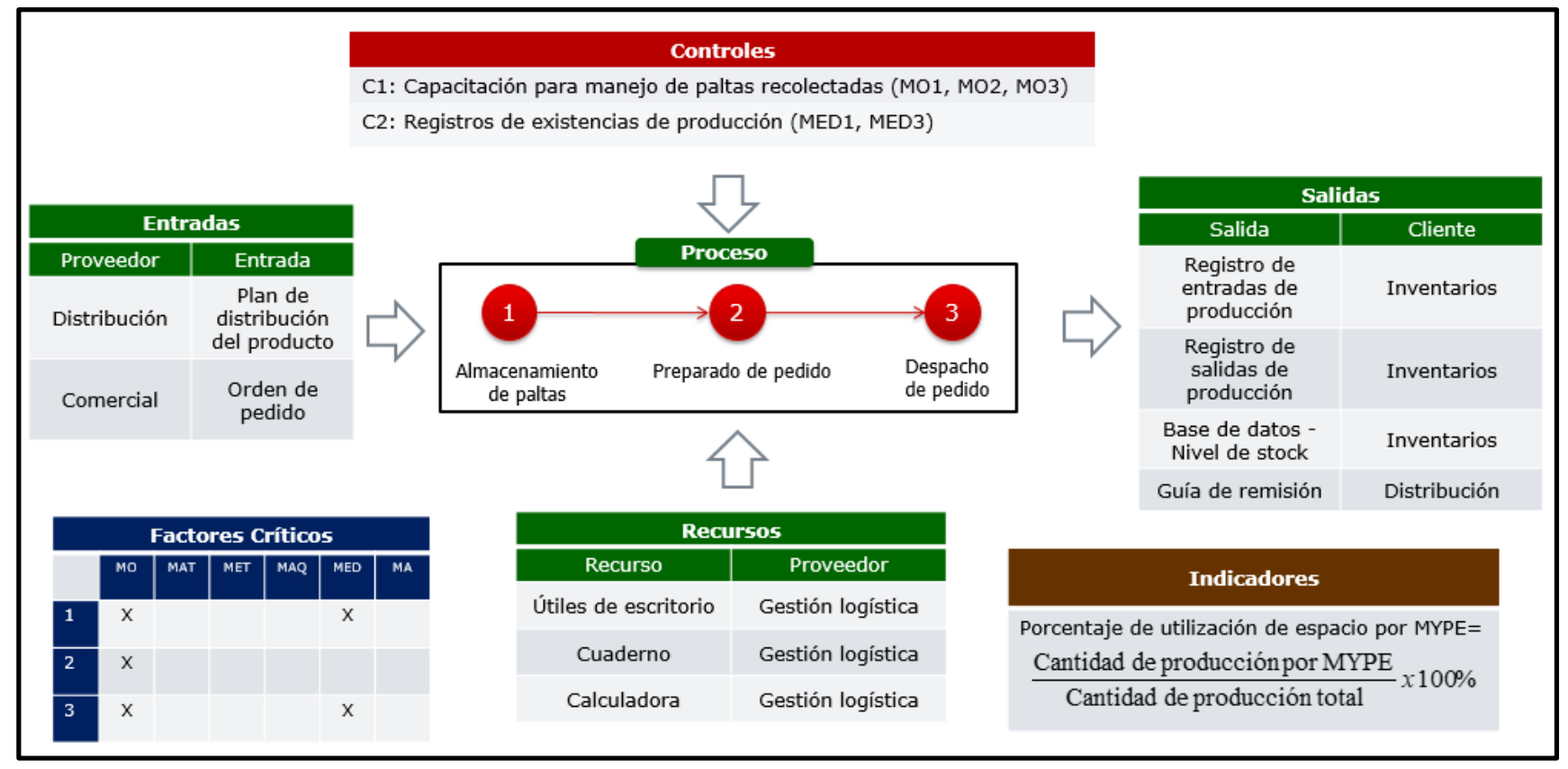

Fuente: Elaboración propia

\subsection{Indicador de la gestión de almacenamiento de la producción}

El indicador para medir la gestión del almacenamiento de la producción es para identificar el espacio que ocupa cada producción de cada MYPE sobre el total. Por ende, lo aceptable es que este porcentaje sea menor a 10\%, ya que es el espacio que ocuparía cada MYPE en relación con la dimensión del almacén, $120 \mathrm{~m}^{2}$. Al excederse estaría ocupando espacio que no le corresponde. También validado por la tesis Indicadores de Gestión para Empresas Agrícolas y Ganaderas de 
la Universidad de la Salle ubicada en Bogotá. A continuación, la ficha del indicador IN-LOG-

\section{Porcentaje de utilización de espacio por MYPE.}

Figura 61: Ficha técnica del indicador de porcentaje de utilización de espacio por MYPE

\begin{tabular}{|c|c|c|c|}
\hline \multicolumn{2}{|c|}{ UTILIZACIÓN DE ESPACIO POR MYPE } & $\begin{array}{c}\text { CÓDIGO } \\
\text { IN-LOG-05 }\end{array}$ & $\begin{array}{l}\text { PÁGINA } \\
1 \text { de } 1\end{array}$ \\
\hline \multicolumn{4}{|c|}{ Utilización de espacio por MYPE } \\
\hline \multicolumn{4}{|c|}{$\begin{array}{l}\text { 2. Objetivo: } \\
\text { Identificar el porcentaje que ocupa cada MYPE con su producción dentro del almacén, } \\
\text { con esto también se tendrá una referencia para las proporciones de producción entre } \\
\text { cada MYPE. }\end{array}$} \\
\hline \multicolumn{4}{|c|}{ Utilización de espacio por MYPE $=\frac{\text { Cantidad de producción por } M Y P E}{\text { Cantidad de producción total }} \times 100$} \\
\hline \multicolumn{4}{|c|}{$\begin{array}{l}\text { Menor a } 10 \% \\
\text { Entre } 10 \% \text { y } 35 \% \\
\text { Mayor a } 35 \%\end{array}$} \\
\hline \multicolumn{4}{|c|}{ Un incremento refleja un crecimiento de la proporción de producción por MYPE. } \\
\hline \multicolumn{4}{|c|}{$\begin{array}{l}\text { 5. Responsable de Gestión: } \\
\text { Encargado de almacén }\end{array}$} \\
\hline \multicolumn{4}{|c|}{$\begin{array}{l}\text { 6. Fuente de Información: } \\
\text { Registro de entradas de producción }\end{array}$} \\
\hline \multicolumn{4}{|c|}{$\begin{array}{l}\text { 7. Frecuencia de Medición: } \\
\text { Antes de despachar los pedidos. }\end{array}$} \\
\hline \multicolumn{4}{|c|}{$\begin{array}{l}\text { 8. Frecuencia de Reporte: } \\
\text { Después de cada campaña }\end{array}$} \\
\hline \multicolumn{4}{|c|}{$\begin{array}{l}\text { 9. Responsable del Reporte: } \\
\text { Encargado de almacén. }\end{array}$} \\
\hline \multicolumn{4}{|c|}{$\begin{array}{l}\text { 10. Usuarios: } \\
\text { Almacén de producción y producción. }\end{array}$} \\
\hline \multicolumn{4}{|l|}{ 11. Observaciones: } \\
\hline $\begin{array}{l}\text { GENERADO POR: } \\
\text { Gestión Logística }\end{array}$ & $\begin{array}{l}\text { REVISADO Y APROBADO POR: } \\
\text { Presidente de la Cooperativa }\end{array}$ & $\begin{array}{r}\text { FECHA DE EN } \\
22 / 06 / 201 \\
\end{array}$ & $\begin{array}{l}\text { IISIÓN } \\
7\end{array}$ \\
\hline
\end{tabular}

Fuente: Elaboración propia

\subsubsection{Subproceso de la distribución de la producción}

\subsection{Flujograma de la distribución de la producción}

En la figura $\mathrm{N}^{\circ} 60$, se observa la secuencia de actividades del subproceso de distribución de la producción, este empieza con el ingreso del informe de cosecha brindado por el área de producción, el cual se utiliza para recolectar la producción por MYPE, de donde sale un registro de recolección donde se identifica la cantidad cosechada y el calibre de las mismas, luego de la recolección, se traslada la producción y, asimismo, se entrega al almacén de producción para el guardado. 
Una vez preparado el pedido debido a una orden de pedido, se carga el pedido en los vehículos de los agricultores con el ingreso de una guía de remisión brindada por almacenamiento y se traslada el pedido hasta el operador logístico donde seguidamente se realiza la entrega. Después de entregar el pedido al operador se recibe una verificación de entrega de producción, en donde se busca que la cantidad de salida del almacén sea la misma que la entregada al operador. Es en este subproceso donde se termina el proceso logístico de la cooperativa. Posteriormente, es Gestión Comercial quien realiza un seguimiento al operador logístico hasta la entrega del pedido al cliente.

De esta manera, luego de analizar el flujograma de este subproceso, se presenta el $\boldsymbol{P}$ LOG-06. Procedimiento de distribución de la producción donde se describe todas las actividades realizadas, así como los responsables, el objetivo, el alcance, es decir, hasta donde abarca este procedimiento, las condiciones básicas para que se pueda realizar el correcto funcionamiento del procedimiento y los documentos de salida que controlan los procesos y su desempeño. 
Figura 62: Flujograma del subproceso de Distribución de la producción

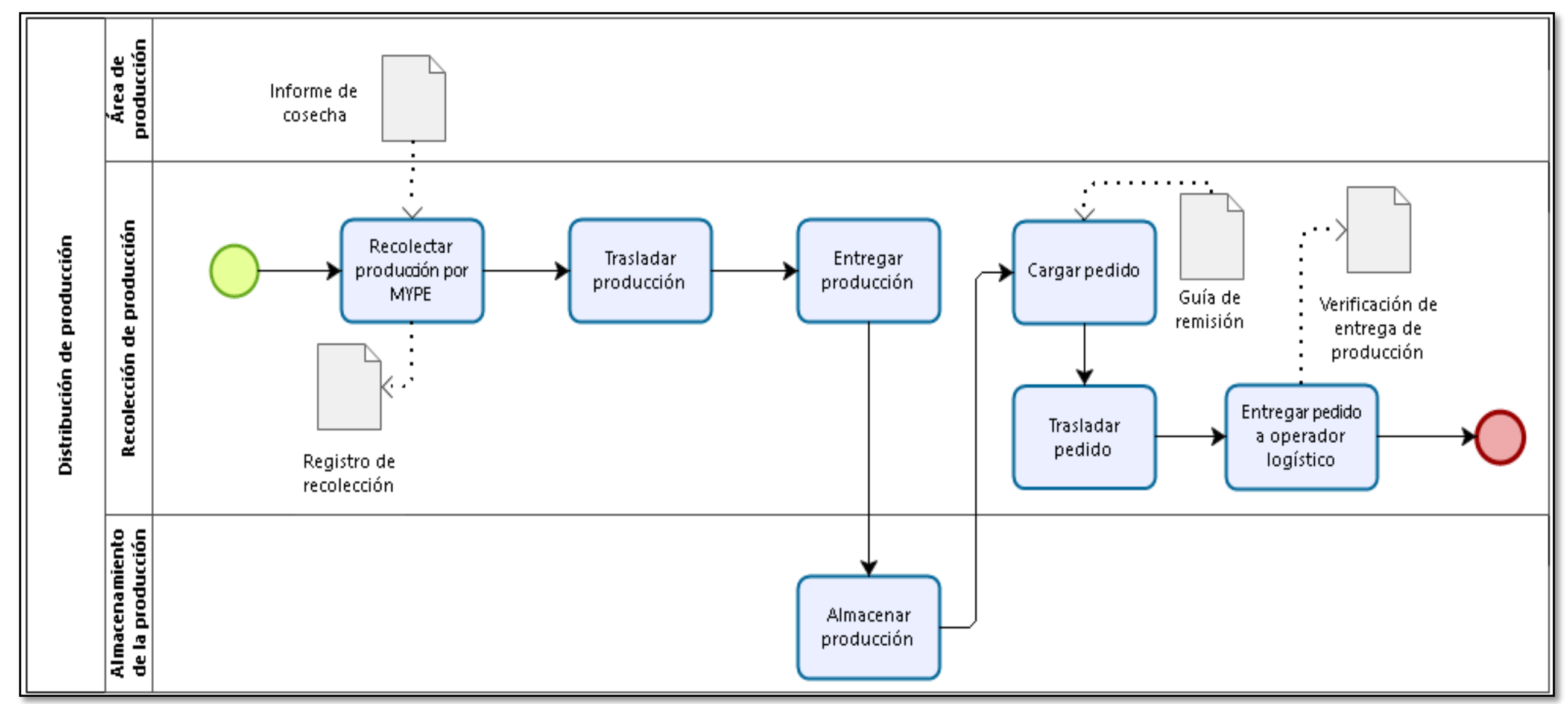

Fuente: Elaboración propia 


\begin{tabular}{|c|c|c|}
\hline PROCEDIMIENTO DE DISTRIBUCIÓN DE LA & CÓDIGO: & PÁGINA: \\
\hline PRODUCCIÓN & P- LOG-06 & $1 \mathrm{de} 2$ \\
\hline
\end{tabular}

\section{OBJETIVO}

El presente procedimiento establece las acciones a realizar para distribuir la producción desde el campo hasta el almacén y desde el almacén hasta el operador logístico.

\section{RESPONSABILIDAD Y ALCANCE}

El presente procedimiento es administrado por la Cooperativa, en especial por el presidente de la asociación, e incluye los pasos a seguir desde que se recolectan las paltas y se trasladan hasta el almacén y luego cuando se traslada hasta el operador logístico.

\section{DOCUMENTOS A CONSULTAR}

* $\quad$ Informe de cosecha

\section{DEFINICIONES}

N/A

\section{CONDICIONES BÁSICAS}

5.1. Se debe contar con vehículos en la cooperativa para realizar las actividades.

\section{DESARROLLO DEL PROCEDIMIENTO}

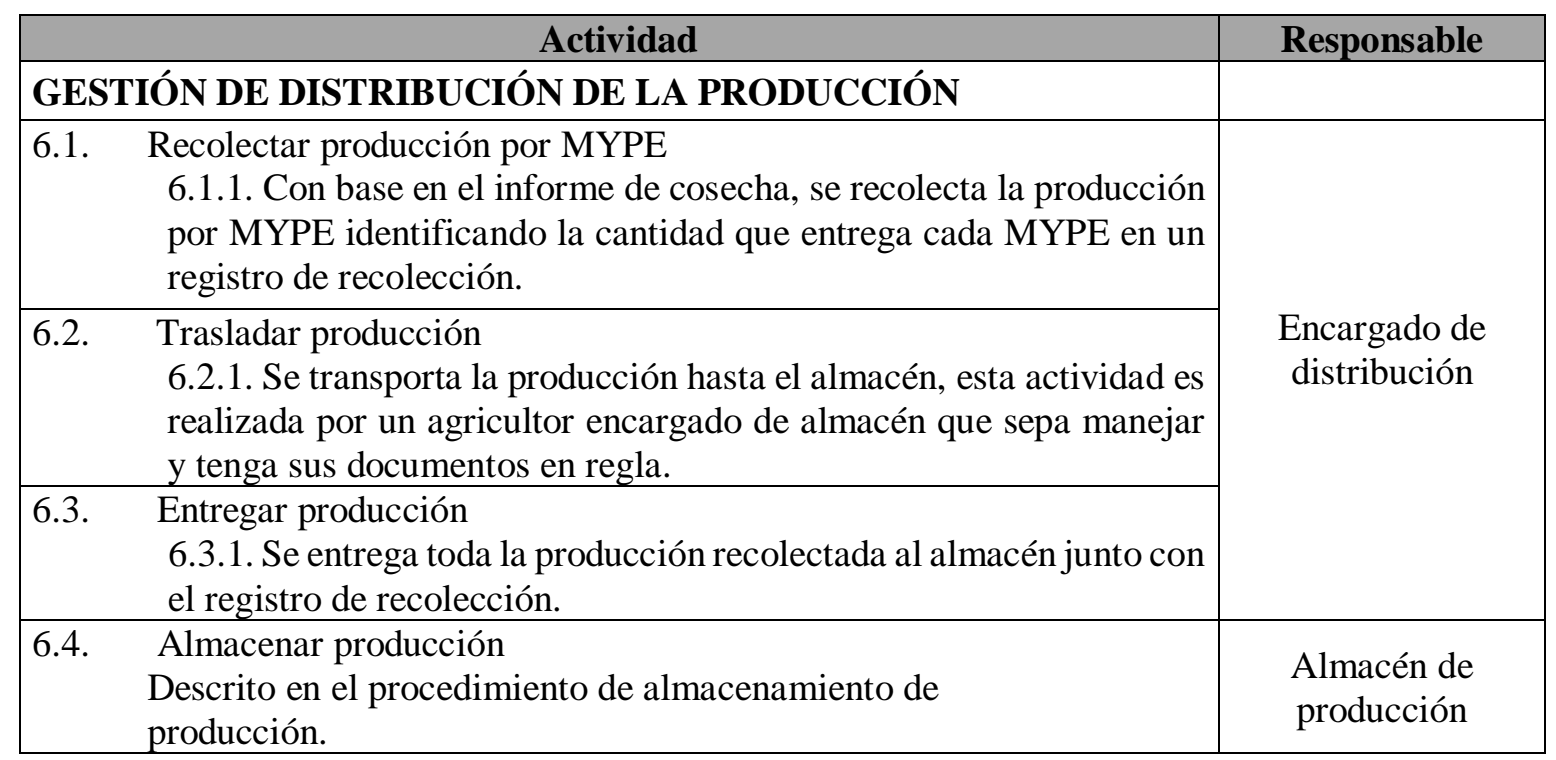

\begin{tabular}{|c|c|c|}
\hline GENERADO POR: & REVISADO Y APROBADO POR: & FECHA DE EMISIÓN: \\
Gestión Logística & Presidente de la Cooperativa & $22 / 06 / 2017$ \\
\hline
\end{tabular}




\begin{tabular}{|l|c|c|}
$\begin{array}{l}\text { PROCEDIMIENTO DE DISTRIBUCIÓN DE LA } \\
\text { PRODUCCIÓN }\end{array}$ & CÓDIGO: & PÁGINA: \\
P- LOG-06 & 2 de 2 \\
\hline
\end{tabular}

\begin{tabular}{|ll|l|}
\hline 6.5. & $\begin{array}{l}\text { Cargar pedido } \\
\text { 6.5.1 Al ingresar la guía de remisión, se procede a recoger el pedido } \\
\text { ubicado en el almacén y subirlo al camión. }\end{array}$ & \\
\cline { 1 - 2 } 6.6. & $\begin{array}{l}\text { Trasladar pedido } \\
\text { 6.6.1. Se realiza el viaje del pedido hasta el operador logístico } \\
\text { ubicado en Lima. }\end{array}$ & \multirow{2}{*}{$\begin{array}{c}\text { Encargado de } \\
\text { distribución }\end{array}$} \\
\cline { 1 - 2 } 6.7. & $\begin{array}{l}\text { Entregar pedido a operador logístico } \\
\text { 6.7.1. Al llegar al operador logístico, se realiza la entrega y se emite } \\
\text { una verificación de entrega de pedido. }\end{array}$ & \\
& & \\
& & \\
&
\end{tabular}

\section{REGISTROS}

\section{* F-LOG-21. Formato de registro de recolección \\ - F-LOG-22. Formato de verificación de entrega de pedido}

\section{ANEXOS}

No hay anexos para este documento.

\begin{tabular}{|c|c|c|}
\hline GENERADO POR: & REVISADO Y APROBADO POR: & FECHA DE EMISIÓN: \\
Gestión Logística & Presidente de la Cooperativa & $22 / 06 / 2017$
\end{tabular}




\subsection{Caracterización de la distribución de la producción}

Las entradas que ingresan al subproceso de distribución de la producción son informe de cosecha, el cual define la cantidad que se ha cosechado por MYPE y la guía de remisión por parte del almacén para ser entregado al subproceso de distribución de producción. Del mismo modo, las salidas de este subproceso son el registro de recolección dirigido para almacén y la verificación de entrega del pedido dirigido para el proceso Comercial. Asimismo, las actividades del proceso empiezan con la recolección de la producción por MYPE, una vez que almacén ya tiene pedido listo, entonces, distribución lo carga y posteriormente, lo entrega al operador logístico. De la misma forma, los recursos identificados son los útiles de escritorio, cuadernos, calculadora, las unidades de transporte para realizar las entregas, un celular para mantener informada a la cooperativa sobre el proceso de distribución y combustible.

Figura 63 Diagrama SIPOC del subproceso de Distribución de producción

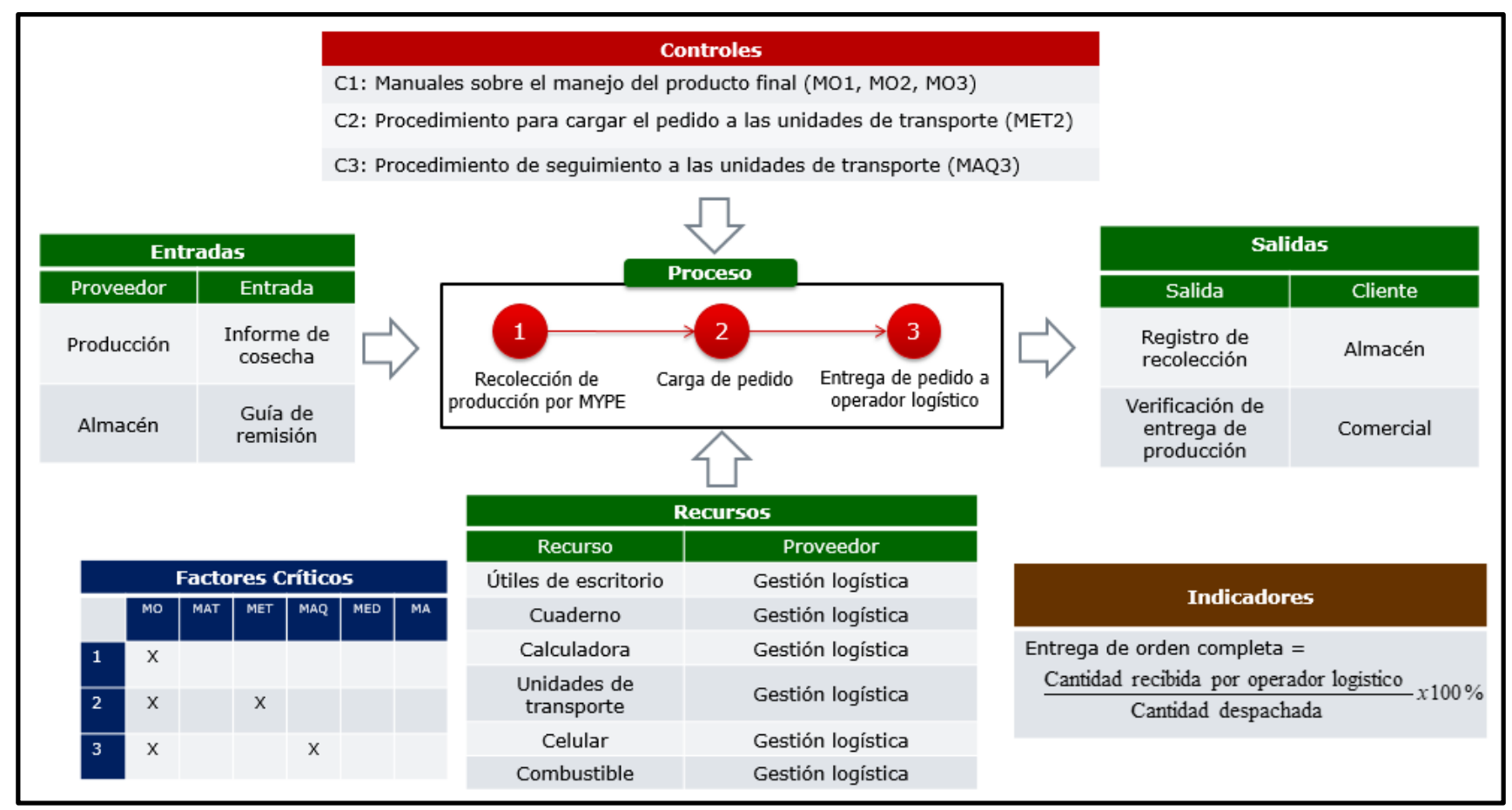

Fuente: Elaboración propia

\subsection{Indicador de la distribución de la producción}

El indicador para medir la gestión de la distribución de la producción compara la cantidad despachada y la recibida, este resultado debe ser mayor a $80 \%$. Como resultado, es aceptable el $50 \%$, ya que se tiene ocurrencias de hurtos en la industria. Estos parámetros han sido basados en la Matriz de Indicadores de Gestión de los Procesos del Ministerio de Agricultura 
y Desarrollo Rural de Colombia. A continuación, la ficha del indicador IN-LOG-06. Entrega de orden completa.

Figura 64: Ficha técnica del indicador de entrega de orden completa

\begin{tabular}{|c|c|c|}
\hline ENTREGA DE ORDEN COMPLETA & CÓDIGO & PÁGINA \\
& IN-LOG-06 & 1 de 1 \\
\hline
\end{tabular}

\begin{tabular}{|c|c|c|}
\hline \multicolumn{3}{|c|}{ Entrega de orden completa } \\
\hline \multicolumn{3}{|c|}{$\begin{array}{l}\text { 2. Objetivo: } \\
\text { Identificar el porcentaje de pérdida de producción durante el transporte al operador } \\
\text { logístico. }\end{array}$} \\
\hline \multicolumn{3}{|c|}{ Entrega de orden completa $=\frac{\text { Cantidad recibida por operador logistico }}{\text { Cantidad despachada }} x 100$} \\
\hline (1) & $\begin{array}{l}\text { Mayor a } 80 \% \\
\text { Entre } 80 \% \text { y } 50 \% \\
\text { Menor a } 50 \%\end{array}$ & 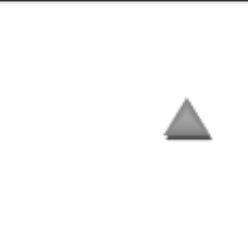 \\
\hline \multicolumn{3}{|c|}{$\begin{array}{l}\text { Un incremento refleja una excesiva pérdida económica para la empresa e indica la } \\
\text { necesidad de revisar el proceso. }\end{array}$} \\
\hline \multicolumn{3}{|c|}{$\begin{array}{l}\text { 5. Responsable de Gestión: } \\
\text { Encargado de distribución de producción }\end{array}$} \\
\hline \multicolumn{3}{|c|}{$\begin{array}{l}\text { 6. Fuente de Información: } \\
\text { Guía de remisión } \\
\text { Verificación de entrega de producción }\end{array}$} \\
\hline \multicolumn{3}{|c|}{$\begin{array}{l}\text { 7. Frecuencia de Medición: } \\
\text { Después de cada reparto }\end{array}$} \\
\hline \multicolumn{3}{|c|}{$\begin{array}{l}\text { 8. Frecuencia de Reporte: } \\
\text { Después de cada campaña }\end{array}$} \\
\hline \multicolumn{3}{|c|}{$\begin{array}{l}\text { 9. Responsable del Reporte: } \\
\text { Encargado de distribución de producción }\end{array}$} \\
\hline \multicolumn{3}{|c|}{$\begin{array}{l}\text { 10. Usuarios: } \\
\text { Distribución de producción, producción y gestión de costos }\end{array}$} \\
\hline \multicolumn{3}{|c|}{ 11. Observaciones: } \\
\hline $\begin{array}{l}\text { GENERADO POR: } \\
\text { Gestión Logística }\end{array}$ & $\begin{array}{l}\text { REVISADO Y APROBADO POR: } \\
\text { Presidente de la Cooperativa }\end{array}$ & $\begin{array}{l}\text { FECHA DE EMISIÓN } \\
22 / 06 / 2017 \\
\end{array}$ \\
\hline
\end{tabular}

Fuente: Elaboración propia

De esta manera, finaliza la propuesta de solución mediante el modelo de gestión presentado, el cual incluye un sistema basado en gestión por procesos y específicamente, un diseño de proceso logístico que permite terminar con las compras independientes, es decir, los desaprovechamientos de las economías de escala, asimismo, contar un almacén acondicionado tanto para la recepción de los insumos como para la entrada de la recolección de la producción, y por último, se realiza un plan de inventarios donde se obtiene la cantidad y cuando se deben realizar las compras. De igual forma, toda la propuesta conjunta de solución se encuentra respaldada mediante el desarrollo de los procedimientos y los formatos que serán utilizados por la cooperativa. 


\section{CAPÍTULO 4. VALIDACIÓN DEL MODELO}

El presente capítulo tiene como principal objetivo realizar la validación de los entregables propuestos en el plan de tesis, así como la validación de la hipótesis general del modelo de Gestión por Procesos y Gestión Logística Integral, las cuales serán analizadas mediante el juicio de expertos y el recuento de cumplimiento de lo ofrecido al inicio del proyecto de investigación.

\subsection{VALIDACIÓN DE LOS ENTREGABLES}

El alcance del presente proyecto de investigación fue propuesto en el plan de trabajo, el cual se plasmó en una lista de entregables para cada uno de los capítulos que se desarrollará a continuación en la Tabla $\mathrm{N}^{\circ} 14$ :

Tabla 15: Cuadro resumen de validación

\begin{tabular}{|c|c|}
\hline Capítulo & Indicador de logro \\
\hline Capítulo 1 & $\begin{array}{l}\text { - Usar } 53 \text { fuentes bibliográficas entre artículos indexados, } \\
\text { páginas web, informes, etc. } \\
\text { - Artículos científicos con una antigüedad no mayor a } 5 \text { años. }\end{array}$ \\
\hline Capítulo 2 & $\begin{array}{l}\text { - Diagnóstico general de la situación actual de las microempresas } \\
\text { de palta Hass en el Perú. } \\
\text { - Diagnóstico específico (proceso de Gestión Logística) }\end{array}$ \\
\hline Capítulo 3 & $\begin{array}{l}\text { - } \text { Mapa de procesos } \\
\text { - } \text { Diagrama de flujos/procedimientos } \\
\text { - } \text { SIPOCS } \\
\text { - Ficha de indicadores } \\
\text { - Anexos }\end{array}$ \\
\hline
\end{tabular}

Fuente: Elaboración propia

\subsubsection{Entregables Capítulo I}

El entregable del Capítulo 1 está dividido en dos aspectos, (1) cantidad de 53 artículos, de los cuales 35 son indexados y (2) fecha de publicación de las fuentes consultadas, así como el factor de impacto y el ISSN, la Tabla No 15 muestra la distribución por tipo de bibliografía. 
Tabla 16. Validación de artículos

\begin{tabular}{|c|c|c|c|c|c|c|}
\hline Numeración & Tema & Paper & Autor & Año & ISSN & $\begin{array}{l}\text { Factor de } \\
\text { impacto }\end{array}$ \\
\hline 1 & & $\begin{array}{c}\text { Effect of Agricultural Research on } \\
\text { Productivity and Rural Poverty: Evidence } \\
\text { from Iran }\end{array}$ & $\begin{array}{l}\text { Esmaeeli y } \\
\text { Sadighi }\end{array}$ & 2017 & 23453737 & 0.44 \\
\hline 2 & $\begin{array}{c}\text { Reducción de la } \\
\text { pobreza - } \\
\text { Crecimiento } \\
\text { económico }\end{array}$ & $\begin{array}{l}\text { Addressing poverty and inequality in the } \\
\text { rural economy from a global perspective. }\end{array}$ & $\begin{array}{l}\text { Rodríguez-Pose } \\
\text { y Hardy }\end{array}$ & 2015 & 1436228 & 1.238 \\
\hline 3 & & $\begin{array}{l}\text { Socio-economic variables and democratic } \\
\text { support in Chile, Peru and Colombia: } \\
\text { Poverty as the key factor. }\end{array}$ & Valdés & 2015 & 0719-0948 & 0.126 \\
\hline 4 & $\begin{array}{l}\text { Crecimiento } \\
\text { económico - } \\
\text { Aumento de PBI }\end{array}$ & $\begin{array}{l}\text { Creative Industries Impact on National } \\
\text { Economy in Regard to Sub-sectors. }\end{array}$ & $\begin{array}{c}\text { Ugne } \\
\text { Daubarainte y } \\
\text { Grazina Startiene }\end{array}$ & 2015 & 18770428 & 0.159 \\
\hline 5 & & $\begin{array}{l}\text { The Impact of Knowledge Generating } \\
\text { Investment on GDP Growth }\end{array}$ & $\begin{array}{l}\text { Bužinskienè y } \\
\text { Rudyté }\end{array}$ & 2014 & 1486195 & 0.436 \\
\hline
\end{tabular}




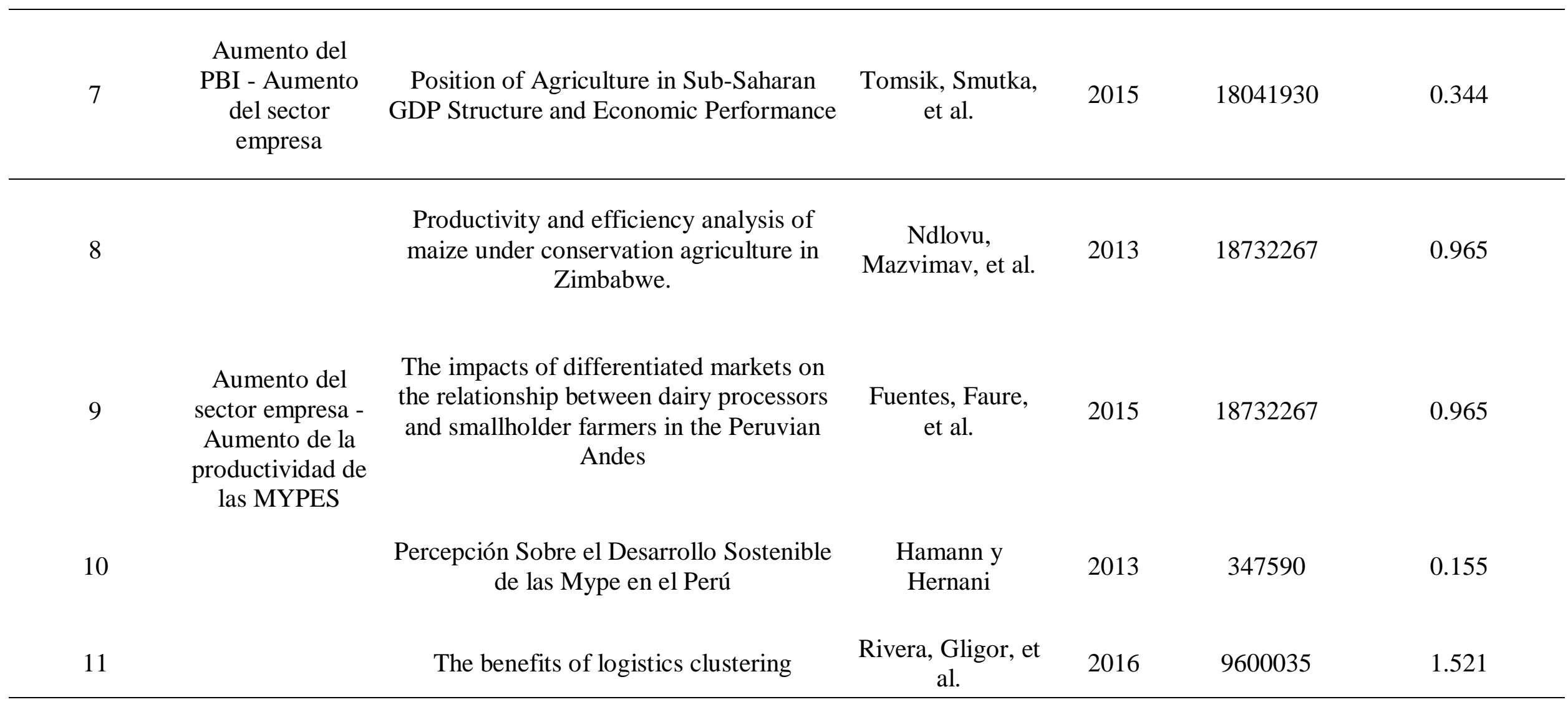


Knowledge Management Process in several organizations:

Alharithy $\quad 2015 \quad 18770509$

0.267

Analytical Study of modeling and several processes

Proof Obligations as A Support Tool for Efficient Process Management in The Field of Production Planning and Scheduling

Aumento de la productividad -

Process management tasks and barriers: functional to processes approach

Da Silva, Damian, et al

14637154

0.573

Process Management 1-2-3 - a maturity model and diagnostics tool

\section{Cronemyr y}

Danielsson

14783363

0.652

16

Business process performance management Sujova, Rajnoha principles used in Slovak enterprises y Merková

2014

18770428

0.159

The importance of logistics and supply

Gestión por

procesos -

Gestión

chain management in the enhancement of

Kherbach y Liviu

2016

18770428

0.159

Logística Romanian SMEs 

performance, lean processes and competitive performance

Prajogo, Oke y

Olhager

Logistics and supply chain process integration as a source of competitive advantage

"Logistics activities in supply chain business process"

Exploring logistics performance management in supplier/retailer dyads

"Strategic purchasing participation, supplier selection,

supplier evaluation and purchasing performance"

Consideration of transport logistics hubs in freight transport demand models
Mellat y Spillan

2013

0957-4093

Penteado y

Chicarelli

0957-4094

1.665

Forslund

09590552

0.472

Nair, Jayaram, et

al.

2015

00207543

1.463

Huber,

Klauenberg y

Thaller 


\section{Liliana Rivera, \\ David Gligor y

Investigating supplier-induced complexity in supply chains

\section{Markus}

Gerschberger, Ila

$2017 \quad 9600035$

1.521

Manuj y Patrick

Freinberger

\section{Martin}

Christopher y

Matthias Holweg

2017

9600035

1.521

28

Retail supply chain service levels: the role

Salam, Panahifar,

2016

17410398

0.575 of inventory storage

et al.
Pratima Mishra y Rajiv Kumar
Sharma 2014 0265671X 0.477

A hybrid framework based on SIPOC and Six Sigma DMAIC for improving process dimensions in supply chain network 
30

31

32

33

34

35
Indicators' role: How do they influence Strategic Environmental Assessment and Sustainable Planning - The Chinese experience

Towards a Framework for Evaluating Usability of Business Process Models with BPMN in Health Sector

Using Group Brainstorming in Industrial Design Context:

Factors Inhibit and Exhibit

Modelo de gestión logística para pequeñas y medianas empresas en México

Qualitative research with families living with autism spectrum disorder:

Recommendations for conducting semistructured interviews

Entrevistas a profundidad

Administering Quantitative Instruments With Qualitative Interviews: A Mixed Research Approach
Jingjing Gao, Per Christensen y Lone Kørnøv

Elvira Rolóna,

$$
\text { Gabriel }
$$

Chaviraa, Jorge

Orozcoa y Juan

Pablo Soto

Amer Shakir

Zainola, Wan

Zaiyana Mohd

Yuso, et al.

$2012 \quad 18770428$

Patricia Cano,

Fernando Orue, José Luis

Martínez y

Yésica Mayett

Elizabeth K.

Cridland, Sandra

C. Jones, Peter Caputi, \&

Christopher A. Magee

Rebecca K. Frels and Anthony $\mathbf{J}$. 2012 
Es así como, se cuenta con 53 artículos en total, de los cuales 35 son indexados y 18 no. Asimismo, se tiene mayor cantidad de publicaciones provenientes del año 2015, tal como se puede evidenciar en la siguiente figura.

Figura 65: Cantidad de artículos según año de publicación

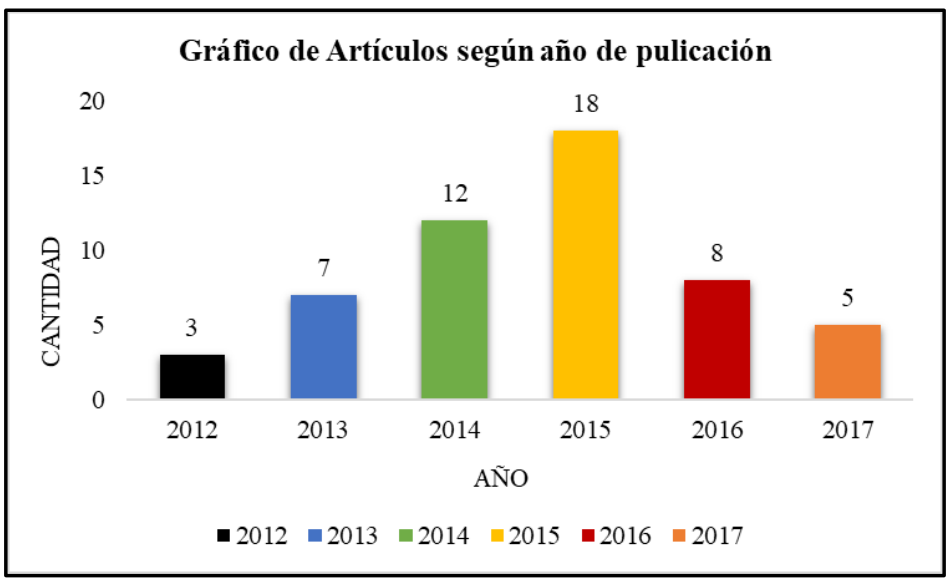

Fuente: Elaboración propia

Figura 66: Cantidad de artículos según tipo

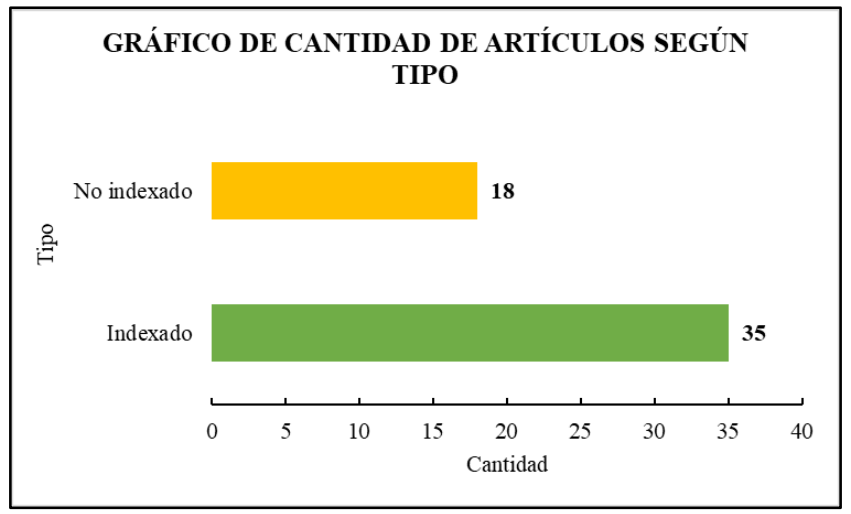

Fuente: Elaboración propia

\subsubsection{Entregables Capítulo II}

El Capítulo 2 tiene como contenido el análisis de la situación actual de las MYPES en el Perú, el comportamiento de la industria agrícola de palta Hass en la actualidad y el resultado de las encuestas a las MYPES del sector a través de las entrevistas semiestructuradas.

Dentro del capítulo para realizar un diagnóstico del sector se utilizó las siguientes fuentes de entidades gubernamentales y no gubernamentales. 
Tabla 17. Validación de fuentes del capítulo 2

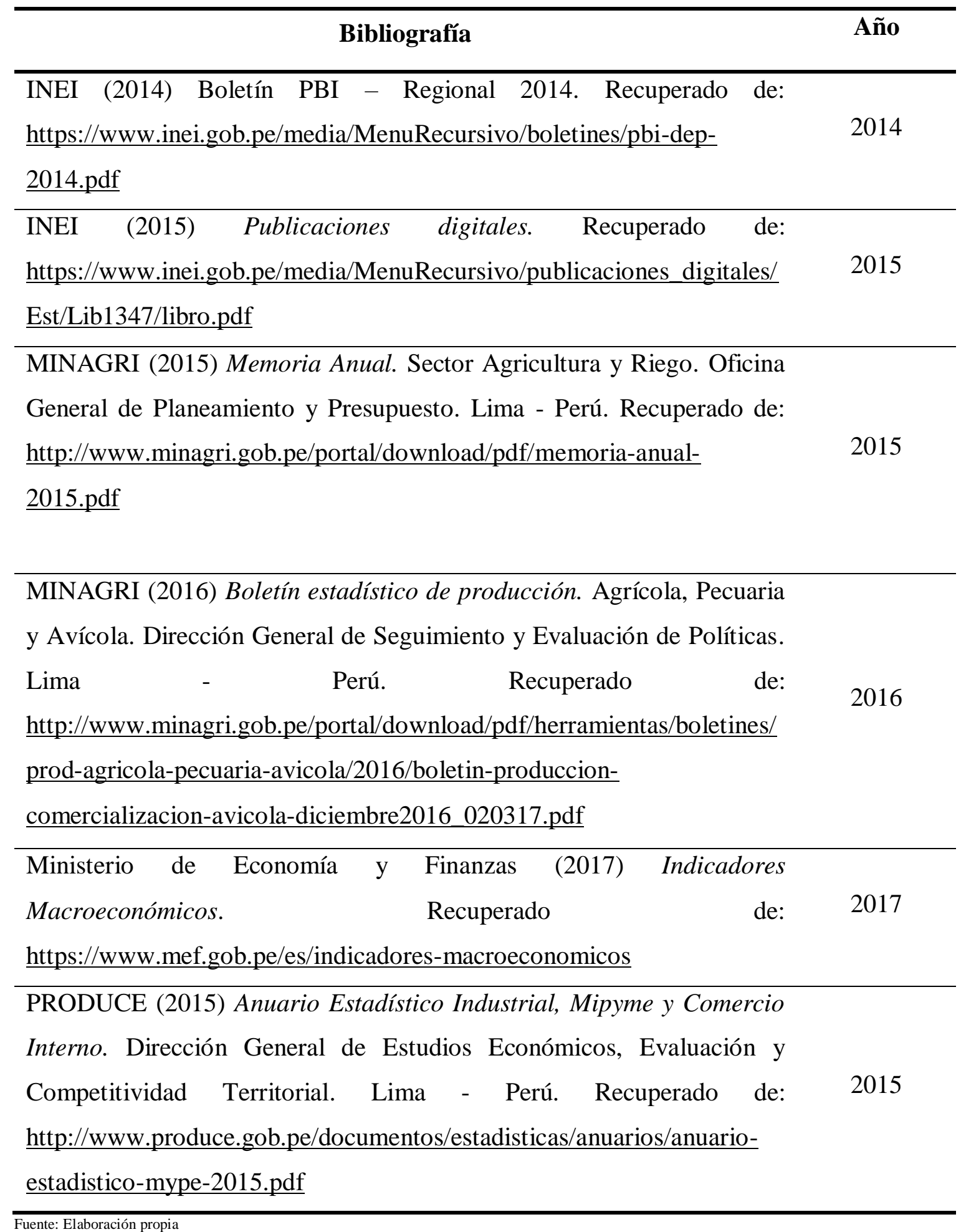

Fuente: Elaboración propia

Asimismo, para la toma de datos se realizó entrevistas semiestructuradas a través de un censo a 13 personas que conforman parte de la cooperativa "AgroInka". Al ser la población menor a 30 personas entonces de optó por realizar un censo. A continuación, la relación de agricultores: 
Tabla 18: Datos de los agricultores

\begin{tabular}{clc}
\hline $\mathbf{N}^{\mathbf{0}}$ & \multicolumn{1}{c}{ NOMBRE } & DNI \\
\hline $\mathbf{1}$ & EUGENIO PABLO CORAHUA MUÑANTE & 9079029 \\
$\mathbf{2}$ & CIRILO ALEJANDRO UCULMANA ESPIRITU & 22278571 \\
$\mathbf{3}$ & JOSE LUIS HUAYRA MELGAR & 22274094 \\
$\mathbf{4}$ & MARCIAL ANTONIO PALOMINO VALDEZ & 2178512 \\
$\mathbf{5}$ & GUILLERMO ANTONIO PORRAS YATACO & 22280692 \\
$\mathbf{6}$ & NORMA ELIZABETH JIMENEZ LOAYZA & 22299375 \\
$\mathbf{7}$ & RAFAEL JOSE NEYRA PUNTRIANO & 22280444 \\
$\mathbf{8}$ & GABINO JULIÁN GERONIMO ALARCÓN & 22278914 \\
$\mathbf{9}$ & WILMER IVÁN ALBERTIS MOREYRA & 43312736 \\
$\mathbf{1 0}$ & GLORIA SIHUAS QUIJAITE & 22252504 \\
$\mathbf{1 1}$ & FRANCISCO JESUS CARTAGENA ESPINO & 21827045 \\
$\mathbf{1 2}$ & ANGEL EDUARDO SOTO HUAMAN & 22278599 \\
$\mathbf{1 3}$ & CARMEN JULIA MEJÍA ESPÍRITU & 22281951 \\
\hline Fuente: Elaboración propia
\end{tabular}

\subsubsection{Entregables Capítulo III}

En el capítulo 3, se presentó una serie de entregables basada en la documentación y formatos de la gestión por procesos. Para el caso de esta tesis los subprocesos fueron delimitados de acuerdo con los conceptos estudiados de Gestión logística, a continuación, en la siguiente tabla se presenta cada uno de estos subprocesos con relación al número de página de sus respectivos entregables dentro del capítulo 3.

Tabla 19: Números de páginas de entregables del modelo

\begin{tabular}{lcccc}
\hline Subproceso & Flujograma & Procedimiento & SIPOC & $\begin{array}{c}\text { Ficha de } \\
\text { indicadores }\end{array}$ \\
\hline Gestión de inventarios & 126 & 127 & 129 & 130 \\
\hline Gestión de compras & 132 & 133 & 135 & 136 \\
\hline $\begin{array}{l}\text { Gestión de almacenamiento de } \\
\text { insumos }\end{array}$ & 138 & 139 & 141 & 142 \\
\hline Repartición de insumos & 143 & 144 & 146 & 147 \\
\hline $\begin{array}{l}\text { Gestión de almacenamiento de la } \\
\text { producción }\end{array}$ & 149 & 150 & 152 & 153 \\
\hline Distribución de la producción & 155 & 156 & 158 & 159 \\
\hline
\end{tabular}


De acuerdo con la cantidad de formatos entregados, estos son:

Tabla 20. Validación de anexos

\begin{tabular}{|c|c|}
\hline Subproceso & Anexos \\
\hline Gestión de inventarios & $\begin{array}{l}\text { - F-LOG-01. Plan de compras } \\
\text { - } \quad \text { F-LOG-02. Registro de existencias }\end{array}$ \\
\hline Gestión de compras & $\begin{array}{ll}\text { - } & \text { F-LOG-01. Plan de compras } \\
\text { - } & \text { F-LOG-04. Lista de proveedores } \\
\text { - } & \text { F-LOG-05. Formato de lista de } \\
& \text { criterios } \\
\text { - } & \text { F-LOG-06. Checklist de criterios } \\
\text { - } & \text { F-LOG-07. Informe de compras } \\
\text { - } & \text { F-LOG-08. Cronograma de entregas }\end{array}$ \\
\hline Gestión de almacenamiento de insumos & $\begin{array}{l}\text { - F-LOG-09. Hoja de devolución. } \\
\text { - } \\
\text { F-LOG-10. Formato de registro de } \\
\text { entradas de insumos } \\
\text { - } \\
\text { F-LOG-11. Reporte de ubicación de } \\
\text { insumos } \\
\text { - } \\
\text { F-LOG-12. Formato de registro de } \\
\text { salidas de insumos } \\
\text { - F-LOG-13. Formato de registro de } \\
\text { control de inventarios }\end{array}$ \\
\hline Repartición de insumos & $\begin{array}{l}\text { - F-LOG-14. Plan de recorrido } \\
\text { - F-LOG-15. Verificación de entrega } \\
\text { de insumos }\end{array}$ \\
\hline
\end{tabular}

Fuente: Elaboración propia

Tabla 21: Validación de anexos

- F-LOG-16. Plan de distribución de producto

- F-LOG-17. Formato de registro de entradas de producción

Gestión de almacenamiento de la - F-LOG-18. Formato de registro de producción salidas de producción

- F-LOG-19. Formato de base de datos de producción

- F-LOG-20. Formato de guía de remisión

- F-LOG-21. Formato de registro de recolección

Distribución de la producción

- F-LOG-22. Formato de verificación de entrega de pedido 


\subsection{VALIDACIÓN DE LA HIPÓTESIS ESPECÍFICA}

La validación del modelo de Gestión Logística Integral estará basada en la metodología del juicio de expertos, los cuales evaluarán el tema de investigación tanto académica como empresarialmente, de modo que con su experiencia y conocimientos puedan validar lo planteado en este proyecto de investigación. Asimismo, los agricultores también forman parte de la validación, la retroalimentación brindada por el agricultor servirá para mejorar a detalle el proceso y buscar que sea adaptable para ellos sin darles ningún tipo de complicación mayor. En base al resultado de los expertos y a los usuarios se realizarán las mejoras respectivas al modelo.

\subsubsection{Presentación de expertos}

De acuerdo con lo mencionado anteriormente, se ha solicitado la ayuda de 5 expertos en el tema de Gestión por Procesos y Gestión Logística Integral tanto en el ámbito académico y empresarial, a continuación, se dará una breve reseña de ellos.

Figura 67 1era experta: HELENA FORSLUND

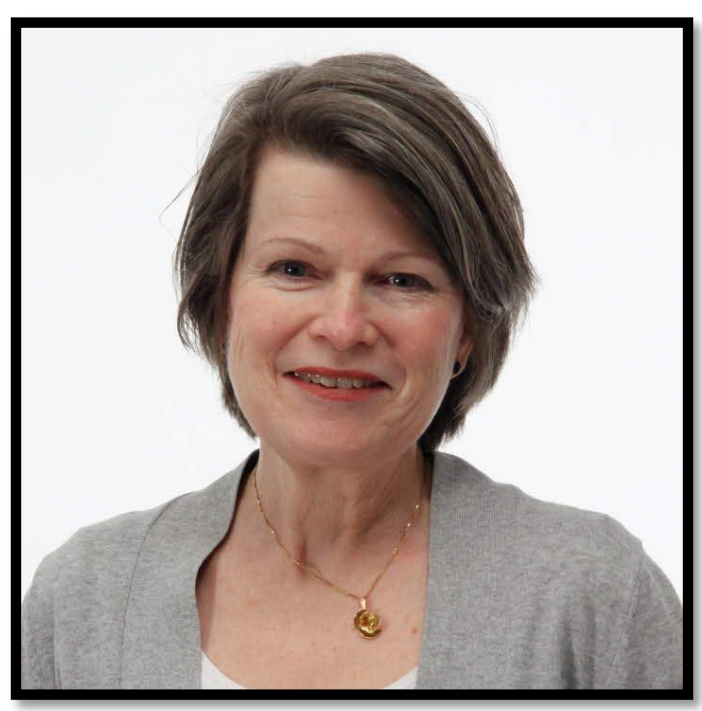

\section{Experiencia laboral}

Tiene una larga experiencia como profesora de logística y gestión de la cadena de suministro en un nivel especialmente avanzado. Es directora del programa de maestría en Procesos de Negocios y Gestión de la Cadena de Suministro. La investigación de Helena Forslund se centra en la gestión del rendimiento y la gestión de la cadena de suministro, utilizando métodos cuantitativos y cualitativos. La investigación ha dado como resultado unas 60 publicaciones científicas, de las cuales 20 se publican en revistas importantes de operaciones, logística y 
gestión de la cadena de suministro (por ejemplo, Revista Internacional de Gestión de Operaciones y Producción, Revista Internacional de Distribución Física y Gestión Logística). Es editora Asociada Senior de la Revista Internacional de Distribución Física y Gestión Logística. Helena es líder de investigación del grupo de investigación en Estudios de la Cadena de Suministro y es la supervisora de cuatro estudiantes de doctorado. Actualmente está trabajando en el proyecto de investigación financiado por Vinnova "RSE relacionada con el transporte para la rentabilidad y la innovación" y ha sido líder de proyectos de investigación en Vinnova.

\section{Publicaciones}

- Björklund, M., Forslund, H., Persdotter Isaksson, M. (2016). Explorar la sostenibilidad ambiental relacionada con la logística en los grandes minoristas. Revista Internacional de Gestión de Distribución y Distribución. 44. 38-57.

- Forslund, H. (2015). Integración de procesos de gestión de rendimiento en cadenas de suministro al por menor. Revista Internacional de Gestión de Distribución y Distribución. 43. 652-670.

- Ülgen, V., Forslund, H. (2015). Gestión del rendimiento logístico en cadenas de suministro de textiles: mejores prácticas y barreras. Revista Internacional de Productividad y Gestión del Desempeño. 64. 52-75.

- Forslund, H. (2014). Exploración de la gestión del rendimiento logístico en diadas proveedoras/minoristas. Revista Internacional de Gestión de Distribución y Distribución. 42. 205-218.

- Forslund, H., Jonsson, P. (2007). El impacto de la calidad de la información pronosticada en el desempeño de la cadena de suministro. Revista Internacional de Operaciones y Gestión de la Producción. 27. 90-107.

- Forslund, H. (2006). Intervalos de desempeño en el proceso de cumplimiento de órdenes diádicas. Revista Internacional de Distribución Física y Gestión Logística. 36. 580-595.

\section{Conferencias}

- Björklund, M., Forslund, H. (2016). Ilustrando y clasificando la innovación logística sostenible. Conferencia LRN 2016: actas.

- Andersson, P., Forslund, H. (2016). Medición del rendimiento de la innovación de la logística sostenible. Actas de la $10^{\mathrm{a}}$ Conferencia de la Performance Measurement Association, Edimburgo, Escocia, 26-29 de junio de 2016. 
- Björklund, M., Forslund, H. (2016). El proceso de innovación logística sostenible: un estudio exploratorio. NOFOMA 2016 - Actas de la 28a Conferencia Anual de la Red de Investigación de Logística Nórdica. 35-51.

- Forslund, H., Hofmann, S., Jonsson, P. (2006). Desafíos de la gestión del rendimiento de la logística en las relaciones diádicas. Actas de la $18^{\text {a }}$ Conferencia Internacional NOFOMA.

Tesis doctoral, monografía (Otros estudios)

- Forslund, H. (2004). La existencia de deficiencias logísticas de calidad y el impacto de la calidad de la información en el proceso de cumplimiento de los mandatos diádicos. Tesis doctoral. Linköping, Prensa Electrónica de la Universidad de Linköping. 187.

Figura 68 2do experto: JAN OLHAGER

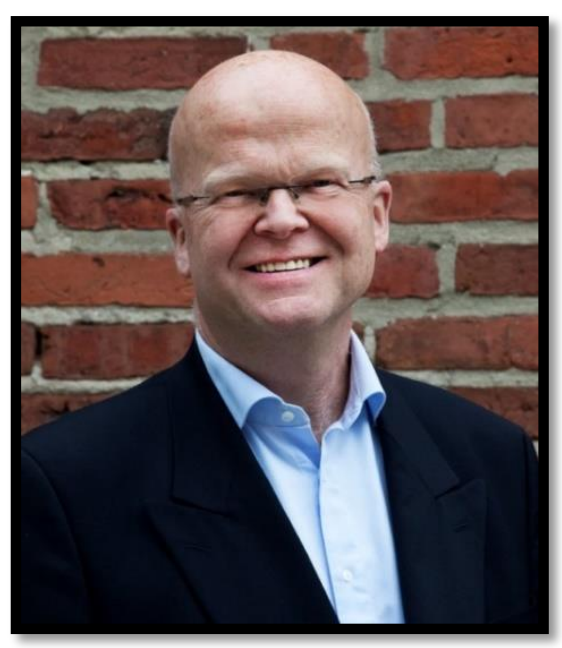

\section{Formación académica}

Se formó en la Universidad de California, Berkeley en 1980 siendo licenciado en Ingeniería Industrial e Investigación Operativa y también estudiando la Maestría en Ingeniería en la misma universidad de los Estados Unidos. Olhager obtuvo su doctorado en 1989 en la Universidad de Linköping con una tesis en la economía de la producción.

\section{Experiencia laboral}

Ha trabajado como profesor en Producción y Gestión de Operaciones en la Universidad de Linköping en el Departamento de Gestión e Ingeniería (IEI) - Economía de la Producción. Se ha desempeñado en la Gestión de la cadena de suministro de la universidad de Monash en el Departamento de Gestión · Gestión de la Cadena de Suministro en Australia · Melbourne. Fue jefe de operaciones en acelerador en la universidad de Lund, además en esta misma universidad fue profesor de en Pediatría combinado con un puesto como especialista/consultor y Profesor 
Asociado Senior Universitario - Modelación Ecológico-Económica. En la actualidad es un profesor sueco de logística técnica con un enfoque en la logística de producción estratégicos en la Universidad de Lund.

\section{Publicaciones}

- Artículo: El impacto de las operaciones globales en la arquitectura de productos: un estudio exploratorio. Ago 2017 • Revista Internacional de Operaciones y Gestión de la Producción. Autor (s): Sebastian Pashaei y Jan Olhager.

- Artículo: Intercambio de información a través de múltiples niveles de la cadena de suministro: estudio Delphi sobre antecedentes. Jun 2017 • Revista Internacional de Economía de la Producción. Autor (s): Joakim Kembro, Dag Näslund y Jan Olhager.

- Artículo: Backshoring de la fabricación: Una revisión sistemática de la literatura. Mayo 2016 · Investigación en Gestión de Operaciones. Autor (s): Jan Stentoft y Jan Olhager

- Artículo: Procesos de la cadena de suministro: Vincular la integración de la logística de suministro, el rendimiento de la oferta, los procesos leves y el rendimiento competitivo. Feb 2016 - Revista Internacional de Operaciones y Gestión de la Producción. Autor (s): Daniel Prajogo, Adegoke Oke y Jan Olhager.

- Artículo: Un Modelo Cumulativo de Evolución de Roles de Planta: Competencias de Producción, Cadena de Suministro y Desarrollo. Enero 2014. Autor (s): Andreas Feldmann y Jan Olhager.

Figura 69 3er experto: ARNOLD MALTZ

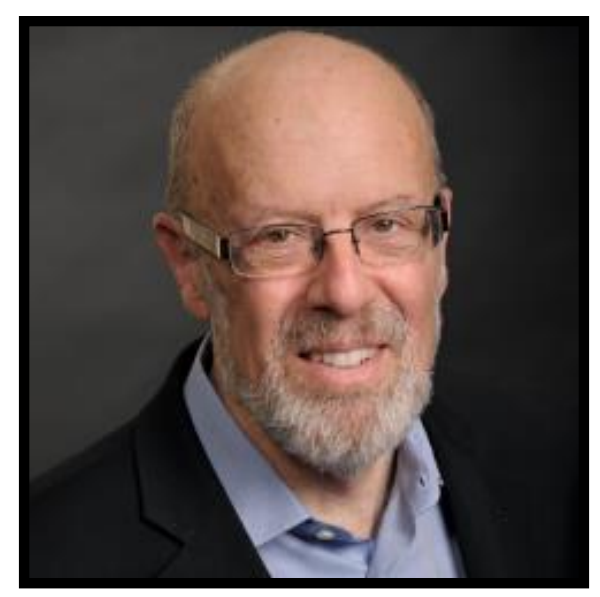

\section{Formación académica}

Ph.D., de la Universidad de Ohio State, 1992; MS, Northwestern University, 1977; MA, Universidad de California - Santa Bárbara, 1971; BS, Universidad de la Trinidad, 1969. Desarrollo de cursos consultores recientes, Accenture, 2009; Servicios de asesoramiento, 
Unified Grocers, 2007; Southwest Gateway: Logística en el Boarder de Arizona / México, Autoridad Portuaria de Yuma, 2007; Servicios de asesoramiento, marcas innovadoras, 2007. Experiencia laboral

Arizona State University: 1997-presente. Citas previas: Universidad Estatal de Nuevo México, Universidad del Estado de Ohio.

\section{Publicaciones}

- Maltz, Arnold. "Fronteras: Implicaciones para la Gestión de la Cadena de Suministro", que se presentará a Journal of Business Logistics.

- Oke, Adegoke, Maltz, Arnold, Christiansen, Poul Erik "El rostro cambiante de abastecimiento global: ¿A dónde vamos desde aquí," Outsourcing Estratégico

- Maltz, Arnold, "Países emergentes encajan dentro de las cadenas mundiales de suministro", que se presentará a Diario de Logística empresarial.

- Carranza, Octavio, y Arnold Maltz, "Entendiendo las consecuencias financieras del efecto Bullwhip en una cadena de suministro de múltiples niveles", Journal of Business Logistics, próximamente.

- Carter, Joseph, Arnold Maltz, Tingting Yan y Elliot Maltz, "Percepción de los gerentes de compras de países y geografías de bajo costo: un enfoque de mapeo perceptual", Revista Internacional de Distribución Física y Gestión Logística, 2009.

- Rabinovich, Elliot, Arnold Maltz, y Rajiv Sinha, "Marcas de Evaluación, Calidad de Servicio y cualidades de producto en el sector minorista de Internet CD de música," Producción y Dirección de Operaciones, 2008.

- Ashenbaum, Bryan, Arnold Maltz, y Elliot Rabinovich, "Estudios de Tendencias en el uso de la logística de terceros: ¿Qué podemos concluir ?, " Journal Transportation, vol. 44, º3, verano 2005, páginas 39-51.

\section{Carrera y Premios Profesionales Recientes}

- Premio de Práctica de la Sociedad de Análisis de Decisión con Craig Kirkwood y Matthew Slaven, 2004; Anbar Citación de Excelencia para Servicio al Cliente en el Canal Distribuidor: Hallazgos empíricos; E. Grosvenor Ploughman Premio a la Mejor Conferencia de Educadores de Papel, Transporte y Logística, 1994.

- Director de Liderazgo Profesional, Consorcio Anual de Estudiantes de Doctorado, Consejo de Gestión Logística, Filadelfia, 2004; Revisora: Journal of Operations Management , 2006; 
Journal of Buisness Logistics , 2003, 2004, 2006; Revista Internacional de Distribución Física y Gestión Logística, 2004.

- Gerente de Liderazgo Corporativo y de Sector Público de Finanzas y Servicios de Distribución, Ross Laboratories, 1982-1988; Vicepresidente Adjunto, Sistemas y Planificación, Commercial Lovelace Motor Freight, 1979-1982; Analista de Operaciones, Preston Trucking Company, 1979.

Figura 70 4ta experta: GÜLGÜN ALPAN

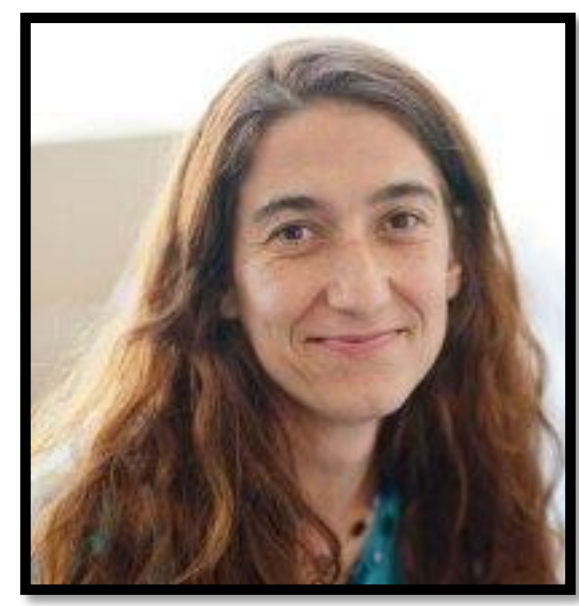

\section{Formación académica}

Se formó en la Universidad Técnica de Oriente Medio siendo Licenciada en Ciencias (BS) y en Ingeniería Industrial entre 1987 - 1991. Además, en la universidad de Rutgers, la Universidad Estatal de Nueva Jersey-New Brunswick hizo su Maestría en Ciencias (MS), Ingeniería Industrial entre 1991 - 1994. En la misma universidad de Rutgers, la Universidad Estatal de Nueva Jersey-New Brunswick se convirtió en Doctor en Filosofía (PhD), Ingeniería Industrial entre 1994 - 1997. A ello le suma su estancia educativa en el Instituto de Tecnología de Grenoble.

\section{Experiencia laboral}

Una de sus primeras experiencias laborales fue en la Escuela de Minas Nancy situado en la Región Nancy (Francia) fue asistente del profesor entre 1998-2001. Seguidamente fue investigador visitante en el Instituto Nacional de Investigación en Informática y Automática (INRIA) también en Francia entre 2001-2003. En el Instituto de Tecnología de Grenoble tuvo dos cargos el primero entre 2012-2016 donde fue Oficial del Programa de Investigación, "Industria: la globalización y la innovación". Luego su segundo cargo fue la de Profesor Asociado (Profesor, HDR), ejerció la Investigación y Docencia en Ingeniería Industrial en 2003. También fue director Adjunto en G-SCOPE el cual es un laboratorio multidisciplinar 
para afrontar los retos científicos planteados por los cambios en la actual y futura del mundo industrial entre 2014.

\section{Publicaciones}

- Empleado semanal de horarios conjunta y diariamente rostering una decisión herramienta de soporte para una plataforma logística. European Journal of Operational Research, vol. 234, No 1, pp. 278-291 de Abril de 2014. Autor (s): Anne-Laure Ladier, Gülgün Alpan, Bernard Penz

- La conciliación de la gestión de ventas y operaciones con dos como proveedores de la industria automotriz: Un enfoque de simulación. Revista Internacional de Economía de la Producción de vuelo. 151, pp. 20-36 del 2014. Autor (s): Lawrence L. Lim Gülgün Alpan, Bernard Penz

- Reducir al mínimo los retrasos en la secuenciación de los vehículos en una línea de montaje multi-modelo. Revista Europea de sistemas automatizados, no. 47 (4-8 / 2013), pp.635-656 del 2014. Autor (s): Karim Aroui, Gülgün Alpan, Yannick Frein

- Un estudio comparativo es arranque de la producción: el estado de la técnica y los nuevos desafíos Planificación y Control de Producción en 2014. Autor (s): Laurene SurbierPrevost, Gülgün Alpan, Eric Blanco.

Figura 71 ta experta: SUSAN GOLICIC

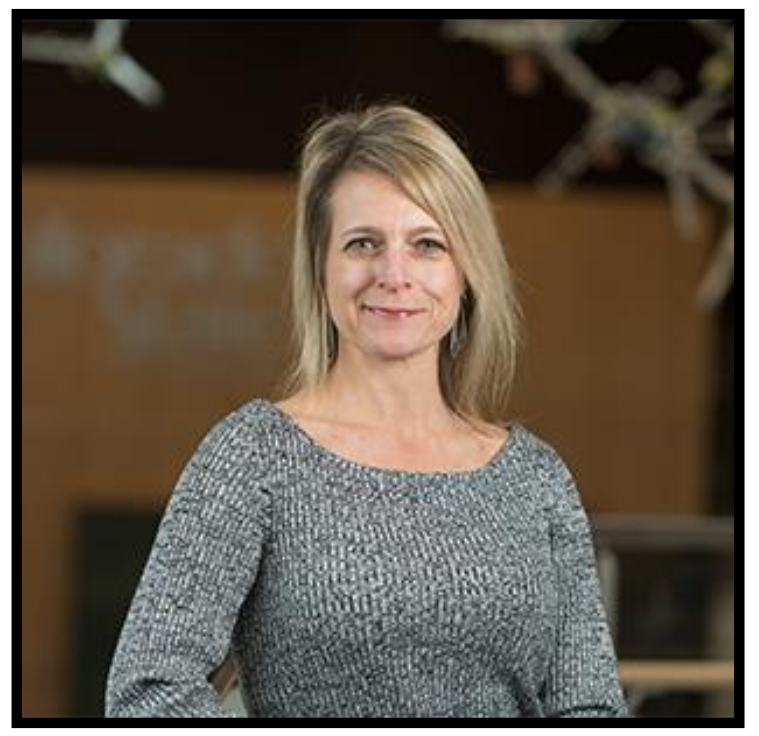

\section{Formación académica}

Se formó en la Universidad del Estado de Wayne en 1989 como Licenciado en Ciencias, especialidad en Ingeniería Química. Además, Doctor en Filosofía en Administración de Empresas, Especialista en Logística y Marketing minorista en la Universidad de Tennessee, 2003. Magister en administración de negocios con el tema concentraciones en la gestión 
logística y operaciones en la Universidad de Tennessee, 1997. Cursos de Posgrado, Ingeniería Ambiental en el Instituto politécnico de Rensselaer, 1991-1992.

\section{Experiencia laboral}

Profesora en la Universidad Estatal de Colorado en julio del 2017 hasta la actualidad.

Seleccionó y coordinó los vinos para las ubicaciones de venta al por menor y las bodegas privadas; proporcionó experiencias de educación / degustación de vinos para entusiastas del vino en la Universidad Estatal de Colorado. Profesor Asociado en la Universidad Estatal de Colorado. Profesor asistente en la Universidad de Oregón. Analista de Logística en la corporación Chrysler. Ingeniera Radiológico/Ambiental en Grupo ecológico científico, Inc., sept. de 1992 - hasta 1995.

\section{Publicaciones}

- Signori, Paola, Daniel J. Flint y Susan L. Golicic, "Hacia la orientación sostenible de la cadena de suministro: mapeo de perspectivas gerenciales", Revista Internacional de Distribución Física y Gestión Logística, 45 (6) 2015: 536-564.

- Ellram, Lisa M. y Susan L. Golicic, "Adoptando las prácticas de transporte ambiental", Transportation Journal, 54 (1) 2015: 55-88.

- Autry, Chad W., Brent D. Williams y Susan L. Golicic, "Multiplexión relacional y de procesos en tríadas verticales de la cadena de suministro: una exploración en la industria de restaurantes de EE. UU.", Journal of Business Logistics, 35 (1) 2014: 52-70 .

- Davis, Donna F., Susan L. Golicic, Courtney Boerstler, Sunny Choi y Hanmo Oh, ¿Sufre el marketing la miopía de los métodos?" Journal of Business Research, 66 2013: 1245-1250.

- Golicic, Susan L. y Donna F. Davis, "Implementación de métodos mixtos de investigación en logística y gestión de la cadena de suministro", Revista Internacional de Distribución Física y Gestión Logística, 42 (8/9) 2012: 726-741.

- Fugate, Brian S., Rodney W. Thomas II y Susan L. Golicic, "Comprender el impacto de lidiar con la presión del tiempo en las relaciones colaborativas comprador-proveedor", Revista Internacional de Distribución Física y Gestión Logística, 42 (7) 2012: 697-725.

- Golicic, Susan L., Donna F. Davis y Brian S. Fugate, "Examinando la información de mercado y la equidad de marca a través de la teoría de ventaja de recursos: una perspectiva de gerente de operador", Journal of Business Logistics, 33 (1) 2012: 20-33.

- Golicic, Susan L. y John T. Mentzer, "Relaciones de transporte en la cadena de suministro: cuestionamiento de las teorías y métodos existentes", Transportation Journal, 50 (4) 2011: 315-345. 


\subsubsection{Matriz de validación}

La matriz utilizada evalúa 6 dimensiones que el modelo debería de cumplir mínimamente. Estas son las siguientes:

1. Claridad: El modelo de gestión propuesto está formulado con un lenguaje apropiado y comprensible para que los agricultores puedan desarrollar las actividades planteadas de fácil manera sin tener mayores complicaciones.

2. Consistencia: El modelo de gestión propuesto cuenta con los elementos necesarios ya sea los flujogramas, caracterizaciones, fichas y formatos para asegurar el aumento de la productividad.

3. Factibilidad: El modelo de gestión propuesto es aplicable para las MYPES del sector.

4. Pertinencia: El modelo de gestión propuesto contribuirá a elevar la productividad de las MYPES.

5. Estructura: El modelo de gestión propuesto presenta una secuencia lógica y ordenada.

6. Medición: El modelo de gestión propuesto incluye indicadores para medir y controlar el desempeño del proceso.

A partir de estas dimensiones, el experto tiene que evaluar del 1 al 5, donde uno significa en totalmente en desacuerdo y 5 significa en totalmente de acuerdo. A continuación, se muestra la matriz de validación. 
Figura 72. Matriz de Validación

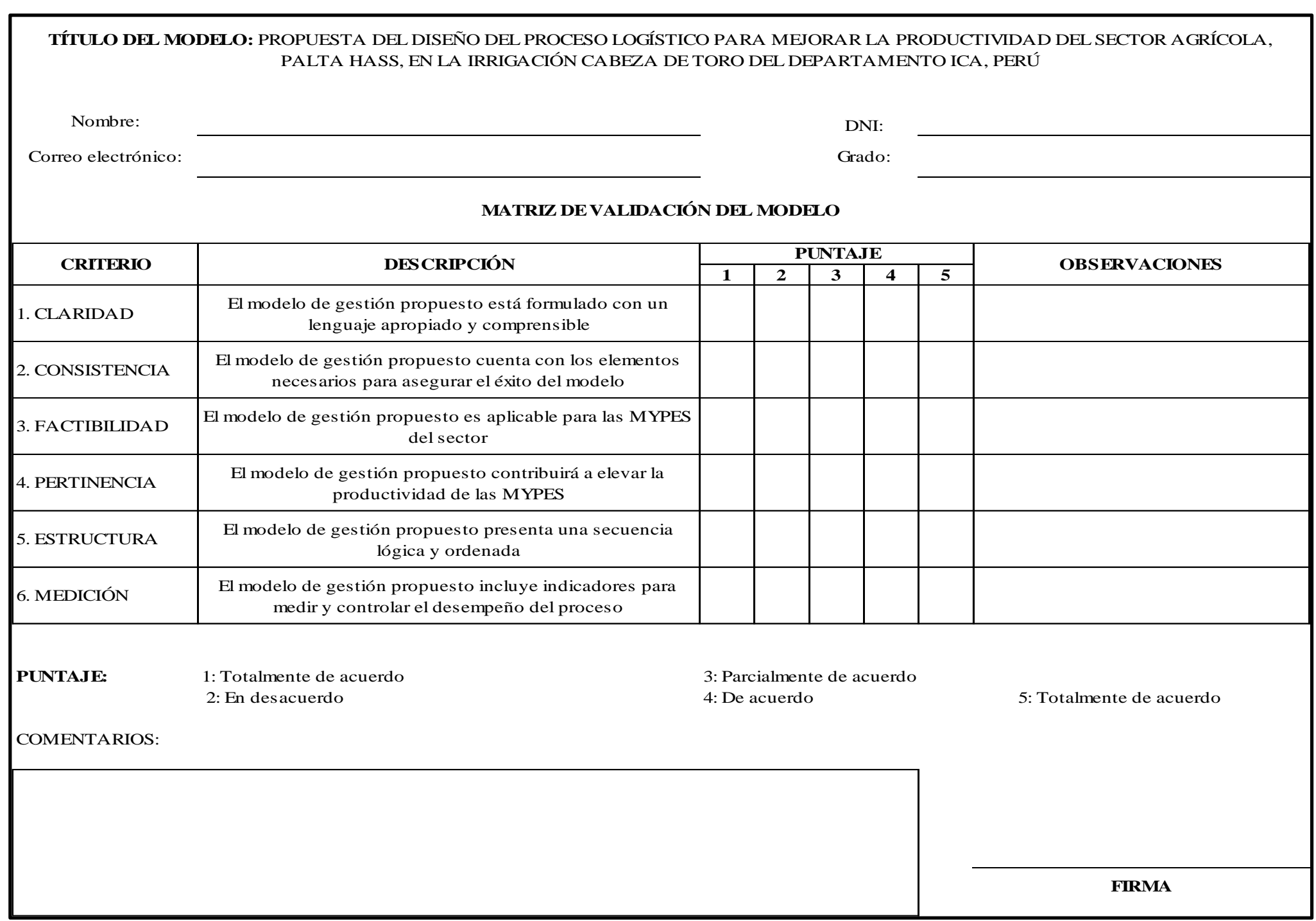

Fuente: Elaboración propia 


\subsubsection{Matriz de impactos}

Se ha considerado tres categorías de análisis. Estos han sido considerados como relevantes, ya que forman parte del desarrollo sostenible de una empresa. Para que una organización pueda desarrollarse y crecer en forma equilibrada se necesita que los parámetros económicos, sociales, así como medioambientales sean tomados en cuenta para la toma de decisiones a nivel estratégico.

\subsubsection{Impactos sociales}

\section{Generación de empleo}

Al aumentar la productividad en rendimiento de la cooperativa, se requerirá de personal para poder cumplir con los futuros pedidos; por ende, mayor contratación de personal.

\section{Disminución de informalidad de las MYPES}

Tener un sistema de gestión por procesos permite estandarizar los procesos, lo cual obliga a los integrantes de la cooperativa a mantener un equilibrio en sus procesos, al mantener este equilibrio, las empresas para realizar acciones contables o legales deben tener todo bajo regla, es así como disminuye la informalidad.

\section{Mejora de condiciones laborales}

Analizar el impacto que posee el modelo de gestión planteado en el clima laboral, el cual influye de sobremanera en la productividad de los trabajadores y por consiguiente de la empresa, generando así mayores ingresos, crecimiento y rentabilidad a largo plazo.

\section{Mejora de calidad de vida de los agricultores}

Al estandarizar los procesos y obtener mayores ingresos, el agricultor busca su bienestar económico con una mejora de la calidad de vida, entonces, al tener un mayor margen de ganancia puede adquirir la calidad de vida que desea.

\subsubsection{Impactos económicos}

\section{Aumento de beneficios económicos}

Medir el impacto de los beneficios económicos que se obtendrán con el modelo de gestión, esto permitirá obtener un mayor margen de ganancia y mayor producción.

\section{Aumento de la productividad}

Con este impacto se puede determinar el éxito o el fracaso de la cooperativa. Con el modelo planteado, se obtendrá una mejora en la productividad.

\section{Mejora la eficiencia y rendimiento de los recursos}


Al tener procesos estandarizados, se busca utilizar la cantidad exacta de recursos mediante el proceso de control y planificación de la producción, asimismo, realizar el proceso productivo de manera óptima y en el tiempo planificado.

\section{Contribuye al crecimiento del PBI}

La importancia del PBI se evidencia en el crecimiento económico de la organización a través de su desarrollo.

\subsubsection{Impactos ambientales}

\section{Fomenta las buenas prácticas agrícolas}

Medir el impacto de las BPA sobre la organización en todos sus campos, por lo cual, se requiere del compromiso de la cooperativa para seguir paso a paso las buenas prácticas.

\section{Aumento de control ante plagas}

Se busca reducir el máximo número de plagas por campaña que ocurran durante el tiempo de siembra y cosecha.

\section{Promueve el uso equilibrado de recursos}

A través de proceso de PCP se planificarán las cantidades a utilizar en todas las etapas de producción hasta la post cosecha. 
Figura 73. Matriz de impactos

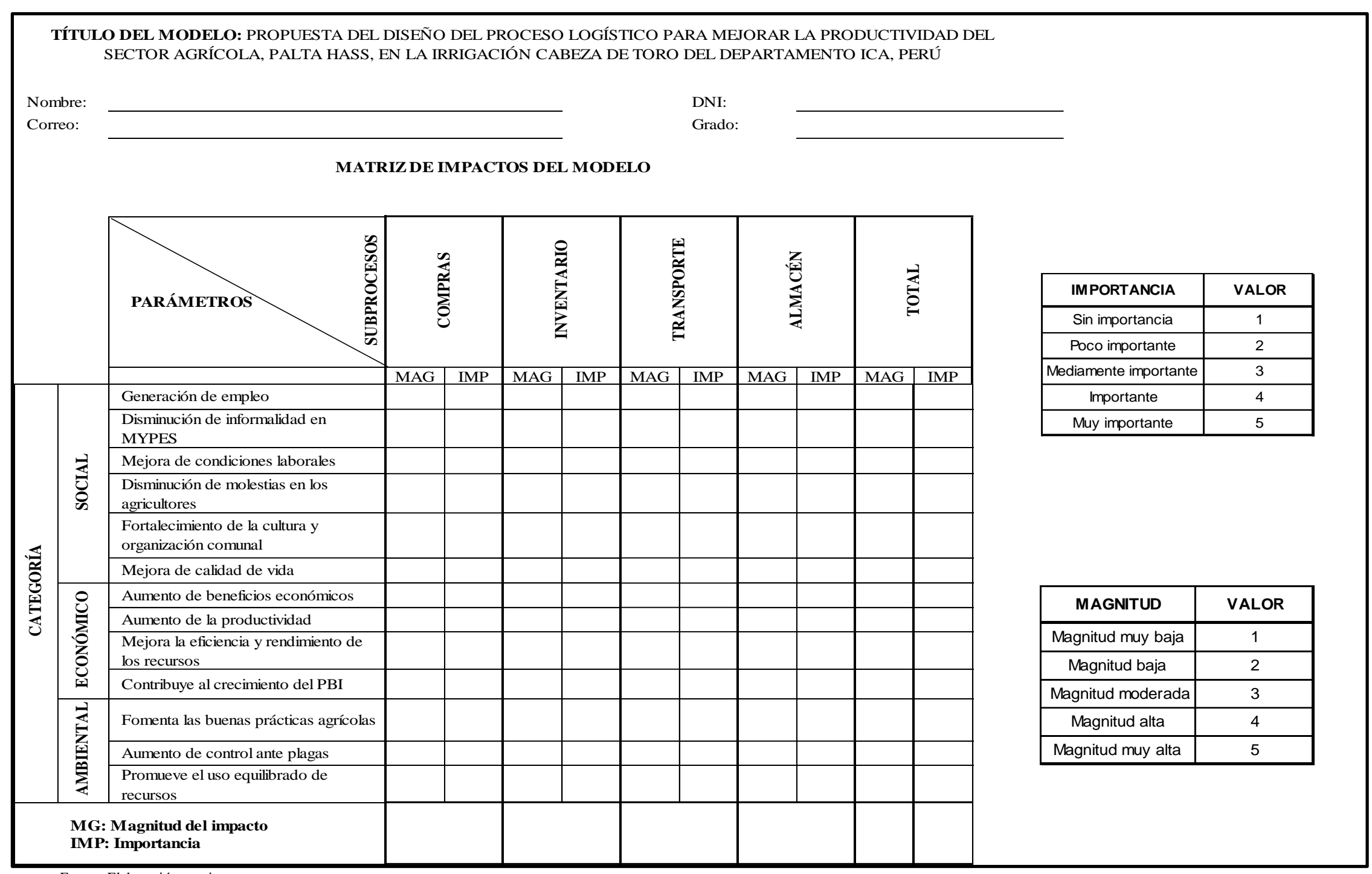

Fuente: Elaboración propia 


\subsubsection{Resultado de expertos}

Para el caso de la matriz de validación del modelo propuesto el rango de los valores se ubica en forma ascendente, es decir, 1 significa que el validador se encuentra en completo desacuerdo mientras que el número 5 quiere decir que se encuentra completamente de acuerdo.

Por otro lado, en la matriz de impactos se analizará dos categorías de evaluación, la primera indica la importancia que ocasionará el modelo en cada parámetro, el cual puede ser sin importancia, poco importante, mediamente importante, importante o muy importante; esto quiere decir que según algunos parámetros el modelo de gestión puede tener un efecto de disminución de la generación de empleo si se implementa en la cooperativa, puede aumentar la calidad de vida de los trabajadores o simplemente no afecta a ninguna de las dimensiones planteadas. Como segunda categoría se tiene a la magnitud del impacto, el cual está expresado cualitativamente entre muy bajo y muy alto, en donde se evidencia la repercusión que podría tener el parámetro en el subproceso.

Según la $1^{\text {era }}$ experta, Helena Forslund, estos fueron los resultados brindados:

Figura 74. Resultados de la matriz de validación del $1^{\mathrm{er}}$ experto

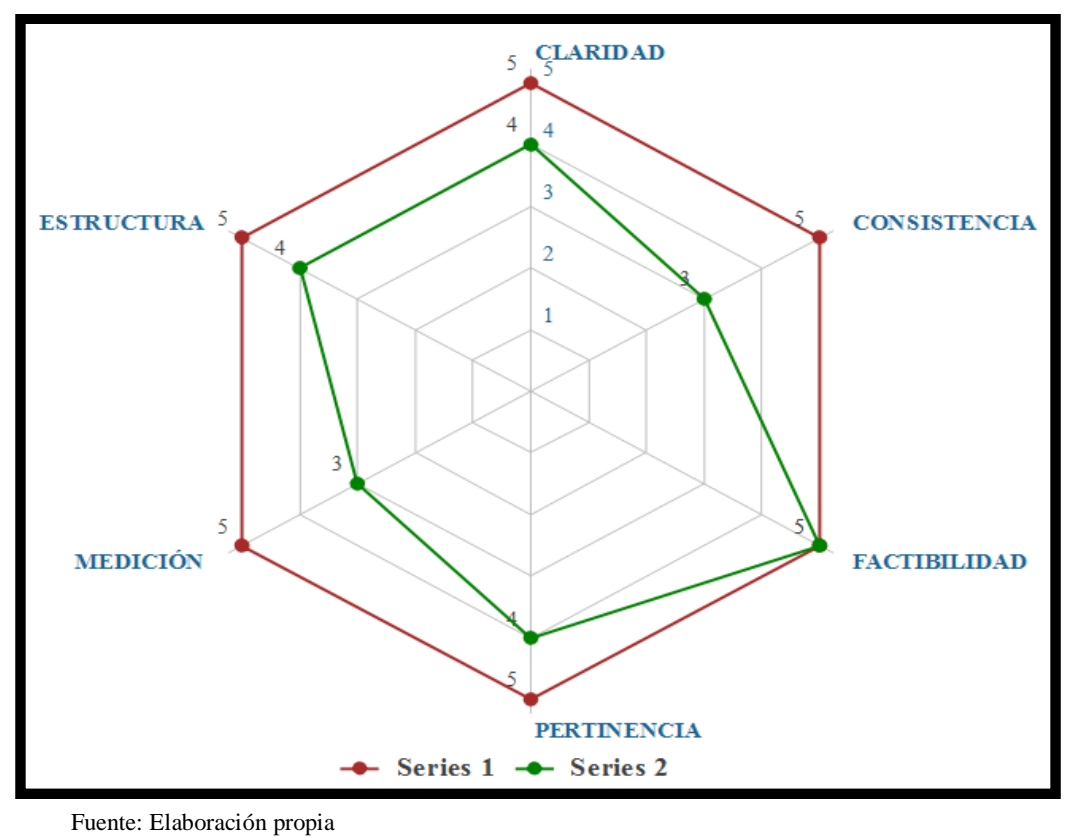

Se obtuvo una puntuación de 23 puntos de 30, debido a que algunas observaciones por la profesora fueron de que encuentra el parámetro de claridad del modelo en un nivel ideal para ser entendido por los granjeros. Asimismo, señala que existen detalles que faltan ser completados para ser implementados, según la evaluación, el modelo es preciso para los agricultores en el lugar mencionado y, por último, señala que los indicadores deberían encontrarse dentro de un rango más posible. 
Asimismo, el proceso de mayor importancia y con mayor magnitud es el de inventarios, donde asegura la disponibilidad de los insumos ya sea para empezar la producción o la cosecha. Contar con registros y base de datos permite controlar los procesos.

Figura 75: Resultado de la matriz de impactos del $1^{\text {er }}$ experto

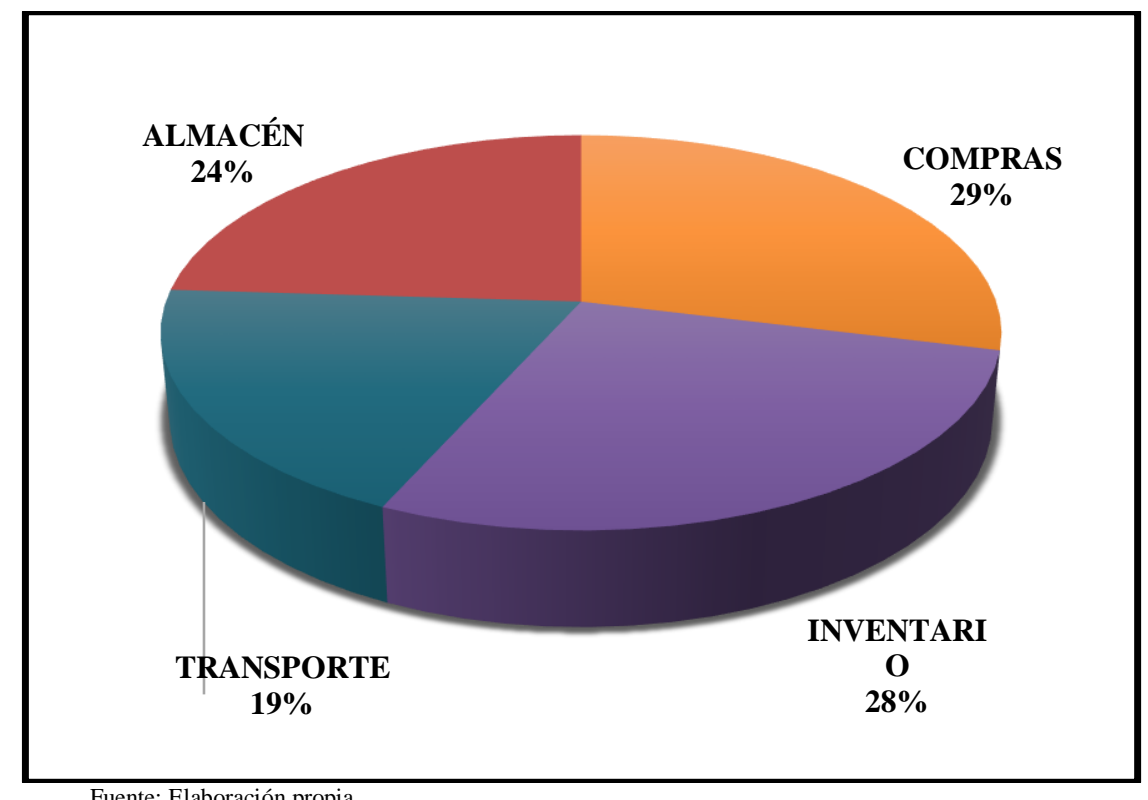

Fuente: Elaboración propia

Según el $2^{\text {do }}$ experto, Jan Olhager estos fueron los resultados brindados:

Figura 76. Resultados de la matriz de validación del $2^{\text {do }}$ experto

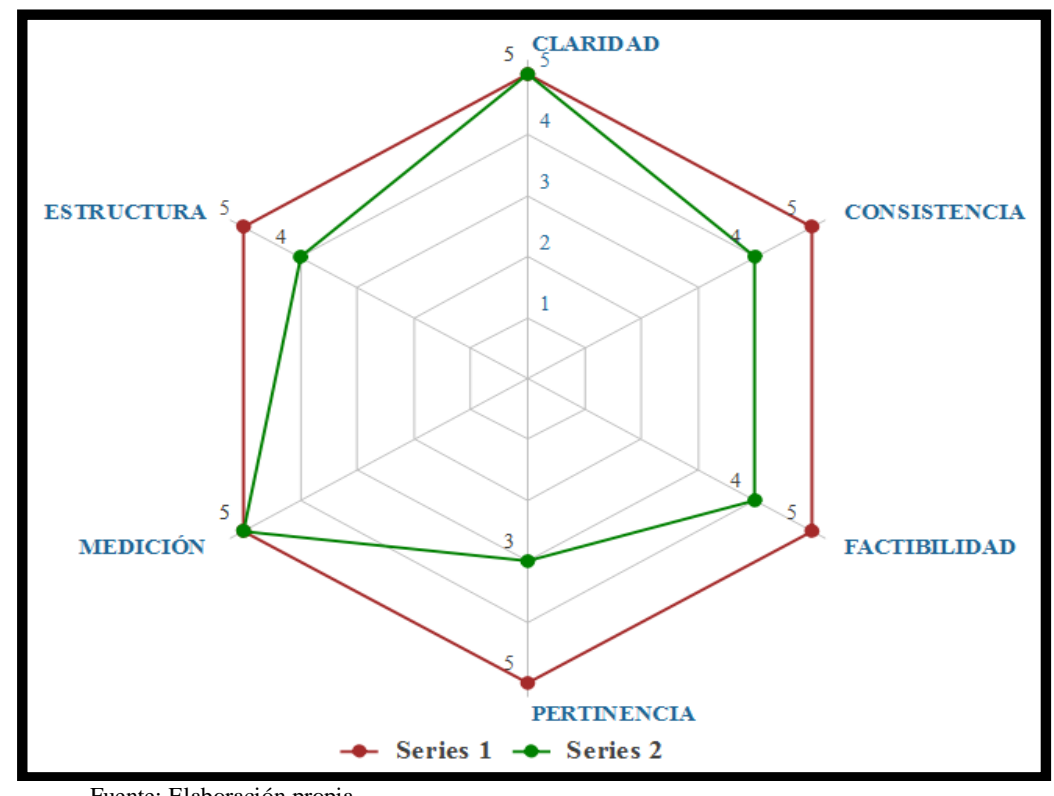

De acuerdo con la matriz de validación, el proceso logístico es parcialmente pertinente y factible en un $80 \%$, ya que el profesor Jan señala que en el modelo se han emitido detalles para la evaluación que resultan en duda de si este estaría listo para implementar. Asimismo, dado que mejorará la gestión de la logística, aumentará su productividad, pero no se evidenciará tal cambio en los indicadores pronto. 
Por otro lado, el proceso de compras es la pieza clave del proceso logístico, seguidamente, del proceso de inventarios para asegurar la consistencia del modelo. Estos procesos al ser iniciales deciden que el desarrollo logístico se lleve con éxito tal como se muestra en la siguiente figura. Figura 77: Resultado de la matriz de impactos del $2^{\text {do }}$ experto

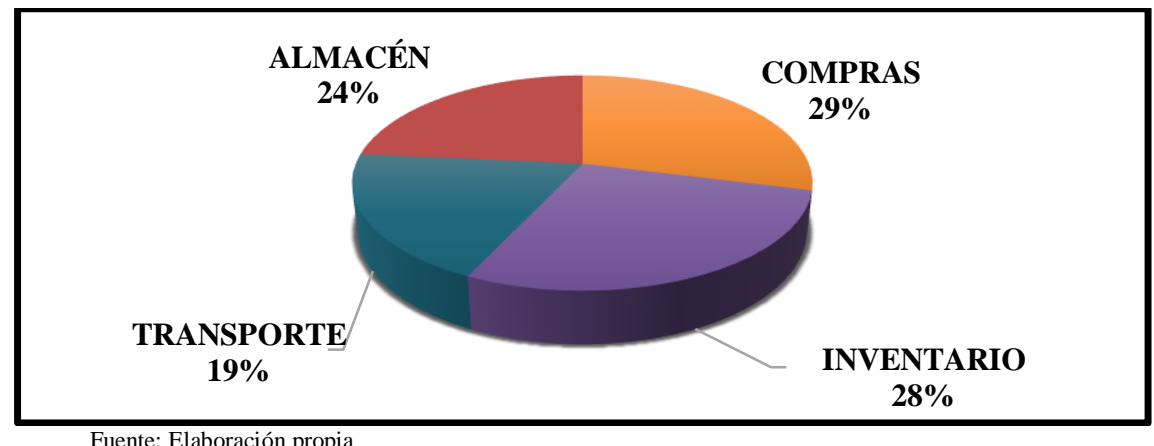

Según el $3^{\text {er }}$ experto, Arnold Maltz, estos fueron los resultados brindados:

Figura 78: Resultados de la matriz de validación del $3^{\text {er }}$ experto

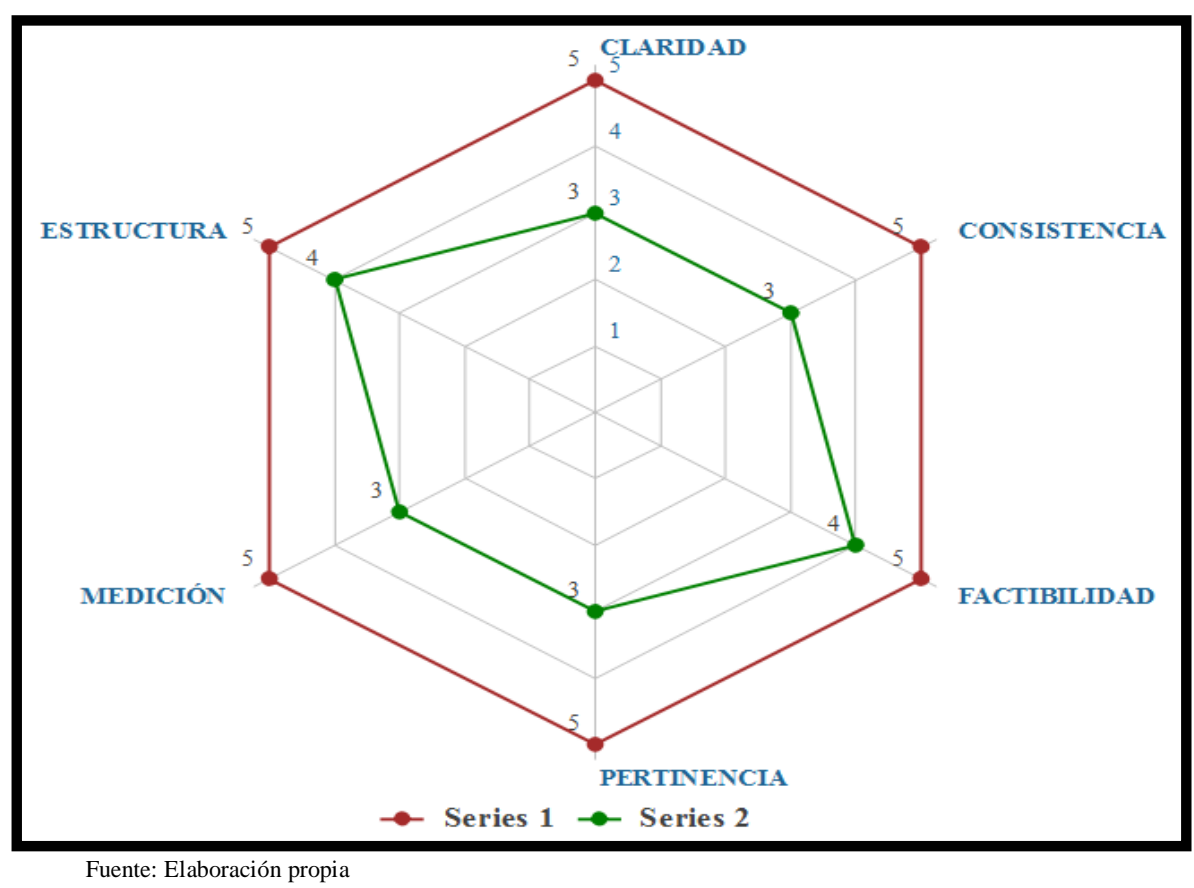

En el caso de la matriz de validación, el profesor Arnold Maltz considero una puntuación de 3 en los parámetros de claridad, consistencia, medición y pertinencia, mientras que se obtuvo una puntuación de 4 tanto en factibilidad y estructura, ya que señala que en el caso del proceso logístico los insumos tienen que estar allí en momentos apropiados para que la producción aumente y que puede depender del clima. Además, comenta que se debe seleccionar a los proveedores y hacer compras antes de que los agricultores hagan sus pedidos, y luego sugiere que las compras no tienen que esperar con la aprobación del presupuesto. Sugiere, si es posible, que los proveedores sean preseleccionados y los precios negociados antes de la temporada. 
Reconoce que puede ser difícil porque la cooperativa es pequeña, pero tal vez podrían cooperar con otros para obtener buenos precios.

Asimismo, en la matriz de impactos el proceso donde la cooperativa debe estar más pendiente es el de almacenamiento, ya que es necesario llevar un control de los insumos y cultivo para continuar con el proceso de compras y seguidamente, distribución. Sin embargo, el proceso de compras se debe iniciar con la negociación de los precios, ya sea para los suministros o los cultivos porque tienen mucho riesgo, por lo general recomienda que al menos una parte del cultivo se preconice, suponiendo que puede confiar en los compradores.

Figura 79. Resultados de la Matriz de impactos del 3er experto

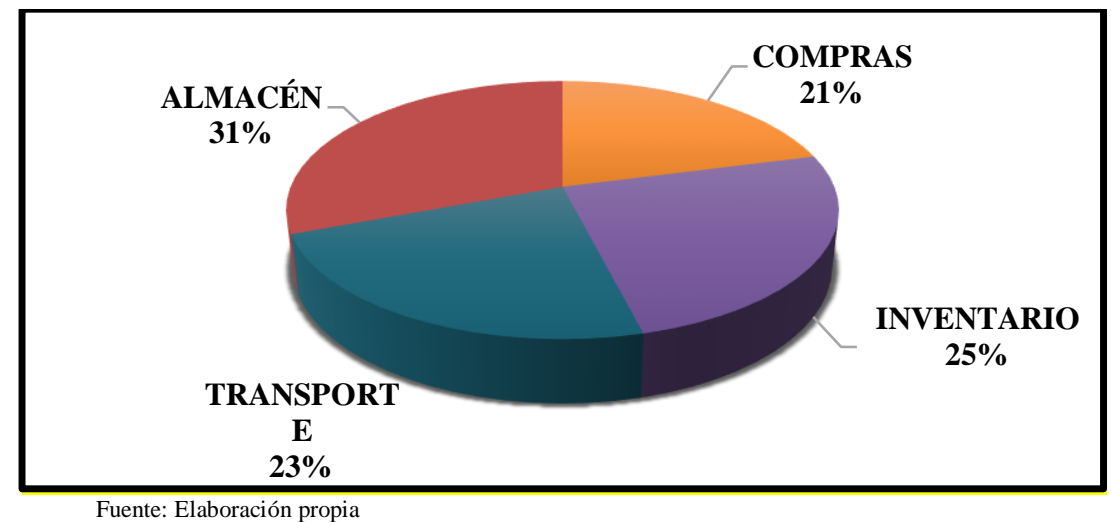

Según la $4^{\text {to }}$ experta, Gülgün Alpan, estos fueron los resultados brindados:

Figura 80: Resultados de la matriz de validación del $4^{\text {to }}$ experto

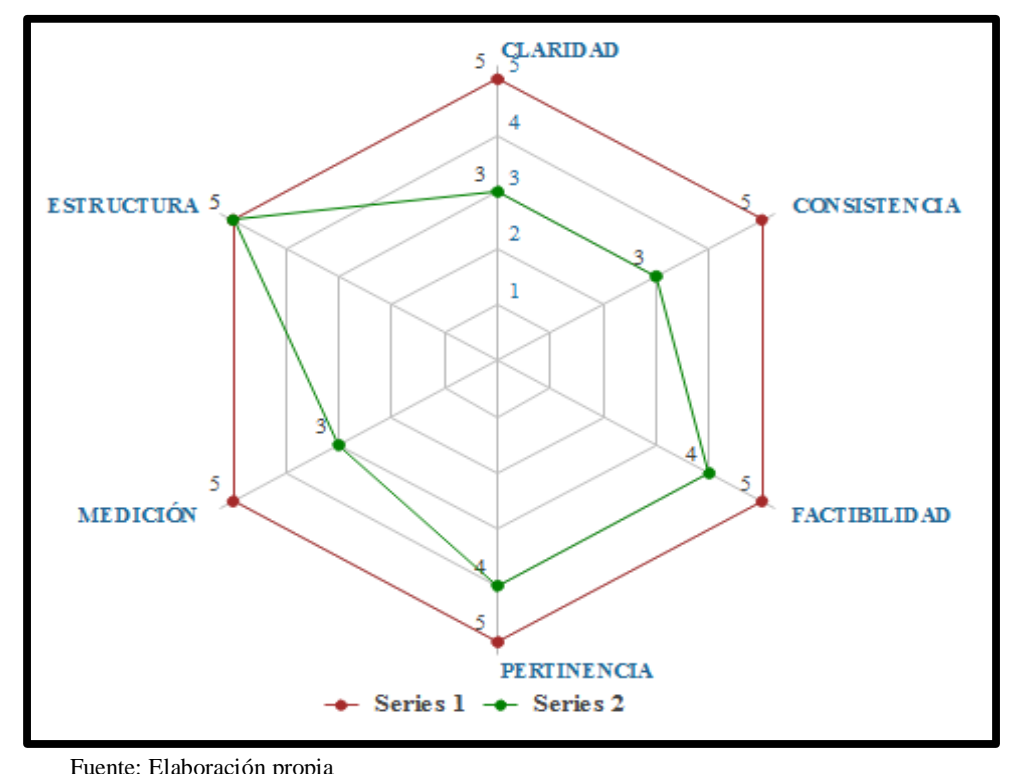

En el caso de la matriz de validación, la profesora Gülgün Alpan considero una puntuación de 3 en los parámetros de claridad, consistencia y medición, ya que afirma que el rango de los indicadores considerados en el documento podrían afectar a la cooperativa, mientras que se 
obtuvo una puntuación de 4 tanto en factibilidad y pertinencia, y por último, una puntuación de 5 en el parámetro de estructura del diseño, ya que señala que estos siguen los pasos correctos y la secuencia de manera organizada.

Asimismo, en la matriz de impactos el proceso donde la cooperativa debe estar más pendiente es el de inventarios, ya que es el primer subproceso donde se da inicio a todo el sistema. Sin embargo, Alpan sugiere que el proceso de inventarios y el proceso de almacenamiento se unan, formando uno solo y que ese sea encargado de todas actividades que correspondan.

Figura 81. Resultados de la Matriz de impactos del $4^{\text {to }}$ experto

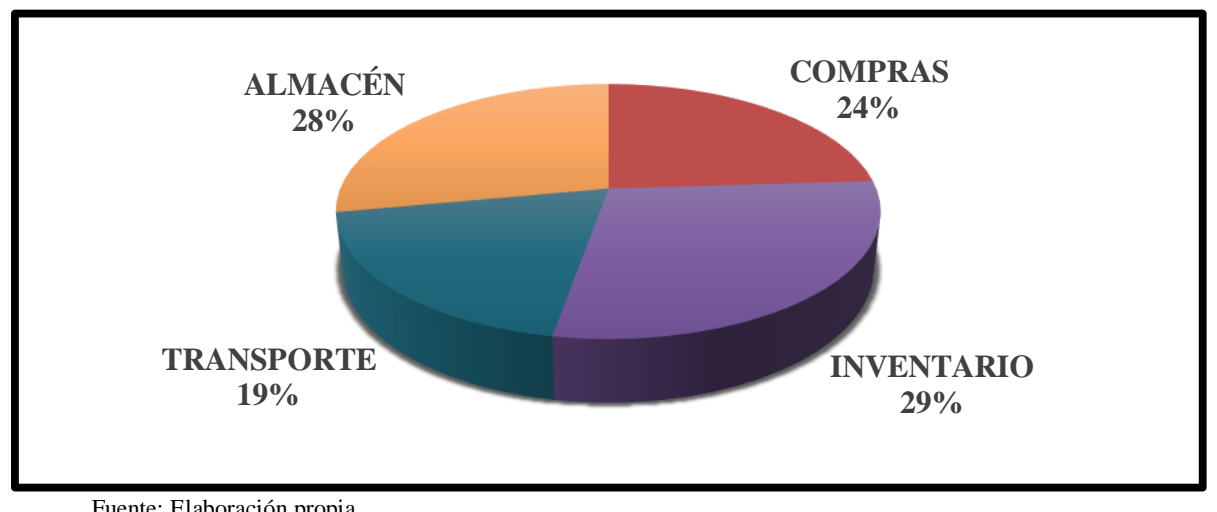

Fuente: Elaboración propia

Según la $5^{\text {ta }}$ experta, Susan Golicic, estos fueron los resultados brindados:

Figura 82: Resultados de la matriz de validación del $5^{\text {to }}$ experto

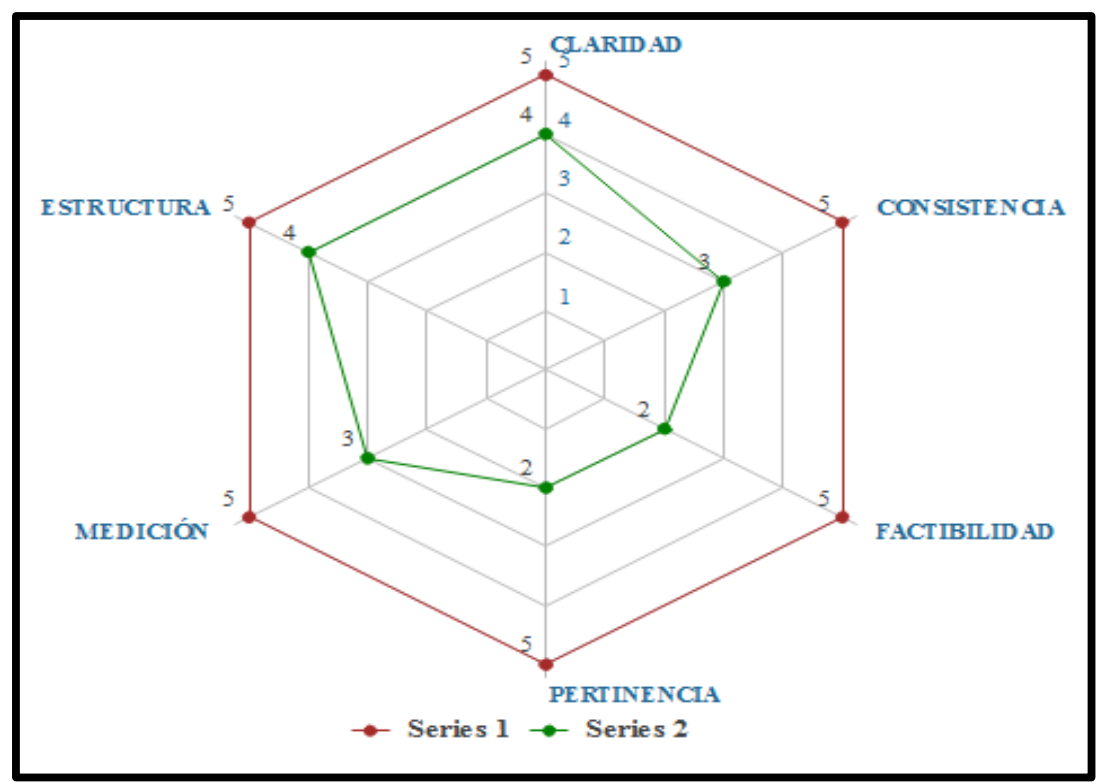

Fuente: Elaboración propia

En el caso de la matriz de validación, la profesora Susan Golicic considero una puntuación de 3 en el parámetro de consistencia y medición, mientras que se obtuvo una puntuación de 2 tanto en factibilidad y pertinencia, y, por último, una puntuación de 4 en el parámetro de estructura, ya que asegura que el documento muestra una sólida comprensión de los procesos de logística 
y de la cadena de suministro; sin embargo, es muy poco probable que una MYPE agrícola implemente procesos estándar.

Asimismo, en la matriz de impactos el proceso donde la cooperativa debe enfocarse más es el de almacenamiento, debido a que el experto asegura que los insumos deben ser verificados antes de ingresar al almacén con una prueba de calidad sin afectar al proceso de producción posterior. Además, el proceso de compras es vital para la organización, debido a que es en este dónde se verifica la capacidad de repuesta de los proveedores junto con la evaluación de criterios para ser seleccionados.

Figura 83. Resultados de la Matriz de impactos del $5^{\text {to }}$ experto

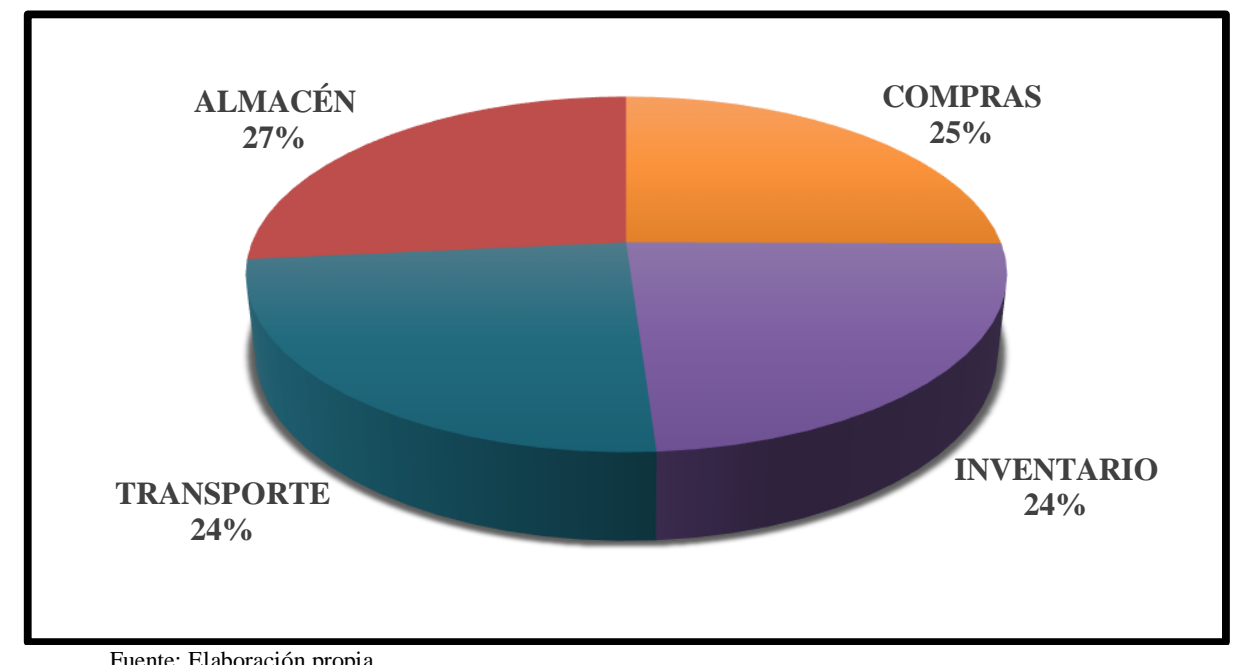

En general, a continuación, se muestra un cuadro resumen con los resultados de la matriz de validación de los 5 expertos quienes evaluaron la presente tesis. 
Figura 84. Resultados de Validación según Expertos

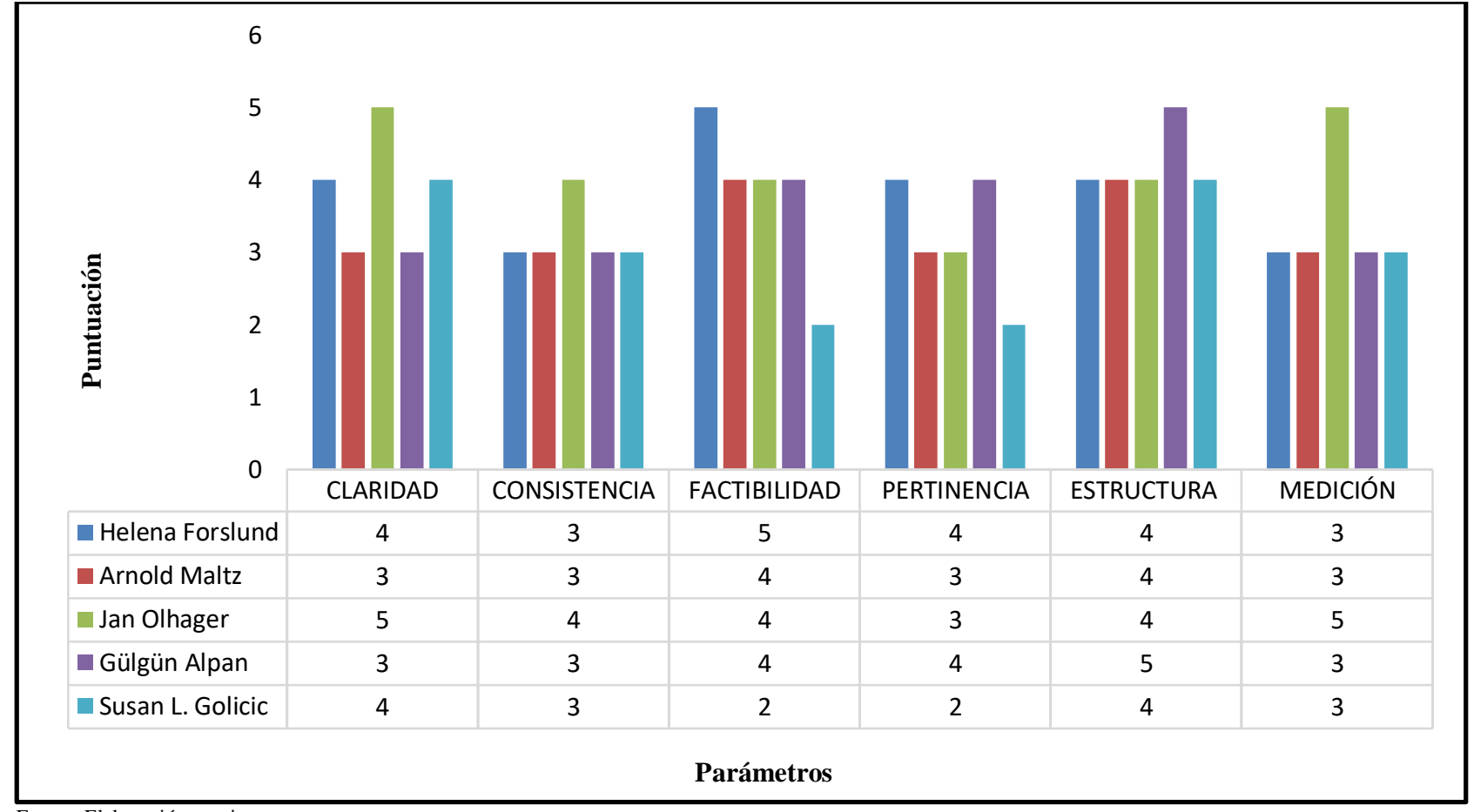

Fuente: Elaboración propia

\subsubsection{Resultado de agricultores}

Tal como se evidencia en las matrices de validación y de impactos, el día 9 de septiembre se llevó a cabo la reunión con los agricultores para obtener la validación y aprobación de nuestra investigación. Por ende, se tiene como validadores a los siguientes agricultores:

Tabla 22. Información del $1^{\text {er }}$ validador a nivel usuario

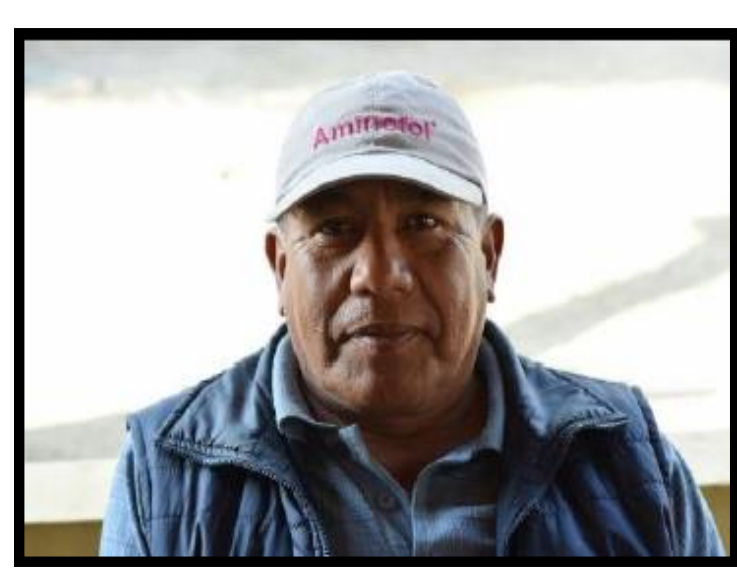

Nombre:

DNI:

País de nacimiento:

Grado académico:

Tiempo de experiencia

en el cultivo de palta

Hass
Cirilo Alejandro

Uculmana Espiritu

22278571

Perú

Superior - Ingeniero

Agrónomo

4 años 
Tabla 23. Información del $2^{\text {do }}$ validador a nivel usuario

\begin{tabular}{lll}
\hline & $\begin{array}{l}\text { Nombre: } \\
\text { DNI: }\end{array}$ & $\begin{array}{l}\text { Francisco Jesús } \\
\text { Cartagena Espino } \\
\text { País de nacimiento: }\end{array}$ \\
& $\begin{array}{l}\text { Perú } \\
\text { Grado académico: }\end{array}$ & Secundaria Incompleta \\
& $\begin{array}{l}\text { Tiempo de experiencia } \\
\text { en el cultivo de palta }\end{array}$ & 2.527045 \\
\hline
\end{tabular}

Fuente: Elaboración propia

Los resultados obtenidos por la evaluación de Don Cirilo Uculmana y por Don Jesús Cartagena fueron los siguientes:

Figura 85. Resultados de la matriz de validación del $1^{\mathrm{er}}$ y $2^{\text {do }}$ usuario

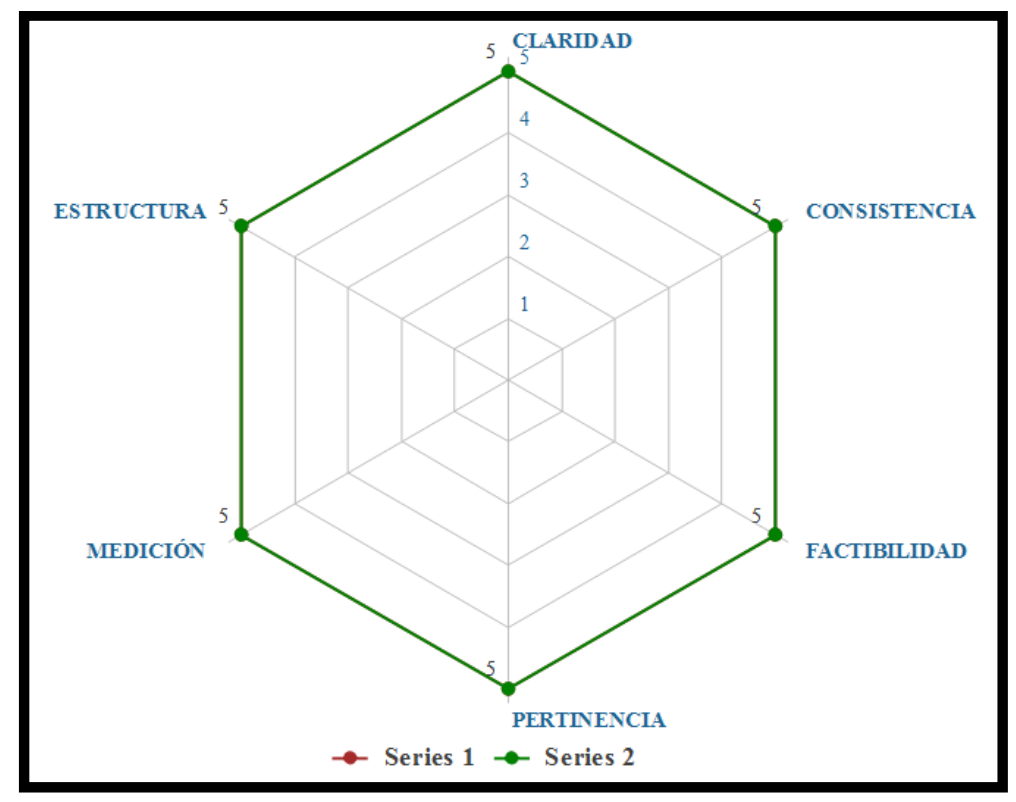

Fuente: Elaboración propia

En el caso de la matriz de validación, ambos agricultores señalaron una puntuación de 5, ya que aseguran que el modelo abarca todos los procesos de producción en el cultivo de paltos, por lo que retribuirá en mejorar la conducción de la cooperativa.

Por otro lado, en el resultado de la matriz de impactos del agricultor Cirilo Uculmana se evidencia que el proceso de inventarios es el más relevante para el desarrollo de su microempresa como señala la siguiente figura. 
Figura 86. Resultados de la Matriz de impactos del $1^{\mathrm{er}}$ usuario

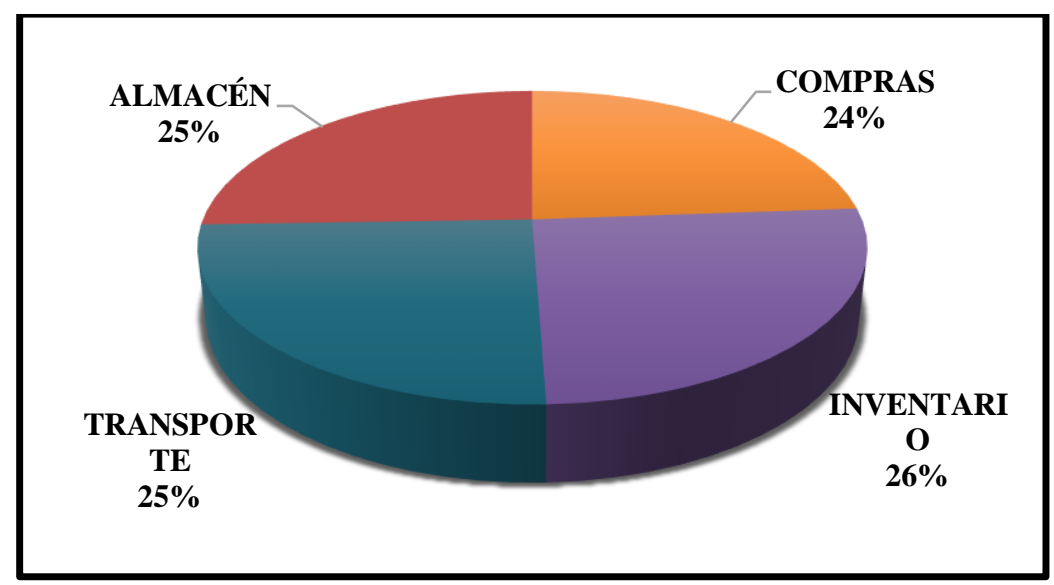

Fuente: Elaboración propia

Por el contrario, para el agricultor Jesús Cartagena el proceso más relevante dentro de la gestión logística es el proceso de compras, ya que con este proceso se obtienen los insumos y además se conocen los costos incurridos en las compras.

Figura 87: Resultados de la Matriz de impactos del $2^{\text {do }}$ usuario

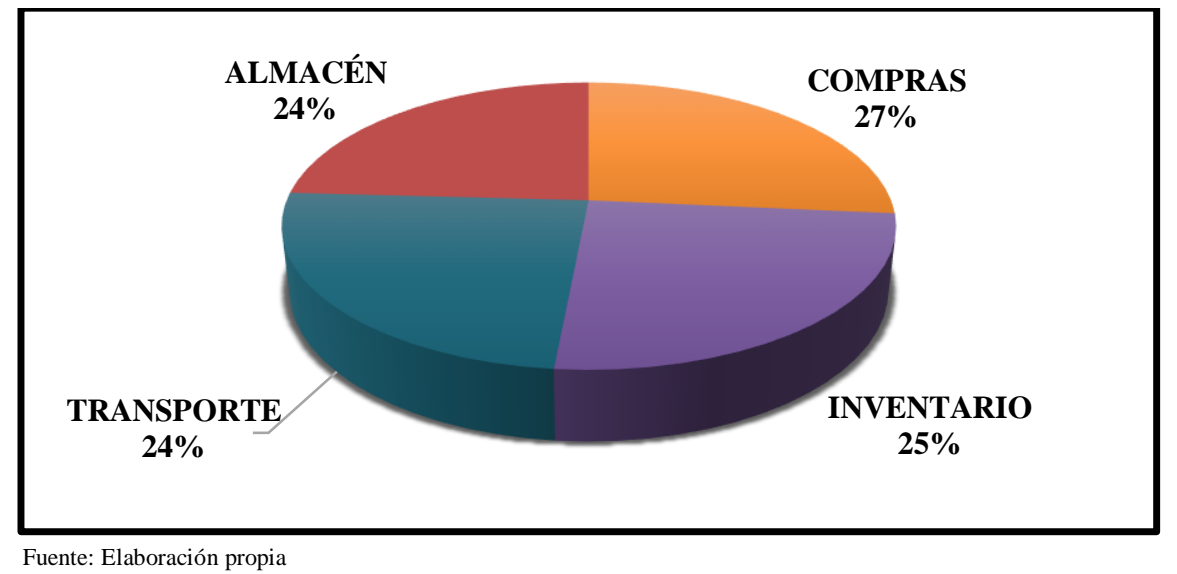

En general, el proyecto de investigación ha sido validado tanto por el apoyo de los expertos como por los agricultores quienes respaldan que nuestro modelo es elemental para la gestión por procesos y así, pueda aumentar la productividad. 


\section{CAPÍTULO 5. CONCLUSIONES Y RECOMENDACIONES}

Este capítulo presenta tanto las conclusiones como las recomendaciones obtenidas como resultado del trabajo de investigación presentado en los capítulos anteriores. Anteriormente, se ha entregado el diagnóstico de las MYPES que forman la asociación y a la vez la propuesta como sistema de gestión integral y particularmente logística, en esta ocasión se relacionarán estos datos mediante una secuencia lógica. A su vez, se mencionarán los puntos para tener en cuenta en la implementación del sistema de gestión integral.

\subsection{CONCLUSIONES}

Se evidencia que la productividad promedio de la palta Hass en Perú es de 11.048tn/ha, asimismo, en Ica en promedio es de 14.514tn/ha, mientras que la cooperativa presenta productividades de 4.46tn/ha, 0.79tn/ha y 6.68tn/ha en los años 2016, 2017 y 2018, respectivamente. Por lo tanto, se observa que la productividad de la cooperativa está muy por debajo de lo esperado, es decir, existe un problema. Por ende, se propone un sistema básico de gestión por procesos para lograr que todos trabajen interconectados y así aumentar la productividad.

Uno de los problemas de mayor relevancia para la gestión logística es la compra de insumos por separado en un $85 \%$ de la asociación, esto genera mayores costos de abastecimiento ya que se manejan precios distintos por cada MYPE generando un efecto posterior en la imprecisión del gasto y costos de producción diferentes dentro de la misma asociación, eso no es solo por el precio sino también por condiciones de venta, como por ejemplo el despacho del producto. Como solución se presenta la evaluación de proveedores, esto requiere de levantamiento de información de los contactados anteriormente e investigación de los posibles proveedores cerca de la zona de estudio como también a los grandes distribuidores en la capital que puedan realizar despacho a provincia. Gracias a esta evaluación se tendría los datos del proveedor cuando se requiera adquirir algún insumo en especial, dando así una capacidad de decisión mucho más efectiva, sin mencionar la capacidad de negociación por la compra por mayor volumen.

Otro problema en las compras de sus insumos es la falta de planificación, esto sucede en el 56\% y como principal efecto se tiene el desabastecimiento de sus insumos y retraso de las actividades incluidas en producción y además se generan mayores compras en cada campaña. Esto se planea 
reducir mediante el análisis del plan de producción brindado por el proceso Planificación y Control de la Producción y el estado de inventario de ese momento en el almacén en común. Por otro lado, también se ha evidenciado el contacto con diferentes proveedores entre agricultores o incluso entre campañas de producción y se desconoce si son los distribuidores oficiales o simplemente intermediarios lo cual también significa un costo adicional a los agricultores ya que mientras más involucrados se encuentren en la cadena logística, mayor será el precio otorgado. Para evitar estos sobre costos también se acude a la evaluación de proveedores, la cual exige una pequeña y simple investigación económica del proveedor, lo suficientemente precisa para poder tomar decisiones y a la vez simple para que los mismos agricultores puedan realizarlo.

Para profundizar los sobre costos logísticos, una de las principales causas encontradas fue la falta de coordinación entre los agricultores para poder contactar y gestionar un pedido a gran escala directamente con el cliente, por ello actualmente se requiere el enlace con la agroexportadora, esta simplifica la labor para los agricultores sin embargo genera menores ganancias para ellos ya que el pago recibido por la cosecha disminuye. Esto se soluciona mediante la interacción del proceso comercial y el logístico ya que siguiendo las pautas del primero se logra el contacto y la negociación de las condiciones del pedido recibiendo así el pago de parte del cliente final; paralelo a esto, se tiene a la gestión logística, esta se encarga de llevar a cabo las condiciones pactadas por el área comercial para entregar la cosecha, como por ejemplo, el empaque de entrega según el tipo de transporte a requerir y el volumen y peso exacto con respecto a lo acordado.

Una vez se realiza la venta, las ganancias pueden ser repartidas para cada MYPE de una manera muy práctica ya que gracias a los procedimientos del sub proceso Almacenamiento de la producción se tiene contabilizado a cantidad exacta de cosecha que cada agricultor pudo obtener con respecto a cada calibre. Los procesos y sub procesos mencionados son los principales para lograr el desenlace con la agroexportadora sin embargo, también se requieren otros como por ejemplo, Gestión de la Calidad e Inocuidad, el cual se encarga de cumplir con los estándares requeridos por el cliente, Planeamiento y Control de la Producción, el cual tiene como principal objetivo de cumplir con las cantidades y fechas acordadas mediante la buena planificación de insumos y de producción y finalmente el sub proceso Distribución de la producción, encargada de transportar el pedido a donde se acuerde con el cliente sea este a un almacén físico en Lima o en un agente logístico. De esta manera se puede lograr el desligamiento con la agroexportadora, una meta a mediano plazo de los agricultores. 
Con lo establecido en el párrafo anterior se puede entender la necesidad de interacción entre muchas partes y la ardua colaboración que debe existir entre los agricultores sin embargo, actualmente no existe dicha colaboración, si bien es cierto son una asociación, desaprovechan las ventajas que esto les puede brindar, solo se unen para realizar las ventas a la agroexportadora y así llegar al volumen y peso requerido por la agroexportadora pero más allá de ello no aprovechan lo cual se traduce en sobre costos logísticos y pérdida de beneficios económicos, para esto se proponen dos sub procesos, el primero es Compras, el cual se encargará de negociar con los proveedores de tal manera que se aprovechen las economías de escala y así conseguir un ahorro en el abastecimiento de los insumos y a la vez exigir el transporte de los productos al almacén en común, de esta manera la asociación se desligaría del gasto de flete generando así más ahorro. El segundo sub proceso es Almacenamiento de insumos, el cual recepcionará los insumos obtenidos y designará la cantidad necesaria para cada MYPE con el fin de tener un solo almacén que maneje con exactitud las cantidades de cada agricultor y en caso se tenga la necesidad de material extra de podrá trabajar mediante préstamos internos de la asociación registrados para evitar problemas en la posteridad.

Se ha mencionado la negociación y el trato con los proveedores en el sub proceso de compras, sin embargo la frecuencia en la cual se realizan estas compras también es importante ya que aunque hoy el día no se trabaje con facturas ni órdenes de compra, se tendrá que realizarlo posteriormente para poder obtener las certificaciones correspondientes como por ejemplo la Global GAP, por consecuencia esto se volverá un gasto adicional, para mitigarlo se busca bajar la frecuencia de compras, de tal manera se reduce la generación de órdenes de compra y procesos de recepción de insumos, sobre todo este punto es importante ya que aunque se realicen compras en conjunto como asociación y se aprovechen las economías de escala, sigue siendo un impedimento gestionar el ingreso de los insumos en el almacén ya que eso requiere de mayor trabajo de los encargados del almacén, esto se logra a través de un plan de compras generado por el sub proceso Inventarios, quien como resultado de la comparación entre el estado actual de los productos en almacén y los requerimientos brindados por Planeamiento y

\section{Control de Producción.}

Durante todas las conclusiones líneas arriba se ha mencionado la necesidad de los registros para evitar problemas, esto se evidenció en el caso de dos agricultores quienes decidieron aprovechar la asociación para más que vender, principalmente realizaban compras juntos, esto les llevó a ahorros significativos sin embargo se tuvieron problemas para estimar la designación de lo correspondiente a cada uno, no a gran complejidad al comienzo, sino mas bien, cuando ya se habían utilizado los insumos y no se supo distribuir lo restante, esto se puede evitar gracias a 
los registros de designación de insumos y de la misma manera con la repartición de ganancias gracias al conocimiento de la cantidad de producción de cada agricultor.

Por otro lado, actualmente no se tiene espacios designados para almacenar los diferentes insumos, ya que algunos no se pueden juntar con otros como por ejemplo, los fertilizantes y pesticidas, esto requiere de una buena distribución en un almacén en conjunto que esté gestionado de manera integral para toda la asociación, esto se puede lograr mediante el procedimiento P-LOG-03 Procedimiento de la gestión de almacenamiento de insumos, de tal manera de reducir también las pérdidas de insumos ya que si bien es cierto las compras se realizan con cierta contingencia, en caso exista algún altercado, la contingencia sería mucho menor si se trabaja en conjunto ya que no se compra de más por cada agricultor sino por toda la asociación, del mismo modo, se reducirán la pérdida por robo de terceros, tenemos que tener en cuenta que el $46 \%$ de los agricultores ha sufrido pérdidas de su inversión tanto por sobre inventario como también por robo, no solo de insumos, sino también de cosecha.

Por otro lado, la pérdida de cosecha no solo se produce por los motivos ya mencionados, sino también por las distintas plagas que atacan a la plantación, esto se puede mitigar con la propuesta descrita en el capítulo 3, mediante la estimación de un inventario de seguridad para las plagas estacionales y aquellas que ya se hayan manifestado en alguna de las MYPES de tal manera en caso se tenga un problema, se pueda tratar apenas se diagnostique y no esperar a poder contactar con el proveedor, si bien es cierto esto podría realizarlo cada agricultor por separado sin embargo mantenerlo en conjunto significaría una inversión menor ya que se tendrá un solo inventario de seguridad en vez de uno por cada agricultor. Para esto se debe realizar un constante seguimiento al inventario en caso se utilicen los insumos de contingencia, ya que se tendría que analizar la posibilidad de contagio con los otros campos, cual en realidad es baja de acuerdo con la cercanía que se manejan, sin embargo se planea incrementar la cantidad de agricultores en la asociación por lo que se debe tener en cuenta este punto, de todas maneras, en caso no se contagie, igual se debe reponer lo gastado para no sufrir las pérdidas por futuras plagas.

Finalmente, los insumos almacenados, evidenciaron problemas en las plantaciones por la utilización de fertilizantes en cantidades erróneas y utilización de insecticidas en zonas sensibles lo cual impactó de manera negativa en el crecimiento de la planta. Esto refleja el desconocimiento de parte de los agricultores de los productos, lo cual se soluciona mediante el correcto manejo de etiquetas de productos en el almacén y el conocimiento del método de aplicación gracias a los procedimientos o manuales de cada insumo como propuesta inicial con el fin de mantenerlo simple para el agricultor, esto se describe en el P-LOG-03 Procedimiento 
de la gestión de almacenamiento de insumos. Los datos esenciales que deben ir gráficamente cerca al insumo como, frecuencia, zona de aplicación, prevenciones requeridas, entre otras. El manejo correcto conllevará a la reducción del gasto innecesario de los insumos, un mejor estado de la plantación y mejor preparación ante plagas.

\subsection{RECOMENDACIONES}

- Se recomienda a las empresas del sector agrícola de palta Hass implementar el sistema de gestión integrado propuesto para poder acceder a los mercados tanto locales como extranjeros, si bien es cierto que la propuesta es un sistema básico, este deberá tener ajustes para poder implementarse en cada MYPE.

- La documentación es una parte fundamental para poder realizar seguimiento a las mejoras logradas por eso, se recomienda completar la mayor cantidad de registros posibles, como se indican en el trabajo de investigación, siguiendo los formatos encontrados en los anexos.

- La cantidad de indicadores dentro del trabajo presentado se debe a la búsqueda de simplicidad necesaria para la correcta implementación de parte de los usuarios, esto se deberá volver a analizar una vez se establezca el proceso logístico en la cooperativa ya que según su mejora y evolución se requerirán indicadores adicionales como por ejemplo, porcentaje de espacio utilizado en el almacén para la evaluación de adquisición de mayor espacio, número de proveedores por producto, porcentaje de utilización de las unidades de transporte, tiempo promedio de distribución de insumos, rotación de insumos, etc.

- Se recomienda a las empresas en estudio gestionar eficientemente el desempeño de sus proveedores, clasificar los artículos que mantienen en almacén, evaluar la criticidad de aprovisionamiento y en el proceso productivo para establecer prioridades de compra.

- Con respecto a la implementación, antes de poder llevar a cabo este proceso se requiere de establecer los puntos principales de Planeamiento y Control de Producción para poder obtener la lista de requerimientos y así empezar con el sub proceso Compras, con respecto a Almacenamiento de Producción y Almacenamiento de Insumos, se necesitará tener los lineamientos de parte de Calidad e Inocuidad para los estándares de limpieza y sanidad que requieren las certificaciones solicitadas por los clientes.

- Para realizar la evaluación de proveedores no solo se deberá considerar los ahorros sino también el presupuesto armado por Gestión de Costos para poder controlar los costos por campaña y la inversión correspondiente. 
- En el modelo se menciona la necesidad de evaluar las rutas óptimas de despacho, para esto no solo se debe tomar en cuenta los tiempos y distancias sino también otros factores involucrados en el rendimiento de la distribución como, el horario permitido para camiones, congestión en rutas y horarios, calidad y estabilidad de las rutas, para evitar tormentosos para la cosecha ya que, aunque la cáscara brinda una gran resistencia al fruto, se debe evitar el mayor daño posible antes de transportarlo vía marítima.

- Como ya se mencionó en líneas anteriores, las rutas disponibles en la zona no son de asfalto, más bien, son caminos de tierra asentados, lo cual no es apropiado para el cuidado de las unidades de transporte y limita la velocidad de estos por ello, se recomienda solicitar como proyecto distrital mejorar las rutas de transporte de toda la irrigación.

- En la propuesta, los sub procesos de almacenamiento y de distribución requieren de gran inversión inicial de parte de los agricultores, esto suele desanimar a los usuarios sin embargo se debe contra atacar esto mediante la exposición de los beneficios de la gestión de los sub procesos relacionados y así evitar el freno del crecimiento de la asociación. Como primera opción se debe acudir a Ministerio de Agricultura y Riego, específicamente al proyecto AGROIDEAS, un programa de compensaciones para la competitividad para buscar financiamiento para las mejoras dentro de la cooperativa, sin embargo en caso que no se consiga el préstamo no reembolsable, se necesitará un préstamo financiero el cual podría ser en el Agrobanco, donde igual se deberá evaluar minuciosamente antes de realizarlo, sobre todo por la tasa de interés y sus beneficios sobre otras entidades bancarias.

- Con respecto al manejo del almacén, se requiere a una persona dedicada a eso ya que sobre todo al comienzo, se va a requerir mucho tiempo y dedicación para establecer orden entre todos los insumos requeridos incluso siguiendo las recomendaciones explicadas en los procedimientos. Como recomendación, el encargado de dicha responsabilidad debería ser uno de los dirigentes de las MYPES que anteriormente haya sido presidente de la cooperativa, este puesto es rotativo y está encargado de gestionar la comunicación con la agroexportadora y el manejo de los papeles de la cooperativa, lo cual manifiesta las habilidades necesarias para la implementación de almacenamiento.

- Finalmente, se recomienda tener integración con los procesos descritos en el sistema de gestión para poder garantizar un crecimiento óptimo dentro de la cooperativa. 


\subsection{FUTURAS LÍNEAS DE INVESTIGACIÓN}

En el proyecto se ha diseñado una propuesta para un sistema básico de gestión de procesos explicando así los puntos necesarios para desarrollar el proceso logístico que ayude a la mejora de las MYPES; sin embargo, hay puntos que se deberían profundizar en futuros proyectos de investigación les son los siguientes:

- Factores de decisión para un agente logístico.

- Condiciones de almacenamiento para diferentes acreditaciones de exportación.

- Modelo de estimación de rutas de transporte.

- Modelo de gestión de inventarios y la evaluación si es necesario manejar distintos modelos para cada MYPE en la cooperativa.

- Adaptación del modelo para MYPES con diferentes frutos principales.

- Beneficios e importancia de diferentes tipos de riego y su respectiva implementación.

- Desventajas e impactos de inadecuadas rutas de transporte.

- Consideraciones y costos logísticos de sanidad dentro de la gestión logística.

- Estrategias de negociación con proveedores.

Teniendo las conclusiones, recomendaciones y las futuras líneas de investigación se concluye este proyecto de investigación que buscar mejorar la productividad de la Cooperativa Agro Inka a través del diseño de un proceso logístico de tal manera que se aprovechen mejor las condiciones de trabajo y de negociación de los agricultores pertenecientes de la cooperativa y todo aquel que quiera unirse para su desarrollo personal y empresarial. 


\section{ANEXOS}

\section{PLAN DE COMPRAS}

Encargado del documento:

Fecha:

\begin{tabular}{|l|l|l|l|}
\hline INSUMO & CANTIDAD & UNIDAD & FECHA REQUERIDA \\
\hline & & & \\
\hline & & & \\
\hline & & & \\
\hline & & & \\
\hline & & & \\
\hline & & & \\
\hline & & & \\
\hline & & & \\
\hline & & & \\
\hline & & & \\
\hline & & & \\
\hline & & & \\
\hline & & & \\
\hline & & & \\
\hline & & & \\
\hline & & & \\
\hline & & & \\
\hline
\end{tabular}

*Nota: La tabla deberá ordenarse según la fecha requerida.

\begin{tabular}{|c|c|c|}
\hline GENERADO POR: & REVISADO Y APROBADO POR: & FECHA DE EMISIÓN \\
Gestión Logística & Presidente de la Cooperativa & $22 / 06 / 2017$ \\
\hline
\end{tabular}


Encargado del documento:

Fecha:

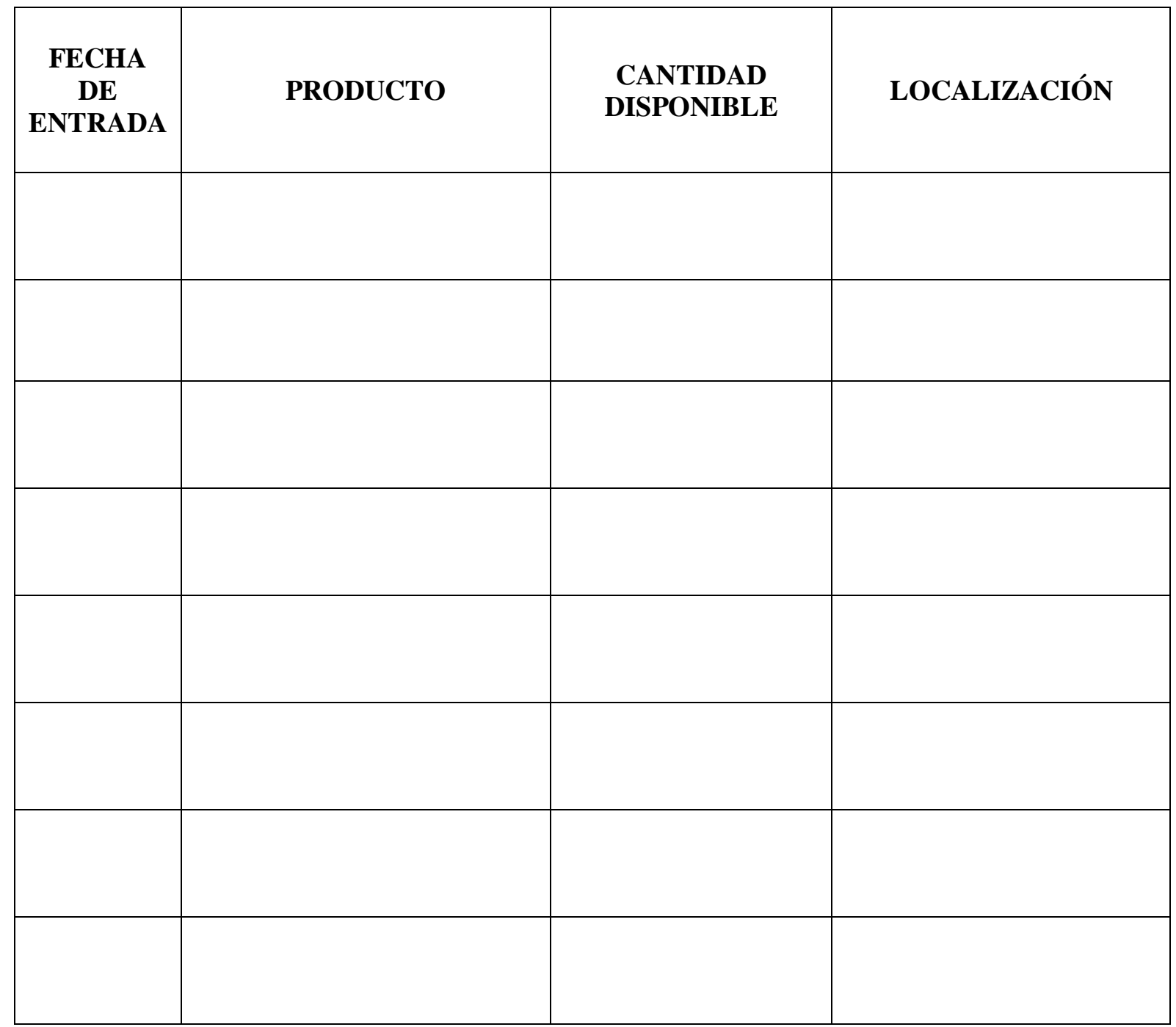

GENERADO POR:

Gestión Logística
REVISADO Y APROBADO POR:

Presidente de la Cooperativa
FECHA DE EMISIÓN

$22 / 06 / 2017$ 


\begin{tabular}{|l|c|c|}
\hline FORMATO DE LISTA DE PROVEEDORES & CÓDIGO: & PÁGINA: \\
& F- LOG-0 4 & 1 de 1 \\
\hline
\end{tabular}

Encargado del documento:

Fecha:

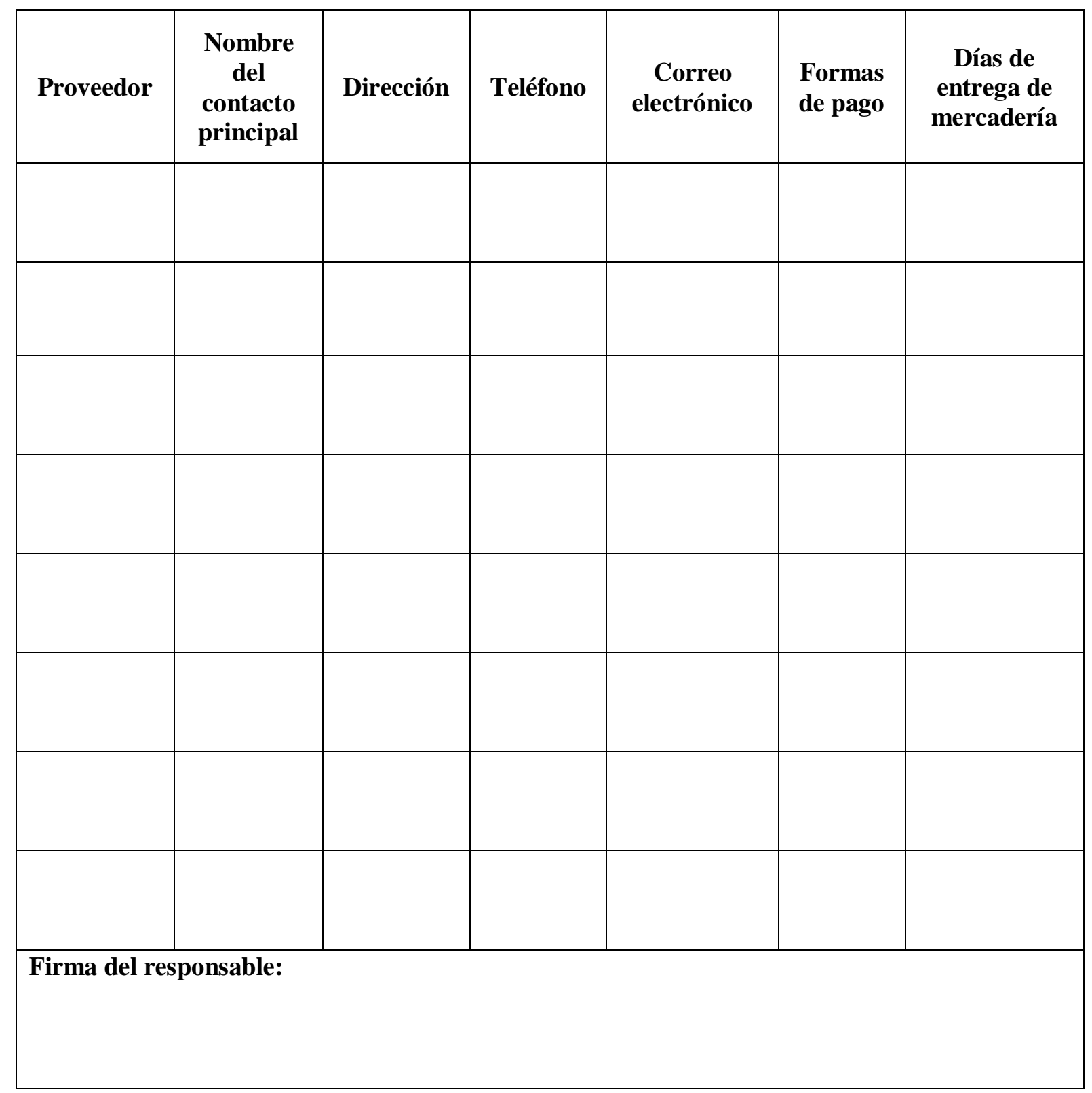

\begin{tabular}{|c|c|c|}
\hline GENERADO POR: & REVISADO Y APROBADO POR: & FECHA DE EMISIÓN \\
Gestión Logística & Presidente de la Cooperativa & $22 / 06 / 2017$ \\
\hline
\end{tabular}




\section{Encargado del documento:}

Fecha:

Firma del encargado:

\begin{tabular}{|c|c|c|c|}
\hline Criterio & Peso & Subcriterio & Peso \\
\hline \multirow{2}{*}{ Entrega de bienes } & \multirow{2}{*}{$24.16 \%$} & Fecha & $69.23 \%$ \\
\hline & & Cantidades & $30.77 \%$ \\
\hline \multirow{2}{*}{ Entrega de servicios } & \multirow{2}{*}{$24.16 \%$} & Fecha & $50.00 \%$ \\
\hline & & Cantidades & $50.00 \%$ \\
\hline \multirow{5}{*}{ Calidad } & \multirow{5}{*}{$24.16 \%$} & Conformidad & $20.00 \%$ \\
\hline & & Funcionalidad & $20.00 \%$ \\
\hline & & Reglamentario & $20.00 \%$ \\
\hline & & Seguridad & $20.00 \%$ \\
\hline & & Ambiental y ergonómico & $20.00 \%$ \\
\hline \multirow{2}{*}{ Poscontractual } & \multirow{2}{*}{$14.69 \%$} & Reclamaciones & $50.00 \%$ \\
\hline & & Servicios Postventa & $50.00 \%$ \\
\hline \multirow{3}{*}{ Gestión } & \multirow{3}{*}{$12.82 \%$} & Facturación & $41.54 \%$ \\
\hline & & Requerimientos & $9.27 \%$ \\
\hline & & Garantías & $49.19 \%$ \\
\hline
\end{tabular}

\section{GENERADO POR:}

Gestión Logística
REVISADO Y APROBADO POR:

Presidente de la Cooperativa
FECHA DE EMISIÓN

22/06/2017 
Insumo correspondiente:

Encargado del documento:

Fecha:

\begin{tabular}{|c|c|c|c|c|c|}
\hline CRITERIO & SUBCRITERIO & $\begin{array}{c}\text { PROVEEDOR } \\
1\end{array}$ & $\begin{array}{c}\text { PROVEEDOR } \\
2\end{array}$ & PROVEEDOR 3 & $\begin{array}{c}\text { PROVEEDOR } \\
4\end{array}$ \\
\hline \multirow{2}{*}{$\begin{array}{l}\text { Entrega de } \\
\text { bienes }\end{array}$} & Fecha & & & & \\
\hline & Cantidades & & & & \\
\hline \multirow{2}{*}{$\begin{array}{l}\text { Entrega de } \\
\text { servicios }\end{array}$} & Fecha & & & & \\
\hline & Cantidades & & & & \\
\hline \multirow{5}{*}{ Calidad } & Conformidad & & & & \\
\hline & Funcionalidad & & & & \\
\hline & Reglamentario & & & & \\
\hline & Seguridad & & & & \\
\hline & $\begin{array}{l}\text { Ambiental y } \\
\text { ergonómico }\end{array}$ & & & & \\
\hline \multirow{2}{*}{$\begin{array}{c}\text { Pos } \\
\text { contractual }\end{array}$} & Reclamaciones & & & & \\
\hline & $\begin{array}{l}\text { Servicios } \\
\text { Postventa } \\
\end{array}$ & & & & \\
\hline \multirow{3}{*}{ Gestión } & Facturación & & & & \\
\hline & Requerimientos & & & & \\
\hline & Garantías & & & & \\
\hline \multicolumn{6}{|c|}{ CALIFICACIÓN } \\
\hline $\begin{array}{l}\text { PRC } \\
\text { SELE }\end{array}$ & $\begin{array}{l}\text { VEEDOR } \\
\text { CIONADO }\end{array}$ & & & & \\
\hline
\end{tabular}

GENERADO POR:

Gestión Logística
REVISADO Y APROBADO POR:

Presidente de la Cooperativa
FECHA DE EMISIÓN

$22 / 06 / 2017$ 
Campaña:

Encargado:

\begin{tabular}{|c|c|c|c|c|c|c|c|c|}
\hline FECHA & $\begin{array}{c}\text { ORDEN DE } \\
\text { COMPRA }\end{array}$ & $\begin{array}{c}\text { COMPROBANTE } \\
\text { DE PAGO }\end{array}$ & PROVEEDOR & $\begin{array}{c}\text { TIPO } \\
\text { DE } \\
\text { PAGO }\end{array}$ & MONEDA & $\begin{array}{c}\text { COSTO } \\
\text { UNITARIO }\end{array}$ & IMPUESTO & $\begin{array}{l}\text { COSTO } \\
\text { TOTAL }\end{array}$ \\
\hline & & & & & & & & \\
\hline & & & & & & & & \\
\hline & & & & & & & & \\
\hline & & & & & & & & \\
\hline & & & & & & & & \\
\hline & & & & & & & & \\
\hline & & & & & & & & \\
\hline & & & & & & & & \\
\hline & & & & & & & & \\
\hline & & & & & & & & \\
\hline & & & & & & & & \\
\hline & & & & & & & & \\
\hline & & & & & & & & \\
\hline & & & & & & & & \\
\hline & & & & & & & & \\
\hline & & & & & & & & \\
\hline & & & & & & & & \\
\hline & & & & & & & & \\
\hline & & & & & & & & \\
\hline & & & & & & & & \\
\hline & & & & & & & & \\
\hline & & & & & & & & \\
\hline & & & & & & & & \\
\hline & & & & & & & & \\
\hline & & & & & & & & \\
\hline & & & & & & & & \\
\hline & & & & & & & & \\
\hline \multicolumn{8}{|c|}{ COSTO TOTAL } & \\
\hline
\end{tabular}

Firma del responsable

\section{GENERADO POR:}

Gestión Logística

\section{REVISADO Y APROBADO POR:}

Presidente de la Cooperativa
FECHA DE EMISIÓN

$22 / 06 / 2017$ 


\begin{tabular}{|c|c|c|}
\hline FORMATO DE CRONOGRAMA DE ENTREGA & CÓDIGO: & PÁGINA: \\
& F- LOG-08 & 1 de 1 \\
\hline
\end{tabular}

Campaña:

Encargado:

\begin{tabular}{|c|c|c|c|c|c|}
\hline ÍTEM & INSUMO & PROVEEDOR & CANTIDAD & UNIDAD & FECHA \\
\hline & & & & & \\
\hline & & & & & \\
\hline & & & & & \\
\hline & & & & & \\
\hline & & & & & \\
\hline & & & & & \\
\hline & & & & & \\
\hline & & & & & \\
\hline & & & & & \\
\hline & & & & & \\
\hline & & & & & \\
\hline & & & & & \\
\hline & & & & & \\
\hline & & & & & \\
\hline & & & & & \\
\hline & & & & & \\
\hline & & & & & \\
\hline & & & & & \\
\hline
\end{tabular}

Firma del responsable

GENERADO POR:

Gestión Logística
REVISADO Y APROBADO POR:

Presidente de la Cooperativa
FECHA DE EMISIÓN

$22 / 06 / 2017$ 


\begin{tabular}{|c|c|c|}
\hline HOJA DE DEVOLUCIÓN & CÓDIGO: & PÁGINA: \\
& F- LOG-09 & 1 de 1 \\
\hline
\end{tabular}

Encargado del documento:

Fecha:

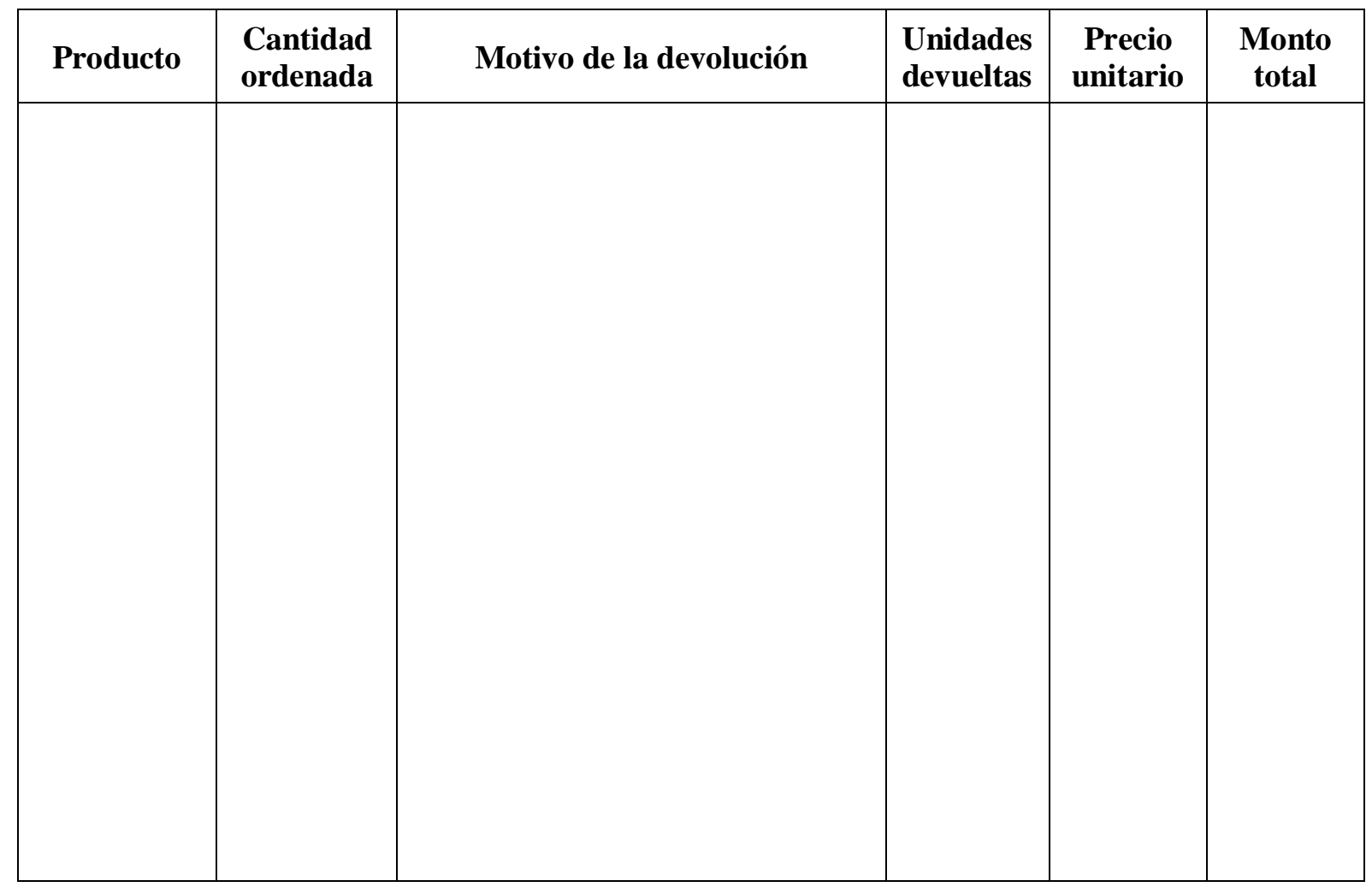

Comentarios especiales:

Firma del responsable:

\begin{tabular}{|c|c|c|}
\hline GENERADO POR: & REVISADO Y APROBADO POR: & FECHA DE EMISIÓN: \\
Gestión Logística & Presidente de la Cooperativa & $22 / 06 / 2017$ \\
\hline
\end{tabular}


Encargado del documento:

Fecha:

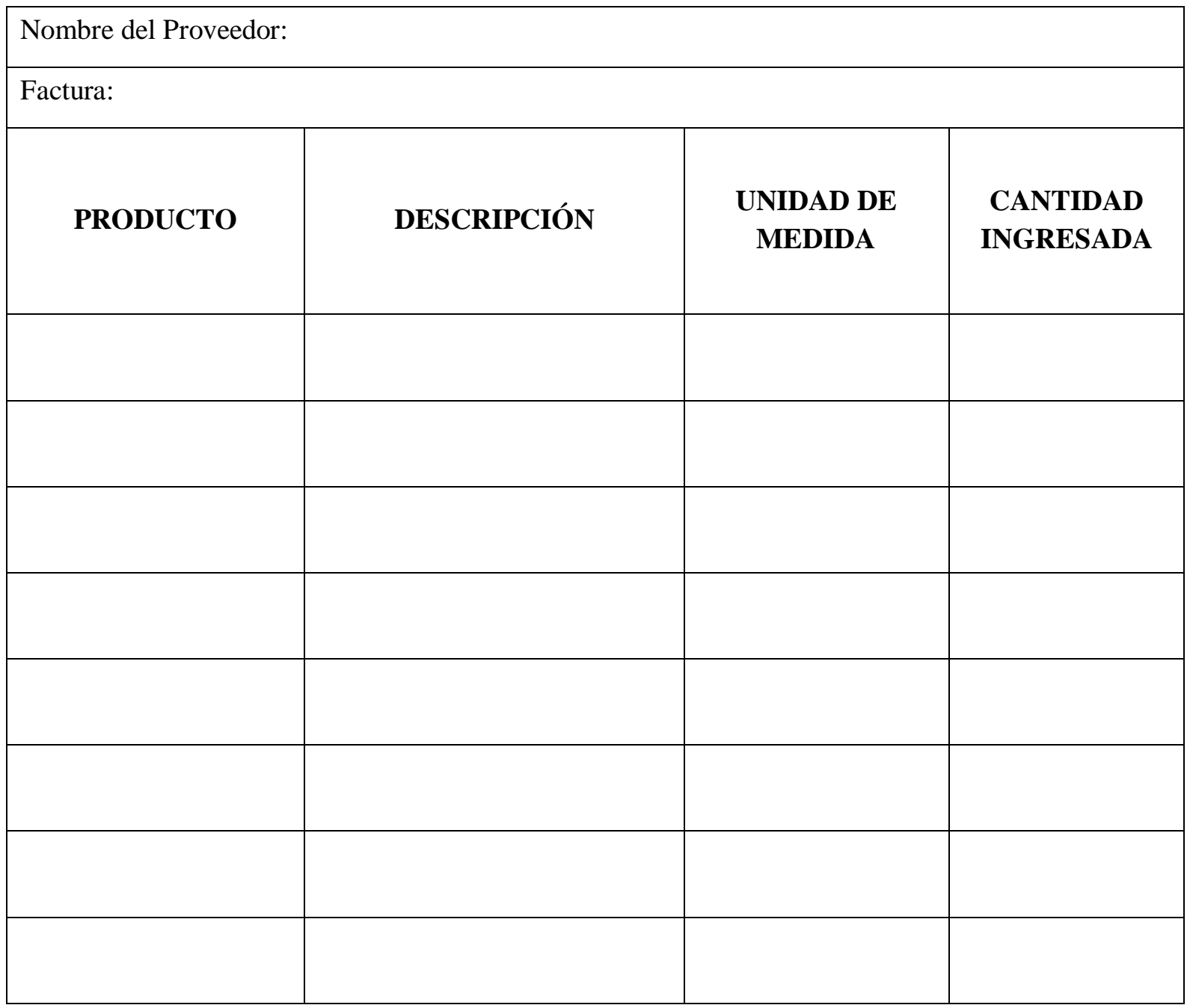

Firma del responsable:

\begin{tabular}{|c|c|c|}
\hline GENERADO POR: & REVISADO Y APROBADO POR: & FECHA DE EMISIÓN: \\
Gestión Logística & Presidente de la Cooperativa & $22 / 06 / 2017$ \\
\hline
\end{tabular}


Encargado del documento:

Fecha:

\begin{tabular}{|l|l|l|}
\hline $\mathbf{N}^{\mathbf{0}}$ ESTANTE & INSUMO & CANTIDAD \\
\hline & & \\
\hline & & \\
\hline & & \\
\hline & & \\
\hline & & \\
\hline & & \\
\hline & & \\
\hline
\end{tabular}

Firma del responsable:

\section{GENERADO POR:}

Gestión Logística
REVISADO Y APROBADO POR:

Presidente de la Cooperativa
FECHA DE EMISIÓN:

$22 / 06 / 2017$ 
Encargado del documento:

Fecha:

\begin{tabular}{|l|l|l|l|l|l|}
\hline FECHA & AGRICULTOR & PRODUCTO & DESCRIPCIÓN & $\begin{array}{c}\text { UNIDAD } \\
\text { DE } \\
\text { MEDIDA }\end{array}$ & $\begin{array}{c}\text { CANTIDAD } \\
\text { DESPACHADA }\end{array}$ \\
\hline & & & & & \\
\hline & & & & & \\
\hline & & & & & \\
\hline & & & & & \\
\hline & & & & & \\
\hline & & & & & \\
\hline & & & & & \\
\hline
\end{tabular}

Firma del responsable:

\section{GENERADO POR:}

Gestión Logística
REVISADO Y APROBADO POR:

Presidente de la Cooperativa
FECHA DE EMISIÓN:

$22 / 06 / 2017$ 
Encargado del documento:

Fecha:

\begin{tabular}{|c|c|c|c|c|c|c|c|}
\hline \multicolumn{8}{|c|}{ Código de la Mercadería: } \\
\hline \multicolumn{5}{|c|}{ Estante $\mathrm{N}^{\mathrm{o}}:$} & \multirow{2}{*}{\multicolumn{3}{|c|}{ Cantidad Máxima: }} \\
\hline \multicolumn{5}{|c|}{ Cantidad Mínima: } & & & \\
\hline \multicolumn{3}{|c|}{ FECHA } & \multicolumn{3}{|c|}{ MOVIMIENTO } & \multirow{2}{*}{$\begin{array}{l}\text { Recibido } \\
\text { Despachado }\end{array}$} & \multirow{2}{*}{ Observaciones } \\
\hline Día & Mes & Año & Entrada & Salida & Existencia & & \\
\hline & & & & & & & \\
\hline & & & & & & & \\
\hline & & & & & & & \\
\hline & & & & & & & \\
\hline & & & & & & & \\
\hline & & & & & & & \\
\hline & & & & & & & \\
\hline & & & & & & & \\
\hline
\end{tabular}

Firma del responsable:

\section{GENERADO POR:}

Gestión Logística

\section{REVISADO Y APROBADO POR:}

Presidente de la Cooperativa
FECHA DE EMISIÓN:

$22 / 06 / 2017$ 
Encargado del documento:

Fecha:

\begin{tabular}{|c|c|c|c|c|c|}
\hline \multirow{2}{*}{ FECHA } & \multicolumn{2}{|c|}{ HORA } & \multirow{2}{*}{ DESCRIPCIÓN DE RUTA } & \multirow{2}{*}{$\begin{array}{c}\text { PESO A } \\
\text { TRANSPORTAR }\end{array}$} & \multirow{2}{*}{$\begin{array}{c}\text { MYPE } \\
\text { DESTINC }\end{array}$} \\
\hline & Desde & Hasta & & & \\
\hline & & & & & \\
\hline & & & & & \\
\hline & & & & & \\
\hline & & & & & \\
\hline & & & & & \\
\hline & & & & & \\
\hline & & & & & \\
\hline & & & & & \\
\hline & & & & & \\
\hline & & & & & \\
\hline & & & & & \\
\hline & & & & & \\
\hline
\end{tabular}

Firma del responsable:

\section{GENERADO POR:}

Gestión Logística
REVISADO Y APROBADO POR:

Presidente de la Cooperativa
FECHA DE EMISIÓN:

$22 / 06 / 2017$ 
Encargado del documento:

Fecha:

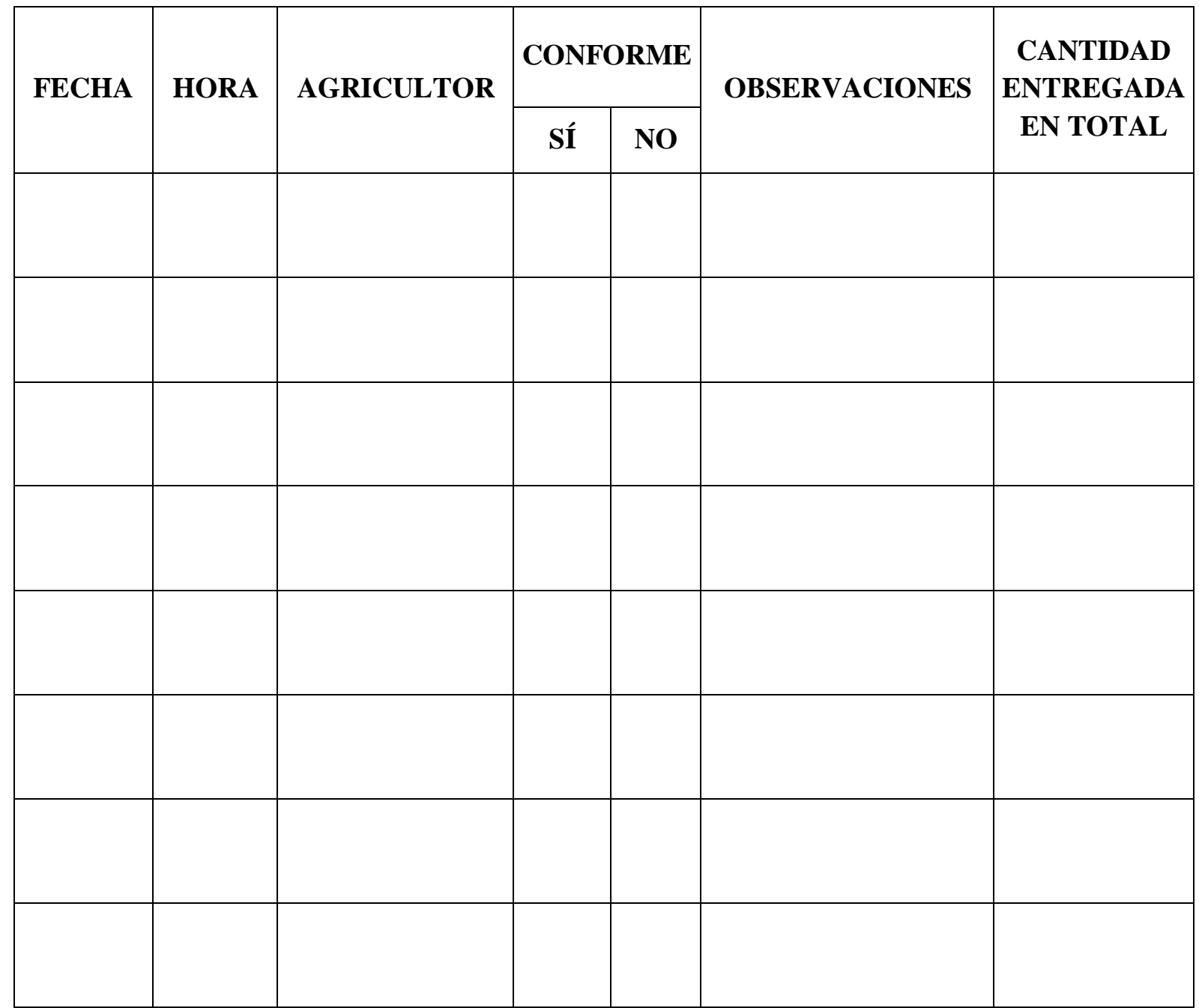

Firma del responsable:

\section{GENERADO POR:}

Gestión Logística
REVISADO Y APROBADO POR:

Presidente de la Cooperativa
FECHA DE EMISIÓN:

$22 / 06 / 2017$ 
Encargado del documento:

Fecha:

\begin{tabular}{|l|l|l|l|}
\hline PRODUCTO & MYPE DE & $\begin{array}{c}\text { UNIDAD DE } \\
\text { MEDIDA }\end{array}$ & $\begin{array}{c}\text { CANTIDAD } \\
\text { INGRESADA }\end{array}$ \\
\hline & & & \\
\hline & & & \\
\hline & & & \\
\hline & & & \\
\hline & & & \\
\hline & & & \\
\hline
\end{tabular}

Firma del responsable:

GENERADO POR:

Gestión Logística
REVISADO Y APROBADO POR:

Presidente de la Cooperativa
FECHA DE EMISIÓN:

$22 / 06 / 2017$ 
Encargado del documento:

Fecha:

\begin{tabular}{|c|c|c|c|c|c|}
\hline FECHA & AGRICULTOR & PRODUCTO & DESCRIPCIÓN & $\begin{array}{c}\text { UNIDAD } \\
\text { DE } \\
\text { MEDIDA }\end{array}$ & $\begin{array}{l}\text { CANTIDAD } \\
\text { DESPACHADA }\end{array}$ \\
\hline & & & & & \\
\hline & & & & & \\
\hline & & & & & \\
\hline & & & & & \\
\hline & & & & & \\
\hline & & & & & \\
\hline & & & & & \\
\hline & & & & & \\
\hline
\end{tabular}

Firma del responsable:

GENERADO POR:

Gestión Logística
REVISADO Y APROBADO POR:

Presidente de la Cooperativa
FECHA DE EMISIÓN:

$22 / 06 / 2017$ 
Encargado del documento:

Fecha:

\begin{tabular}{|l|l|l|l|l|}
\hline \multirow{2}{*}{ FECHA } & \multirow{2}{*}{ AGRICULTOR } & \multicolumn{2}{|c|}{ CONFORME } & $\begin{array}{c}\text { CANTIDAD } \\
\text { ENTREGADA EN } \\
\text { TOTAL }\end{array}$ \\
\cline { 3 - 5 } & & Sí & NO & \\
\hline & & & & \\
\hline & & & & \\
\hline & & & & \\
\hline & & & & \\
\hline & & & & \\
\hline & & & & \\
\hline & & & & \\
\hline
\end{tabular}

Firma del responsable:

\begin{tabular}{|c|c|c|}
\hline GENERADO POR: & REVISADO Y APROBADO POR: & FECHA DE EMISIÓN: \\
Gestión Logística & Presidente de la Cooperativa & $22 / 06 / 2017$ \\
\hline
\end{tabular}




\section{Correo de resultados de $1^{\text {er }}$ experto - Helena Forslund}

De: Helena Forslund <helena.forslund@inu.se>

Enviado: lunes, 14 de agosto de 2017 01:12:11 a.m.

Para: u201312321 (Mendoza Silva, Patricia Helen)

Asunto: SV: Model validation request

(3) 1 archivos adjuntos (63 KB)

mpact-and-Validation-Matrices filled xlsx

Hi Patricia Mendoza,

Attached the matrices filled with some obse rvations that I suggest you should take into conside ration for the consistency of your model.

On the other hand, I consider that the proposal containsthe necessary processes to be carried out, but some of the KPIs don't seem controllable: how can a warehouse be responsible for \% rejections? For on time delivery, can't those goals be set before routing? And am I reading it right that no farmer should get more than $10 \%$ of the warehouse space for avocado storage? What if one becomes extremely productive? As for theft, is the re anyway to improve $30 \%$ losses, especially if the logistics operator picks up vs. farmer delivering to ope rator?

I hope I've helped

Best wishes

Helena Forslund, PhD, Professor

Research leader; Supply Chain Studies

Director; master programme in Business Process \& Supply Chain Management

School of Business and Econom ics

Linnaeus Unive rsity

SE-351 95 Växjö, Swe den

$+46470708784$

+46705777822

helena.forslund@Inu.se

https://lnu.se/en/staff/hele na.forslund/

https://lnu.se/en/re search/se archresearch/supply-chain-studies/

\section{Correo de resultados de $2^{\text {do }}$ experto - Jan Olhager}

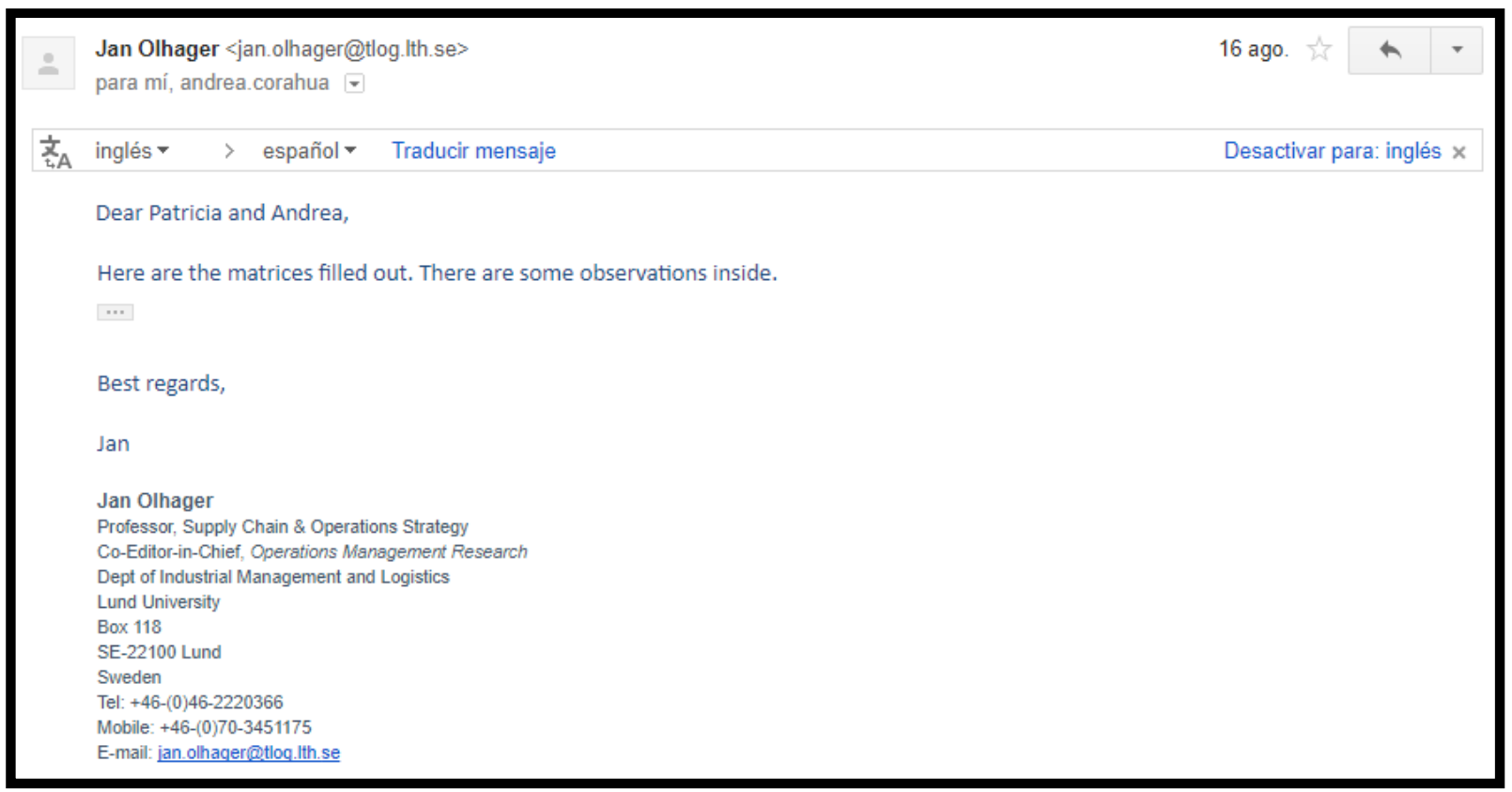




\title{
Correo de resultados de $3^{\text {er }}$ experto - Arnold Maltz
}

De: Arnold Maltz<arnie.maltz@asu.edu>

Enviado: miércoles, 27 de septiembre de 2017 06:54:53 p.m.

Para: u201312321 (Mendoza Silva, Patricia Helen)

Asunto: Re: Model validation request

Here are the matrices filled out. Please note that the impact/magnitude rankings are assuming that your processes are successfully executed. However, as my comments indicate, I think some of these processes may be difficult to put into practice, and I'm sure part of the problem for me is that you had to translate what you did-sorry I don't speak or read Spanish.

Still, you should really have time goals and forecasts to go with this work; I don't think waiting for a farmer to order supplies is going to give you enough responsiveness in the system to work in an agricultural setting, although I could be wrong about that. Similarly, negotiating prices, either for the supplies or the crops, has a lot of risk-we usually recommend at least some part of the crop be precommitted, assuming you can trust the buyers.

You noted that the farmers don't track cost at this point-that's a significant educational task, and my guess is that record keeping at the warehouse wil be a problem as well, unless the farmers coop can afford to bring in a professional (the coop may be too small. Do they rotate tasks now? Do they even have a warehouse?)

As you will see, if at all possible, the logistics operator should pick up at the warehouse, and maybe also deliver supplies. They will do a better job, assuming they are honest and competent. Again, the issue may be the coop is just too small and they have to do it themselves.

I will be in Peru November 9 and 10 if you wish to speak some more.

Best of luck

Arnold Maltz

Associate Professor, Supply Chain Management

Arizona State University

Arnie.maltz@asu.edu

\section{Correo de resultados de $4^{\text {to }}$ experto - Gülgün Alpan}

\section{RV: Model validation request}

\author{
Gülgün Alpan<gulgun.alpan@grenoble-inp.fr> \\ Iun 14/08/2017 03:55 a.m. \\ Para:u201312321 (Mendoza Silva, Patricia Helen) <u201312321@upc.edu.pe> \\ Q8 1 archivos adjuntos (31 KB)
}

mpact-and-Validation-Matrices Alpan.xIsx

Hello,

Here are the matrices filled out. Tell me if you have any doubt.

I'll answer you soon.

Regards,

Gülgün ALPAN

Associate Professor of Industrial Engineering

Deputy Director - Laboratoire G-SCOP

46 Ave. Félix Viallet, 38031 Grenoble, cedex 1, France

tel : (+33) $476 \quad 57 \quad 43 \quad 33$

fax : (+33) $4 \quad 76 \quad 57 \quad 4695$

http://WWW.g-scop.fr/ gaujalg 


\section{Correo de resultados de $5^{\text {to }}$ experto - Susan Golicic}

Golicic,Susan<Susan.Golicic@colostate.edu>

jue 05/10/2017 02:30 p.m.

Bandeja de entrada

Para:u201312321 (Mendoza Silva, Patricia Helen) <u201312321@upc.edu.pe>:

(3) 1 archivos adjuntos (27 KB)

Peru Logistics Management Model Verification SG.xls $x$.

Patricia,

I have reviewed your paper and completed the validation matrix - I do not know what to do with the impact matrix as I stated. This shows a very strong unde rstanding of business, supply chain and logistics processes; however, I am not sure how feasible this is for agricultural MSEs unless the processes you have are more directed to those busine sses? Maybe work with one of the companies interviewed for the background research to help with this? I wish you the best of luck on this re se arch and finished your university work!

Have a joyful day!

Susan

Susan L. Golicic, Ph. D.

Professor of Supply Chain Management

Director, CSU Supply Chain Forum

Colorado State University

235 Rockwell Hall

Fort Collins, CO 80523-1275

(970) 491-4938

"Once you make a decision, the universe conspires to make it happen." Ralph Waldo Emerson 


\section{Referencias bibliográficas}

Arellano, A., Carballo, B., Orrantia, M., \& Salazar, R. (2013). Diagnóstico de la madurez de los procesos de la cadena de valor de una pequeña empresa mexicana de productos de maíz. Pensamiento \& Gestión, núm. 34, pp. 122-136.

Adrianzen, C. (2013). Crecimiento y Pobreza en el Perú: 2001-2011. Revista De Economía Y Derecho, vol.: 10, núm. 37, pp. 35-66.

Bužinskienė, R. \& Rudyte, D. (2014) The Impact of Knowledge Generating Investment on GDP Growth. Economics \& Business, vol.: 26, pp. 9-14. doi: 10.7250/eb.2014.014

Cano, P., Orue, F., Martínez, J., Mayett, Y. y López, G. (2015) Modelo de gestión logística para pequeñas y medianas empresas en México. Contaduría y Administración 60 (1), pp. 181-203.

Carvalho, L., Costa, T. (2014). Small and Medium Enterprises (SME) and competitiveness: An empirical study. Management Studies, vol.: 2, núm 2, pp. 88-95.

Cridland, E., Jones, S., Caputi, P. y Magee, C. (2015) Qualitative research with families living with autism spectrum disorder: Recommendations for conducting semistructured interviews. Journal of Intellectual \& Developmental Disability, Vol. 40, Issue. 1, pp.7891, doi: 10.3109/13668250.2014.964191

Cronemyr, P. \& Danielsson, M. (2013) Process Management 1-2-3 - a maturity model and diagnostics tool, Total Quality Management \& Business Excellence, vol.: 24, pp.7-8.

Colombiana de Salud (2012) Manual de Calidad - Ficha de Indicadores. Recuperado de: http://www.colombianadesalud.org.co/FICHAS\%20TECNICAS/compras.pdf

Da Silva L., Damian I. \& and De Pa'dua S. (2012) Business Process Management Journal, vol.: 18, núm. 5 , pp. $762-776$.

Daubaraite, U., \&. Startienè, G. (2015) Creative Industries Impact on National Economy in Regard to Sub-sectors. Procedia - Social and Behavioral Sciences (2013) 129-134. Doi: https://doi.org/10.1016/j.sbspro.2015.11.415

Diario El Peruano. (2016) Informe destaca reducción de la pobreza de $58.7 \%$ a $22.7 \%$. Recuperado de: http://www.elperuano.com.pe/noticia-informe-destaca-reduccion-depobreza-587-a-227-37242.aspx

Diario La República. (2017) Destacan reducción de la pobreza del Perú en 10 años. Recuperado de: http://larepublica.pe/impresa/economia/837994-destacan-reduccionde-la-pobreza-del-peru-en-10-anos 
Dos Santos, L. \& De Barros, C. (2014). Social Responsibility, Sustainability and MicroEnterprises: Contributions Made by a Micro-Enterprise. Megatrend Review, cap.:11, núm. 3, pp. 123-134.

Esmaeeli, A., \& Sadighi, H. (2017) Effect of Agricultural Research on Productivity and Rural Poverty: Evidence from Iran. Journal of Agricultural Science and Technology, 19: 2132. Recuperado de: http://jast.modares.ac.ir/article_15950_31e2fac7045409bb774257ff4994499f.pdf

Espejo, M. (2016) Exactitud de inventarios para eliminar discrepancias. Réplica de Revista Énfasis Logística - Mexico, pg. 50-52. Recuperado de: http://approlog.org/?p=1118\#.WbQQGsiLRPY

Frels, R. y Onwuegbuzie, A. (2013), Administering Quantitative Instruments with Qualitative Interviews: A Mixed Research Approach. Journal of Counseling \& Development, 91: 184-194. doi:10.1002/j.1556-6676.2013. 00085.x

Fuentes, E., Faure, G., Cortijo, E., De Nys, E., Bogue, J., Gomez, C., Mercado, W., Gamboa, C., Le Gal, P-Y. (2015). The impacts of differentiated markets on the relationship between dairy processors and smallholder farmers in the Peruvian Andes. Agricultural Systems, vol.: 132, pp. 145-156. doi: http://dx.doi.org/10.1016/j.agsy.2014.10.003

GIL, J., PARRA, J., OCAMPO, D. (2017) Indicadores de gestión para empresas agrícolas y ganaderas. Universidad de la Salle.

Garrido, J. (2013). Sobre la Pobreza: Orígenes, Cuentas y Evolución en el Perú y el Mundo. Revista de Economía y Derecho, vol.: 10, núm. 39, pp. 103-138.

García, N. (2015). Las microempresas un segmento fundamental en el desarrollo empresarial y la generación de empleo en Colombia y Perú. Revista Horizonte Empresarial, vol.: 2, núm. 2.

Gomero, A. (2015). Concentración de las MYPES y su impacto en el crecimiento económico. Quipukamayoc, vol.: 23, núm. 43, pp. 29-39.

González, J., Holguín, P., Lumbreras, E. y Nuñez, G. (2017) La entrevista en profundidad y la metodología Kano para conocer los requisitos de los usuarios en una unidad de quemados. Revista de Calidad Asistencial, Vol. 32 Issue: 1, pp. 21-26, doi: https://doi.org/10.1016/j.cali.2016.06.009

Hamann, A. \& Hernani, M. (2013). Percepción Sobre el Desarrollo Sostenible de las Mype en el Perú. RAE - Revista de Administración de Empresas, vol.: 53, núm. 3, pp. 290-302. 
Hrušecka, D. (2016) Proof obligations as a support tool for efficient process management in the field of production planning and scheduling. Serbian Journal of Management. 2016, vol. 11, issue: 2 , p. $235-243$.

Iluzia, A. (2015). Modern Methods of Process Management Used in Slovak Enterprises. Procedia Economics and Finance, 23, 889-893. 13 de abril de 2017, De Science Direct Base de datos.

INEI (2017) Principales indicadores macroeconómicos. Recuperado de: https://www.inei.gob.pe/estadisticas/indice-tematico/economia/

INEI (2016) Evolución de la pobreza monetaria. Recuperado de: https://www.inei.gob.pe/media/MenuRecursivo/publicaciones_digitales/Est/Lib1347/li bro.pdf

IV Jornadas Técnicas de la CTCL (2013) Indicadores de eficiencia en compras. Mesa: Los presupuestos, las compras, el ahorro y la eficiencia. Recuperado de: http://www.ctcl.es/site/documentos/cuartasjornadas/Taller-Compra-IV-JornadasResultados-Mesa.pdf

Kurczewski, P. (2013) Life cycle thinking in small and medium enterprises: the results of research on the implementation of life cycle tools in Polish SMEs-part 1: background and framework. The International Journal of Life Cycle Assessment, vol.: 19, issue: 3, pp. 593-600, doi: 10.1007/s11367-013-0675-0

Llanes-Font, M., Isaac, Cira, Moreno, M. \& García, G. (2014). De la gestión por procesos a la gestión integrada por procesos, vol.: 35, núm. 3, pp. 255-264.

Leimbach, M., Kriegler, E., Roming, N. \& Schwanitz, J. (2017). Future growth patterns of world regions - A GDP scenario approach. Global Environmental Chang, vol.: 42, pp. 215-225. doi: https://doi.org/10.1016/j.gloenvcha.2015.02.005

Mallar, Miguel Ángel. (2010). La Gestión por Procesos: un enfoque de gestión eficiente. Visión de futuro, 13(1) Recuperado en 15 de mayo de 2017, de http://www.scielo.org.ar/scielo.php?script=sci_arttext\&pid=S1668$87082010000100004 \& \operatorname{lng}=$ es\&tlng=es.

MINAGRI (2017) Memoria Anual. Sector Agricultura y Riego. Oficina General de Planeamiento y Presupuesto. Lima - Perú. Recuperado de: http://minagri.gob.pe/portal/download/pdf/pcm/2018/memoria-anual-2016.pdf

MINAGRI (2016) Boletín estadístico de producción. Agrícola, Pecuaria y Avícola. Dirección General de Seguimiento y Evaluación de Políticas. Lima - Perú. Recuperado de: http://www.minagri.gob.pe/portal/download/pdf/herramientas/boletines/prod-agricola- 
pecuaria-avicola/2016/boletin-produccion-comercializacion-avicoladiciembre2016_020317.pdf

Ministerio de Agricultura y Desarrollo Rural. (2013). Matriz de indicadores de Gestión de los Procesos. Colombia.

Ministerio de Comercio Exterior y Turismo (2016). Análisis integral de la logística en el Perú.

Ministerio de Economía y Finanzas (2017) Indicadores Macroeconómicos. Recuperado de: https://www.mef.gob.pe/es/indicadores-macroeconomicos

Mohammed, A. (2015) Knowledge Management Process in several organizations: Analytical Study of modeling and several processes. Procedia Computer Science, vol.: 65, pp. 726 - 733. doi: https://doi.org/10.1016/j.procs.2015.09.017

Mungaray, A., Osuna, J., Ramírez, M., Ramírez, N., \& Escamilla, A. (2015). Emprendimientos de micro y pequeñas empresas mexicanas en un escenario local de crisis económica: El caso de Baja California, 2008-2011. Frontera norte, vol.: 27, núm. 53, pp. 115-146.

Mustafa, L. (2016). Challenges and managing of Small and Medium Enterprises in Kosova. Proceedings of the Multidisciplinary Academic Conference, pp. 258-267.

Ndlovu, P., Mazvimavi, K., An, H. \& Murendu, C. (2014). Productivity and efficiency analysis of maize under conservation agriculture in Zimbabwe. Agricultural Systems, vol.: 124, pp. 21-31. doi: https://doi.org/10.1016/j.agsy.2013.10.004

Palinkas, L. (2014). Qualitative and Mixed Methods in Mental Health Services and Implementation Research Journal of Clinical Child \& Adolescent Psychology, Vol. 43, Issue. 6, pp. 851-861. doi: 10.1080/15374416.2014.910791

Prajogo, D., Oke, A., \& Olhager, J. (2016). Supply chain processes. International Journal of Operations \& Production Management, 36(2), 220-238. Recuperado de https://search.proquest.com/docview/1752983668?accountid=43860

Perú21. (2017). Perú liderará crecimiento económico para el 2017. Recuperado de: http://peru21.pe/economia/peru-liderara-crecimiento-economico-2017-2268677

Perú21. (2017, enero 24). Perú liderará crecimiento económico para el 2017. Recuperado de: http://peru21.pe/economia/peru-liderara-crecimiento-economico-2017-2268677

PRODUCE (2015) Anuario Estadístico Industrial, Mipyme y Comercio Interno. Dirección General de Estudios Económicos, Evaluación y Competitividad Territorial. Lima - Perú. Recuperado de: http://www.produce.gob.pe/documentos/estadisticas/anuarios/anuarioestadistico-mype-2015.pdf 
Prostean, G., Seifert, R., Pettinger, R. (2016). The Importance of Logistics and Supply Chain Management in the Enhancement of Romanian SMEs. Procedia - Social and Behavioral Sciences, 221, 405-413. 13 de abril de 2016, De Scient Direct Base de datos.

Tello, S. (2014). Importancia de la micro, pequeñas y medianas empresas en el desarrollo del país. LEX, vol.: 12, núm. 14, pp. 199-218. doi: http://dx.doi.org/10.21503/lex.v12i14.623

Tomšík, K., Smutka, L., Lubanda, E., \& Rohn, H. (2015) Position of Agriculture in SubSaharan GDP Structure and Economic Performance. AGRIS on-line Papers in Economics and Informatics, 2015, vol. 7, issue 1. Recuperado de: http://ageconsearch.tind.io/record/207058/files/agris_online_2015_1_tomsik_smutka_lubanda_rohn.pdf

Torres, A. (2014) Orientaciones para implementar una gestión basada en procesos Ingeniería Industrial, Instituto Superior Politécnico José Antonio Echeverría La Habana, Cuba, vol. 35, núm. 2, pp. 159-171.

Tomsik, k., Smutka, L., Lubanda, E. \& Rhon, H. (2015). Position of Agriculture in Sub-Saharan GDP Structure and Economic Performance. Papers on Economic Performance, vol.: 8, issue: 1 , pp. 69-80.

Rivera, L., Gligor, D. y Sheffi, Y. (2016) The benefits of logistics clustering, International Journal of Physical Distribution \& Logistics Management, Vol. 46 Issue: 3, pp.242-268, doi: 10.1108/IJPDLM-10-2014-0243

Rodríguez-Pose, A. \& Hardy, D. (2015) Addressing poverty and inequality in the rural economy from a global perspective. Applied Geography, vol.: 61, pp. 11-23.

SIICEX (2017) Ficha Comercial de la palta. Siicex.gob.pe. Recuperado de: http://www.siicex.gob.pe/siicex/portal5ES.asp?_page_=172.17100\&_portletid_=sficha productoinit\&scriptdo=cc_fp_init\&pproducto=145\&pnomproducto=Palta

Sujova, A. \& Marcinekova, K. (2015). Modern Methods of Process Management Used in Slovak Enterprises. Journal Procedia Economics and Finance, vol.: 23, pp. 889-893. doi: https://doi.org/10.1016/S2212-5671(15)00381-0

Valdés, I. (2015). Socio-economic variables and democratic support in Chile, Peru and Colombia: Poverty as the key factor. Si Somos americanos, vol.: 15, núm. 1, pp. 199222.

Vázquez, A. (2014). Crecimiento, desigualdad y pobreza: Estado de la cuestión. Revista de Economía Institucional, vol.: 16, núm. 31, pp. 101-1 
